\title{
Post transcriptional gene silencing and peptide microarray as a way to perform drug target validation
}

Citation for published version (APA):

Tack, F. B. (2008). Post transcriptional gene silencing and peptide microarray as a way to perform drug target validation. [Doctoral Thesis, Maastricht University]. Maastricht University. https://doi.org/10.26481/dis.20080612ft

Document status and date:

Published: 01/01/2008

DOI:

10.26481/dis.20080612ft

Document Version:

Publisher's PDF, also known as Version of record

\section{Please check the document version of this publication:}

- A submitted manuscript is the version of the article upon submission and before peer-review. There can be important differences between the submitted version and the official published version of record.

People interested in the research are advised to contact the author for the final version of the publication, or visit the DOI to the publisher's website.

- The final author version and the galley proof are versions of the publication after peer review.

- The final published version features the final layout of the paper including the volume, issue and page numbers.

Link to publication

\footnotetext{
General rights rights.

- You may freely distribute the URL identifying the publication in the public portal. please follow below link for the End User Agreement:

www.umlib.nl/taverne-license

Take down policy

If you believe that this document breaches copyright please contact us at:

repository@maastrichtuniversity.nl

providing details and we will investigate your claim.
}

Copyright and moral rights for the publications made accessible in the public portal are retained by the authors and/or other copyright owners and it is a condition of accessing publications that users recognise and abide by the legal requirements associated with these

- Users may download and print one copy of any publication from the public portal for the purpose of private study or research.

- You may not further distribute the material or use it for any profit-making activity or commercial gain

If the publication is distributed under the terms of Article $25 \mathrm{fa}$ of the Dutch Copyright Act, indicated by the "Taverne" license above, 
POST TRANSCRIPTIONAL GENE SILENCING AND PEPTIDE MICROARRAY AS A WAY TO PERFORM DRUG TARGET VALIDATION

Frederik Bert Tack 
ISBN nº: 978-90-9023085-6

Druk en omslagontwerp: K15.be

閛 2 


\section{POST TRANSCRIPTIONAL GENE SILENCING AND PEPTIDE MICROARRAY AS A WAY TO PERFORM DRUG TARGET VALIDATION}

\section{PROEFSCHRIFT}
Ter verkrijging van de graad van doctor aan de Universiteit Maastricht, op gezag van de Rector Magnificus, Prof, mr. G.P.M.F Mols
volgens het besluit van het College van Decanen
in het openbaar le verdedigen op
donderdag 12 Juni 2008 om 14:00u

door

\section{Frederik Bert Tack}

Geboren op 4 februari 1979 te Lebanon, Tennessee, U.S.A. 


\section{Promoteres}

Prof. dr. F.C.S. Ramaekers

Prof. dr. M. Borgers

\section{Copromotor}

Dr. M. Janicot

\section{Beoordelingscommissie}

Prof. dr. J. Geraedts (Voorzitter)

Prof. dr. A. Griffioen

Prof. dr. J. De Mey

Prof. dr. E.W. Meijer (Technische Universiteit Eindhoven)

Prof. dr. B. De Spiegeleer (Universiteit Gent)

The investigations described in this thesis were carried out at the department of Oncology R.E.D. Europe, Ortho Biotech Oncology Research \& Development Division of Janssen Pharmaceutica N.V., Beerse Belgium 


\section{CONTENTS}

Chapter 1

Aim and Introduction

Chapter 2

Cyclodextrin Based Polymer Gene Delivery

Chapter 3

Polypropylene Imine Dendrimer Gene Delivery

Chapter 4

Colloidal Gold Particle Gene Delivery

\section{Chapter 5}

Fluorescent Cell Line Generation And Application

Chapter 6

Autophosphorylation at S305 on PLK4

Chapter 7

General Discussion

Chapter 8

Summary and Conclusions

Chapter 9

Samenvatting en Conclusies

Dankwoord 
Chapter 1

INTRODUCTION AND AIM OF THESIS 


\section{INTRODUCTION}

The pharmaceutical industry has known a phenomenal growth, with a peak in 1994 when 44 new drugs were launched, in the 1990's averaging 30 new drug approvals per year. The success is based on a deep understanding of physiology and pharmacology coupled to brilliant chemistry. The ability to rapidly clone and manipulate genes heralded the start of molecular biology era that culminated in 2001 with the publication of the first draft of the human genome sequence. This combined with breakthroughs in compound screening technology (HTS) and chemical synthesis (combinatorial chemical screening), have boosted the pharmaceutical research. These successive technology platforms, each of which was initially welcomed by the pharmaceutical industry as a "magical bullet" for reducing the cost and time lines and improving the success rate of the drug discovery process, have been viewed as only having had a limited impact.

In research and development nearly $50 \$$ billion is spent per year and the cost of developing a new drug has risen from $230 \$$ million in 1987 to over $1 \$$ billion in 2007 (U.S. Gov. Acc. Office 2006). As investors expect a $10 \%$ annual growth, a pharmaceutical company must launch, on average, 4 new chemical entities (NCEs) per year with average sales of $\$ 350$ million. However from 1996 to 2001, the industry launched on average less than one NCE per year per company and of all drugs launched since 1996 only $25 \%$ had sales in excess of $\$ 350$ million (Solari R 2005). A recent survey by Accenture (Kola I et al. 2004) defined the business case for large pharmaceutical companies in terms of NCEs required to remain a growth company on the basis of their current revenues and their desired percentage growth. Per $5 \$$ billion in revenues, a company will have to generate 1 NCE per year. On the basis of this calculation, Pfizer, with pharmaceutical revenues in 2003 of approximately $45 \$$ billion, will need to generate approximately nine high-quality NCEs per year. GlaxoSmithKline, with revenues in excess of $£ 18$ billion ( $\sim 32 \$$ billion), will need to generate about six high quality NCEs per year.

Strikingly, although the FDA has over 400 Investigational New Drug (IND) applications for cancer in its portfolio only one fifth will advance to become a New Drug Application (NDA). With the attrition rate so high that only 1 in 10 compounds entering clinical trials will make it to the market place and only 1 in 8 of these will recoup its investment costs, companies are continuously searching for ways to ensure that the data seen in preclinical trials will be representative for the human results (Kola I et al. 2004, Graul Al et al. 2007, Pharm. Res. \& Manu. Assoc. 2005). Adding to these pressures are the looming patent expirations for many of the world's top selling drugs. It has been reported that a large amount of the blockbuster drugs, worth more than $100 \$$ billion, would lose patent exclusivity within the next 5 years and lose over $80 \%$ of their revenue to generics within 6months (Graul AI et al. 2007).

As many people will argue the only true validated targets are those for which there are already drugs shown to be efficacious in man. In undertaking target discovery, one would ideally perform clinical studies and obtain cell/tissue samples using normal and diseased human patients. In reality, this is unethical and/or impractical, which means that we must use cellular and/or animal models. Therefore generating as much confidence as possible that a drug against the target will modify the disease or treat the symptoms is vital. The 
reasons for the low number of successful drugs against novel targets are controversial, although it is undoubtedly related to the higher attrition rate during development, particularly from issues related to failures of on-target biological hypotheses and on- and off- target safety concerns. The major causes of attrition in the clinic in 2000 (Figure 1) were lack of efficacy (accounting for approximately $30 \%$ of failures) and safety (toxicology and clinical safety accounting for a further approximately $30 \%$ ).

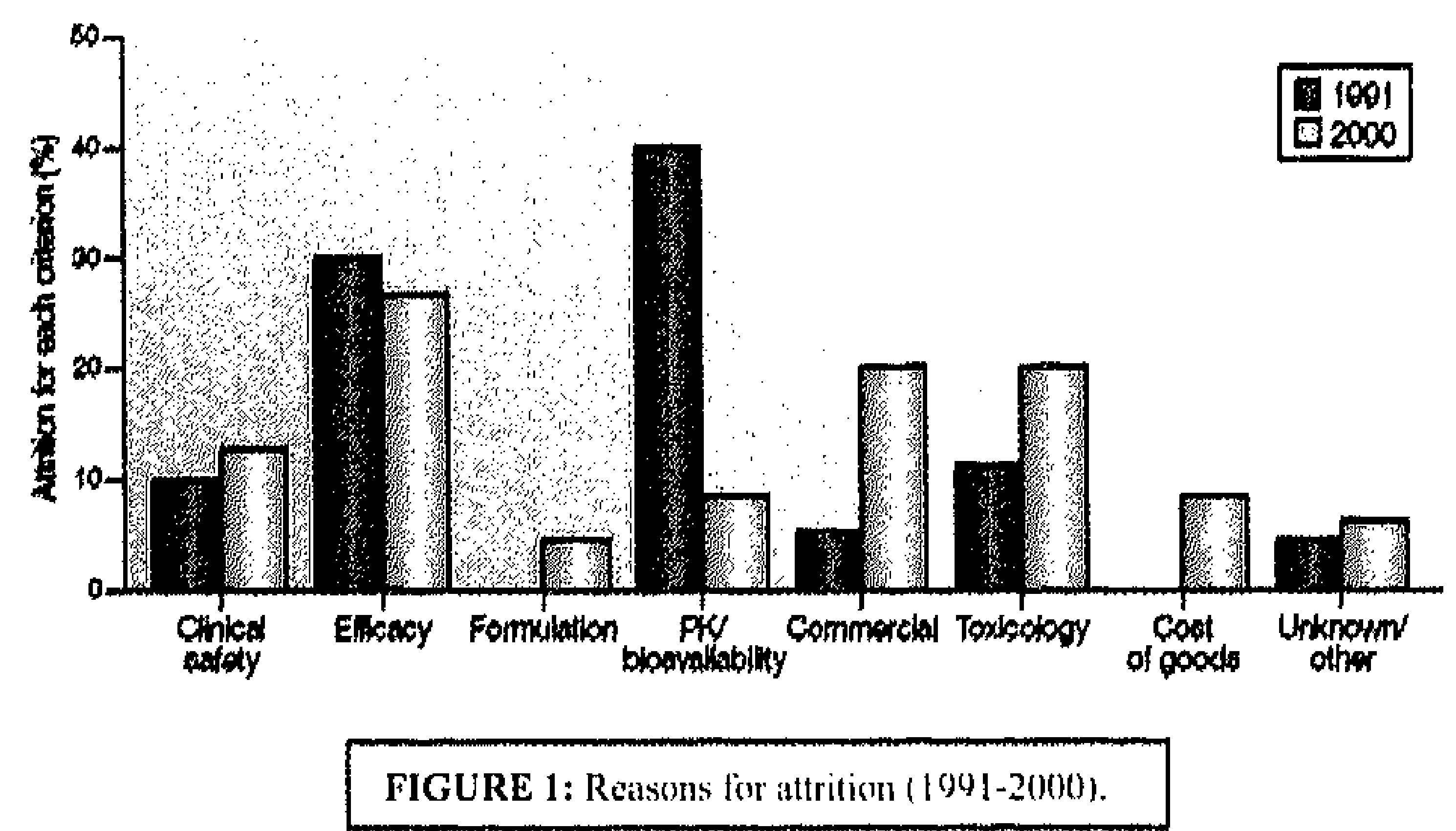

Even the rate of failures in Phase III trials - a stage which accounts for over $70 \%$ of the costs of discovering and developing a drug - is far too high: approximately $45 \%$ of all compounds that enter this phase of full development undergo attrition and in some therapeutic areas, such as oncology, it is as high as $59 \%$. (Kola I et al. 2004)

Front-loading, a work method where much of these issues are tackled earlier in the discovery process, is applied in most pharmaceutical companies at present. Early validation can assist in reducing this attrition rate using front loading. This target validation can occur on various fronts. First, one would want to confirm that the protein levels are also differentially expressed across multiple independent patient samples. At this point one has a correlation between protein expression and some observed physiology or pathophysiology. Then demonstrating that the expression of this particular target is either causative of the disease or some of the symptoms of the disease are required. Placing a candidate in the context of a disease requires the use of model systems, cell based and animal. These models, which are designed using information derived from clinical studies, normally attempt to reproduce one or more phenotypes that have been implicated in the disease. Unfortunately, they often suffer from a number of significant problems that can make them poor predictors of human disease. In cell models, the complexity simulating the numerous biological interactions in human tissue is no longer found. Animal models can reproduce a particular disease phenotype, genomic differences and the difficulty of identifying and replicating the long-term environment influences, means that underlying causes could be different. Realistically speaking the most significant problem in target discovery, in respect to target validation, is the provision of models that are truly predictive of the disease. It is therefore necessary to have cell models that mimic the in vivo milieu and take into account factors such as intercellular interactions and environmental effects. Similarly, although 
Chapter 1

animal models permit the investigation of the disease as well as its development, it is important that they not only manifest the relevant phenotype but that the underlying changes are similar to the human disease. For example, most pharmaceutical companies still use xcnograft models for oncology testing, in which a tumour cell line that might have little relevance to the tumour in vivo is injected into a nude mouse (which does not resemble the immunology of the host; nor does the artificial location of the tumour significantly resemble what happens in vivo during tumorigenesis). The use of appropriate genetic models (for example, transgenic and gene knockout animals) of tumorigenesis might be more pathophysiologically relevant.

The number of options for drug development targets obtained from the knowledge of the human genome sequencing project, opens the door for questioning which of these actually causes or modifies the disease. Checking for appropriate potency, selectivity and ADMET properties together with activity in predictive animal models and lacking toxicology results, are the first steps in belicving that a target has a bright future in its drug development program. Unfortunately, there is still a considerable attrition rate in drug discovery when moving from animals to patients. The relevance of animal models to the human condition due to the lack of understanding of the human disease condition and various nuances in the signaling pathways remain hurdles in lowering the compound attrition rate. Although it may occur that the animal model is seen as highly robust and predictive, the limitations, concerning side effects of the novel compound and suboptimal ADMET properties, may lead to eg. a limited human exposure. Also in complex traits ea. cancer, a failure to replicate is often observed between patient samples and patient populations. Finally, managerial decisions must be taken as early as possible. It is estimated that near $25 \%$ of the drugs that are eliminated from company pipelines are discarded due to managerial decisions regarding shifting priorities, marketing reassessment or loss of management interest when development takes longer than expected (Cuatrecasas P, 2006). Involving marketing and due diligence upfront may aid in deciding to discontinue a development program due to competitors portfolio and clinical trial results, patent inmaneuverability, etc.) in an earlier and cost saving timepoint.

\section{AIM OF THE STUDY}

As one of the initial steps in target validation includes assessing the necessity of the protein for its role in the pathophysiology of the disease, the gene can be either overexpressed or knocked down. Oligonucleotides have been used for inhibiting the gene of interest for over 30 years. The most challenging aspect of the use of oligonucleotides is delivering these molecules to their site of action, the RNA target located within the cytoplasm or nucleus. Delivery requires that the oligonucleotides survive transfection, local or systemic administration (in the case of in vivo applications) long enough to bind to the target cells, cross the cytoplasmic membrane or become released from an endosomal/lysosomal vesicle, pass through the nuclear membrane (or cross the endoplasmic reticulum), and be able to functionally hybridize to the target RNA. Novel technologies for delivering 
oligonucleotides were assessed in vitro and in vivo. Three delivery agents were tested for their toxicity, transfection efficiency and ability to deliver functional DNAzymes in carcinoma cells. For those modified agents shown to be promising in vitro, the delivery capabilities in vivo was also assessed. A cyclodextrin based polymer (CDP) carrying stabilizing and targeting particles was evaluated in collaboration with a US-based company Insert Therapeutics ${ }^{\prime \prime}$. Secondly, in collaboration with SyMo-Chem various generations and modified polypropylene-imine dendrimers were tested for their use as DNA delivering agent. Finally, the use of colloidal gold nanoparticles coated with polyethylene-imine and PEG were applied in the delivery of DNAzymes to carcinoma cells.

Another aspect in aiding the swift progression of target validation was to use better animal models. In order to easier assess the functional effect of the above mentioned delivered oligonuclcotides, a novel animal model was simultaneously set up. Using the highly fluorescent proteins, ZsGreen and DsRed2, stable expressing A2780 and 3LLp cell lines were produced. An in-house established whole body imaging allowed the use of fluorescent xenografts to be visualized and measured in real time on non-anaesthetized mice. The drawback of that system at the time was the lack of high fluorescent tumor cell lines difficulting accurate measurements. Therefore prior to evaluating the functional effect of the delivered oligonucleotide these novel fluorescent cell lines were validated. They were evaluated in vitro for comparable growth rate to their respective parental cell line and in vitro response to agents of particular therapeutic class. Subsequentially, they were injected subcutaneously in nude mice and the tumor take and growth rate were assessed. Also an anti-tumor efficacy study, using one of the drugs tested in vitro, was performed to demonstrate the usefulness in anti-cancer studies. In a second validation step, we attempted to knockdown the fluorescent protein. Targeting a RNA encoding the gene of a fluorescent protein, alters the functional readout from a biological to optical manner. This would aid in speeding up the evaluation of the DNA delivery agents significantly. To proceed with evaluating the reduction of the oligonucleotide-based RNA knockdown on the fluorescent cells and eventually tumors, it was chosen to perform gene knockdown studies using siRNAs targeting ZsGreen, the fluorescent protein stably present in our mouse tumor model. As siRNAs had developed into the technology of choice for knocking down a gene/protein, we moved away from DNAzymes. The siRNAs designed against ZsGreen were screened for potency. Extracting RNA enabled the gene specific knockdown to be assessed and the intensity of fluorescence was a measure for the ZsGreen protein reduction. To ensure that no aspecific immune response was induced due to siRNA treatment, this was also evaluated. Due to long protein half-life, the amount of endogenous protein was difficult to reduce to a level that would be visible in our in vivo setting. However, the feasibility of siRNA in gene knockdown in vitro was shown to be effective and the possibility to use this oligo for the in vitro evaluation of gene delivery systems was evident. In a second aspect of this dissertation we applied target validation on an oncology relevant target: Polo like kinase 4 (PLK4). Polo like kinases are relative new targets in the field of oncology drug development. As polo like kinases are active in the cell cycle, inhibiting these proteins was thought to have an effect on apoptosis and cell proliferation. As no known substrate existed, measuring its block of activity and therefore the link between inhibitory effect and oncogenesis was difficult. Recombinant DNA technology and peptide microarray allowed us to identify the first ever reported auto phosphorylation site on PLK4. 
Chapter 1

This can be used as a marker of its own activity and we have suggested its function to play a role in regulating protein stability. Finally, we observed an asynchronically distribution between PLK4 protein and its activity during the cell cycle in centriole biogenesis.

Target validation has progressed immensely over the past decade and its importance is ominously known. As we demonstrate in this study, various approaches may aid in validating a target in the early stages of drug development. As more effort is placed in this field, the future attrition rate may decrease in time benefiting the investigator, the pharmaceutical company and eventually the customer.

\section{REFERENCES}

Cuatrecasas P. : Drug discovery in jeopardy ; J Clin Invest, 116: 2837 (2006)

Graul AI., Prous JR. : Overcoming the Challenges in the Pharma/Biotech Industry; Drug News Perspect 20(1), (Jan-Feb 2007)

Kola I, Landis $\mathrm{J}:$ Can the pharmaceutical industry reduce attrition rates? Nature Reviews Drug Discovery 3;711 (2004)

Pharmaceutical Research and Manufacturers Association. What goes into the cost of prescription drugs? ...And other questions about your medicines. (June 2005). Available at: http://www.phrma.org/files/Cost_of Prescription_Drugs.pdf

Roberto Solari : The Drug Discovery Process, Molecular Anaylsis and Genome Discovery (27 Sept 2005)

United States Government Accountability Office document number GAO-07-49. New drug development. Science, business, regulatory and intellectual property issues cited as hampering drug development efforts. (November 2006) Available at: http://www.democrats.reform.house.gov/Documents/20061219094529-73424.pdf 


\section{Chapter 2}

TARGETED DELIVERY OF RNA-CLEAVING DNA ENZYME (DNAZYME) TO TUMOR TISSUE BY TRANSFERRIN-MODIFIED, CYClOdEXTRIN-BASED PARTICles

Suzie H. Pun, Nathalie C. Bellocq, Jianjun Cheng, Brendan H. Grubbs, Gregory S. Jensen, Mark E. Davis, Frederik Tack, Marcus Brewster, Michel Janicot, Boudewijn Janssens, Wim Floren, Annette Bakker

published in Cancer Biol Ther. 2004 Jul; 3(7):641-50. 
Chapter 2

\section{$\underline{\text { ABSTRACT }}$}

Efficient in vivo delivery of oligonucleotides remains a major limitation for the therapeutic application of these molecules. We report herein on the preparation of transferrin-modified nanoparticles containing DNAzymes (short catalytic single-stranded DNA molecules) for tumor targeting as well as their biodistribution using various methods of administration in the mouse. Linear, $\beta$-cyclodextrin-based polymers are complexed with DNAyzme molecules to form sub-50 nm particles termed "polyplexes". The surface properties of the cyclodextrin-containing polyplexes are modified by exploiting the ability of the $\beta$ cyclodextrin substructure and adamantane to form inclusion complexes. Accordingly, conjugates of adamantane with poly(ethylene glycol) (PEG) are prepared and combined with the polyplexes. The adamantane form inclusion complexes with the surface cyclodextrins of the polyplexes to provide a sterically stabilizing layer of PEG. The stabilized polyplexes are also modified with transferrin for increasing targeting to tumor cells expressing transferrin receptors. The preparation, characterization, and in vitro application of these nanoparticles are discussed. The transferrin-polyplexes containing fluorescently-labeled DNAzyme molecules are administered to tumor-bearing nude mice and their biodistribution and clearance kinetics are monilored using a fluorescence imaging system. Four methods of administration are studied: intraperitoneal bolus and infusion, intravenous bolus, and subcutaneous injection. DNAzymes packaged in polyplex formulations are concentrated and retained in tumor tissue and other organs, whereas unformulated DNAzyme is eliminated from the body within 24 hours post-injection. Intravenous and intraperitoneal bolus injections result in the highest fluorescent signal (DNAzyme) at the tumor site. Tumor cell uptake is observed with intravenous bolus injection only, and intracellular delivery requires transferrin targeting.

\section{INTRODUCTION}

One of the greatest barriers to realizing the therapeutic potential of antisense oligonucleotides, catalytic nucleic acids (ribozymes, DNAzymes), and small, interfering ribonucleic acids (siRNA) is their delivery to the site of action (Juliano et al., 1999). Numerous in vitro and in vivo studies have utilized unformulated nucleic acids. This approach tends to require large amounts of the nucleic acid and generally lacks cell specificity. The use of delivery agents has been shown to facilitate cellular uptake in vitro, thus reducing the quantity of nucleic acid required for efficacy. Bennet et al. showed enhanced cellular uptake and nuclear localization of oligonucleotides using a cationic lipid delivery system in vitro (Bennell et al., 1992). Several studies have compared the in vitro delivery of oligonucleotides by lipid and polymer formulations. Jaaskelainen et al, claim that polymeric systems are ineffective as oligonucleotide delivery agents while lipid-based systems can provide for efficient cellular delivery (Jaaskelainen et al., 2000). In contrast, other investigators have shown that specific polylysines, polyethylenimine (Kang et al., 1999), and cationic 
dendrimers (Helin et al., 1999; Yoo and Juliano, 2000) can deliver functional oligonucleotides. Although the conclusions reached may be expression-assay dependent, the overall consensus from literature suggests that lipid-based systems tend to be superior to polycations. A possible explanation may be the lack of intracellular release of oligonucleotides by high molecular weight polycations.

When used in vivo, synthetic delivery systems can suffer from interactions with serum components, cause complement activation and show toxicity that are all associated with their polyvalency (Ward et al., 2001). These shortcomings have obvious implications for therapeutic applications, although exceptions to this behavior have been noted (Lewis et al., 1996; Kang et al., 1999). Delivery of short nucleic acids by non-viral systems that overcome these problems and show utility for in vivo applications remains a high priority for investigation since they have the potential to be of therapeutic relevance.

Recently, a new multi-component, cyclodextrin-based nucleic acid delivery system has been described (Davis et al,, 2003). The first component of this system is a short (approximately five repeat units giving on average ten charges per polymer chain), cyclodextrin-containing polycation (CDP, Figure lA) that can self-assemble with nucleic acids via electrostatic interactions and form uniformly sized, sub- $100 \mathrm{~nm}$ particles termed "polyplexes" (Felgner et al., 1997) (Figure 2A). The CDPs are capable of providing the in vitro delivery of plasmids in the presence of serum (Gonzalez et al., 1999; Hwang et al., 2001; Popielarski et al., 2003; Reineke and Davis, 2003a; Reineke and Davis, 2003b). The CDPs demonstrate low toxicity in vitro (for $\beta C D P 6$, a CDP containing 6 methylene units between charges, $\mathrm{IC}_{50}=$ $1.1 \mathrm{mM}$ to BHK-21 cells) and in vivo (for $\beta C D P 6, L_{40}=200 \mathrm{mg} / \mathrm{kg}$ in mice) and may be suitable for oligonucleotide delivery due to their low degree of polymerization (short polycations are known to minimize complement activation (Ward et al., 2001)). Polyplexes formed using CDPs can be modified to impart stability in biological fluids and cell targeting specificity by surface decoration with adamantane-based modifiers (Figures 1B, $1 \mathrm{C}, 2 \mathrm{~B}$ and $2 \mathrm{C}$ ) (Pun and Davis, 2002). The adamantane (AD) forms an inclusion species with exposed cyclodextrins on the polyplexes by complexation, an enthalpically driven physical phenomenon based on van der Waal's interactions between the cyclodextrin cavity interior and the molecular surface of the adamantine derivatives (Pun and Davis, 2002). Transferrinmodified, poly(ethylene glycol) (PEG)-stabilized polyplexes (Tf-PEG-polyplexes) are prepared by polyplex modification with transferrin-PEG-AD and PEG-AD conjugates (Figure 2C). Transferrin was chosen as a model ligand for oligonucleotide delivery to tumors because the transferrin receptor (Tf-R) is often upregulated in rapidly growing cells (Thorstensen and Romslo, 1993). These Tf-PEG-polyplexes have been shown to facilitate plasmid delivery and in vitro transgene expression via transferrin receptor-mediated endocytosis (Bellocq et al., 2003b).

Joyce and coworkers used in vitro selection to obtain single-stranded DNA capable of catalytic cleavage of RNA (Breaker and Joyce, I994; Tsang and Joyce, 1996; Santoro and Joyce, 1997). These enzymatic DNAs (DNAzymes) have been successful in site-specific RNA cleavage in both in vitro and in vivo settings (Santiago et al., 1999; Warashina et al., 1999; Wu et al., 1999). The potential advantages of DNAzymes include their catalytic efficiencies, relative stabilities and cost of production.

Expression of the c-myc proto-oncogene can correlate with cell proliferation. Therefore, cmyc has been investigated as a target for down-regulation by oligonucleotides and catalytic 
Chapter 2

nucleic acids for diseases that involve undesired cell growth such as cancer (Giles et al., 1999; Putney et al., 1999; Cheng et al., 2000; McGuffie et al., 2000) and restenosis (Shi et al., 1994; Cairns et al., 1999; Sun et al., 1999). For example, DNAzymes targeting the translation initiation region of c-myc RNA have been reported to site-selectively cleave full length RNA and downregulate c-myc gene expression in smooth muscle cells (Cairns et al., 1999; Sun et al., 1999).

The objective of this work is to assess the ability of the cyclodextrin-containing polycation delivery system (Gonzalez et al., 1999; Pun and Davis, 2002; Davis et al., 2003) to provide for the in vivo delivery of anti-c-myc DNAzymes (Cairns et al., 1999; Sun et al., 1999) to subcutaneous tumors in mice. The study focuses on the preparation of transferrin-modified polyplexes and their biodistribution in tumor-containing nude mice. This is the first report of oligonucleotide delivery using the CDP system. We show that this delivery system lacks significant toxicity, is able to deliver DNAzymes in the presence of serum, and can target tumor tissue via transferring-mediated targeting when the construct is systemically injected.

\section{MATERIALS \& METHODS}

\section{Cells, animals and materials}

The following human cell lines were used in this study: the cervical carcinoma HeLa cell line, cultured in minimum essential medium, the ovarian carcinoma A2780 cell line, cultured in RPMI 1640, and the colorectal carcinoma cell line, HT29, cultured in McCoys $5 \mathrm{~A}$. Culture media were supplemented with $10 \%$ fetal calf serum, $50 \mu \mathrm{g} / \mathrm{ml}$ gentamycin, and $2 \mathrm{mM}$ L-glutamine. Cells were grown at $37^{\circ} \mathrm{C}$ in a humidified incubator with $5 \% \mathrm{CO}_{2}$. All media and supplements were purchased from Invitrogen (Paisley, UK).

Male NMRI mice were purchased from Janvier (Le Genest-St-Isle, France). All animal experiments were carried out with animal ethical committee approval. The ethical guidelines that were followed met the standards required by the UKCCCR guidelines. Mice were inoculated subcutaneously in the inguinal region with $10^{7}$ cells $/ 200 \mu \mathrm{l}$ serum-free medium using $26 \mathrm{GA}$ syringes $(B D, 26 \mathrm{GA} 3 / 8 \mathrm{lml}$ ). Mice were used 14-16 days after cell suspension injection.

5'-Fluorescein-labeled and 5'-Cy-3-labeled DNAzymes (5'-labelTGAGGGGCAGGCTAGCTACAACGACGTCGCGGx-3' with $x=3$ ' ${ }^{\prime}$ (G5') were purchased from Eurogentec (Seraing, Belgium). In order to improve stability, a 3'dG5'-3' thymidylate inversion was incorporated at the 3' end. CDP-Imid, AD-PEG s000 , AD-glugluPEG-gal, and AD- $P E_{3400}$-Tf were synthesized following analogous protocols described previously (Jensen et al., Bellocq et al., 2003b). Fluorescein-labeled transferrin (Tf-fluor) was prepared by conjugation of fluorescein-5-thiosemicarbazide to transferrin by reductive amination according to literature procedures (Bellocq et al., 2003b).

\section{Polyplex formulation and characterization}

Unmodified polyplexes were prepared by adding an equal volume of CDP-Imid (Figure 1A) solution to a DNAzyme solution at the desired polymer-to-DNA charge ratios (Figure 
2A). Transferrin-modified polyplexes (Tf-PEG-polyplex) (Figure 2C) were formulated by mixing three equal volume aliquots of the three polymer components (CDP-Imid, AD-PEG (adamantane-poly(ethylene glycol)(Figure 1B)) or AD-PEG/AD-glu-glu-PEG-gal (Figure $1 B$ ) at 60:40 molar ratio, and AD-PEG-Tf (adamantane-poly(ethylene glycol)-transferrin) (Figure $1 C)$ ) and adding the resulting polymer solution to an aliquot of DNAzyme solution (volume of DNAzyme solution is $25 \%$ of final volume). For example, to prepare $0.3 \mathrm{~mL}$ of Tf-PEG-polyplex solution at $5 \mathrm{mg}$ DNAzyme $/ \mathrm{mL}, 75 \mu \mathrm{L}$ of CDP-Imid $(125 \mathrm{mg} / \mathrm{mL}), 75$ $\mu \mathrm{L}$ of AD-PEG/AD-gluglu-PEG-gal (40:60 mixture of $395 \mathrm{mg} / \mathrm{mL}$ AD-PEG and 430 $\mathrm{mg} / \mathrm{mL}$ AD-gluglu-PEG-gal) and $75 \mu \mathrm{L}$ of Tf-PEG-AD $(132 \mathrm{mg} / \mathrm{mL})$ were mixed together and then added to $75 \mu \mathrm{L}$ of DNAzyme $(20 \mathrm{mg} / \mathrm{mL})$. For formulations without AD-PEG-Tf (PEG-polyplex) (Figure 2B), an aliquot of $5 \%$ glucose solution was added in lieu of the AD-PEG-Tf solution. All polyplexes used for in vivo injections were prepared in $5 \%$ sterile glucose and contained CDP-Imid at a charge ratio of 2.5 (defined as ratio of moles of polymer amidines to moles of nucleic acid phosphates), AD-PEG or AD-PEG/AD-glugluPEG-gal at 98:100 (ratio of moles of adamantane to moles of cyclodextrin), and AD-PEGTf at 2:100 (ratio of moles of adamantane to moles of cyclodextrin). As has been shown previously, the adamantane modifiers that contain anionic segment are used to tune the surface charge of the formulated particles. Here, AD-gluglu-PEG-gal (gluglu is the anionic segment) is employed to modify the nature of the surface charge of the formulated particles since we have already reported that this component can work well to vary particle zeta potentials (Davis et al., 2003).

The extent of DNAzyme complexation was monitored by gel electrophoresis. Polyplexes were prepared as described above. Aliquots containing $1 \mu \mathrm{g}$ DNA were diluted to $16 \mu \mathrm{L}$ with distilled water. $4 \mu \mathrm{L}$ of sample buffer were added to each aliquot, and transferred to a $1 \%$ agarose/TAE (40 mM Tris-acetate/ $/ \mathrm{mM}$ EDTA) gel containing $6 \mu \mathrm{g}$ ethidium bromide $/ 100 \mathrm{~mL}$. Samples were electrophoresed for 2 hrs at $50 \mathrm{~V}$.

Polyplex morphology was visualized by transmission electron microscopy. Unmodified, PEGylated and transferrin-modified polyplexes containing $1 \mu \mathrm{g}$ of DNAzyme were prepared. Five microliters of sample were then applied to glow-discharged, 400-mesh carbon-coated copper grids for $45 \mathrm{~s}$, after which excess liquid was removed by blotting. The samples were then negatively stained with $2 \%$ uranyl acetate for $45 \mathrm{~s}$ before observation.

Images were recorded using a Philips 201 electron microscope operated at $80 \mathrm{kV}$.

In vitro analysis.

A2780, HT29, and HeLa cells were analyzed for relative levels of transferrin receptor expression. Cells were plated at 300,000/well in 6-well plates 24 hrs prior to transfection. Cells were then washed with PBS and exposed to $1 \mathrm{~mL}$ of antibiotic-free culture media containing $1 \% \mathrm{BSA}$ and various concentrations of fluorescein-labeled transferrin (ranging from $25 \mathrm{nM}$ to $500 \mathrm{nM}$ ) for $1 \mathrm{hr}$. The cells were washed twice with PBS, collected by trypsin treatment, washed twice in FACS buffer $(25 \mathrm{~mL}$ of Hank's Buffered Salt Solution supplemented with $2 \mathrm{mM} \mathrm{MgCl} 2$ and containing $10 \mu \mathrm{L}$ DNase), and resuspended in Hanks Buffered Salt Solution for analysis by flow cytometry using a FACSCalibur from Becton Dickenson (San Jose, CA). 
The polyplexes were tested for their ability to bring DNAzymes into A2780, HT29, and HeLa cells. Cells were plated at 300,000/well in 6-well plates $24 \mathrm{hr}$ prior to transfection. For in vitro analysis, unmodified polyplexes were prepared by mixing CDP-Imid and fluorescein-labeled DNAzyme at various polymer-to-DNA charge ratios as described above. Immediatcly before the uptake experiments, cells were washed with OptiMEM and exposed to unmodified particles containing $5 \mu \mathrm{g}$ of DNAzyme in $0.5 \mathrm{~mL}$ OptiMEM. After $1 \mathrm{hr}$, cells were then washed twice with PBS, collected by trypsinization, washed twice in FACS buffer and Cell Scrub Buffer (Gene Therapy Systems, San Diego, CA) and analyzed for uptake by flow cytometry.

\section{In vivo tumor delivery of fluorescently tagged oligonucleotides \\ Microscopy.}

A whole body imaging (WBI) system was used to investigate the in vivo tumor delivery of fluorescently tagged DNAzymes. This imaging system consists of a fluorescence stereomicroscope (Olympus) SZX12 equipped with a green fluorescent protein (GFP, excitation: 485-501 nm; emission: $510 \mathrm{~nm}$ ) and a red fluorescent protein (RFP, excitation $540-552 \mathrm{~nm}$; emission: $568-643 \mathrm{~nm}$ ) filter set (Bakker et al., 2001). Images (752x582 pixels) were acquired at $1 / 60^{\text {th }}$ of a second using a (Jai) CV-M90 3-CCD RGB color camera and analyzed using in-house developed application software that is based on IMAQ Vision software components and LabVIEW (National Instruments).

Intracellular DNAzyme delivery was investigated on tumor sections using fluorescence microscopy. Briefly, at the end of cach animal experiment, fluorescent tumors were extracted, cryofixed and sectioned. Twelve- $\mu m$ sections were observed using a AxioPlan2 (Zeiss) fluorescence microscope coupled to a AxioCam HR (Zeiss) CCD camera and high resolution pictures $(1300 \times 1030$ pixels) were captured and further analyzed using AxioVision software (Zeiss). Intracellular distribution of Cy-3 labeled DNAzyme (red) was investigated using a FITC (green) phalloidin cytoskeleton staining. Intracellular distribution of FITC (green) labeled DNAzyme was investigated using a Sytox (orange) Orange nuclear staining.

\section{DNAzyme administration in vivo.}

Male NMRI mice were treated with $1 \mathrm{mg}$ Cy3-conjugated c-myc DNAzyme (Cy3DNAzyme) or polyplex formulations containing $1 \mathrm{mg}$ of Cy3-DNAzyme. Several administration methods were assessed: intraperitoneal bolus injection, intraperitoneal infusion, subcutaneous injection and intravenous injection. For intraperitoneal injections, $200 \mu \mathrm{L}$ of Tf-PEG-polyplex solution or Cy3-DNAzyme were injected into the peritoneal cavity. Continuous intraperitoneal delivery was obtained by using osmotic pumps (Alzet $2001 \mathrm{D})$ with a flow rate of $8 \mu \mathrm{L} / \mathrm{hr}$ implanted in the peritoneal cavity. The pumps were filled with DNAzyme $(5 \mathrm{mg} / \mathrm{ml})$ alone or DNAzyme encapsulated in various polyplex formulations at the same concentration. The stability of the modified polyplexes was verified by following their particles sizes by dynamic light scattering for 24 hours at $37^{\circ} \mathrm{C}$. Tf-PEG-polyplex was formulated as described above and incubated at a $37^{\circ} \mathrm{C}$ water bath. Particle size was monitored before incubation and 24 hrs after incubation by dynamic light scattering. The DNAzyme after incubation was submitted for Maldi-Tof mass spectroscopy along with fresh DNAzyme in solution. The analysis confirmed that no degradation 
occurred. Intravenous injections were administered via the tail vein at injection rates of $-200 \mu \mathrm{L} / 10 \mathrm{sec}$. Mice were sacrificed at specified times and organs (tumor, liver, and kidney) extracted for WBI as described above.

DNAzyme clearance after intraperitoneal injection was monitored by WBI at 3,8 , and 24 hrs post-injection. In addition, mice were sacrificed at the specified times and organs (tumor, liver, and kidney) extracted for whole organ imaging and histological analysis. For the other administration methods, mice were imaged at 24 hrs based on results from the intraperitoneal injection time course studies. In addition to WBI, animals were sacrificed at $24 \mathrm{hrs}$ and tumor and organs extracted for whole organ imaging and histological analysis for comparison of tumor distribution of the different formulation via the various administration routes.

\section{RESULTS}

DNAzyme formulations for in vitro studies

The nucleic acid delivery system under investigation here consists of two classes of

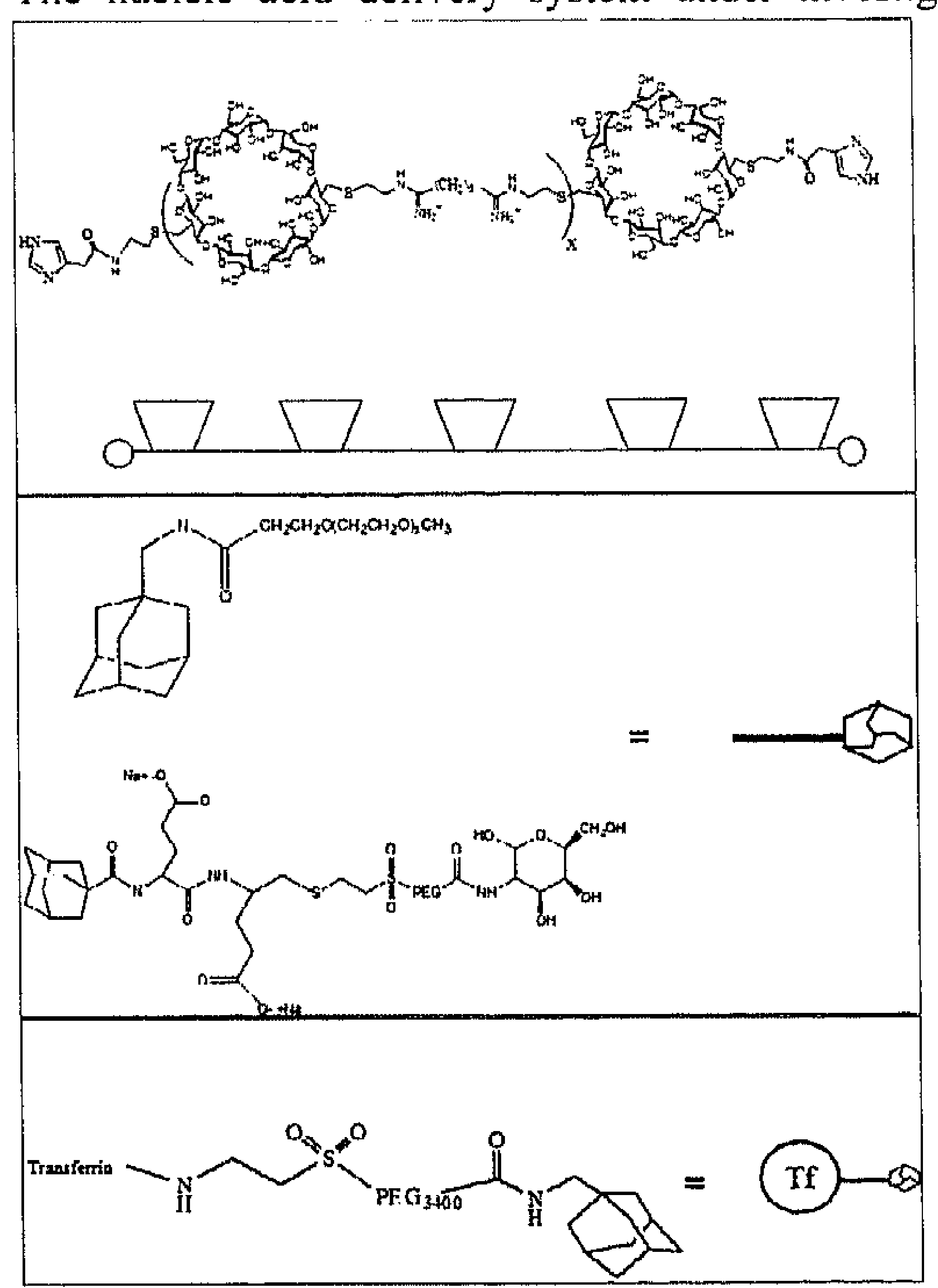
components: linear, cyclodextrin-based polycations that condense nucleic acids to form small nanoparticles and adamantane-based conjugates that modify the surface of the polyplexes. For these studics, a cyclodextrin-based polycation that is end-modified with imidazole (CDP-Imid) is used as the nucleic acid condensing agent, adamantane-poly(ethylene glycol) (AD-PEG) serves as a particle stabilizer, adamantane-diglutamatepoly(ethylene glycol)-galactose (ADgluglu-PEG-gal) tunes the polyplex surface charge by neutralizing excess cationic charges, and adamantanepoly(ethylene glycol)-transferrin (ADPEG-Tf) imparts tumor-targeting specificity to the particles via the transferrin ligand. The structures of the components are shown in Figure 1.

FIGURE 1: comprolents of lintur. cycledestrin polymer-based delwery sysem firr nueleic acids:

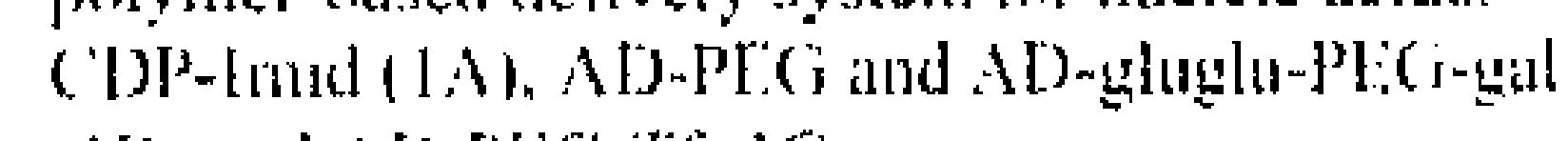
(IB) and AD)-PlG If (IC) 
Chapter 2

Polyplexes were prepared by mixing the polymer solutions together and then adding the mixture to the DNAzyme in solution. The CDP-Imid binds to DNAzyme via electrostatic interactions and the AD-based modifiers interact with surface cyclodextrin by inclusion complex formation. The DNAzyme-binding profile of CDP-Imid was determined by gel electrophoresis. CDP-Imid was mixed with DNAzyme at various charge ratios (moles of positive amidine charges on CDP-Imid to moles of negative phosphate charges on DNAzymes) and run on a $1 \%$ agarose gel. Unformulated DNA migrates down the gel and is visualized by ethidium bromide, while bound DNA remains in the loading wells of the gel. The majority of DNAzyme is observed to be bound with CDP-Imid at a charge ratio of 1 (Figure 3).

\section{In vitro delivery of DNAzymes}

The DNAzyme delivery efficiency of CDP-Imid-based particles prepared at various charge ratios of CDP-Imid to DNAzyme was determined by using a fluoresceinlabcled DNAzyme (fluorDNAzymc) in the formulations. Polyplexes were prepared at charge ratios ranging from 2 to 10 . Particle sizing analysis by dynamic light scattering revealed small, condensed particles, confirming that fluorescein does not interfere with DNAyzme condensation (data not shown). Polyplexes were exposed to several cell lines for one hour before cells were washed with PBS and Cell Scrub Buffer (for removing surfaceassociated polyplexes) and assayed for fluor-DNAzyme internalization by flow cytometry. CDP-Imid is able to efficiently mediate DNAzyme uptake to all cell lines at all charge

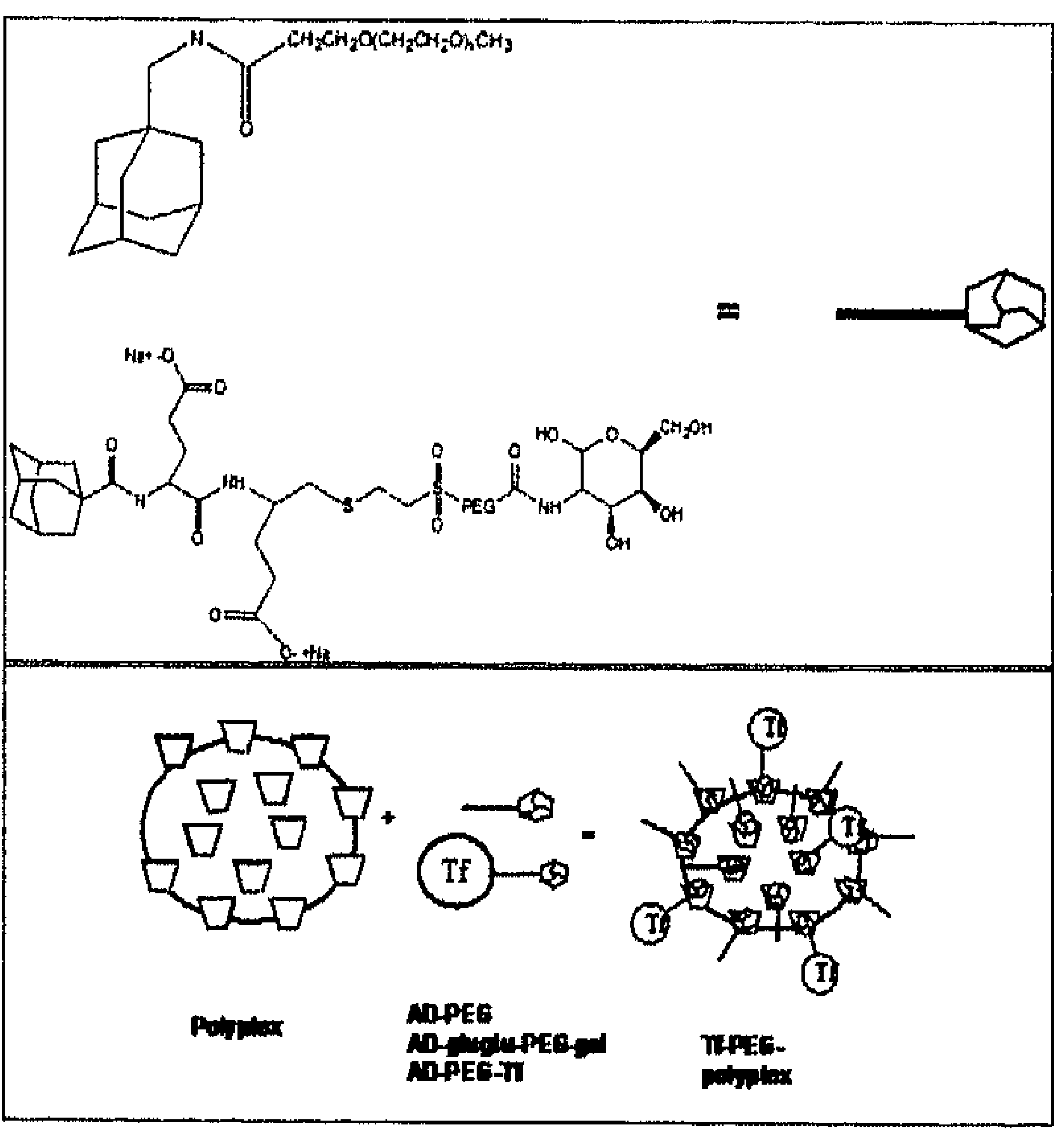

FIGURE 2: Assembly of pulypies fornulations: polyplex (2A). PE: (i-

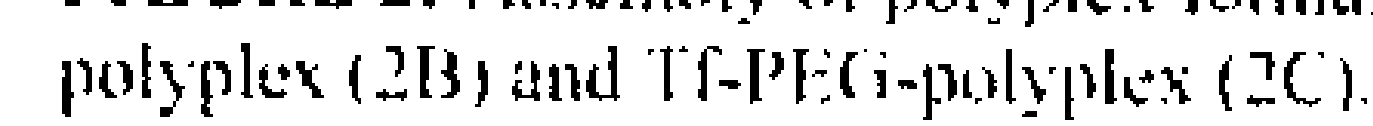

ratios tested (Figure 4). Polyplexes formulated at a charge ratio of 2 are internalized by over $95 \%$ of A2780 and HT-29 cells. HeLa cells are transfected at $83 \%$ and $97 \%$ cfficiencies with polyplexes formulated at charge ratios 2 and 5 , respectively. Unformulated DNAzymes are not readily endocytosed by cells ( $<2 \%$ positive cells for all cell lines). 


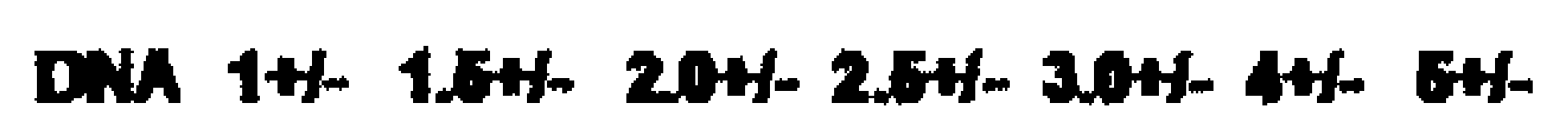

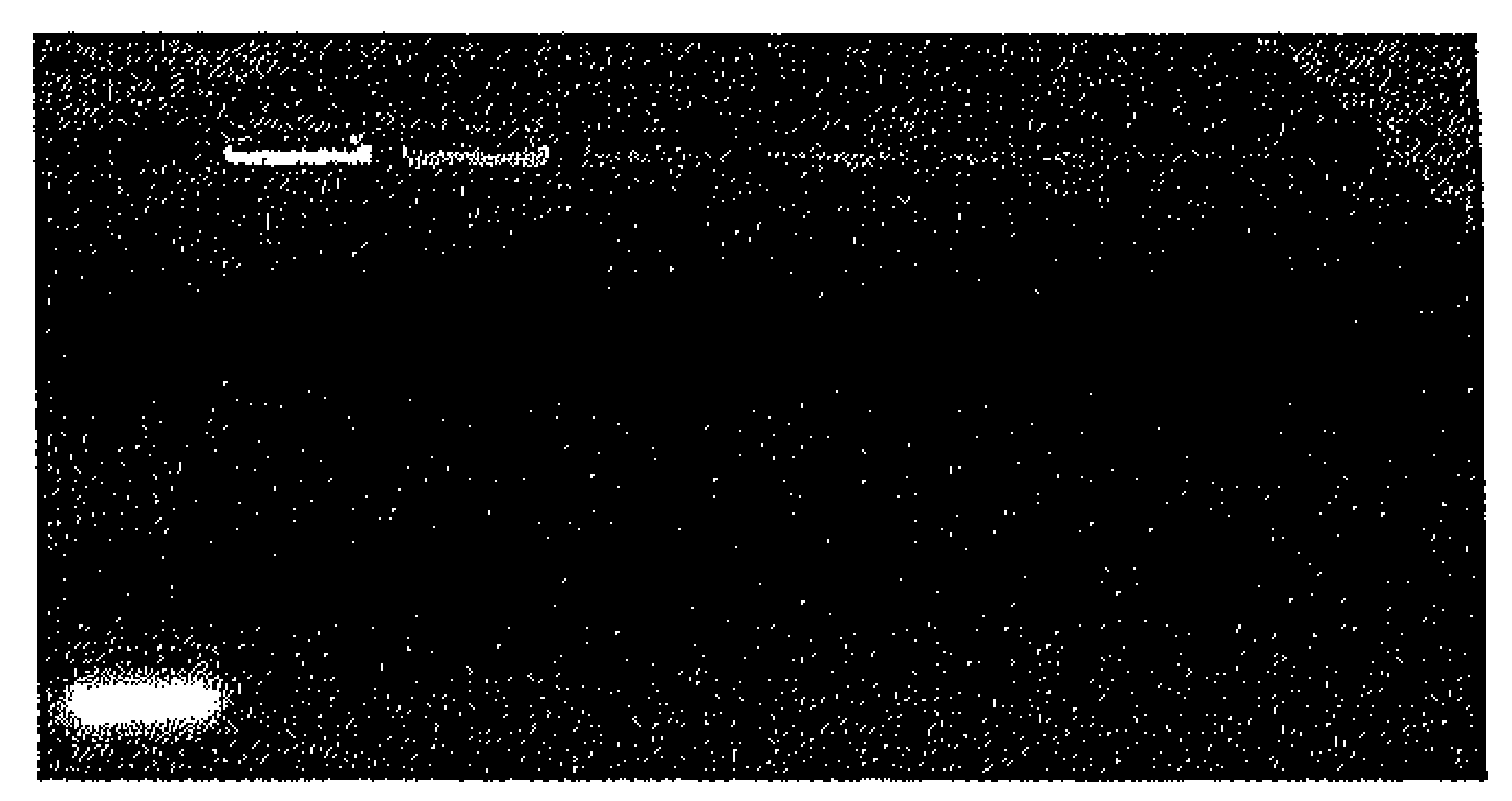

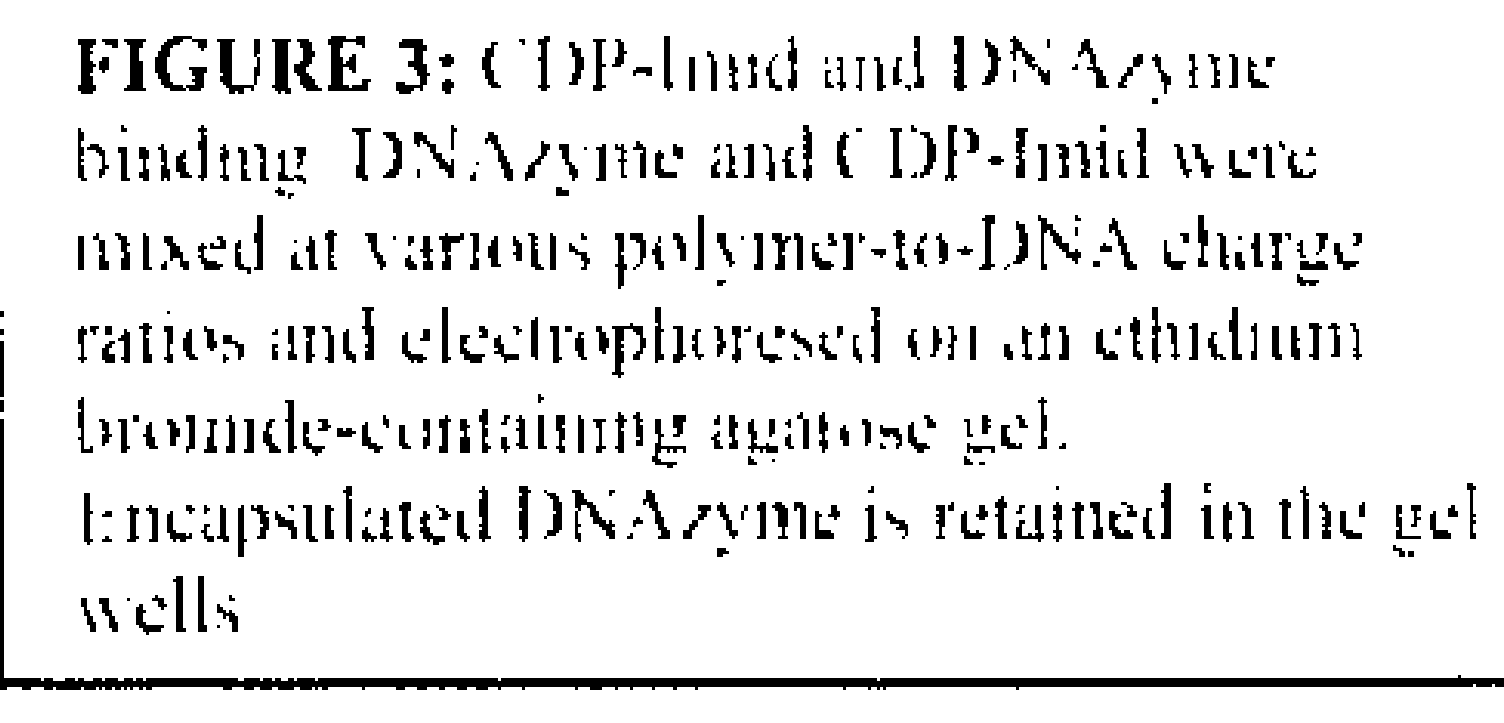

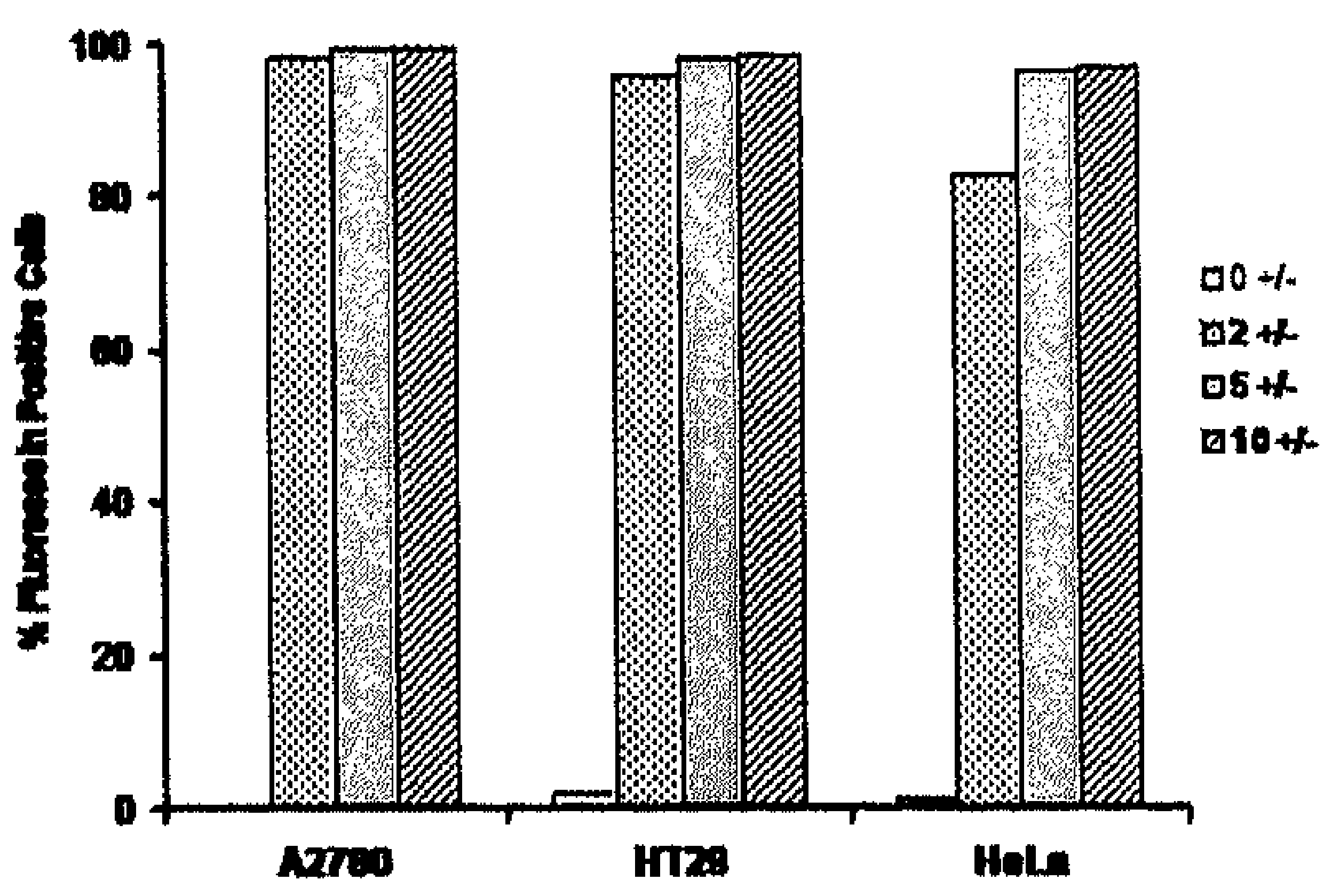

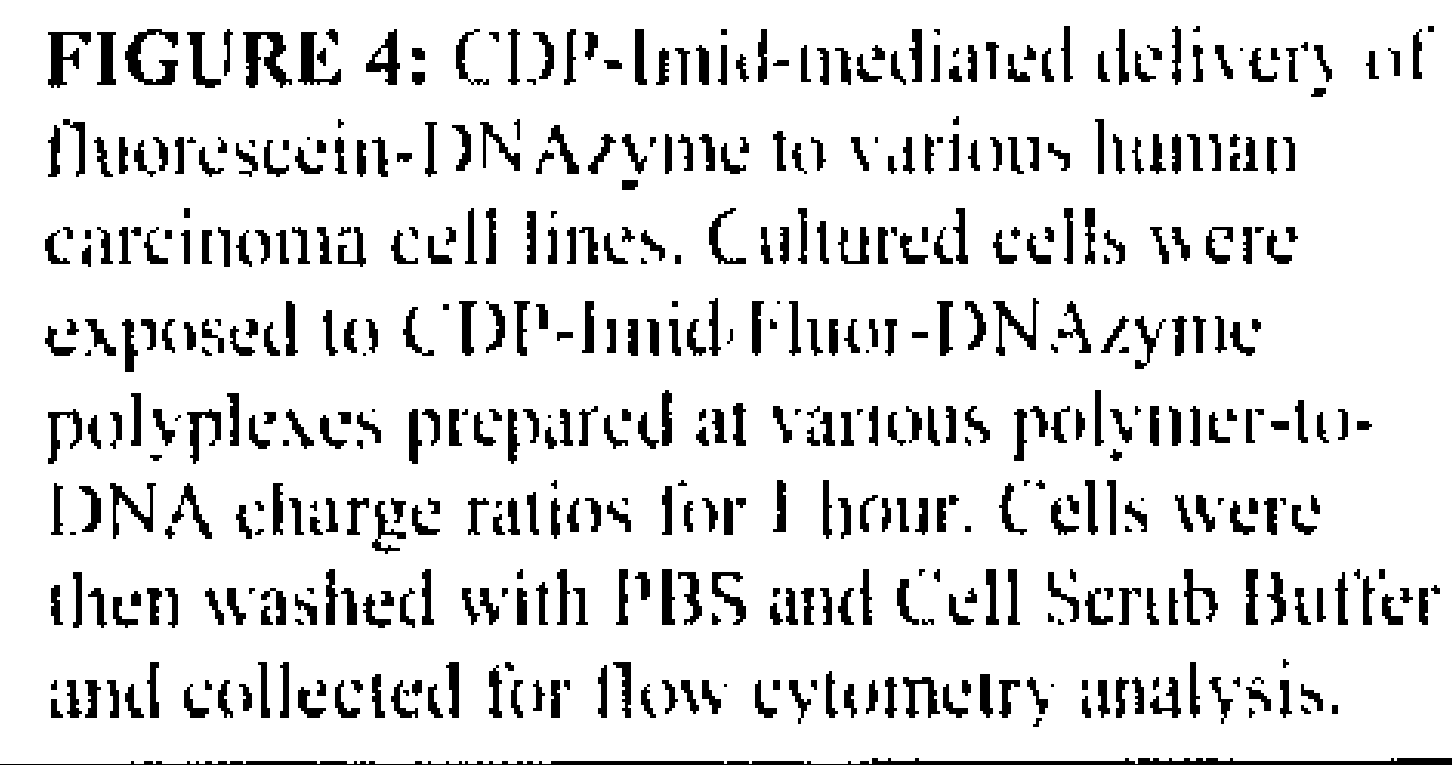

Transferrin receptor expression in various carcinoma cell lines

Several carcinoma cell lines were tested for their relative levels of transferrin receptor expression in order to identify a suitable cell line for a mouse xenograft model. Three human carcinoma cell lines (A2780, HT-29 and HeLa) were exposed to various concentrations of fluorescently-labeled transferrin (Tf-fluor) for $1 \mathrm{hr}$, washed to minimize non-specific interactions, and analyzed for levels of transferrin association by flow cytometry. Results are shown as the percentage of total cells with a positive fluorescence signal (Figure 5). Higher levels of fluorescence indicate more Tf-fluor association that in turn, is likely proportional to the number of cell surface transferrin receptors. Of the cell lines tested, HeLa cells have the highest transferrin uptake: $99 \%$ of HeLa cells were associated with Tf-fluor at $500 \mathrm{nM} \mathrm{Tf}$-fluor. HT-29 cells have intermediate transferrin uptake ( $60 \%$ of HT-29 cells fluorescein positive at $500 \mathrm{nM}$ Tf-fluor) while the A2780 cells have relatively low levels of transferrin uptake ( $14 \%$ of A2780 cells fluorescein positive at $500 \mathrm{nM}$ Tf-fluor). HT-29 cells were thus used to develop xenograft tumors in a nude mouse model for in vivo studies since we did not wish to arbitrarily bias the results by using cell lines with high or low transferrin uptake. 


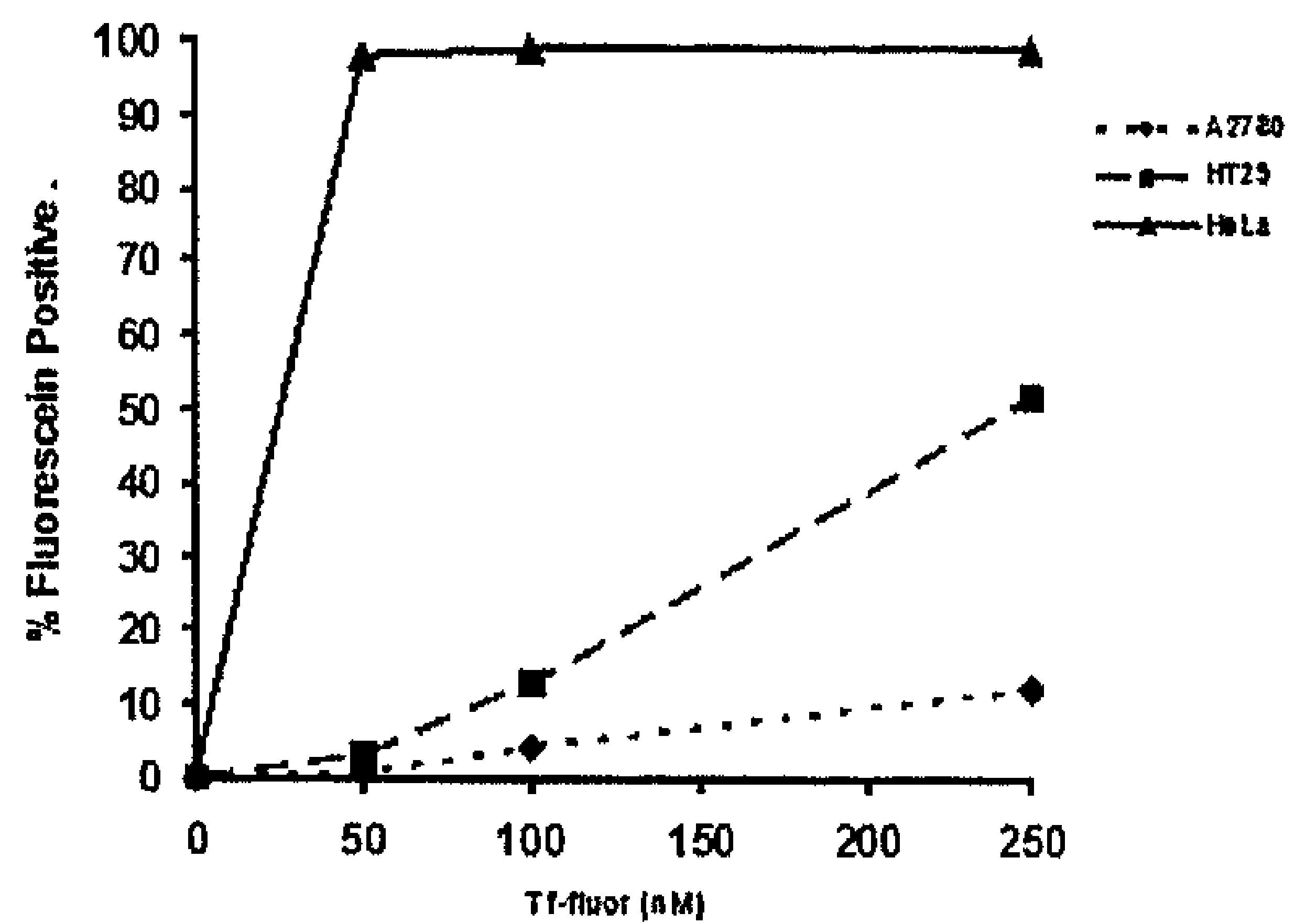

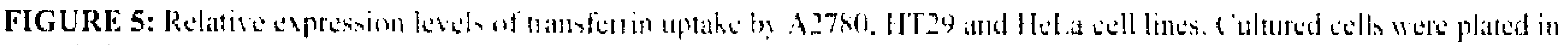

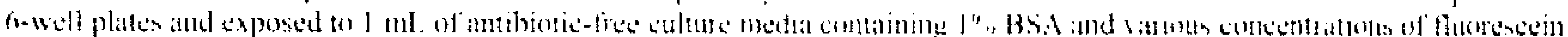

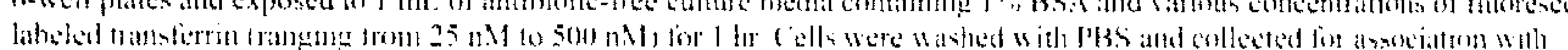

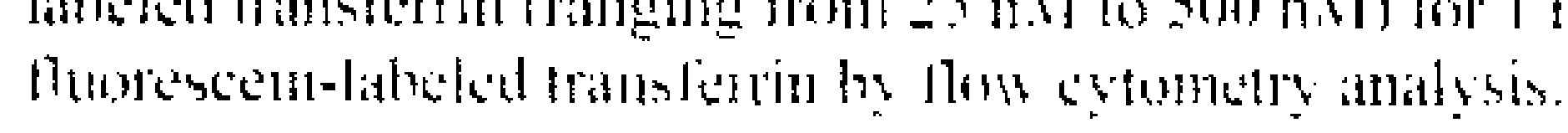

DNAzyme formulations for in vivo studies

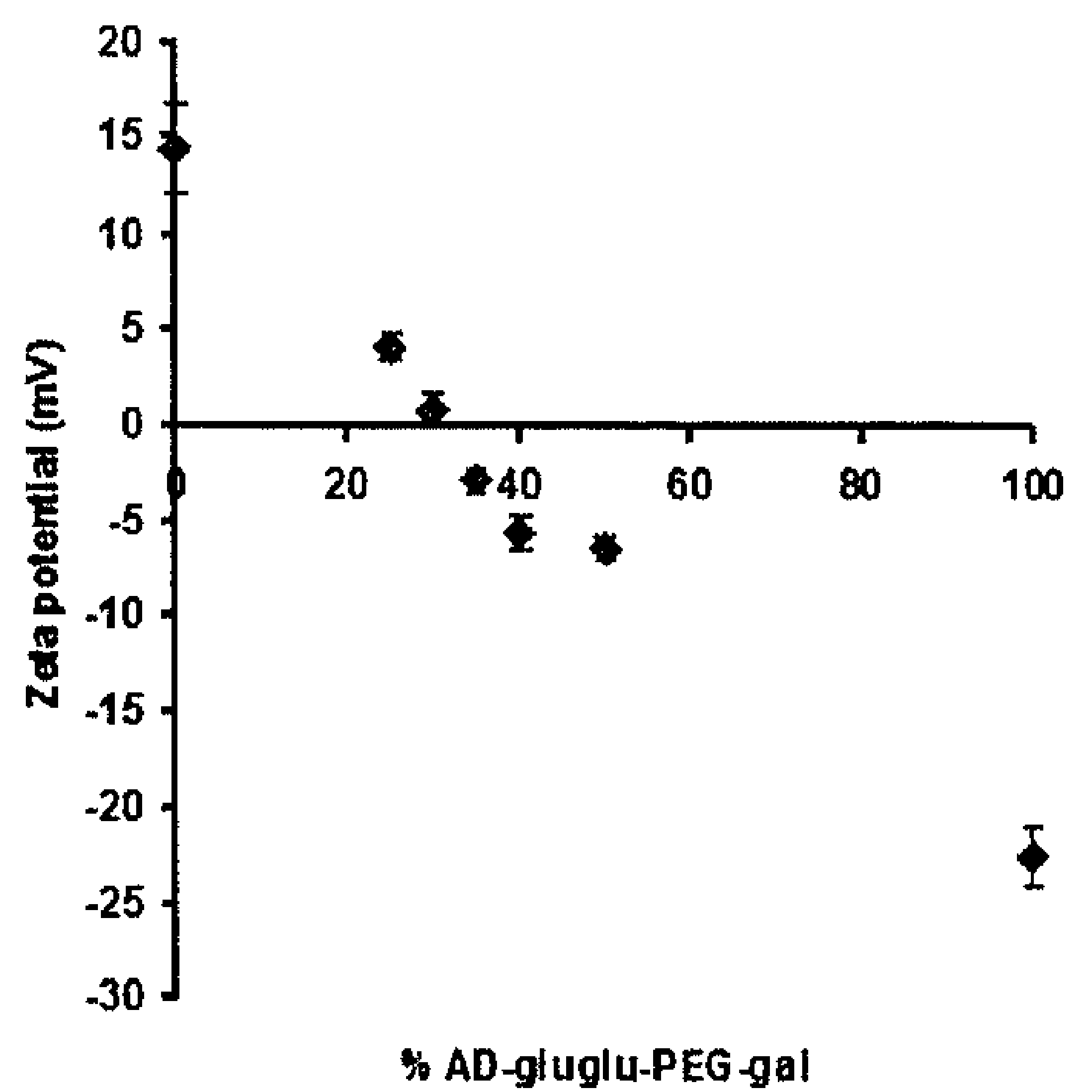

FIGURE 6: 1 thmpg of particle eta putential by modification with AD-gluglu-P'E(j-gall. Polyplexes,

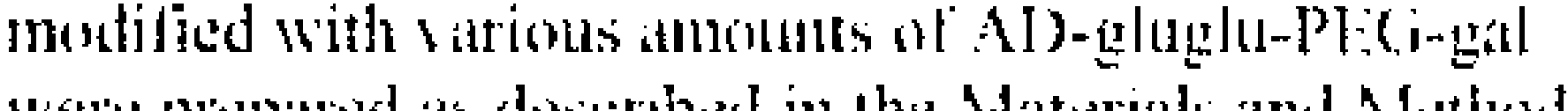
wert preparted ats described in the Materials and Metilods stetion. The seta puttential of the partecles was

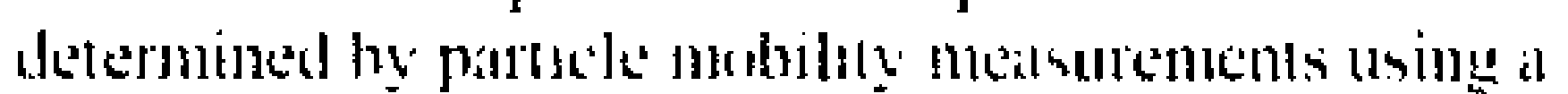
Zetalpals dynamic light scattering detector (Brook haven Instruntents). Zattia potential is repurted as the mean SD of 4 meisurements.
The DNAzyme-containing particles require surface modification to bc suitable for in vivo applications. In order to achieve this, the particles were modified by several adamantane (AD)based conjugates. We have previously shown that polyplexes can be stabilized against salt-induced aggregation by formulation with $\mathrm{AD}$ PEG at 1:1 AD-PEG to cyclodextrin ratios (mole to mole) (Pun and Davis, 2002). In addition, polyplex surface charge can be tuned by the addition of an adamantane-PEG modifier containing anionic residues such as AD-gluglu-PEG-gal. For example, polyplexes formulated at a charge ratio of 3 and modified with $100 \%$ AD-PEG have positive zeta potential $(\sim+15$ $\mathrm{mV}$ ) while modification with increasing ratios of $A D$-gluglu-PEGgal to AD-PEG results in particles with negative zeta potentials (Figure 6). Our preliminary studies as well as reports 
from others in the field indicate that particles with slightly negative surface charge display prolonged circulation and improved passive tumor targeting (Moghimi et al., 2001). Therefore, modification with 40:60 AD-gluglu-PEG-gal to AD-PEG gives particles with zeta potentials of $-6 \mathrm{mV}$ and were used for the animal studies. The final component used in the formulation, AD-PEG-Tf, introduces transferrin as a targeting agent.

Fully formulated polyplexes were prepared by first mixing the delivery system components (CDP-Imid, AD-PEG, AD-gluglu-PEG-gal, AD-PEG-Tf) and then adding the polymer solutions to a solution of DNAzyme. Three types of polyplexes were prepared: unmodified polyplexes (Figure 2A, CDP-Imid + DNAzyme), PEGylated polyplexes (Figure 2B, "PEGpolyplex", CDP-Imid + AD-PEG + DNAzyme), and transferrin-modified, PEGylated polyplexes (Figure 2C, "Tf-PEG-polyplex", CDP-Imid + AD-PEG/AD-gluglu-PEG-gal + AD-PEG-Tf + DNAzyme). All polyplexes were formulated at a charge ratio of 2.5 (CDPImid to DNAzyme charge ratio). PEG-polyplexes include 1:1 AD-PEG/AD-gluglu-PEGGal (40:60 ratio) to cyclodextrin (by mole) and Tf-PEG-polyplexes include 2:100 ADPEG-Tf to cyclodextrin and 98:100 AD-PEG/AD-gluglu-PEG-gal to cyclodextrin (both by mole). The morphologies of the three polyplex formulations were imaged by transmission electron microscopy. Polyplexes, prepared as described, were deposited in solution on glow-discharged, carbon-coated copper grids and negatively stained with uranyl acetate. The three formulations yielded particles with similar morphology and size (Figure 7). DNAzymes were fully condensed to uniform, spherical particles with diameters ranging from $\sim 30 \mathrm{~nm}$ (for unmodified polyplexes) to $\sim 50 \mathrm{~nm}$ (for Tf-PEG-polyplex).

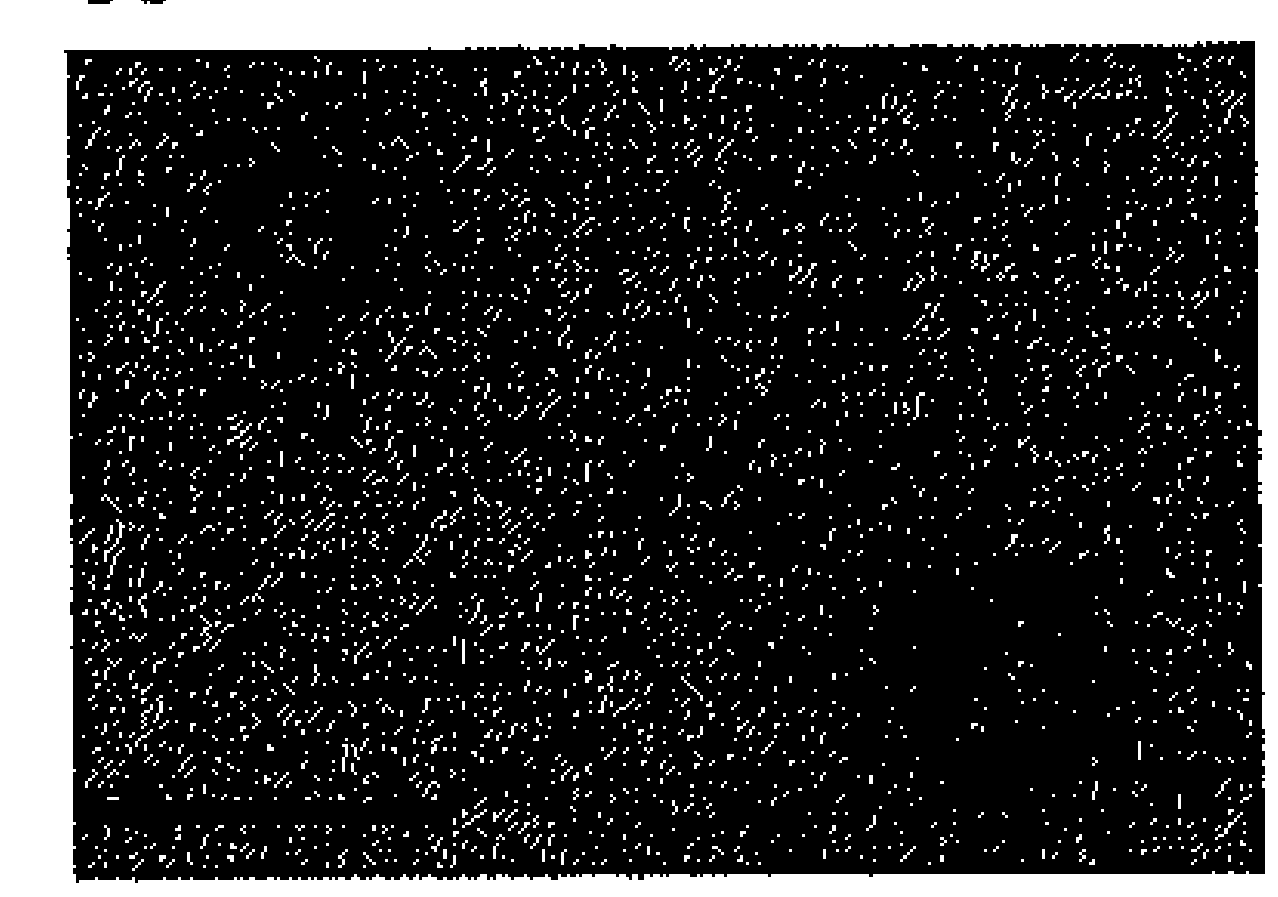

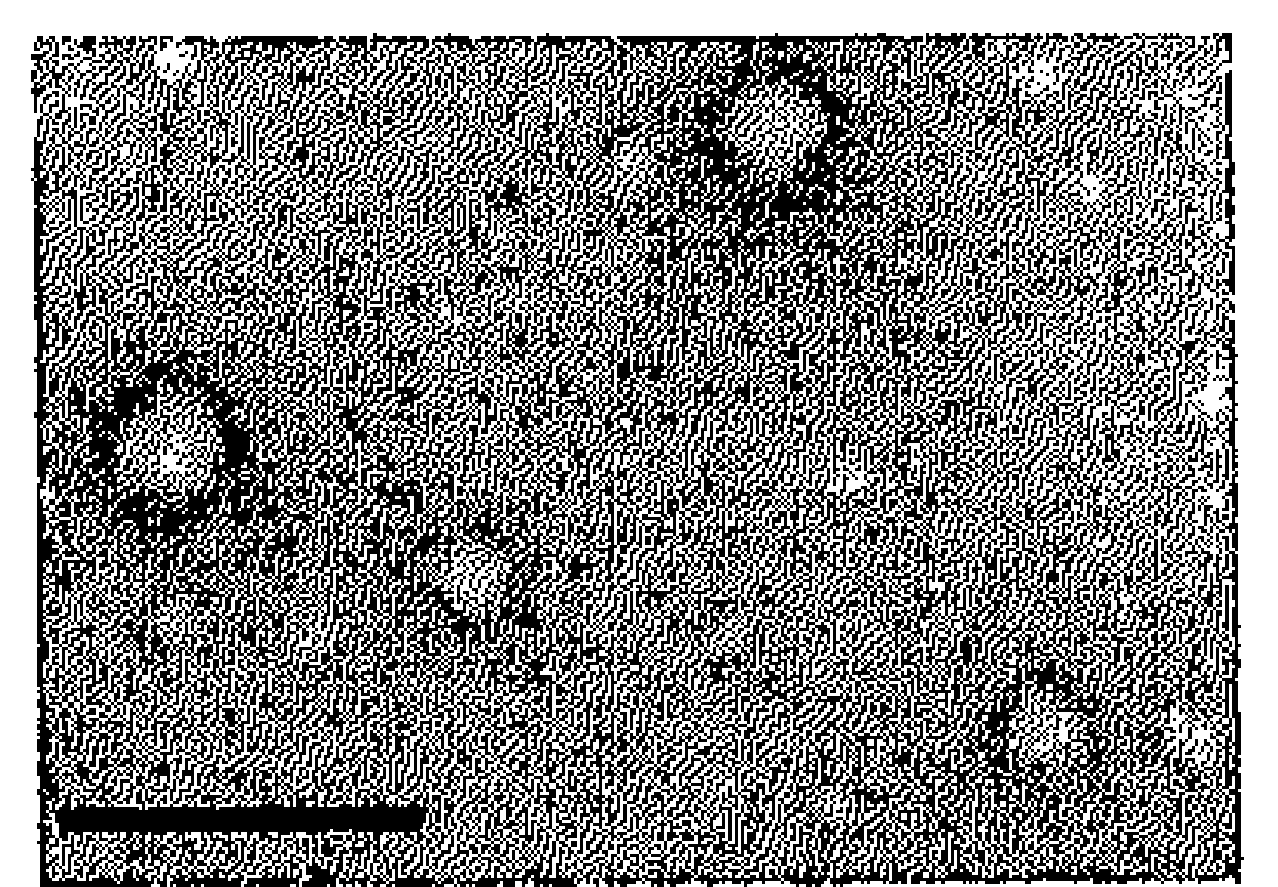

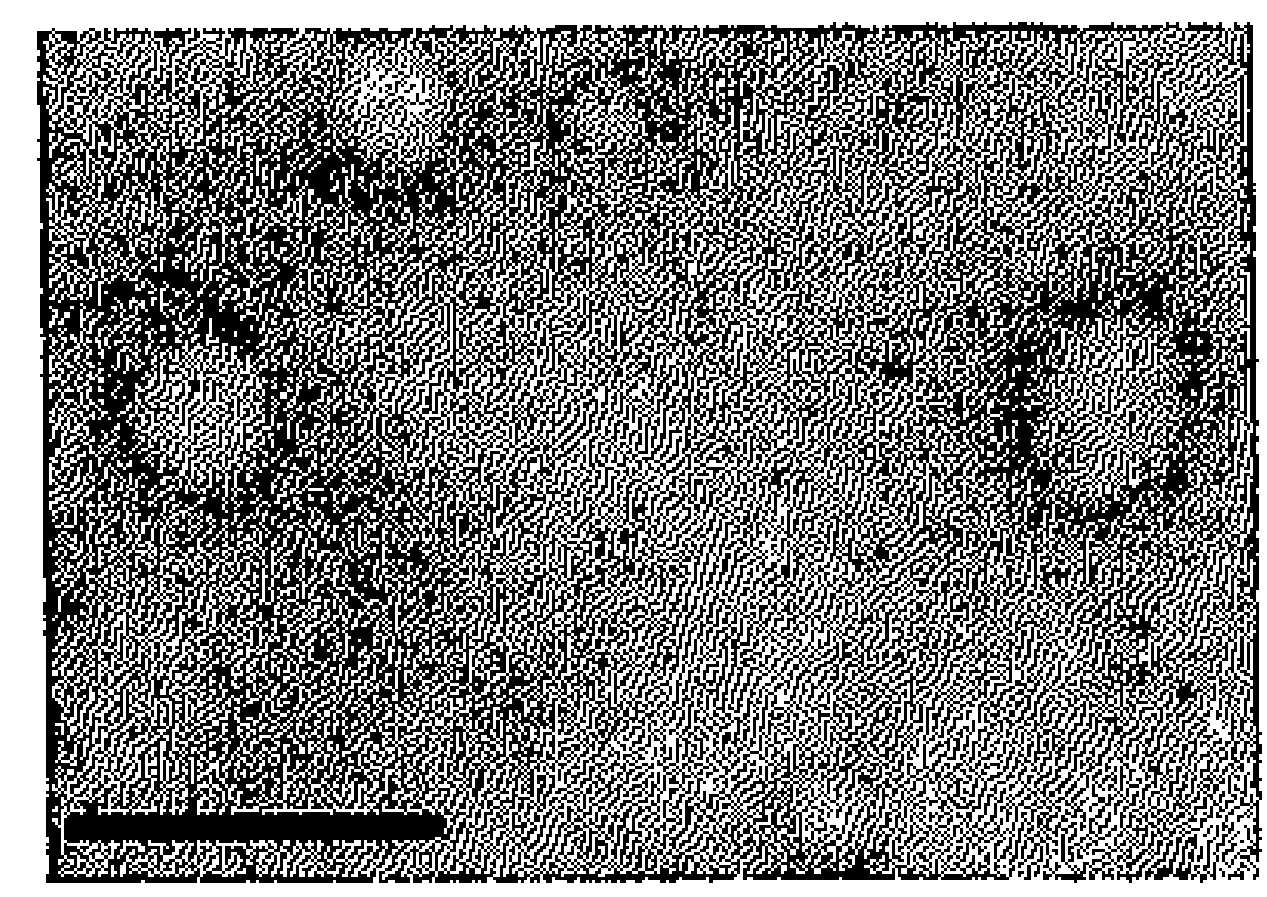

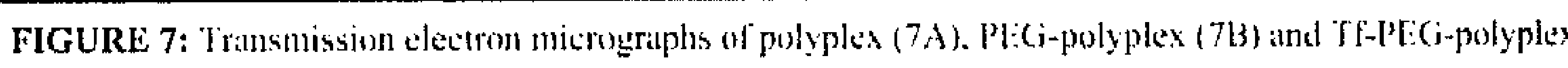
(7C). Bar tepresents $100 \mathrm{~nm}$.

In vivo administration of non-formulated DNAzymes compared to DNAzymecontaining polyplexes using the CDP-based delivery system.

Male NMRI mice bearing HT-29 tumors were injected in the peritoneal cavity with $1 \mathrm{mg}$ of Cy-3-labelled DNAzyme (Cy3-DNAzyme) either alone or in Tf-PEG-polyplex formulations. The fluorescence distributions were monitored by whole body imaging (WBI) using an Olympus fluorescence stcreomicroscope attached to a Jai CCD color camera (Figure 8). Animals were sacrificed 3, 8, and 24 hrs post-injection and tumor, liver, and kidneys harvested for immediate imaging. The organs were then cryofixed to assess efficiency, specificity and retention of DNAzyme delivery to tumor. Intraperitoneal 
Chapter 2

treatment of unformulated DNAzyme leads to a time-dependent decrease in fluorescence intensity in the tumor, liver and kidney. At 3 hrs post-injection, the tumors from mice treated with the unformulated DNAzyme had higher fluorescence intensity than those treated with the formulated DNAzyme (data not shown). The macroscopic tumor fluorescence intensity was approximatcly equal in all mice 8 hrs after injection, but by 24 hrs after treatment, clear differences between formulated and unformulated DNAzyme were observed (Figure 9). WBI of the live mouse showed no fluorescence in the mouse injected with unformulated DNAzyme; however, intense fluorescence was still visible in the peritoneal cavity of mouse injected with Tf-PEG-polyplex even 24 hours after injection. The tumors and organs from mice treated with unformulated DNAzyme were not fluorescent while the tumor and organs from micc treated with formulated DNAzymes continued to manifest a bright fluorescence. Therefore, although formulating the DNAzyme does not improve initial delivery specificity, the delivery system enables the DNAzyme to remain in the organs for a longer period of time.

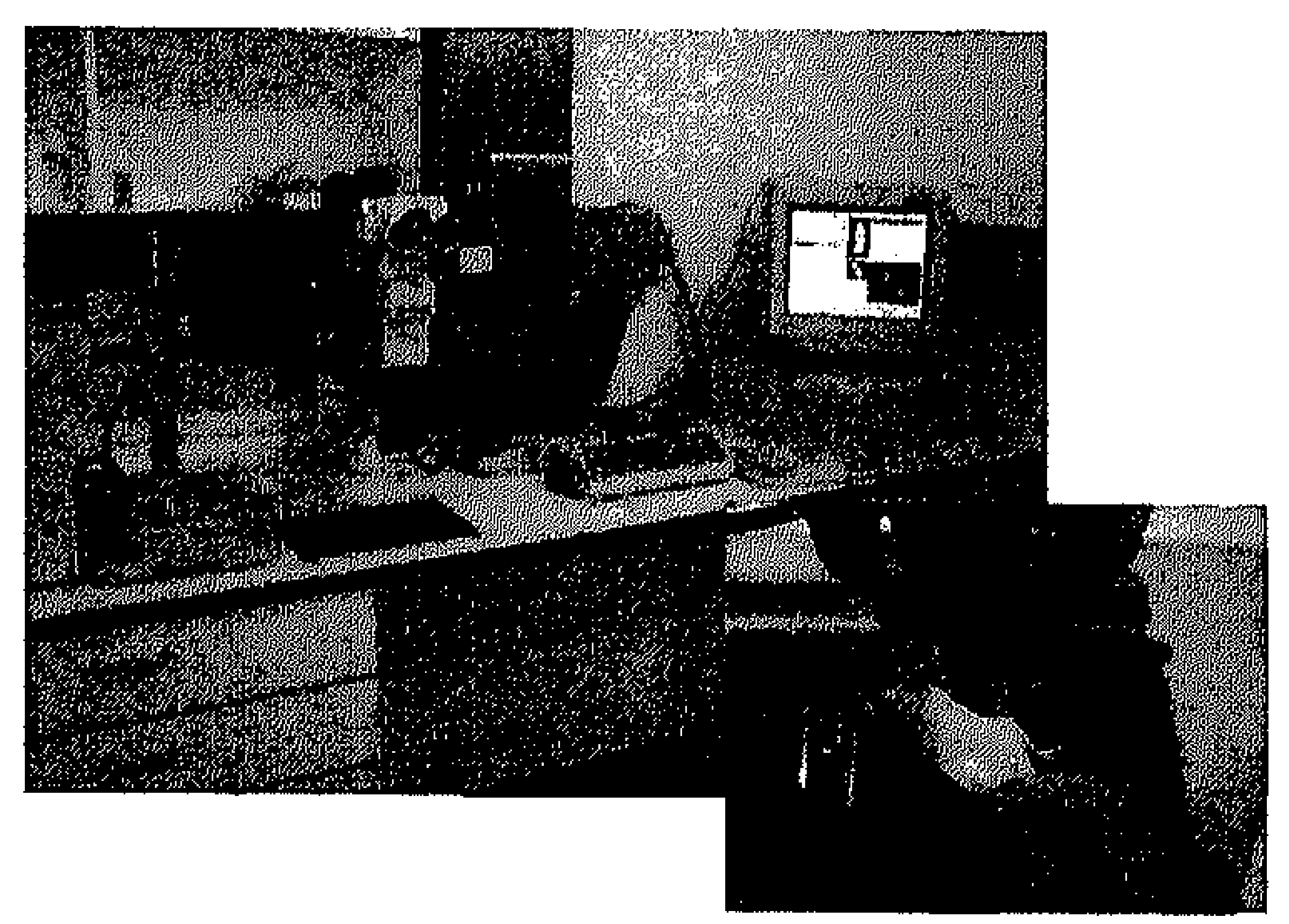

FIGURE 8: A whole body imagna

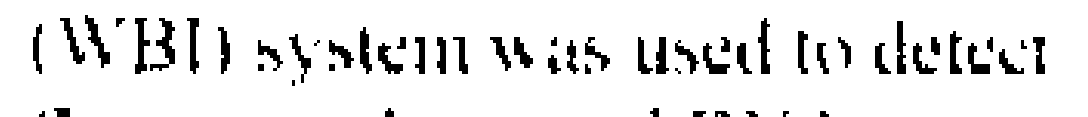
flumencently tagged DNA A symes. A

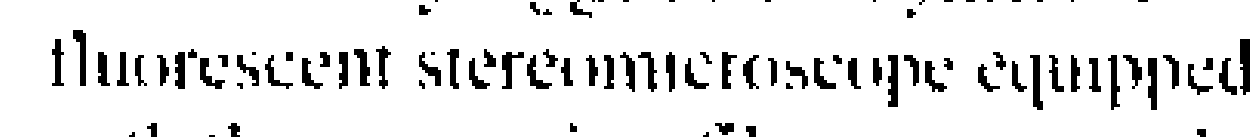
with the apprepriate tilterset captured

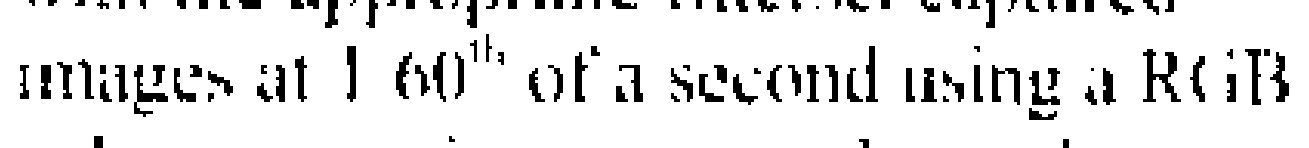
color cillosera in non-inatestletized immonas. The acquired images sele antaly zed using in in-lumas developed applicattion based on IMAO Vision sultware components and Lathlie:

\section{Comparison of Administration Methods}

Cy-3-DNAzyme (alone and in Tf-PEG-polyplex formulations) was administered to tumorbearing mice by intraperitoneal infusion, subcutaneous injection, and intravenous injection. Based on the studies described above, all animals were imaged and sacrificed at $24 \mathrm{hrs}$ post-injection and tumors, kidneys, and livers harvested for histology analysis. To determine if a prolonged DNAzyme treatment results in significant improvement in cellular tumor delivery in comparison to a bolus injection, the Alzet minipump system was employed. Osmotic pumps containing formulated or unformulated DNAzyme at $5 \mathrm{mg}$ DNAzyme/mL) were implanted in the peritoneal cavity. DNAzyme solutions were released at an average flow rate of $8 \mu \mathrm{L} / \mathrm{hr}$ for 24 hours; thus, mice were treated with the same amount of DNAzyme $(1 \mathrm{mg})$ but over a $24 \mathrm{hr}$ period compared with the intraperitoneal bolus studies. WBI of the mice before sacrifice revealed an intense fluorescence in the peritoneal cavity. When comparing the WBI images of the tumors after intraperitoneal 
bolus treatment and after intraperitoneal infusion, no significant difference was observed. Subcutaneous injection of unformulated DNAzyme and Tf-PEG-polyplex near the tumor site did not result in any observable delivery of material to major organs or tumor; all material stayed at the injection site. Administration of material by intravenous injection into
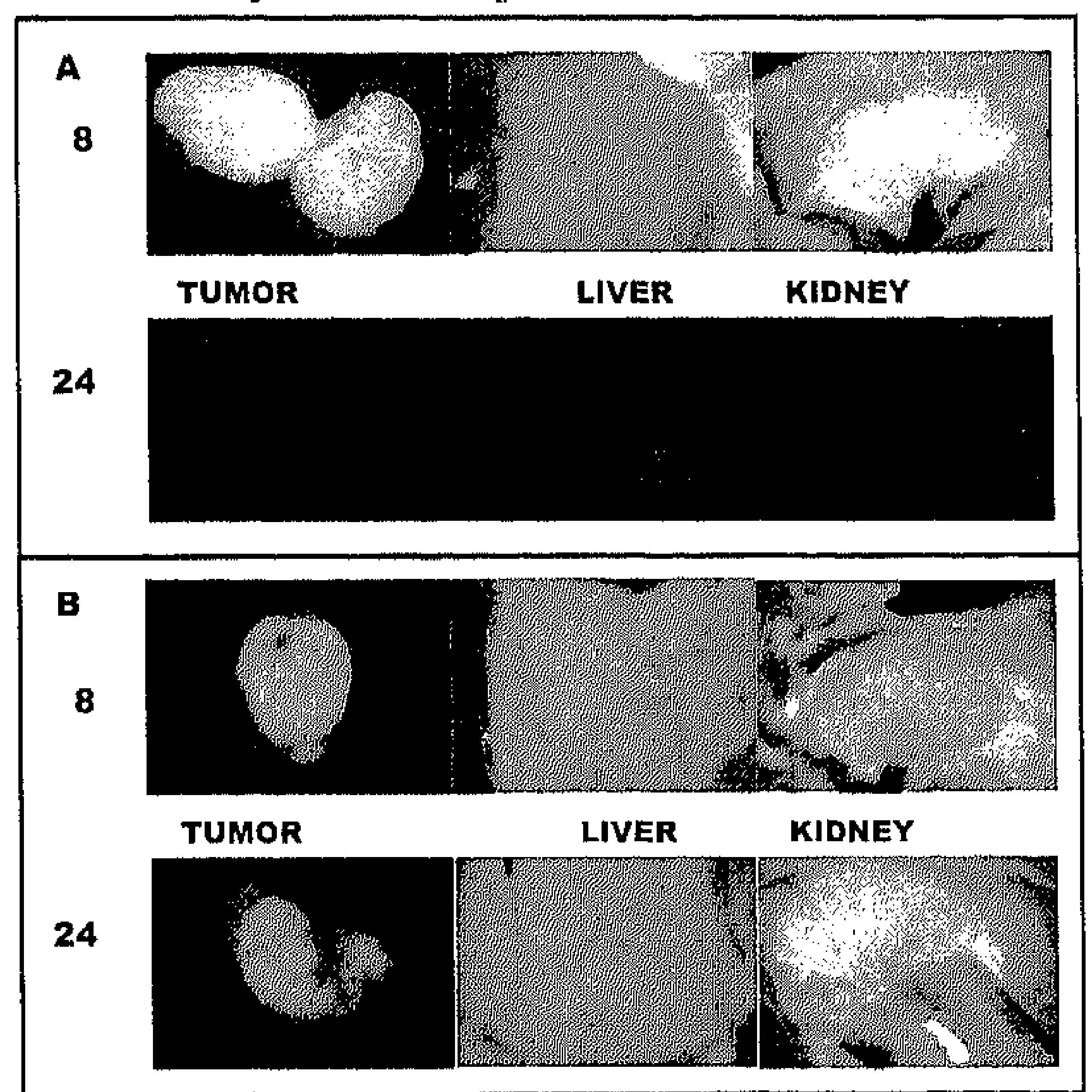

the tail vein was completed under low volume $(0.20 \mathrm{~mL})$ conditions. As observed with the intrapcritoneal bolus administration, WBI imaging of the tumors, kidneys and livers at 24 hours revealed bright fluorescence in mice treated with Tf-PEGpolyplex. Mice treated with unformulated DNAzyme had no visible fluorescence remaining in the body at 24 hours post-injection.

FIGURE 9: $\mathrm{A}$ : Cy-3 cistupled unformulated DNAsyme injected ip was detected by whI for specificity and relention ability in the the tumor. liver and kidtey of mode mice. Eight hous atter milectlon the Humescence cill stitl be delected. Twetty-finte alter injertion all lluoresente bad disappeared in all three cesamined tissues. B. A Cy. 3 coupled Tf.Pl(i 3400$)$ formulated bNaymi injected in was delacted in all enalnined lisbles hours and 2t lourts afler ingection.

Intracellular delivery compared between intravenous and intraperitoneal treatment. As stated above, WBI images of the organs acquired 24 hours after intraperitoneal bolus, intraperitoneal infusion and intravenous bolus injections of Tf-PEG-polyplex formulated DNAzyme showed no significant difference between treatments. The intracellular DNAzyme delivery efficiency from the intraperitoneal bolus injection, intraperitoneal infusion, intravenous bolus injection were thus compared by histology analysis. Tumors were sectioned to $12-\mu \mathrm{m}$ slices. Intracellular distribution of Cy-3-labeled DNAzyme was investigated using a FITC-phalloidin cytoskeleton staining and in a second set of experiments intracellular distribution of FITC-labeled DNAzyme was investigated using a Sytox Orange nuclear staining.

The tumors from the mice that had been treated by either intraperitoneal bolus or intraperitoneal infusion demonstrated accumulation of the DNAzyme in the cap of the tumor (Figure 10A). No intracellular localization of DNAzyme was observed with intraperitoneal administration. In contrast, the tumors in the mice treated by intravenous injection showed a significant intracellular fluorescence (Figure 10B) displayed in a colocalization study where the fluorescein-phalloidin (green) stained cytoskeleton of the cell overlaps with the $\mathrm{Cy} 3$ (red) labeled formulated DNAzyme (Figure 10B marked with arrows). 

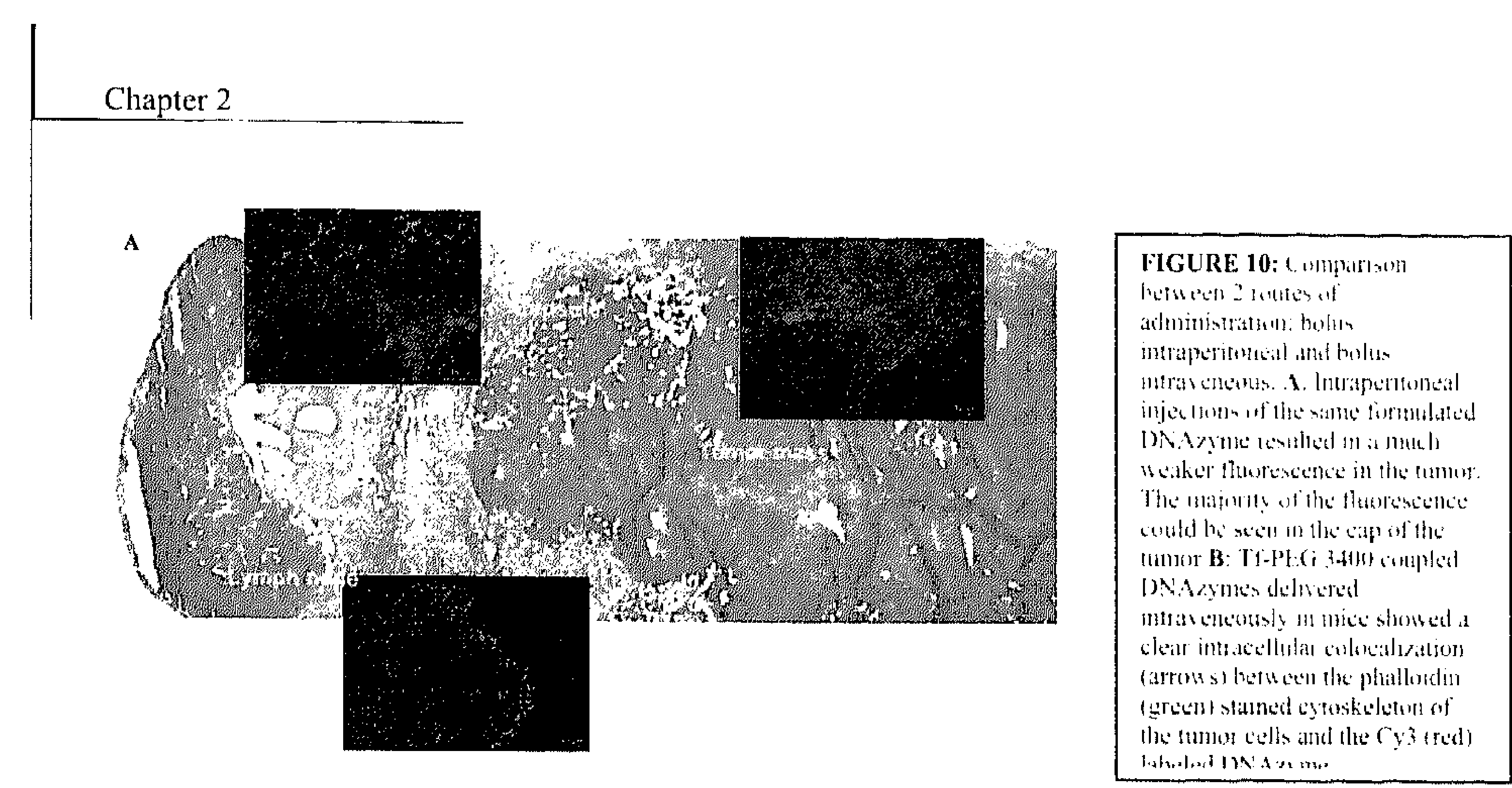

The effect of polyplex formulation on DNAzyme delivery from intravenous injections was therefore studied in more detail. The intratumoral distribution of unformulated DNAzyme and Tf-PEG-polyplex injections were compared first. As shown in Figure 11, the unformulated DNAzyme did not result in an intracellular localization; the only colocalization was found in the fibers of the tissue. In contrast, the tumors treated with the formulated DNAzyme showed an evenly spread cytoplasmic signal of DNAzyme that colocalized with the cell cytoskeleton. The intravenous administration studies were also repeated with fluorescein-labeled DNAzyme.

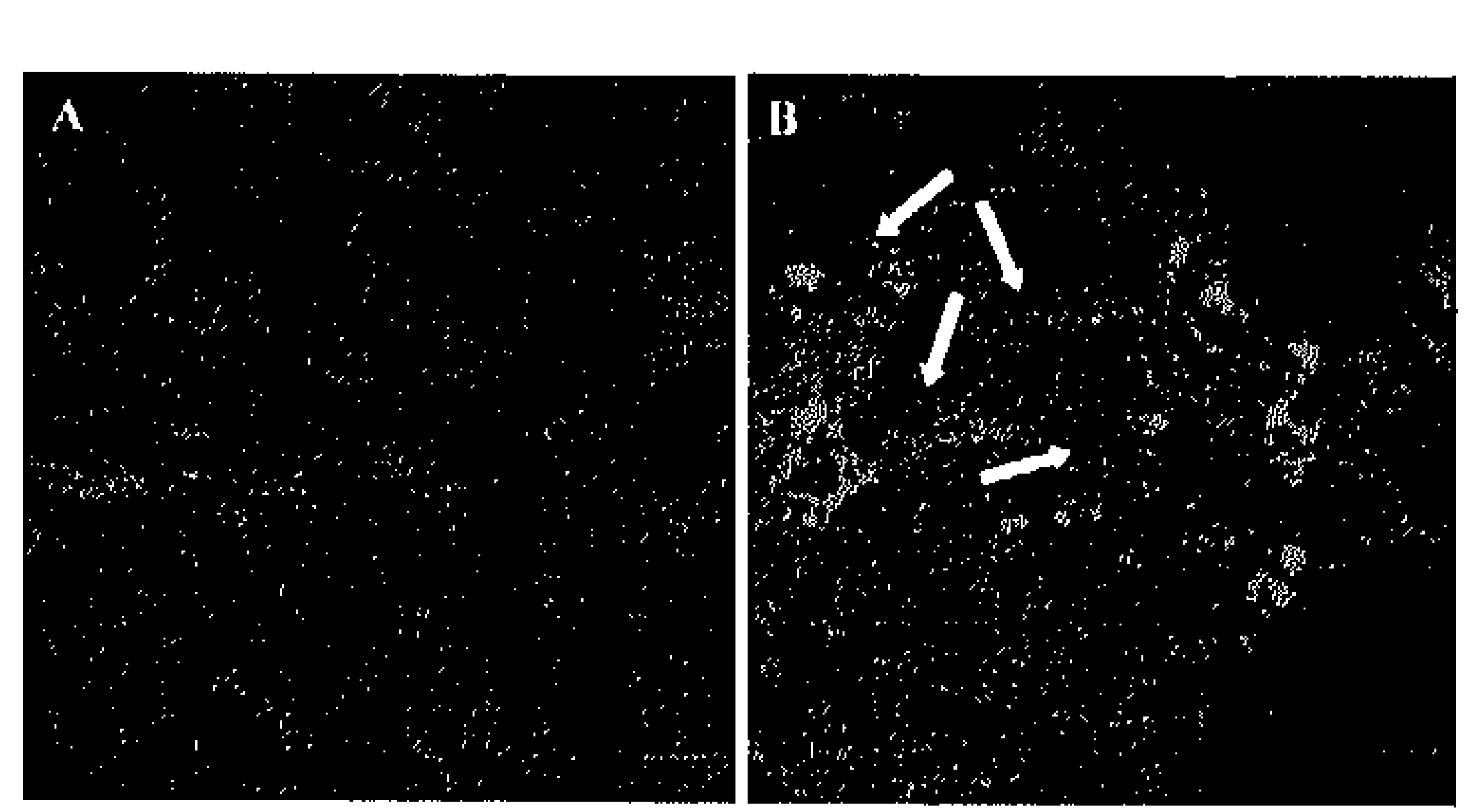

Three DNAzyme formulations (unformulated DNAzyme, PEG-polyplex, and Tf-PEG-polyplex), each containing 1 $\mathrm{mg}$ of fluor-DNAzyme, were administered via low pressure tail vein injections. Mice were sacrificed 24 hrs post-injection and tumors extracted and processed for histology analysis (Figure 12). Cell nuclei were stained with Sytox orange for contrast with the fluorescein-labeled

FIGURE 11: ('omparison of tumors from mice teated iv w atth unformulated (A) and formulated (B) DNAzyme. The tumors from mice treatled with the unformulated only show a wetak colocalization in the fibers, In cuntrast in the tumors from the mice treated with the formulated IN NAsyme. a much brighter and crenly spread colocialization (atrows) cant be seen.

DNAzyme. Again, the same phenomena were observed as with the Cy3-labelled DNAzyme. Unformulated DNAzyme does not readily enter tumor cells. Only one small area of fluorescence was found in the tumor sample (shown in Figure 12A). PEG-polyplex is retained in the tumor area but remains extracellular (Figure 12B). The highest tumor fluorescence was observed with the Tf-PEG-polyplex administration (Figure 12C). In addition, intracellular fluorescence was observed in several cell patches. Therefore, intravenous administration is the only preferred method of treatment for the cyclodextrin-based delivery system that gives intracellular delivery in tumors. Transferrin targeting is required for successful intracellular delivery of DNAzymes to tumor tissue. 


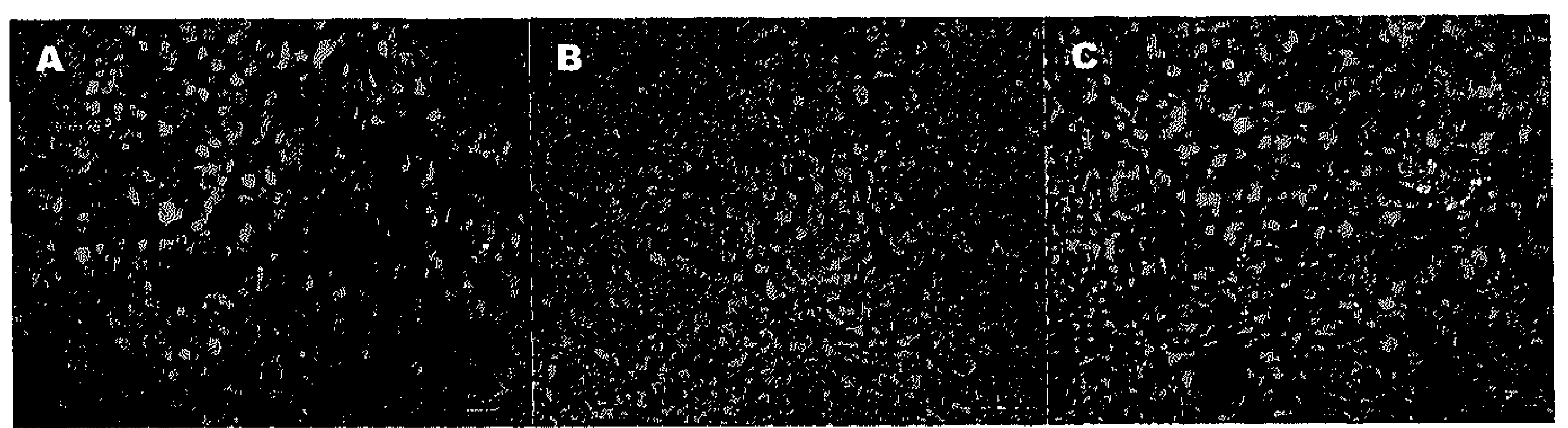

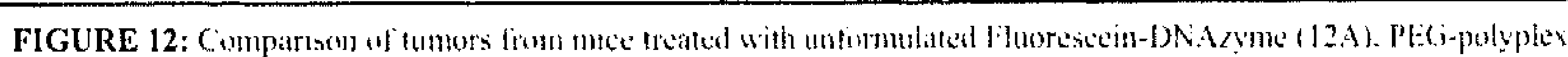

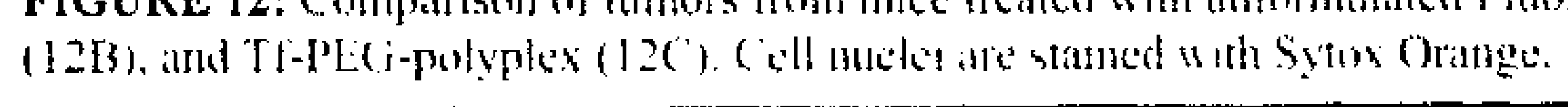

\section{DISCUSSION}

Therapeutic oligonuclcotides (antisense oligonucleotides, ribozymes, DNAzymes, and siRNAs) are promising anti-cancer agents because of their ability to reduce expression of target proteins. Advantages of such trcatment over traditional chemotherapeutics include target specificity and the potential of reduced side effects. For cancer applications, systemic administration of the oligonucleotides is preferred for accessibility to disseminated tumors. However, efficient delivery of these materials to their target site remains a challenge. Injection of unformulated oligonucleotides requires extremely high doses due to nonspecific distribution throughout the body, degradation, and rapid excretion. In this study, we examined the ability of a cyclodextrin-based, polymeric delivery system to provide transport of a c-myc DNAzyme to tumor cells in a nude mouse model using a variety of different administration methods.

The DNAzyme is packaged into nanoparticles by condensation with a cyclodextrin-based polycation (Figure 2A, CDP-Imid). The imidazolated polymer is used because the imidazole moiety has been shown to enhance endosomal escape, thereby increasing delivery efficiency (Davis et al., 2003). CDP-Imid self-assembles with the DNAzyme by electrostatic interactions to form small particles called polyplexes. Complete DNAzyme loading in the polyplexes is confirmed by gel electrophoresis. Solutions of CDP-Imid and DNAzyme are mixed at various molar charge ratios of polymer to nucleic acid. No nonbound DNAzyme is observed at charge ratios of 1 and above, indicating that the majority is bound (Figure 3). Polyplexes with a positive surface charge are obtained by formulation at charge ratios greater than 1 . The positively charged polyplexes can interact with negativelycharged cell surface proteoglycans for uptake by endocytosis (Mislick and Baldeschwieler, 1996). The effect of charge ratio on polyplex uptake into three human carcinoma cell lines (A2780, HT-29 and HeLa) was studied by using a fluorescein-labeled DNAzyme with analysis by flow cytometry. Polyplex uptake at all investigated charge ratios (2 to 10$)$ was 
efficient and rapid (Figure 4); over $80 \%$ of cclls have internalized DNAzyme within 15 minutes of exposure. Polyplex uptake studies to HeLa cells wcre conducted in 10, 20, 30 and $40 \%$ serum without any significant impact on delivery efficiencies (data not shown). In contrast, incubation of HeLa cells with unformulated DNAzyme for over 1 hour results in a maximum of $2 \%$ fluorescein positive cells. Thus, the C.DP-Imid is able to package and protect the DNAzyme and provide for intracellular uptake to a variety of cultured cell lines and in serum-containing media.

Several additional considerations arise for particle administrations distal to a desired site. The polyplexes nced to be small enough to circulate and diffuse to the target site. In addition, the colloidal particies should be stabilized against salt and serum-induced aggregation and non-specific interactions with serum components and undesired cells. Finally, the particles should ideally incorporate a targeting ligand for more specific delivery and retention. Transferrin, an iron-carrying protein, was chosen as the targeting ligand because rapidly growing cells, especially many cancer cells, up-regulate expression of the transferrin receptor in an effort to process more iron. In order to identify a suitable cell line for preparing a mouse xenograft tumor model, the relative levels of transferrin uptake in three human carcinoma cell lines (A2780, HT-29 and HeLa) was determined (Figure 5). The HeLa cell line has the highest level of transferrin uptake, while the A2780 cell line has very low levels of transferrin uptakc. The HT-29 cell line was chosen for the tumor xenograft model for its intermediate transferrin uptake because very high levels of uptake, as in the HeLa cell line, present an unrealistic tumor model that may not yield results translatable to other animals and ultimatcly humans. Moreover this cell line shows low background fluorescence.

For in vivo studies, polyplexes were prepared at a charge ratio of 2.5 and modified to address the aforementioned concerns for use in vivo by self-assembly with adamantanebased conjugates. The adamantane molecules form inclusion complexes with cyclodextrins on the surface of the polyplexes, thereby decorating the surfaces of the particles as illustrated in Figure 2. PEGylation is a well-established method for stabilizing nanoparticles against salt-induced aggregation and protein binding by providing a protective brush layer. However, PEGylation of cationic nanoparticles does not prevent non-specific association and uptake by cells; the nanoparticles continue to interact with anionic cell surface proteins. Neutralization of excess surface charge lowers the zeta potential of the particles and reduces non-specific binding. Studies utilizing polycation/DNA complexes have demonstrated that tumor targeting is facilitated with neutral or negative particles as compared to positively-charged particles that accumulate primarily in the liver (Kircheis et al., 2001).

Positive particle surfaces can be moderated by "charging" with an anionic moiety (Finsinger et al., 2000). The inclusion of two glutamates in the AD-PEG conjugate (AD-gluglu-PEGgal) results in a modifier that can tune particle zeta potential while also providing steric stabilization via PEG. With 40:60 AD-gluglu-PEG-gal: AD-PEG, particles have average zeta potential of $-6 \mathrm{mV}$ (Figure 6); therefore, this ratio was used in particle formulations for in vivo injections. Transferrin-modified polyplexes were prepared by including $2 \%$ (by mole to cyclodextrin) AD-PEG-Tf in the PEG-polyplex formulation (Bellocq et al., 2003b). Thus, the CDP-Imid component addresses the first issue of particle size by condensing the nucleic acid to small particles, the AD-PEG component provides steric stabilization in 
physiologic milieus, AD-gluglu-PEG-gal mediates particle surface charge, and the ADPEG-Tf introduces targeting capability. The three formulations, polyplex, PEG-polyplex, and Tf-PEG-polyplex were imaged by clectron microscopy (Figure 7). All formulations result in small and uniform spherical particles. The average particle diameter ranges from $-30 \mathrm{~nm}$ (polyplex) to $-50 \mathrm{~nm}$ (Tf-PEG-polyplex). The slight difference in size between the formulations likely represents the effect of modilication by PEG and Ti-PEG. Polyplexes containing DNAzymes are smaller than plasmid-bearing particles $(-80-120 \mathrm{~nm})$ formulated under similar conditions (Gonzalez, et al. 1999).

Unformulated Cy-3 DNAzyme and Tf-PEG-polyplexes containing Cy-3-labeled DNAzyme were administered to mice by intraperitoneal injection. The biodistribution of the DNAzyme was followed by WBI and by whole organ analysis at 3, 8, and 24 hours postinjection. The majority of DNAzyme was eliminated from the body by excretion in the urine, although some fluorescence was also observed in the stool. In addition to strong fluorescence in the tumor and liver, a large amount of DNAzyme was also visualized in the peritoneal cavity of Tf-PEG-polyplex-treated mice 24 hours post-injection. The three tissues with visible fluorescence (tumor, liver, and kidney) were extracted and imaged. These tissues all have high transferrin receptor expression (liver has 26 clones/gene, kidney has 16 clones/gene and lung has 14 clones/gene). At 3 and 8 hours post-injection, fluorescence was observed in liver, kidncy and tumor in mice injected with both unformulated Cy-3 DNAzyme and Tf-PEG-polyplex. However, by 24 hours post-injection, no fluorescence was observed in unformulated Cy-3 DNAzyme-treated mice, whereas significant levels of fluorescence was still obscrved in tumors of Tf-PEG-polyplex-treated mice (Figure 9). Therefore, while unformulated DNAzyme diffuses relatively rapidly throughout the body, DNAzyme in the cyclodextrin polymer-based nanoparticle delivery system concentrates in and is retained in several target organs (tumor, liver, kidney).

The effect of administration method on biodistribution was studied by comparing tumor, kidney, and liver fluorescence 24 hours following intrapcritoneal bolus, intraperitoneal infusion, subcutaneous bolus and intravenous bolus injections of DNAzyme. The high fluorescence level sustained in the peritoneal cavity 24 hours post- intraperitoneal injection of Tf-PEG-polyplex formulations suggested a slow release of material from the cavity. Unlike unformulated DNAzyme, the Tf-modified particles likely have limited diffusivities due to their size. Indeed, a comparison of intraperitoneal bolus injection and intraperitoneal infusion (via the Alzet pump) of Tf-PEG-polyplex revealed similar biodistribution. Subcutaneous injection of formulations did not result in fluorescence outside of the injection site even 24 hours after administration. It is not surprising that the nanoparticles are unable to traverse several tissue layers due to their size and hydrophilicity. In contrast, intravenous administration results in very efficient delivery of material throughout the animal; very little material is retained at the injection site. At 24 hours, the mice treated with Tf-PEG-polyplex revealed high tumor, liver, and kidney fluorescence, whereas mice that were administered unformulated DNAzyme had no remaining fluorescence.

The fluorescent tumors from intraperitoneal bolus, intraperitoneal infusion and intravenous bolus injections of Tf-PEG-polyplexes were compared by histology analysis. Polyplexes delivered by intraperitoneal bolus and intraperitoneal infusion did not penetrate the tumor cap and remained extracellular (Figure 10A). In contrast, polyplexes administered by intravenous infusion were internalized by tumor cells (as evidenced by co-localization with 
phalloidin) even several cell layers past the vessel locations (Figure 10B). The various formulations were then injected intravenously and analyzed by histology. Unformulated and PEGylated polyplexes were not efficiently internalized by tumor cells (Figure 12). Transferrin-modified formulations were successfully internalized in several cell clusters throughout the tissue. Thus, transferrin targeting does not affect biodistribution of material to the tumor; however, targeting is required for uptake and retention by tumor cells. A similar effect was observed in application of transferrin targeting for plasmid delivery; the ratio of plasmid delivered to liver versus tumor is unaffected by targeting but transgene expression is observed only in animals treated with transferrin-targeted polyplexes (Belloco et al., 2003a). This study therefore demonstrates the ability of transferrin-modified, cyclodextrin polymer-based polycations to mediate tumor-targeted uptake of DNAzymes from systemic administrations. Advantages of the delivery system include longer tumor retention of DNAzyme and more efficient tumor cell targeting.

\section{REFERENCES}

Bakker A, Floren W, Voeten J, Janssens B, Smets G, Wouters W and Janicot M (2001) Automation of whole body imaging of GFP-expressing tumors in living animals. G.I.T. Imaging and Microscopy 03/2001:52-54.

Bellocq N, Davis M, Engler H, Jensen G, Liu A, Machemer T, Maneval D, Quijano E, Pun S, Schleup T and Wen S (2003a) Transferrin-targeted, cyclodextrin polycationbased gene vector for systemic delivery, in American Society of Gene Therapy, Washington, D.C.

Bellocq N, Pun S and Davis M (2003b) Transferrin-containing, cyclodextrin polymer-based particles for tumor-targeted gene delivery (submitted)

Bennett C, Chiang M, Chan H, Shoemaker J and Mirabelli C (1992) Cationic lipids enhance cellular uptake and activity of phosphorothioate antisense oligonucleotides. Mol Pharmacol 41:1023-1033.

Breaker R and Joyce G (1994) A DNA enzyme that cleaves RNA. Chem Bio 1:223-229.

Cairns M, Hopkins T, Witherington C, Wang L and Sun L (1999) Target site selection for an RNA-cleaving catalytic DNA. Nat Biotech 17:480-486.

Cheng J, Luo J, Zhang X, Hu J, Hui H, Wang C and Stern A (2000) Inhibition of cell proliferation in HCC-9204 hepatoma cells by a c-myc specific ribozyme. Cancer Gene Ther 7:407-412.

Davis M, Pun S, Bellocq N, Reincke T, Popielarski S, Mishra S and Heidel J (2003) Selfassemblying nucleic acid delivery vehicles via linear, water-soluble, $\mathrm{CD}$-containing polymers. Curr Med Chem in press.

Felgner P, Barenholz Y, Behr J-P, Cheng S, Cullis P, Huang L, Jessee J, Seymour L, Szoka J, FC, Thierry A, Wagner E and Wu G (1997) Nomenclature for Synthetic Gene Delivery Systems. Hum Gene Ther 8:511-512. 
Finsinger D, Remy J-S, Erbacher P, Koch C and Plank C (2000) Protective copolymers for nonviral gene vectors: synthesis, vector characterization and application in gene delivery. Gene Ther 7:1183-1192.

Giles R, Spiller D, Clark R and Tidd D (1999) Identification of a good c-myc antisense oligodeoxynucleotide target site and the inactivity at this site of novel NCH triplettargeting ribozymes. Nucleosides Nucleotides 18:1935-1944.

Gonzalez H, Hwang S and Davis M (1999) New class of polymers for the delivery of macromolecular therapeutics. Bioconjugate Chem 10:1068-1074.

Helin V, Gottikh M, Mishal Z, Subra F, Malvy C and Lavignon M (1999) Cell cycledependent distribution and specific inhibitory effect of vectorized antisense oligonucloetides in cell culture. Biochem Pharm 58:95-107.

Hwang S, Bellocq N and Davis $M$ (2001) Effects of Structure of Beta-CyclodexirinContaining Polymers on Gene Delivery. Bioconjugate Chem 12:280-290.

Jaaskelainen I, Peltola S, Honkakoski P, Monkkonen J and Urtti A (2000) A lipid carrier with a membrane active component and a small complex size are required for efficient cellular delivery of anti-sense phosphorothioate oligonucleotides. Eur J Pharm Sci 10:187-193.

Jensen GS, Pun SH, Cheng J and Davis ME. Preparation of cyclodextrin polymer-based nanoparticles with controlled physicochemical properties for systemic administration. (Mantscript in preparation).

Juliano R, Alahari S, Yoo H, Kole R and Cho M (1999) Antisense pharmacodynamics: critical issues in the transport and delivery of antisense oligonucleotides. Pharm Res 16:494-502.

Kang S, Zirbes E and Kole R (1999) Delivery of antisense oligonucleotides and plasmid DNA with various carrier agents. Antisense Nucleic Acid Drug Dev 9:497-505.

Kircheis R, Blessing T, Brunner S, Wightman L and Wagner E (2001) Tumor targeting with surface-shielded ligand-polycation DNA complexes. $J$ of Control. Rel. 72:165-170.

Lewis J, Lin K-Y, Kothavale A, Flanagan W, Matteucci M, DePrince R, Mook J, RA, Hendren $R$ and Wagner $R$ (1996) A serum-resistant cytofectin for cellular delivery of antisense oligodeoxynucleotides and plasmid DNA. Proc Natl Acad Sci USA 93:3176-3181.

McGuffie EM, Pacheco D, Carbone GMR and Catapano CV (2000) Antigene and Antiproliferative Effects of a c-myc-targeting Phosphorothioate Triple Helixforming Oligonucleotide in Human Leukemia Cells. Cancer Res 60:3790-3799.

Mislick K and Baldeschwieler J (1996) Evidence for the role of proteoglycans in cationmediated gene transfer. Proc Natl Acad Sci USA 93:12349-12354.

Moghimi S, Hunter A and JC M (2001) Long-circulating and target-specific nanoparticles: theory to practice. Pharmacological Reviews 53:283-318.

Popielarski SR, Mishra S and Davis ME (2003) Structural effects of carbohydratecontaining polycations on gene delivery. 3. CD type and functionalization. Bioconjugate Chem 14:672-678.

Pun SH and Davis M (2002) Development of a Non-Viral Gene Delivery Vehicle for Systemic Application. Bioconjugate Chem 13:630-639. 
Putney S, Brown J, Cucco C, Lee R, Skorski T, Leonetti C, Geiser T, Calabretta B, Zupi G and Zon G (1999) Enhanced anti-tumor effects with microencapsulated c-myc antisense oligonuclcotide. Antisense Nucleic Acid Drug Dev 9:451-458.

Reineke TM and Davis ME (2003a) Structural effects of carbohydrate-containing polycations on gene delivery. 1. Carbohydrate size and its distance from charge centers. Bioconjugate Chem 14:247-254.

Reineke TM and Davis ME (2003b) Structural effects of carbohydrate-containing polycations on gene delivery. 2. Charge center type. Bioconjugate Chem 14:255-261.

Santiago FS, Lowe HC, Kavurma MM, Chesterman CN, Baker A, Atkins DG and Khachigian LM (1999) New DNA enzyme targeting Egr-1 mRNA inhibits vascular smooth muscle proliferation and regrowth after injury.

Nat Med 5:1264-1269.

Santoro S and Joyce G (1997) A general purpose RNA-cleaving DNA enzyme. Proc Natl Acad Sci USA 94:4262-4266.

Shi Y, Fard A, Galeo A, Hutchinson H, Vermani P, Dodge G, Hall D, Shaheen F and Zalewski A (1994) Transcatheter delivery of c-myc antiscnse oligomers reduces neointimal formation in a porcine model of coronary artery balloon injury. Circulation 90:944-951.

Sun L-Q, Cairns MJ, Gerlach WL, Witherington C, Wang L and King A (1999) Suppression of Smooth Muscle Cell Proliferation by a c-myc RNA-cleaving Deoxyribozyme.

$J$ of Biol Chem 274:17236-17241.

Thorstensen K and Romslo I (1993) The Transferrin Receptor: Its Diagnostic Value and its Potential as Therapeutic Target. Scand J Clin Lab Invest 53:113-120.

Tsang $\mathrm{J}$ and Joyce $\mathrm{G}$ eds (1996) In vitro evolution of randomized ribozymes. Academic Press, Orlando.

Warashina M, Kuwabara T, Nakamatsu Y and Taira K (1999) Extremely high and specific activity of DNA enzymes in cells with a Philadclphia chromosome. Chem Biol 6:237-250.

Ward CM, Read ML and Seymour LW (2001) Systemic circulation of poly(L-lysine)/DNA vectors is influenced by polycation molecular weight and type of DNA: differential circulation in mice and rats and the implications for human gene therapy. Blood 97:2221-2229.

Wu Y, Yu L, McMahon R, Rossi J, Forman S and Snyder D (1999) Inhibition of bcr-abl oncogene expression by novel deoxyribozymes (DNAzymes). Hum Gene Ther 10:2847-2857.

Yoo $\mathrm{H}$ and Juliano R (2000) Enhanced delivery of antisense oligonucleotides with fluorophore-conjugated PAMAM dendrimers. Nuc Acids Res 28:4225-4231. 


\section{Chapter 3}

MODIFIED POLY (PROPYLENE IMINE) DENDRIMERS AS EFFECTIVE TRANSFECTION AGENTS FOR CATALYTIC DNA ENZYMES (DNAZYMES)

Frederik Tack, Annette Bakker, Sophie Maes, Nathalie Dekeyser, Monique Bruining, Cristina ElissenRoman, Henk M. Janssen, B.F.M. de Waal, P.M. Fransen, X. Lou, E.W. Meijer, Michel Janicot \& Marcus Brewster

published in Journal of Drug Targeting 2006; 14(2): 69-86

patent filed 08 July 2005 with filing number EP05106266.9 named Efficient Dendritic Transfection Agents for DNAzymes 
Chapter 3

\section{ABSTRACT}

The major bottleneck in gene therapy remains the issue of delivery. In this work, various modified poly(propylene imine) (PPI) dendrimers are introduced as gene transfection agents. Commercially available PPI-dendrimers have been modified (i) at the exterior primary amines with acetyl groups or glycol gallate (PEG-like) groups and (ii) at the interior tertiary amines with $\mathrm{MeI}$ or $\mathrm{MeCl}$ to produce multiple quaternized cationic sites in the corc of the dendrimer. The prepared materials have been tested with respect to their binding capabilities to DNA, their toxicity in cell cultures, their in vitro transfection efficiency and their in vivo delivery possibilities. In all cases, a 33-mer oligonucleotide (DNAzyme) was used. PAGE studies have demonstrated strong but reversible binding, where the quarternized and higher generation dendrimer species have shown more potent binding. Typically, for the modified $4^{\text {th }}$ PPI-dendrimers, binding is observed at a concentration of about $4 \mu \mathrm{M}$ DNA and a dendrimer-DNA charge ratio of around 2:1-1:1. All the tested PPI-dendrimers display a low cellular toxicity, especially when higher serum contents are used in the culture medium. For example, most of the prepared $4^{\text {th }}$ generation PPI-dendrimers are not or hardly toxic up to at least $20 \mu \mathrm{M}$ in $20 \%$ serum. An in vitro characterisation has revealed a high dendrimer-mediated intracellular uptake of the DNAzyme: all tested $4^{\text {th }}$ generation PPI-dendrimers display transfection efficiencies close to or exceeding $80 \%$, even when the concentration of serum in the medium is incrcased from 10 to $40 \%$. Finally, the potential of using modified PPI-dendrimers for in vivo gene therapy experiments is demonstrated. Injecting a G4-PEG(MeI) - ssDNA complex intravenously into nude mice has resulted in a high nuclear uptake as confirmed by colocalisation studies.

\section{INTRODUCTION}

Dendrimers are synthetic macromolecules with a well-defined, highly branched molecular structure that are synthesized in an algorithmic step-by-step fashion. Every repeated sequence of reactions produces a higher generation $(G)$ molecule that has a practically doubled molecular weight and a doubled (discrete) number of functional end-groups. Since 1985, numerous chemically different types of dendrimers have been developed, such as Tomalia's poly (amido amino) PAMAM-dendrimers, Newkome's arborols, Fréchet's poly ether dendrimers, Meijer and Mülhaupt's poly(propylene imine) PPI-dendrimers and Moore's phenylacetylene dendrimers (Schlüter DA, 1999). Because of their defined structure, narrow polydispersity, defined nanoscale size and the ease of modification of the end groups, dendrimers are considered interesting candidates for various functions in life sciences and medicinal chemistry. In particular, their function as binding-and-release agents in drug and gene delivery has been investigated (Patri AK et al 2002; Esfand R et al. 2001, Liu $M$ et al 1999. Stiriba SE et al. 2002, Bosman AW et al 1999, Tang MX et al 1997). 
Among dendrimers, PAMAM dendrimers have received most attention as potential transfection agents for gene delivery, as these dendrimers are positively charged and can bind DNA at physiological $\mathrm{pH}$. Some other dendrimer types have also been studied (Loup C et al. 1999, Choi JS et al. 2000, Ohasaki M et al, 2002, Shah DS et al. 2000, Liu MJ et al. 1999, Joester D et al. 2003). Haensler et al. 1993 were the first to present DNA-transfection that was successfully mediated by PAMAM dendrimers, as evidenced by in vitro tests. Later, other studies on the association and transfection behavior of PAMAM-dendrimers have been published (Tang MX et al. 1996, Kukowski-Latallo J et al. 1996, DeLong R et al. 1997, Bielinska A et al. 1996, Shehepinov MS et al. 1997, Qin L et al. 1998, Yoo H et al. 1999. Cheng H et al. 2000, Ottaviani MF et al 2000, Kihara F et al. 2003, Hong S et al. 2004, Thomas TP et al. 2004, Wu J et al. 2005). Successful transfection for PAMAM dendrimers has been reported for charge ratios of around 5-20, where the charge ratio is defined as the number of terminal cationic amine sites in the PAMAM to the number of phosphates in DNA. Therefore, an excess of transfection agent has to be used (Haensler J et al. 1993, Bielinska AU et al. 1999).

Important factors that determine the usefulness of a transfection agent are the toxicity and the efficiency of the agent. While some (Roberts JC et al. 1996) have shown that PAMAM dendrimers have toxicities depending on their generation and others (Haensler et al. 1993) have demonstrated that PAMAM dendrimers are less toxic than polylysine (pLys), Malik et al. have concluded that especially amine terminated PAMAM dendrimers display haemolitic and cytotoxic behaviour, whereas PAMAM dendrimers with terminal carboxylate groups are non-toxic (Duncan $R$ et al. 1996, Malik $N$ et al. 2000). Unfortunately, it seems that transfection is more efticient when PAMAM-dendrimers with high grades of amine-functionalization are used, presumably becausc this creates more cationic sites for DNA-binding at physiological $\mathrm{pH}$ (see for example Figure 7 in Tang MX 1996, or Luo D et al. 2002 where partially glycol-modified PAMAMs are used for transfection of DNA, but where high concentrations of transfectant are used).

Poly propylene imine (PPI) dendrimers are a specific class of dendrimers that have been developed at DSM Research ${ }^{(}$(Geleen, the Netherlands) (de Brabander-van-den Berg EMM et al. 1993) and independently in Mülhaupt's group (Wörner et al. 1993). The Supplementary Information can be consulted for details on the structure of these type of dendrimers. The amine functionalized PPI-dendrimers degrade slowly in water and, more importantly, are generally too toxic to allow for their direct use in DNA-delivery systems (Malik $\mathrm{N}$ et al. 2000, Omidi Y. et al 2005, Kuo JH ct al. 2005), although reports on binding (Kabanov VA et al. 2000) and transfection, using the much less toxic lower generation PPI-dendrimers (Zinselmayer BH et al. 2002, Hollins AJ et al. 2004, Lim YB et al, 2002), have appeared. Data from literature strongly suggest that the terminal or surface groups (the exterior) of dendrimers determine the toxicity of the total dendritic structure, irrespective of the internal structure (Malik $\mathrm{N}$ et al. 2000). As a consequence, it seems promising to chemically modify the surface of PPIdendrimers to create delivery systems with a low toxicity, a preserved water solubility and an increased stability towards hydrolysis.

Apart from modification of the exterior, it is also possible to modify the interior of PPIdendrimers by quaternizing the internal tertiary amines to create multiple cationic ammonium sites. In fact, quaternization of PPI-dendrimers has been reported before (ElissenRoman C et al. 1997, Pan Y et al. 1999, Pan Y et al. 2000). Kreider et al. 2001 have presented G2 and G4 PPI-dendrimers with short glycol chains at the exterior and quaternized interior 
Chapter 3

sites, but the authors have not investigated or reported on their use as transfection agents. Recently, PPI-dendrimers quaternized with methyl iodide (MeI) at both the extcrior and interior have been presented as gene delivery agents, but also for these systems only the lower generation dendrimers show a limited toxicity (Schatzlein AG et al. 2005). PAMAMs with cationically modified interiors have been reported as well: their transfection efficiency as measured with a luciferase gene expression test was lower than that of PEI or an unmodified PAMAM reference (Lee JH et al. 2003). Although the authors do not mention this, internally quaternized PAMAMs are possibly prone to exhibit retro Michael reactions, implying that these cationically modified PAMAM-dendrimers possibly degrade in water and are not stable.

In the present report, several modified poly (propylene imine) dendrimers are introduced that are modified at both the extcrior and the interior with the aim to create water soluble, hydrolytically stable and non-toxic transfection agents. The PPI-dendrimers have been modified at the exterior with acetyl groups or with tri-glycol gallate (PEG-like) groups, as these groups preserve the water solubility, while it is anticipated that blocking the amine end groups generates non-toxic species. The interior of the PPI-dendrimers has also been modified by reacting the internal tertiary amines with $\mathrm{MeI}$, thus creating a microenvironment with multiple quaternary cationic sites. Depending on the generation of the PPI-dendrimer, the amount of cationic sites can be varied from 2 to 60 for the $1^{\text {st }}$ and $5^{\text {th }}$ generation, respectively, provided that the quaternization reaction procceds quantitatively. The high local concentration of cationic sites in the interior of the dendrimer is anticipated to make this type of dendritic molecule well-capable of forming complexes with DNA and other multi-anionic species such as RNA, especially those with a relatively low number of base-pairs (oligo-DNAs or oligo RNAs, for example). In this work, we have used a 33-mer single stranded catalytic DNA enzyme (DNAzyme) as a nuclcic acid model to investigate the binding and transfection ability of the newly prepared PPI-dendrimer based DNAcarriers. The transfection tests have mainly been executed in vitro, although first in vivo tests are presented here as well.

\section{MATERIAL \& METHODS}

\section{Cells, animals and materials}

The following, all human, cell lines were used in this study: the mammary carcinoma MCF7 cell line and the malignant melanoma Malme-3M cell line, both cultured in dulbecco's minimum essential medium. The ovarian carcinoma A2780 cell line, the colorectal adenocarcinoma cell line HT29 and the leukemia cell line K562-C1000 were cultured in RPMI 1640. These culture media were supplemented with $5 \%$ fetal calf serum (FCS), $50 \mu \mathrm{g} / \mathrm{ml}$ gentamycin, and $2 \mathrm{mM} \mathrm{L-glutamine.} \mathrm{MCF7} \mathrm{cell} \mathrm{culture} \mathrm{medium} \mathrm{and}$ Malme-3M culture media was also supplemented with $1 \mathrm{mM}$ sodium pyruvate. Cells were grown at $37^{\circ} \mathrm{C}$ in a humidified incubator with $5 \% \mathrm{CO} 2$. All media and supplements were purchased from Invitrogen (Paisley, UK). 
Male NMRI mice were purchased from Janvier (Le Genest-St-Isle, France). All animal experiments were carried out with animal ethical committee approval. The ethical guidelines that were followed meet the standards required by the UKCCCR guidelines.

5'-Fluorescein-labeled and non-labeled DNAzyme 33-mers (5'-labelTGAGGGGCAGGCTAGCTACAACGACGTCGCGGx-3') with $\mathrm{x}=3^{\prime} \mathrm{dG}^{\prime}$ ' were purchased from Eurogentec (Seraing, Belgium). In order to improve stability, a 3'-3' guanine inversion was incorporated at the 3'-end.

\section{Cellular toxicity of modified PPI-dendrimers}

The toxicity of modified PPI-dendrimers of different generations (G2, G2(Mcl) and $\mathrm{G} 2(\mathrm{MeCl}), \mathrm{G} 4, \mathrm{G} 4(\mathrm{MeI})$ and $\mathrm{G} 4(\mathrm{MeCl})$ and $\mathrm{G} 5-\mathrm{PEG}$ and $\mathrm{G} 5-\mathrm{PEG}(\mathrm{MeI}))$ was profiled on 4 cell lines (Malme-3M, K562, HT29 and MCF7) using the MTT-test. A cytotoxicity assay, in which cells were plated at 2000 cells/well in 96-well plates 24 hours prior to transfection, was used for this purpose. The dendrimer was added to the cells at various concentrations dependent on the generation of dendrimer. The $2^{\text {nd }}$ generation dendrimer was added at concentrations ranging from $500 \mu \mathrm{M}$ to $1 \mu \mathrm{M}$. The $4^{\text {th }}$ and the $5^{\text {th }}$ generation dendrimers were added at concentrations ranging from $100 \mu \mathrm{M}$ to $0.2 \mu \mathrm{M}$ and from $2.5 \mu \mathrm{M}$ to $50 \mathrm{nM}$, respectively. Cells were treated with the dendrimer for 4 hours and then refreshed with complete media and further incubated for 4 days. After this incubation period the cells were checked for the mitochondrial dehyrogenase enzyme, which is only present in living cells. When present, an added yellow MTT salt will be reduced by the enzyme to form a blue formazane crystal, which can be dissolved in DMSO and measured using a spectrophotometer $(\lambda \max$ at $540 \mathrm{~nm})$. The found absorption is then divided by the absorption of cells that undergo the same experimental procedure, but that are untreated with the dendrimer, to give the MTT-viability versus the control that is displayed in all Figures.

An MTT protocol was also followed when the cytotoxicity of a range of modified $4^{\text {th }}$ generation PPI-dendrimers was examined in more detail. Acetylated or pegylated dendrimers, either quarternized (with $\mathrm{MeI}$ or $\mathrm{MeCl}$ ) or non-quartemized were tested, employing a concentration range (from $1 \mu \mathrm{M}, 2 \mu \mathrm{M}, 5 \mu \mathrm{M}, 10 \mu \mathrm{M}$ to $20 \mu \mathrm{M}$ ), while also investigating an increasing amount of serum $(10 \%, 20 \%, 30 \%, 40 \%)$. These MTT- tests were performed on the A2780 cells that were chosen due to their suitability as in vivo models in our department.

\section{In vitro delivery of fluorescently tagged DNAzymes}

A fluorescence activated cell sorter (FACS) analysis was performed to determine the cellular uptake of the FITC-labeled DNAzyme using $4^{\text {th }}$ generation dendrimers as transfecting agents. $2 * 10 \mathrm{E}+6 \mathrm{~A} 2780$ cells/well were seeded in a 6 well plate $24 \mathrm{~h}$ prior to transfection. The dendrimer and DNAzyme were both diluted in culture medium to a final concentration of $1 \mu \mathrm{M}$, achieving a charge ratio of about 1 upon complexation. A 15 minute incubation period enabled complexation of the two components. The complex was subsequently added to the cells and after a 4 hour incubation, cells were washed twice with PBS, collected by trypsinization, washed twice in FACS buffer and Cell Scrub Buffer (Gene Therapy Systems, San Diego, CA). Propidium Iodide was added to each sample at a final concentration of $20 \mu \mathrm{g} / \mathrm{ml}$ to determine the quantity proportion of dead cells. Finally, 
Chapter 3

the cells were analyzed for DNAzyme uptake by llow cytometry (FACScan, Becton Dickenson). Non-transfected cells were applied as baseline control to determine autofluorescence of the cell. Cells treated with DNAzyme alone were applied as negative control. Thus, auto-fluorescence and transfection due to the DNAzyme alone are accounted for in the values of the transfection efficiencies in all Figures.

\section{In vivo delivery of fluorescently tagged DNAzymes}

Microscopy

A whole body imaging (WBI) system was used to investigate the in vivo tumor delivery of fluorescently tagged DNAzymes. This imaging system consists of a fluorescence stercomicroscope (Olympus) SZX12 equipped with a green fluoresent protein (GFP) (excitation: $485-501 \mathrm{~nm}$; emission: $510 \mathrm{~nm}$ ) and a red fluorescent protein (RFP) (excitation 540-552 $\mathrm{nm}$; emission: 568-643 nm) filter set (see Bakker $A$ et al. for details). Images (752x582 pixels) were acquired at 1/60th of a second using a (Jai) CV-M90 3-CCD RGB color camera and analyzed using in-house developed application software that is based on IMAQ Vision software components and LabVIEW (National Instruments).

Intracellular DNAzyme delivery was investigated on tumor sections using fluorescence microscopy. Briefly, at the end of each animal experiment, fluorescent tumors were extracted, cryofixed and sectioned. $12 \mu \mathrm{m}$ sections were observed using a AxioPlan2 (Zeiss) fluorescence microscope coupled to a AxioCam HR (Zeiss) CCD camera and high resolution pictures (1300 × 1030 pixels) were captured and further analyzed using AxioVision software (Zeiss). Intracellular distribution of FITC (green) labeled DNAzyme was investigated using a nuclear dye TOPRO3 (red). $\beta$-Actin staining was obtained using bodipy phalloidin (blue).

DNAzyme administration in vivo

Male NMRI mice were injected in the inguinal region with 107 A2780 ovarian carcinoma cells $/ 200 \mu \mathrm{l}$ serum-free medium using $26 \mathrm{GA}$ syringes $(\mathrm{BD}, 26 \mathrm{GA} 3 / 81 \mathrm{ml}$ ). After 14 days the tumors had reached adequate size for WBI measuring. Of a first group of mice, the control mice $(n=5)$ were treated Iv. with $1 \mathrm{mg}$ FITC-conjugated c-myc DNAzyme (FITCDNAzyme), while the test mice $(n=5)$ were treated with dendrimer-DNAzyme complex formulations containing $1 \mathrm{mg}$ of FITC-DNAzyme and ca. $3 \mathrm{mg}$ of G4-PEG(MeI) achieving a CR of 1 (i.e. a final concentration of $50 \mu \mathrm{M}$ of DNA and dendrimer in the mouse, if dilution into a blood volume of ca. $2 \mathrm{~mL}$ in the mouse is assumed). Intravenous (i.v.) injections were administered via the tail vein at injection rates of $200 \mu \mathrm{l} / 10 \mathrm{sec}$. The mice $(n=10)$ were sacrificed at $45^{\prime}$ (minutes) and the tumor was immediately cryofixed in TissueTek (Triangle Biomedical Sciences). Apart from these treated mice $(n=10)$, a few untreated mice were used as a negative control. A second group of mice $(n=10)$ were injected with the same DNAzyme-dendrimer complex and were checked after a period of $24 \mathrm{~h}$ for fluorescence in the tumor using WBI. After 24h this second group of mice was sacrificed and the interior was examined for fluorescence. DNAzyme clearance after iv. injection was monitored by WBI at $5^{\prime}$ (minutes), 15',30' and $45^{\prime}$ (for the first group of mice) and at 24 hrs (for the second group of mice) post-injection. 


\section{RESULTS AND DISCUSSION}

Synthesis and characterization of dendritic transfection agents for nucleic acids

The synthesis of poly(propylene imine) transfection agents is summarized in Figure 1 illustrating the conversion steps of the $2^{\text {nd }}$ generation dendrimer. PPI-dendrimers of other generations have been converted in an analogous way.

In the first step, the primary amine endgroup is amidated by reaction with an activated carboxylic acid derivative "RCOOH" (either acetic anhydride or a gallyl chloride derivative have been used here; other types of activated carboxylic acids are also possible, see e.g. Kreider JL et al. 2001). In the second step, the interior tertiary amines are quaternized by reaction with methyliodidc. In the third step, the iodide counter-anion is exchanged for chloride. All prepared dendrimers are soluble in water and alcohols and most of them are also soluble in more apolar solvents such as chloroform. The recorded ${ }^{1} \mathrm{H}$ NMR and ${ }^{13} \mathrm{C}$ NMR data are in agreement with the assigned structures. In $\mathrm{CDCl}_{3}$ and in $\mathrm{CD}_{3} \mathrm{OD}$, all protons and carbons from the dendrimer interior are quite broad, especially for the higher generation dendrimers. Upon methylation (quaternization) the broad signals around 2.2-2.5 ppm from the methylene protons adjacent to the tertiary amines shift to $3.5-4.0 \mathrm{ppm}$ for the acetylated dendrimers and to around $2.7-2.9 \mathrm{ppm}$ for the pegylated dendrimers.

A

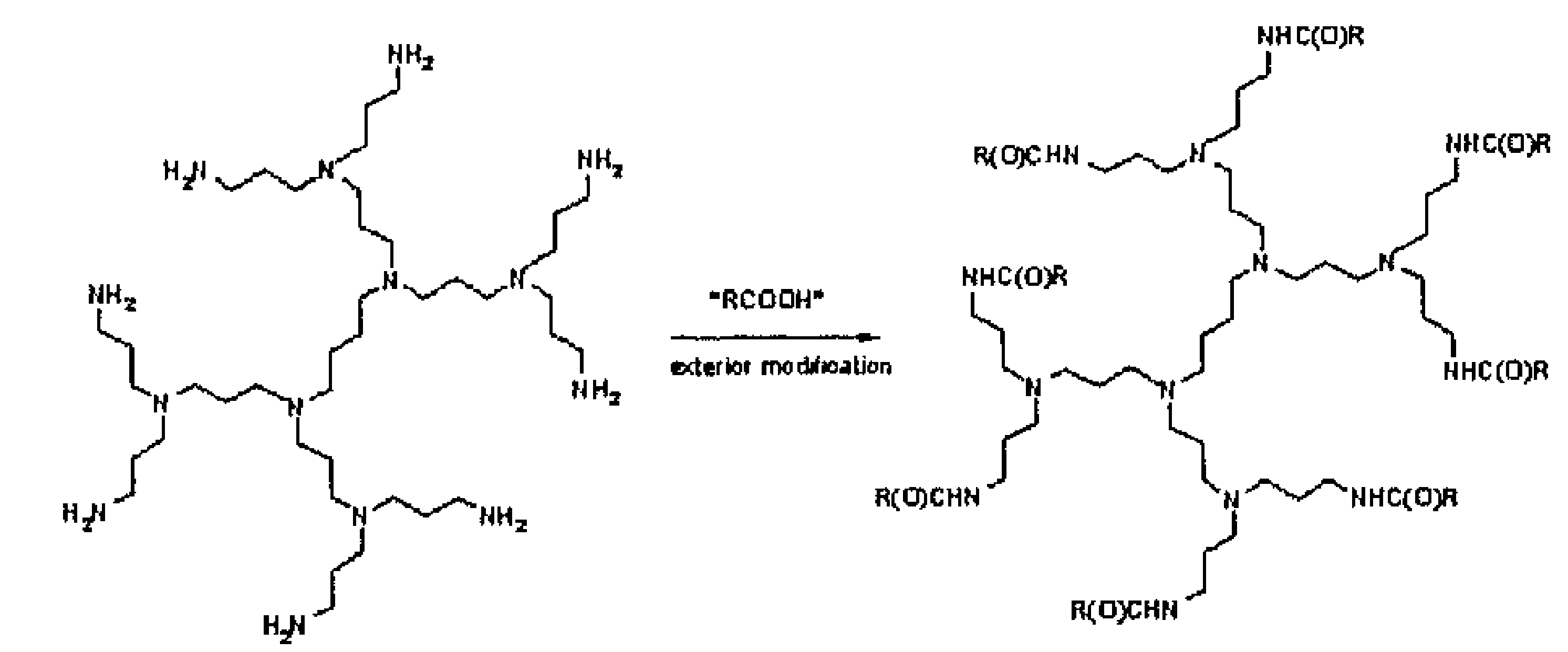

B
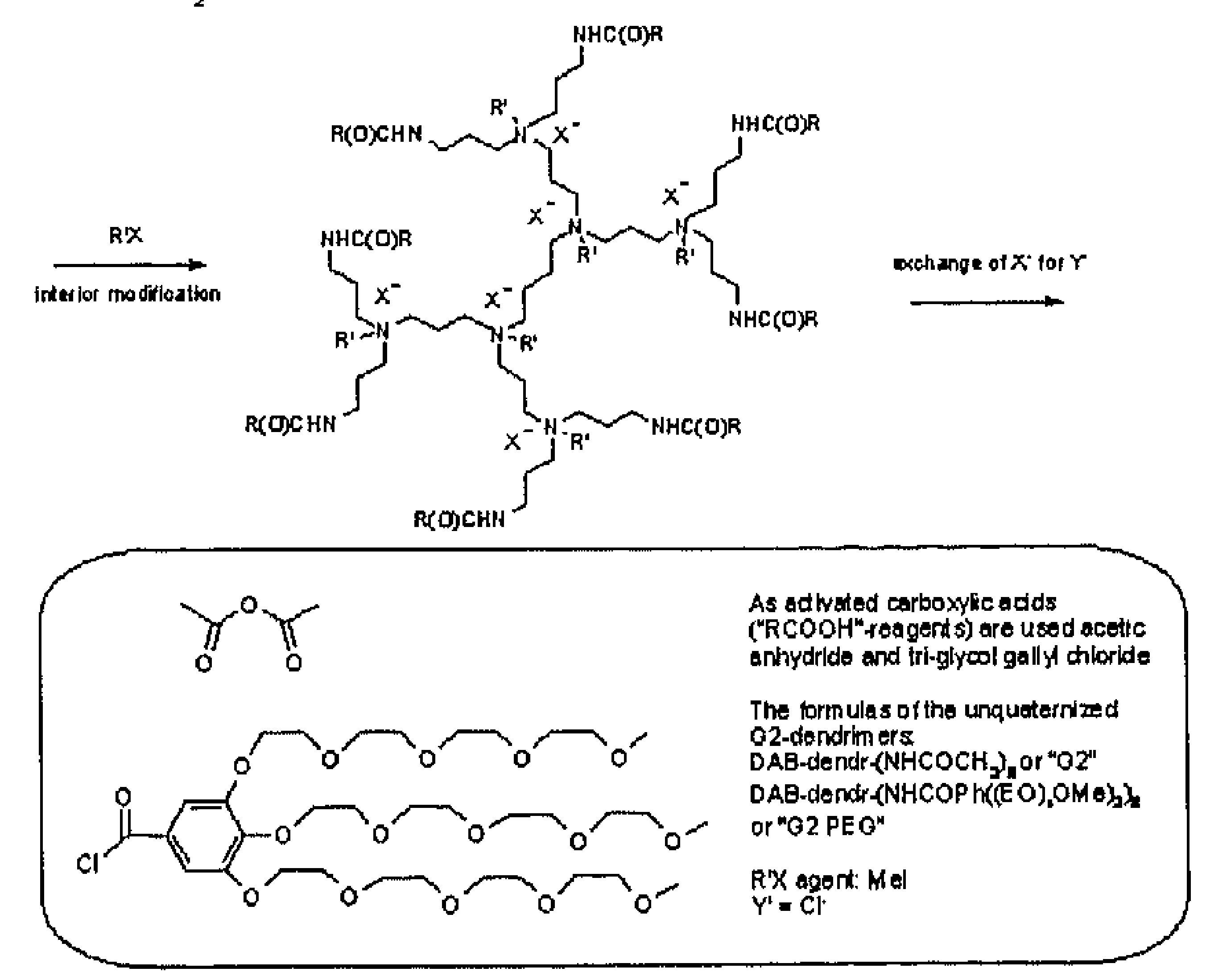

FIGURE 1: The applied synthesis of cationically modified PPI-dendrimers as generation PPl-dendrimer. In the first step the exterior primary anines are amidated prinaty animes aro mingated derivative ("RCOOH") while in the in the second sup the inceror tertiary amines are alkylated produce positively charged quaternary ammonium sites. In the third step the anjom is exchanged. The complete fornula of the timal product is I)AB-dendr-(NHCOR) t $^{\text {. }}$ 6R'Y, or G? (R'Y I. B. In the box the various $R, R$ ', $X$ and

$Y$-proups atre shown that have been used in this study. 
In $\mathrm{CDCl}_{3}$ and in $\mathrm{CD}_{3} \mathrm{OD}$, all protons and carbons from the dendrimer interior are quite broad, especially for the higher generation dendrimers. Upon methylation (quaternization) the broad signals around $2.2-2.5 \mathrm{ppm}$ from the methylene protons adjacent to the tertiary amines shift to $3.5-4.0 \mathrm{ppm}$ for the acetylated dendrimers and to around $2.7-2.9 \mathrm{ppm}$ for the pegylated dendrimers. In ${ }^{13} \mathrm{C}$ NMR one sees for both type of dendrimers that these methylene carbons shift from around $50-55 \mathrm{ppm}$ to around $60 \mathrm{ppm}$, while extra signals appear at around $50 \mathrm{ppm}$ for the introduced methyl groups. In $\mathrm{D}_{2} \mathrm{O}$ the signals of the methylenes next to the tertiary or quaternary amines are less broad. All the NMR-data arc in agreement with earlier reported results on other quaternized dendrimers.

It should be noted that the NMR data prove that the quaternization has proceeded quite wcll, but they do not prove that methylation has occurred completely, i.e. not necessarily all tertiary amines have been converted to quaternized cationic sites. It is possible to acquire mass data on the lower generation unquaternized dendrimers, but MS-analysis of the quaternized dendrimers has failed so far, possibly due to the many charges on the dendritic

\begin{tabular}{|c|c|c|}
\hline formuls dendrlmor: & $\begin{array}{l}\text { corrosponding } \\
\text { short formula }\end{array}$ & $\begin{array}{l}\text { theorestlacil } \\
\text { molecular } \\
\text { woightir }\end{array}$ \\
\hline $\mathrm{OAB}$-dendr-( $\mathrm{NHCOCH})_{1}$ & G2 & 1109 \\
\hline DAB-dendr-( $\left(\mathrm{NHCOCH}_{3}\right)_{6}+6 \mathrm{Mel}$ & G2(Mol) & 1961 \\
\hline DAB.dendr.( $\mathrm{NHCOCH}_{2 h}+6 \mathrm{MoCl}$ & G2(MBCl) & 1413 \\
\hline DAE-dendr. $\left(\mathrm{NHCOCH}_{2}\right)_{32}$ & G4 & 4859 \\
\hline DAE-dendr- $\left(\mathrm{NHCOCH}_{3}\right)_{32}+30 \mathrm{Mal}$ & GA(Mel) & 9117 \\
\hline $\begin{array}{c}\left.\text { DAB-dendr-( } \mathrm{NHCOCH}_{3}\right)_{32}+ \\
30 \mathrm{MaCl}\end{array}$ & G4(MaCl) & 6974 \\
\hline $\mathrm{DAB}-\mathrm{dendr} \cdot\left(\mathrm{NHCOPh}(\mathrm{EO})_{4} \mathrm{OMe}\right)_{32}$ & G4.PEG & 26544 \\
\hline 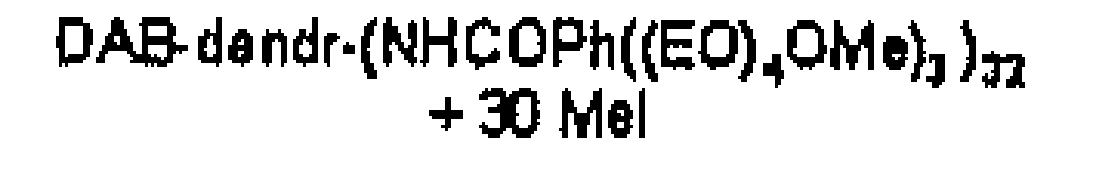 & G4-PEG(MeI) & 30903 \\
\hline $\begin{array}{l}\mathrm{DAB} \cdot d \theta \text { ndr. }\left(\mathrm{NHCOPh}\left((\mathrm{EO})_{4} \mathrm{OM}\right)_{3}\right)_{32} \\
30 \mathrm{MeCl}\end{array}$ & GA.PEG(MACD) & 28161 \\
\hline DAB-dondr.(NHCOPh((EO) $\left.\left.)_{4} \mathrm{OMe}\right)_{3}\right)_{64}$ & G5.PEG & 53429 \\
\hline $\begin{array}{c}D A B \cdot d e n d r \cdot\left(\mathrm{NHCOPh}\left((\mathrm{EO})_{4} \mathrm{OM}\right)_{3}\right)_{04}+ \\
62 \mathrm{MBI}\end{array}$ & G5-PEG(MOD) & 62228 \\
\hline
\end{tabular}
molecules. For convenience, all drawn structures in this paper are the perfect, totally methylated species.

Table I gives an overview of the modified PPI-dendrimers that are presented in this work, where the second column shows the abbreviations that are used throughout this paper. The presented synthetic method enables the production of similar structures with other dendrimer generations, other type of glycol chains, other quaternizations, other counter anions, etc. See for example Kreider JL et al. 2001.

TABLE I: Formulas of the prepared and investigited modified PPl-dendrimers as presented to this paper: the given theoretical unolecular weights are thosse of the pertiect structures.

Stability of the modified PPI-dendrimers in water

The designed and prepared (quaternized) dendrimers can only be well-defined transfection agents if their stability under physiological conditions is ensured. Therefore, a selection of dendrimers has been tested by daily monitoring the ${ }^{1} \mathrm{H}$ NMR and ${ }^{13} \mathrm{C}$ NMR spectra of $\mathrm{D}_{2} \mathrm{O}$ solutions of these dendrimers that were kept at ca. $37^{\circ} \mathrm{C}$ during 4 days. Spectra have been recorded for the $2^{\text {nd }}$ generation dendrimers $\mathrm{G} 2, \mathrm{G} 2(\mathrm{Mel})$ and $\mathrm{G} 2(\mathrm{MeCl})$, and for the $4^{\text {th }}$ generation dendrimer $\mathrm{G} 4(\mathrm{MeI})$. All dendrimers show similar spectral characteristics before, 
during and after the test period of 4 days, so that significant hydrolysis of the dendrimers is not indicated under the mimiced physiological conditions.

Even stronger evidence for the stability of the dendrimers has been acquired by monitoring aqueous solutions kept at $37^{\circ} \mathrm{C}$ of $4^{\text {th }}$ generation dendrimers G4-PEG and G4-PEG(MeCl) applying SEC (size exclusion chromatography), a technique that is usually applied to investigate the molecular weight (distribution) of macromolecules. The SEC-data are collected in Figure 2. During the several days of the experiment, the SEC-chromatograms of both samples do not change their shape at all. Apparently, no degradation of the dendrimers takes place, as this would have resulted in emerging peaks representing lower molecular weight material. The SEC-trace shows a shoulder at the higher molecular weight (left) side of the chromatogram. Presumably, this shoulder points at the presence of limited amounts of dimerized dendrimer species. It should be noted that the shoulder is also present in the SEC-trace of the $4^{\text {th }}$ generation amine terminated dendrimer that is the starting point of the synthesis.
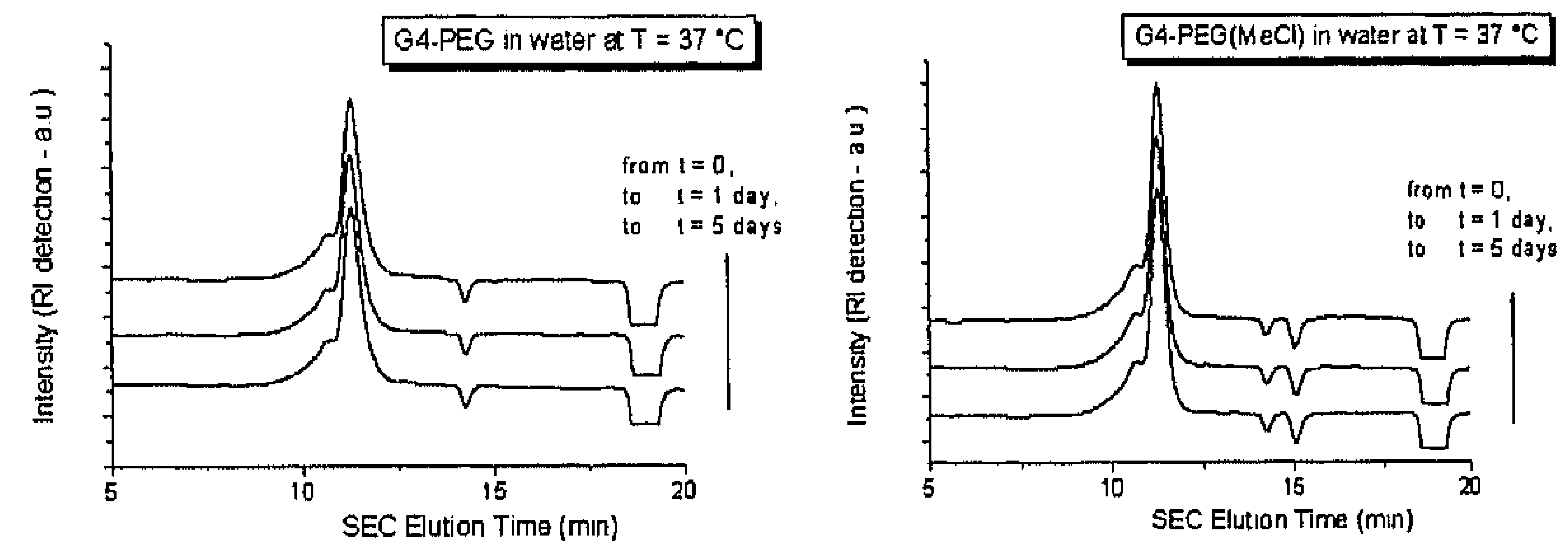

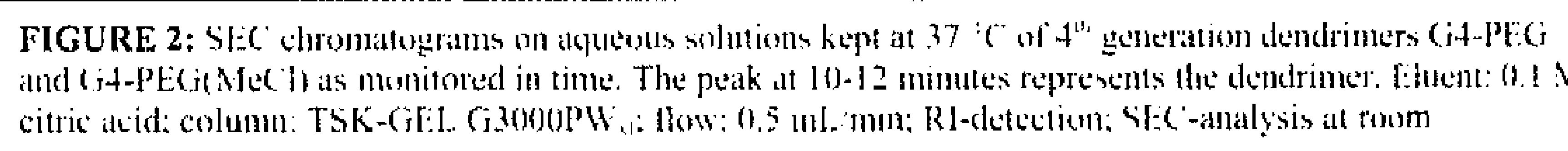
temperature

\section{Dendrimer-DNAzyme binding experiments using PAGE}

Polyacrylamide gel electrophoresis (PAGE) is a technique that is frequently used in the analysis of proteins and nucleic acids. The elution of the species under investigation is dependent on its size and on its charge. SDS-PAGE (addition of sodium dodecyl sulfate to the gel-buffer), for instance, is applied to assess the molecular weight of (unfolded) proteins.

Here, PAGE has been performed to investigate the binding properties of several poly(propylene imine) dendrimer structures to a 33-mer DNAzyme (for details see the experimental section). After elution and staining the free DNAzyme appears as a single band on the gel. If upon mixing of the DNAzyme with another species binding occurs, the elution behavior of the DNAzyme in the mixture alters compared to that of the free DNAzyme, as the volume and/or the charge of the DNA-species has changed. This results in a DNA-band at the same position, but with a lower intensity (a fraction of the DNA is complexed), in a band at another position on the gel or in a complete disappearance of the 
band. To assess the binding capacity of the set of prepared dendrimers, the DNAzyme and the dendrimer have been mixed in different charge ratios, where the charge ratio is defined as the number of tertiary plus quaternary amines in the dendrimer divided by the number of negatively charged phosphate groups on the DNA.

The binding of the DNAzyme molecule with the different dendrimers given in Table I has bcen investigated. Here, three gels are selected and shown in Figure 3 to illustrate the findings; the gels were prepared and run in a TBE buffer of $\mathrm{pH}=7$. In the Supplementary Information more of the recorded PAGE gels are collected.

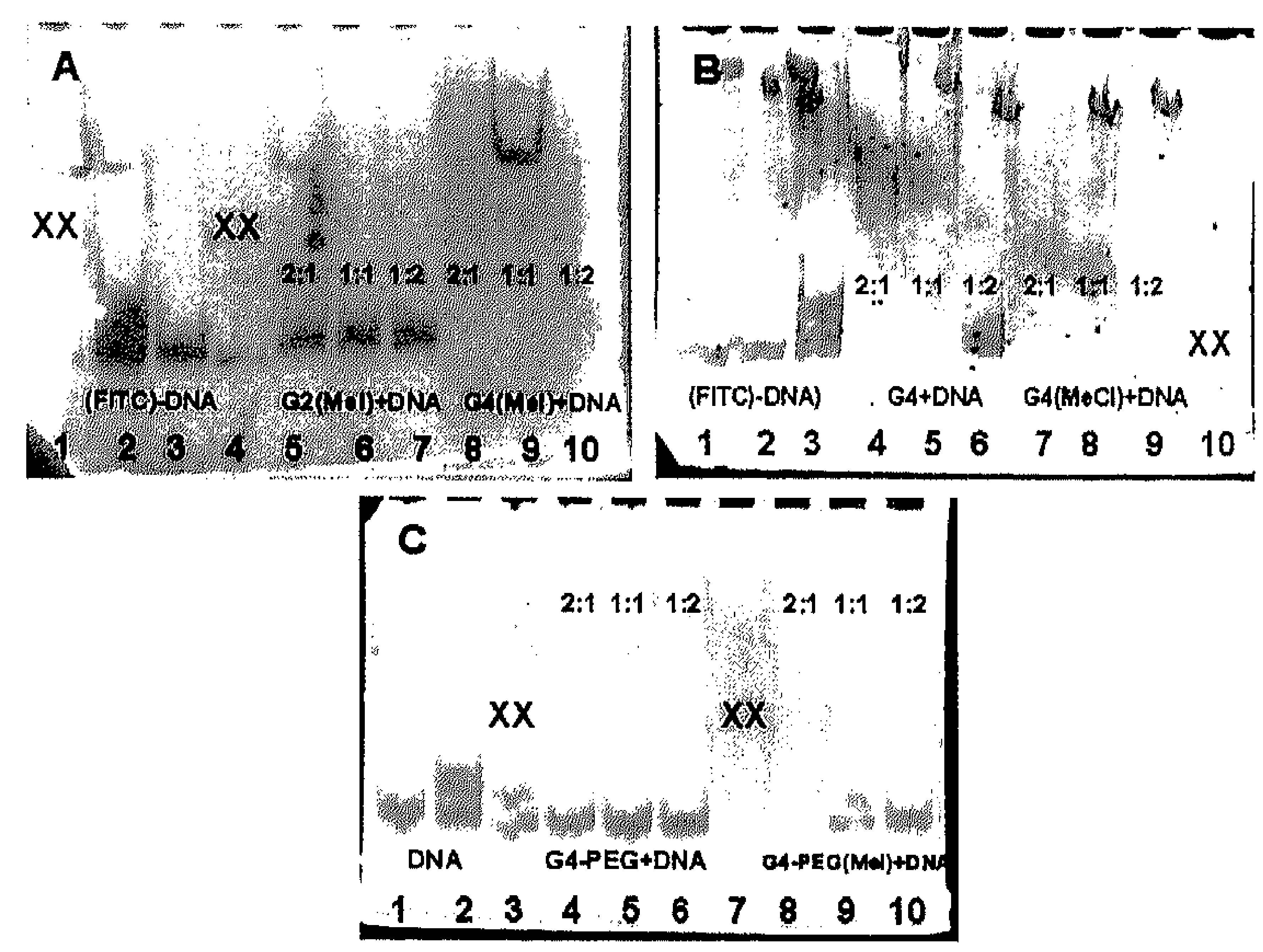

FIGURE 3: PAGE gels on mixtures of the 33-mer DNA Ayme and the indicated modified PPl-dendrmers. The used

dendrimer:DNA charge rattos are giren in the lines. Linnes that are not used are indicated witl, XX. Conditions: 17". PA-gels

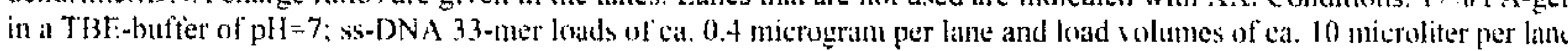
have been used; Ag-staining. Note that in the DNA reference lanes sometimes a mixture of ss-DNA-7yne and FlTC-laheled ss-DNA-ryme has been used, resulting in two DNA-spots in one lane. Further details are given in the Experimental Section (Supplementary Info)

Gel A shows a comparison between the acetylated and methyliodide quaternized dendrimers $\mathrm{G} 2(\mathrm{MeI})$ and $\mathrm{G} 4(\mathrm{MeI})$. Clearly, the $4^{\text {th }}$ generation dendrimer binds the DNAzyme better than the $2^{\text {nd }}$ generation counterpart that does not seem to induce binding at the investigated concentration. This observation can be explained by the fact that the G4(MeI) dendrimer bears many more cationic sites per molecule than the G2(Mel) dendrimer (30 versus 6) and its design is therefore more matched to the 33 negative charges in the DNAzyme (ideally, for the G4(Mel) dendrimer only one molecule has to bind to (almost) cancel the charges in a $1: 1$ complex, whereas for the G2(MeI) dendrimer about 6 molecules are required giving a $6: 1$ complex. Thus, in this analysis, the G4(MeI)-DNA complex is entropically favored over the G2(MeI) complex). Gel B compares acetylated $4^{\text {th }}$ generation 
dendrimers that are quaternized $(\mathrm{G} 4(\mathrm{MeCl}))$ or not $(\mathrm{G} 4)$. Both dendrimers are able to bind the DNAzyme quite effectively, but the quaternized $\mathrm{G} 4(\mathrm{MeCl})$ species is more potent, as even at a $1 / 2$ dendrimer-DNA charge ratio almost all DNA is bound. Finally, gel $C$ compares glycolgallate modified $4^{\text {th }}$ generation dendrimers that are quaternized (G4PEG(Mel)) or not (G4-PEG). Again it is clear that the quaternized species bind the DNAzyme better, but the results also shows that acetylated G4-dendrimers (gel B) give a better binding to the DNA than the pegylated G4-dendrimers (gel C), as higher cxcesses of the pegylated dendrimers are necessary to bind the DNAzyme effectivcly.

G4-PEG(MeI) has been selected for a concentration-range binding study. DNA-loads per lane of $0.1,0.2,0.4,0.8$ and 1.6 microgram in 12.5 microliter have been used, while charge ratios were varied from $2: 1$ to $3: 2$ to $1: 1$ (excess dendrimer). Naturally, the PAGE-study shows that binding is reduced at lower concentrations: at a load of 0.1 microgram the DNA is almost completely unbound, while at loads of 0.8 microgram or higher all DNA is bound even at the lowest charge ratio of 1:1 (see the Supplementary Information for the acquired PAGE-gels of this concentration binding study).

Finally, the binding properties of the dendrimers at a $\mathrm{pH}$-value of 4.4 using an acetic acid/ $\beta$-alanine buffer has also been studied (no gels shown). In comparison with the measurements at $\mathrm{pH}=7$, the investigated unquaternized dendrimers seem to bind better, while the quatemized dendrimers bind the DNA to a somewhat lesser extent. This result can be explained by the protonation of the unquatcrnized dendrimers at lower $\mathrm{pH}$-values, so that these dendrimers also have multiple cationic sites in their interior, promoting binding to the DNAzyme.

The results demonstrate that the synthesized dendrimers with multiple cationic sites in their interior can bind the 33-oligomer DNAzyme at concentrations of around 40 microgram DNA per $\mathrm{mL}$ (corresponding to a molar concentration of about $4 \mu \mathrm{M} \mathrm{DNA}$ ), and at charge ratios of around 2:1-1:1 (slight excess dendrimer). Transfection agents reported in literature usually require higher concentrations and/or higher charge ratios to allow for efficient complexation with DNA. Moreover, the concentration-range binding study on the G4PEG(MeI) species shows that binding between dendrimer and DNAzyme is reversible, enabling dissociation of the complex and release of the DNAzyme.

\section{In vitro toxicity of modified PPI-dendrimers}

In order to assess their suitability as gene transfection agents, the toxicity of a selection of modified PPI-dendrimers has been investigated on 4 different cell lines, MCF7, Malme$3 \mathrm{M}, \mathrm{HT} 29$ and $\mathrm{K} 562-\mathrm{C} 1000$, using the MTT-test (data not shown). The $2^{\text {nd }}$ generation acetylated dendrimers $\mathrm{G} 2, \mathrm{G} 2(\mathrm{MeI})$ and $\mathrm{G} 2(\mathrm{MeCl})$ do not exert a toxicity on all 4 cell lines below concentrations of $100 \mu \mathrm{M}$, while the $4^{\text {th }}$ generation acetylated dendrimers $\mathrm{G} 4$, $\mathrm{G} 4(\mathrm{Mel})$ and $\mathrm{G} 4(\mathrm{MeCl})$ show no sign of toxicity below a level of $20 \mu \mathrm{M}$ for these cells. Finally, the $5^{\text {th }}$ generation dendrimers G5-PEG and G5-PEG(MeI) are non toxic at the highest level investigated $(2.5 \mu \mathrm{M})$. These concentrations are 20, 20 and 5 times higher than the levels that we use for standard in vitro transfection experiments with the respective $2^{\text {nd }}, 4^{\text {th }}$ and $5^{\text {th }}$ generation dendrimers (only transfection data of the $4^{\text {th }}$ generation dendrimer are presented in this paper, vide infra). 


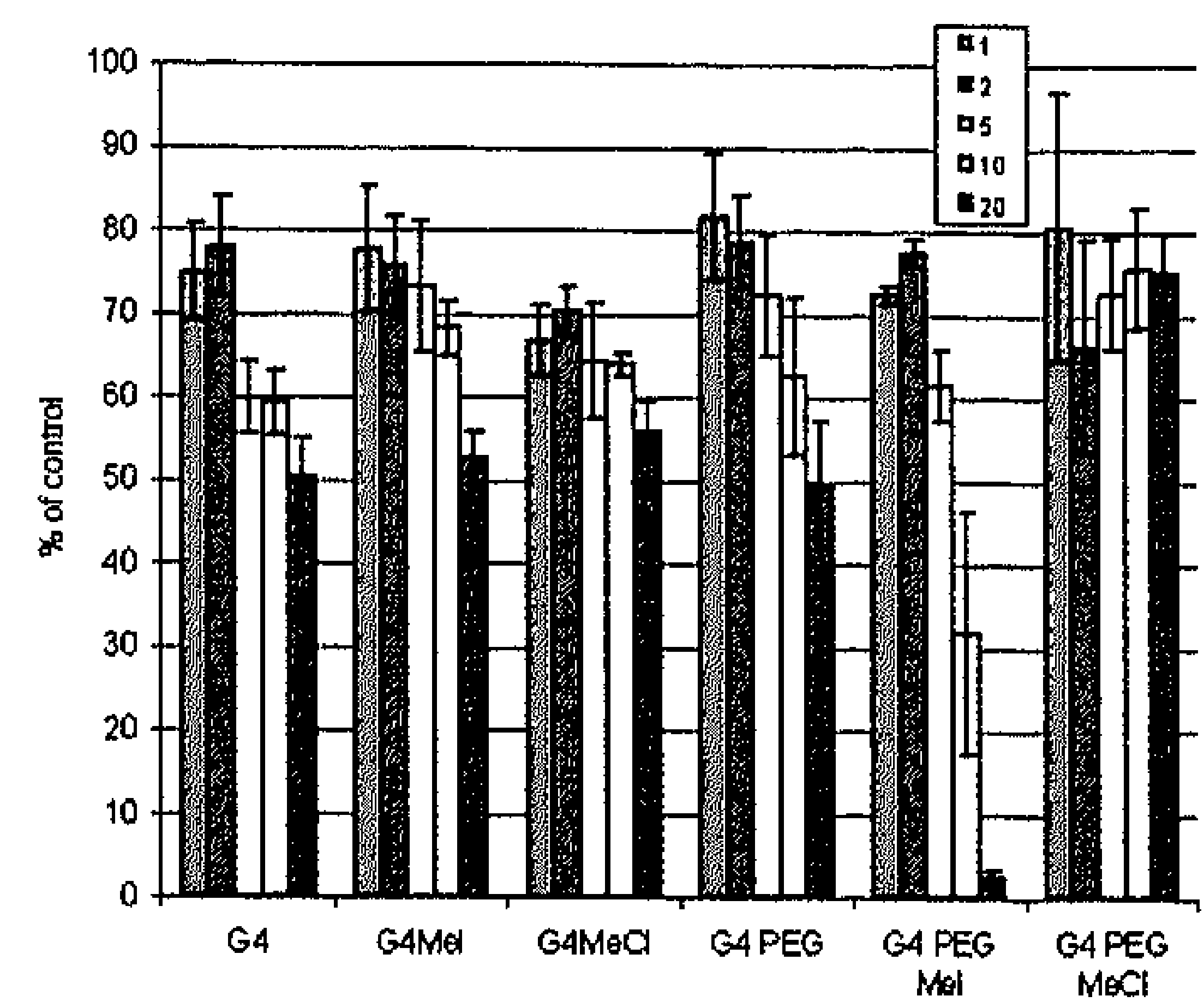

FIGURE 4: loxleity NTT-assay on A2780 watrian carcinoma celts that alre exposed to sartints $4^{\text {th }}$ genteration modhlied P'l-dendrimers. For wery lested dendrimer, the vability percentage of the cells is shoms with increasing concentration of dentrmer: $1 \mu . M .2 \mu N .5 \mu N, 10 \mu M$ and 20 p.M. A serom concentration in the medhem of 10 "', is thed Further details are given in the fixperinkentil secten
The toxicity of $4^{\text {th }}$ generation dendrimers has been investigated in more detail, as the $4^{\text {th }}$ generation dendrimers have been found to bind the DNAzyme more effectively than their $2^{\text {nd }}$ generation counterparts (see the PAGE tests described above). For each of the six studied dendrimers (i.e. G4, $\mathrm{G} 4(\mathrm{Mel}), \quad \mathrm{G} 4(\mathrm{MeCl}), \quad \mathrm{G} 4-\mathrm{PEG}, \mathrm{G} 4-$ PEG(Mel) and G4-PEG(MeCl)) the cellular toxicity was assessed using the MTT test, while applying varying dendrimer $(1 \mu \mathrm{M}, 2 \mu \mathrm{M}, 5 \mu \mathrm{M}, 10 \mu \mathrm{M}$ and $20 \mu \mathrm{M}$ ) and serum concentrations $(10 \%, 20 \%, 30 \%$ and $40 \%$ fetal calf serum). As can be seen in Figure 4 each dendrimer, apart from G4-PEG( $\mathrm{MeCl})$, shows a decrease in cellular proliferation with increasing concentration. At concentrations of 1-5 $\mu \mathrm{M}$, all six dendrimers exert no specific

toxicity and $>70 \%$ of the cells survive after a 4 day treatment. At higher cconcentrations, however, especially G4-PEG(MeI) shows a definite toxicity as cell survival rates drop clearly below $50 \%$. The other dendrimers still show a low cell death of about $30 \%$ at a concentration of $10 \mu \mathrm{M}$, and a partial toxicity of $30-60 \%$ at $20 \mu \mathrm{M}$. G4-PEG(MeCl) retains its low toxicity even at a $20 \mu \mathrm{M}$ level. A serum level of $10 \%$ was used in the data shown in Figure 4.

Each of the six G4-dendrimers has also been tested for its toxicity in the presence of increasing quantities of serum, applying levels from $10 \%$ to $40 \%$. All dendrimers exert a lower cellular toxicity when higher quantities of serum are used (Figure 5). Remarkably, when $20 \%-40 \%$ of serum is used, the toxicity of the dendrimers seems (almost) independent of the concentration that is used; even at a $20 \mu \mathrm{M}$ level, the cell survival is clearly above $50 \%$ for all dendrimers, except for dendrimer G4-PEG(MeI) that becomes toxic at concentrations above $10 \mu \mathrm{M}$.

It can be concluded from the MTT toxicity tests described here that almost all designed and prepared PPI-dendrimers show low levels of toxicity. Possibly, the counter anions in the quaternized dendrimers determine to some extent the toxicity of the species, and it seems favorable to use chloride counter anions in stead of iodides. 

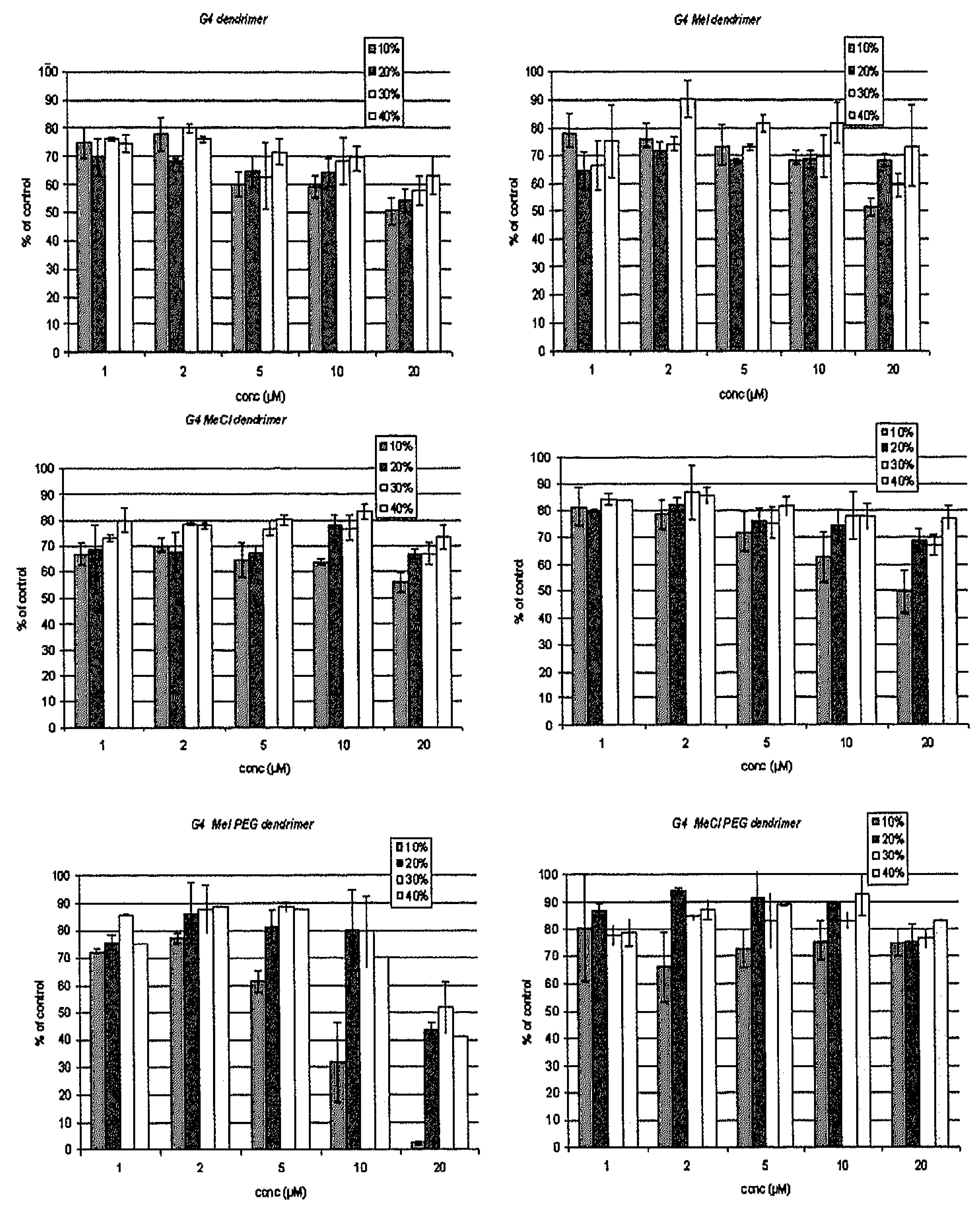

FIGURE 5: Toxicity MTT-assay on A2780 ovarian carcinoma cells that are expused to varions $4^{\text {th }}$ genteraten noditied ppl-dendrimers. For every dendrimer, the viahility percentage of the cells is shown with incleasing concentration of

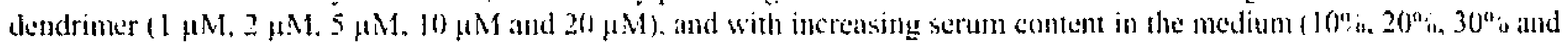

40"v. Furtler details are given in the Experimential Section 
In vitro transfection of DNAzyme using modified G4 PPI-dendrimers

The transfection of DNAzyme using $4^{\text {th }}$ generation modified PPI-dendrimers as delivery agents has been investigated on A2780 ovarian carcinoma cells appyling a fluorescence activated cell sorting (FACS) analysis. A dendrimer-DNAzyme charge ratio of $C R=1$ and a concentration of $1 \mu \mathrm{M}$ is used in all transfection tests to retain a low level of toxicity (see the MTT toxicity tests presented above), and to stay in the concentration domain where binding between DNA and dendrimer is anticipated (see the PAGE binding test presented above). An increasing level of serum in the medium has been examined $(10 \%, 20 \%, 30 \%$ and $40 \% \mathrm{FCS}$ ) to mimic in vivo conditions.

All 6 dendrimers show high transfection efficiencies usually exceeding 80\%, with the acetylated quaternized dendrimers $\mathrm{G} 4(\mathrm{MeI})$ and $\mathrm{G} 4(\mathrm{MeCl})$ displaying the best results (Figure 6). Remarkably, in the class of the pegylated dendrimers there is hardly a difference in efficiency when the unquaternized system G4-PEG is compared to the quaternized systems G4-PEG(MeI) and G4-PEG(MeCl). Finally, the transfection tests show that the amount of serum in the medium does hardly affect the efficiency of in vitro delivery. Free DNAzyme, i.e. when no dendrimer transfection agent is used, transfects with an efficiency of only $5-10 \%$, as established in a control experiment. In a confirmation of the toxicity tests, a cellular toxicity of approximately $15 \%$ has been found in these in vitro delivery tests, as revealed by propidium iodide staining.
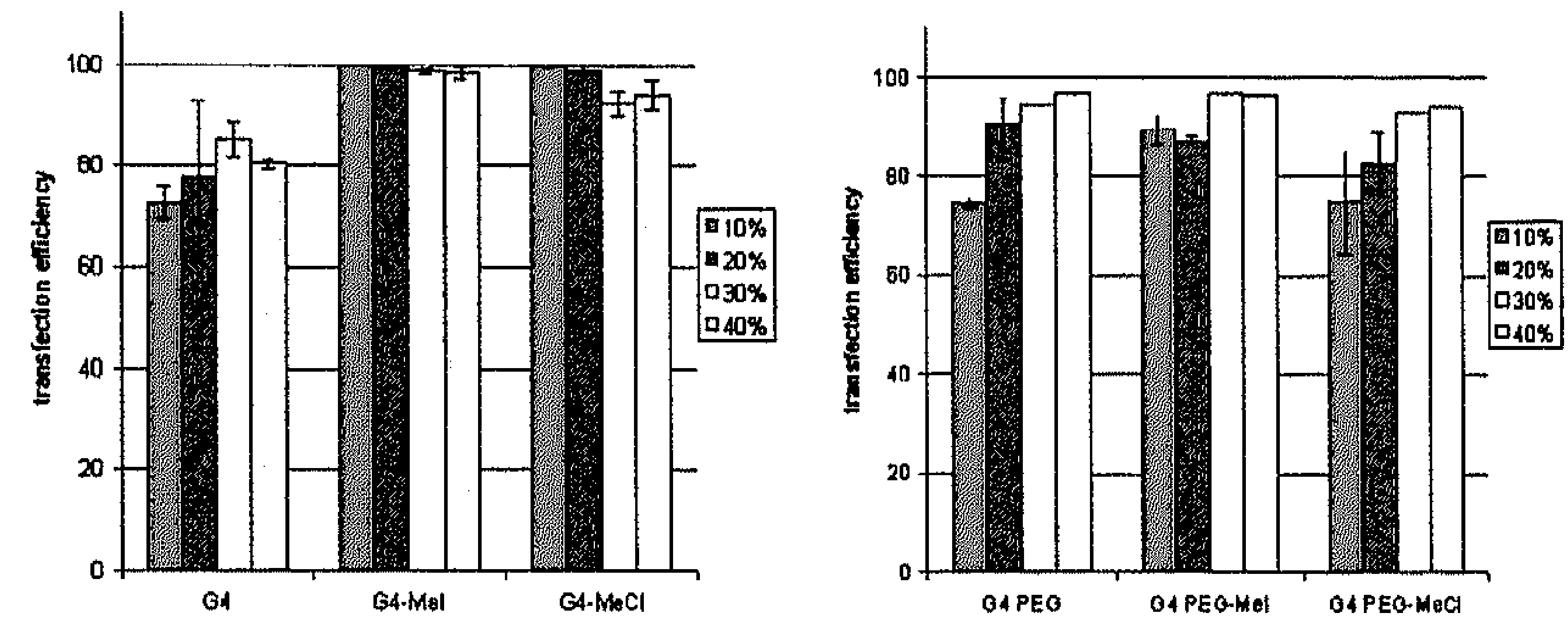

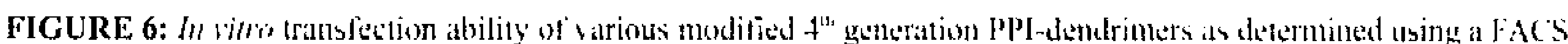

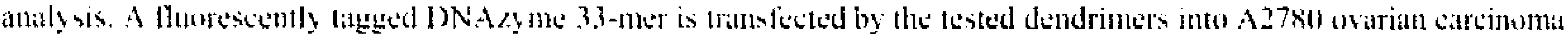

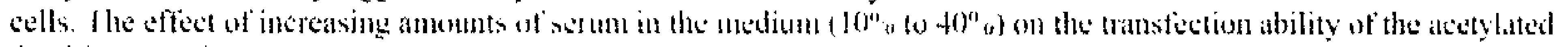

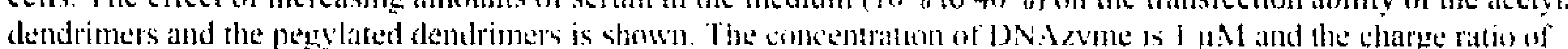

dendrimer to DNAzyme is 1 . Further tetails ane given in the Experinestial Seetion.

The transfection efficiencies found for the dendrimer systems are similar to what is found in the same setup when a cationic liposomal transfection agent, DOTAP ${ }^{(\hat{)})}\left(\right.$ Roche $\left.^{(0)}\right)$, is used $(\mathrm{MW}=$ ca. 700$)$. However, this liposome can only neutralize one negative charge per molecule, so that the amount needed to reach a CR of 1 is such that the toxicity of the transfection mix is high. Induction of inflammatory reponse elements TNF $\alpha, 1 \mathrm{~L}-12$ and IFN- $\gamma$ were observed using the liposome in an in vivo setting (Tan $Y$ et al 2001). More 
importantly, although DOTAP was able to deliver a functional plasmid DNA to the lungs in adult mice, the N/P ratio that was used was low $(<5)$. At the concentration our DNAzyme was used in, a N/P ratio of 30 was required for neutralization, a high animal mortality was observed (Bragnozi A et al 1999). Concludingly, the use of DOTAP delivery methods seems disabled in vivo.

\section{In vivo delivery of DNAzyme using modified G4 PPI-dendrimers}

The in vivo experiments that are presented here have been executed using the G4PEG(MeI) dendrimer. The acetylated quaternized dendrimers $\mathrm{G} 4(\mathrm{MeI})$ and $\mathrm{G} 4(\mathrm{MeCl})$ that show the most convincing in vitro transfection ability have been rejected for this purpose, as they produce insoluble precipitates when mixed with the DNAzyme at concentrations that are required for preparing samples for in vivo studies (for example, G4(Mel) and DNAzyme give a white precipitate when mixed at a concentration of ca. $700 \mu \mathrm{M}$, a concentration that is much higher than those used in the binding, toxicity or in vitro transfection tests described above).

After treating the mice intravenously with the dendrimer / FITC-labeled DNAzyme complex, the fluorescence has been visualized using whole body imaging (WBI) (data not shown). After 5 minutes the fluorescence is visible everywhere in the body. After 45 minutes the fluorescence is no longer externally detectable in three of the five mice using WBI, although the fluorescence had locally accumulated in the beginning of the duodenum as was visualized after dissection post mortem. Two of the five mice, however, show a weak externally visible fluorescence near the tumor. These two samples have been analyzed using confocal microscopy to determine whether the fluorescence observed with WBI is indeed intracellular co-localized. A day $(24 \mathrm{~h})$ after injection no fluorescence can be seen, neither externally nor internally post mortem.

In the two samples that show externally visible accumulation of the FITC label, sectioning the tumor and analyzing the section via confocal microscopy results in an intensive spotty like accumulation of the FITC label in the tissue (Figure 7). The reason for this spotty like pattern and for the extensive accumulation in the nucleus is still unclear. There is a high colocalization with the TOPRO3 (red) dye indicating the FITC label is present in the nucleus. An additional staining (Bodipy phalloidin (blue)) has been performed to observe the $\beta$-actin levels of the cell. 
Chapter 3

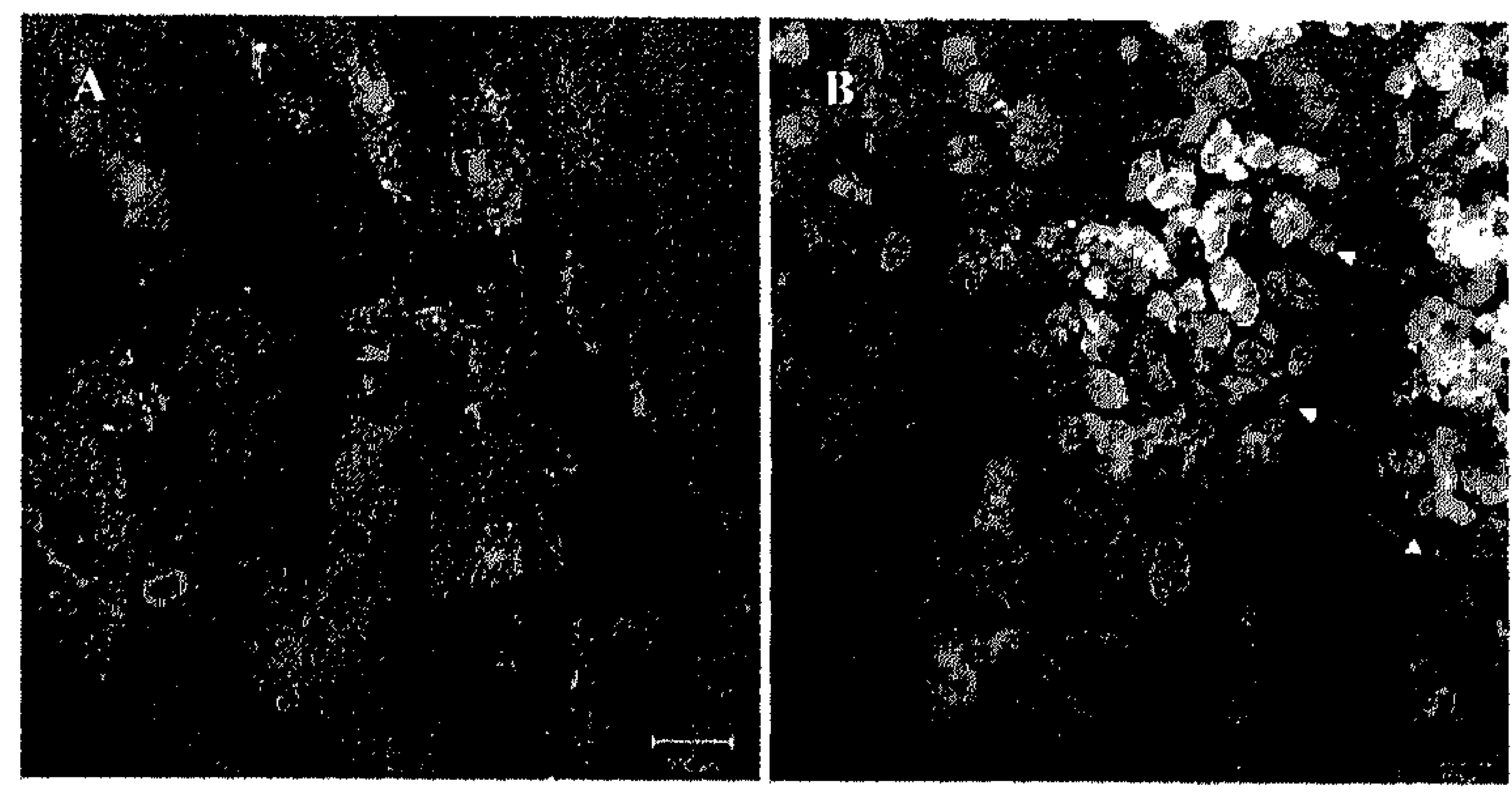

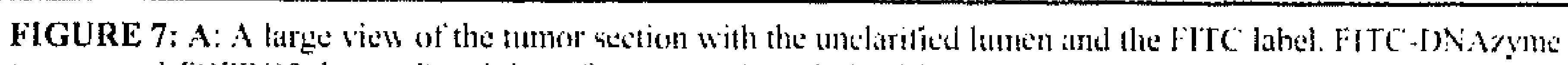

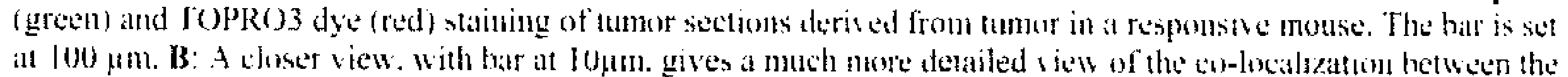

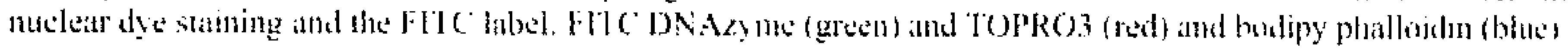

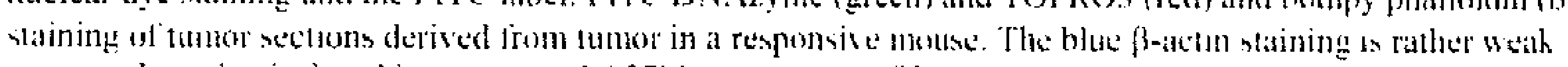

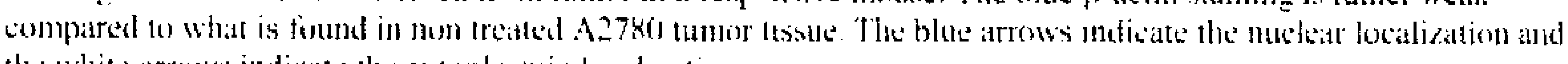
the white arrows indicite the crtoplasmic locallaratiom.

In the sections preparcd from the tumors excised from the treated mice large lumen like holes are seen and appear to bc present in the vicinity of the majority of the accumulated FITC label. The sections obtained from the tumors from the untreated mice did not have these lumen like structures. As to how and why these lumen are crcated is not clear at present. Whether they work as a trap for the oligoDNA or if they are created by the dendrimer-DNAzyme complex or a part of the complex (the dendrimer alone) requires further investigation. Non treated samples have a much better $\beta$-actin staining around the nucleus. This is however almost not detectable in the areas that contain FITC labeling in the treated samples.

\section{CONCLUSION}

As the field of post transcriptional gene silencing is constantly advancing with new additional players e.a. siRNA and miRNA, the field of drug delivery is under more and more pressure to present a better and safer transfection agent to accommodate the needs in oligonucleotide therapy. Although most delivery agents on the market claim to achieve high transfection efficiency and low toxicity in a large number of cell types, at present none have profilated themselves as a decent in vivo drug delivery tool.

In this report, we have introduced modified PPI-dendrimers-some of which have never been reported before - that can easily be prepared and that can act as transfection agents in gene therapy. We demonstrate that the designed and prepared PPI-dendrimers are stable in 
aqueous environments and that these dendrimers enable in vitro delivery of a DNAzyme into ovarian carcinoma cells, while inducing only a low cellular toxicity. In fact, for the first time, PPI-dendrimer based materials of the higher G4 and G5 generations are presented that display low cytotoxicities as measured with MTT-assays. The in vitro delivery is efficient as the binding and transfection of the DNAzyme can proceed at low concentrations and low charge ratios (i.e. low excesses of dendrimer still enable transfection). Moreover, preliminary in vivo experiments show that delivery is feasible as well, although much more work is required to answer questions as to what the kinetics and dynamics of the delivery are. Also, the extent of in vivo toxicity needs to be investigated.

Finally, initial PAGE binding studies in our labs have shown that double stranded siRNA (a 44-mer) also binds to the PPI-dendrimers described here, so that binding and transfection of nucleic acids does not seem to be restricted to the DNAzyme model that has been used in this study. Further investigations would be required to see if and how the introduced transfection agents can deliver higher molecular weight DNA, such as plasmids.

\section{$\underline{\text { REFERENCES }}$}

Bakker A, Floren W, Voeten J, Janssens B, Smets G, Wouters W and Janicot M. (2001). Automation of whole body imaging of GFP-expressing tumors in living animals. G.I.T.Imaging \& Microscopy, 03/2001:52-54.

Bielinska A, Kukowska-Latallo JF, Johnson J, Tomalia DA and Baker JR Jr. (1996). Regulation of in vitro gene expression using antisense oligonucleotides or antisense expression plasmids transfected using starburst PAMAM dendrimers. Nucleic Acids Res., 24:2176-2182.

Bielinska AU, Chen C, Johnson J and Baker JR Jr. (1999). DNA complexing with polyamidoamine dendrimers: implications for transfection. Bioconjug. Chem, 10:843-850.

Bosman AW, Janssen HM and Meijer EW. (1999). About Dendrimers: Structure, Physical Properties, and Applications. Chem Rev, 99:1665-1688.

Cheng H, Zhou R, Liu L, Du B and Zhuo R. (2000). Cyclic core dendrimer as a new kind of vector for gene transfer into mammalian cells. Genetica, 108:53-56.

Choi J, Joo DK, Kim CH, Kim K and Park JS (2000). Synthesis of a Barbell-like Triblock Copolymer, Poly(L-lysine) Dendrimer-block-Poly(ethylene glycol)-block-Poly(Llysine) Dendrimer and its self-assembly with plasmid DNA. J Am Chem Soc 122, 474-480.

de Brabander-van den Berg EMM and Meijer EW. (1993). Poly(propylene imine) dendrimers: Large scale synthesis by heterogenously catalyzed hydrogenations. Angew. Chem. Int. Ed. Engl., 32, 1308-1311.

Delong R, Stephenson K, Loftus T, Fisher M, Alahari S, Nolting A and Juliano RL. (1997). Characterization of complexes of oligonucleotides with polyamidoamine starburst dendrimers and effects on intracellular delivery. J Pharm.Sci, 86:762-764. 
Duncan R and Malik N. (1996).: Dendrimers: Biocompatibility and potential for delivery of anticancer agents. Proceed. Int. Symp. Control. Rel. Bioact. Mater., 23, 105-106.

Elissen-Roman C, van Hest JCM, Baars MWPL, van Genderen MHP and Meijer EW. (1997). Amphiphilic block copolymers based on quaternized poly(propylene imine) dendrimers, PMSE, 77, 145-146.

Esfand R and Tomalia DA. (2001). Poly(amidoamine) (PAMAM) dendrimers: from biomimicry to drug delivery and biomedical applications. Drug Discov.Today, 6:427-436.

Haensler J and Szoka FC Jr. (1993). Polyamidoamine cascade polymers mediate efficient transfection of cells in culture. Bioconjug. Chem, 4:372-379.

Hong S, Bielinska AU, Mecke A, Keszler B, Beals JL, Shi X, Balogh L, Orr BG, Baker JR Jr. and Banaszak Holl MM. (2004). Interaction of poly(amidoamine) dendrimers with supported lipid bilayers and cells: hole formation and the relation to transport. Bioconjug. Chem, 15:774-782.

Joester D., Losson M., Pugin R., Heinzclmann H., Walter E., Merkle HP and Diederich F. (2003). Amphiphilic dendrimers: novel self-assembling vectors for efficient gene delivery. Angew Chem Int Ed Engl, 42:1486-1490.

Kabanov VA, Sergeyev VG, Pyshkina OA, Zinchenko AA, Zezin AB, Joosten JGH, Brackman, J., Yoshikawa, K. (200)). Interpolyelectrolyte complexes formed by DNA and astramol poly(propylene imine) dendrimers, Macromolecules, 33, 9587-9593.

Kihara F, Arima H, Tsutsumi T, Hirayama F and Uekama K. (2003).: In vitro and in vivo gene transfer by an optimized alpha-cyclodextrin conjugate with polyamidoamine dendrimer. Bioconjug. Chem, 14:342-350.

Kreider JL and Ford WT. (2001). Quaternary ammonium ion dendrimers from methylation of poly(propylene imine)s, J. Polym. Sci., Part A.: Polym. Chem., 39, 821-832.

Kukowska-Latallo JF, Biclinska AU, Johnson J, Spindler R, Tomalia, DA and Baker JR Jr. (1996). Efficient transfer of genetic material into mammalian cells using Starburst polyamidoamine dendrimers. Proc.Natl.Acad.Sci U.S.A. 93:4897-4902.

Lee JH, Lim YB, Choi JS, Lee Y, Kim TI, Kim HJ, Yoon JK, Kim K and Park JS. (2003). Polyplexes assembled with internally quaternized PAMAM-OH dendrimer and plasmid DNA have a neutral surface and gene delivery potency. Bioconjug. Chem, 14:1214-1221.

Liu M, Kono K and Frechet JM. (1999). Water soluble dendrimer polyethylene glycol starlike conjugates as potential drug carriers. J Polym Sci Part A: Polym Chem 37, 3492-3503.

Liu M and Frechet JM. (1999). Designing dendrimers for drug delivery. Pharm. Sci. Technol. Today, 2:393-401.

Loup C, Zanta MA, Caminade AM, Majoral JP and Meunier B. (1999). Preperation of Water-Soluble Cationic Phosphorus-Containing Dendrimers as DNA Transfecting Agents, Chem Eur J., 5, 3644-3650.

Luo D, Haverstick K, Belcheva N, Han E and Saltzman WM. (2002). Polyethylene gylcol conjugated PAMAM dendrimer for biocompatible, high efficiency DNA delivery. Macromolecules 35, 3456-3462. 
Malik N, Wiwattanapatapee R, Klopsch R, Lorenz K, Frey H, Weener JW, Meijer EW, Paulus W and Duncan R. (2000). Dendrimers: relationship between structure and biocompatibility in vitro, and preliminary studies on the biodistribution of 1251 labelled polyamidoamine dendrimers in vivo. J Control Release, 65:133-148.

Ohsaki M, Okuda T, Wada A, Hirayama T, Niidome T and Aoyagi H. (2002). In vitro gene transfection using dendritic poly(L-lysine). Bioconjug. Chem, 13:510-517.

Ottaviani MF, Furini F, Casini A, Turro NJ, Jockusch S, Tomalia DA and Messori L. (2000). Formation of supramolecular structures between DNA and starburst dendrimers studied by EPR, CD, UV and melting profiles. Macromolecules 33, 7842-7851.

Pan Y and Ford WT. (1999). Dendrimers with both hydrophilic and hydrophobic chains at every end, Macromolecules, 32, 5468-5470.

Pan Y and Ford WT. (2000). Amphiphilic dendrimers with both octyl and triethylenoxy methyl ether chain ends, Macromolecules, 33, 3731-3738.

Patri AK, Majoros IJ and Baker JR. (2002). Dendritic polymer macromolecular carriers for drug delivery. Curr.Opin.Chem.Biol., 6:466-471.

Qin L, Pahud DR, Ding Y, Bielinska AU, Kukowska-Latallo JF, Baker JR Jr. and Bromberg JS. (1998). Efficient transfer of genes into murine cardiac grafts by Starburst polyamidoamine dendrimers. Hum. Gene Ther, 9:553-560.

Roberts JC, Bhalgat MK and Zera RT. (1996). Preliminary biological evaluation of polyamidoamine (PAMAM) Starburst dendrimers. $J$ Biomed.Mater:Res., 30:53-65.

Schlüter DA. (1999). Chapter 12: The synthesis and Characterization of Dendritic Molecules. In: Janssen, HM. and Meijer EW. Synthesis of Polymers, Materials Science and Technology Series. Wiley-VCH Verlag GmbH D-69469 Weinheim, Germany.

Shah DS, Sakthivel T, Toth I, Florence AT and Wilderspin AF. (2000). DNA transfection and transfected cell viability using amphipathic asymmetric dendrimers. Int J Pharm., 208:41-48.

Shchepinov MS, Udalova IA, Bridgman AJ and Southern EM. (1997). Oligonucleotide dendrimers: synthesis and use as polylabelled DNA probes. Nucleic Acids Res., 25:4447-4454.

Stiriba SE, Frey H and Haag R. (2002). Dendritic Polymers in Biomedical Applications: From Potential to clinical Use in Diagnostics and Therapy. Angew Chem Int Ed 41, 1329-1334.

Tang MX, Redemann CT and Szoka FC Jr. (1996). In vitro gene delivery by degraded polyamidoamine dendrimers. Bioconjug. Chem, 7:703-714.

Tang MX and Szoka FC. (1997). The influence of polymer structure on the interactions of cationic polymers with DNA and morphology of the resulting complexes. Gene Ther., 4:823-832.

Thomas TP, Patri AK, Myc A, Myaing MT, Ye JY, Norris TB and Baker JR Jr. (2004). In vitro targeting of synthesized antibody-conjugated dendrimer nanoparticles. Biomacromolecules., 5:2269-2274.

Wörner C, Mülhaupt R. (1993). Polynitrile- and polyamine-functional poly(trimethylene imine) dendrimers, Angew. Chem. Int. Ed. Engl., 32, 1306-1308. 
Wu J, Zhou J, Qu F, Bao P, Zhang Y and Peng L. (2005). Polycationic dendrimers interact with RNA molecules: polyamine dendrimers inhibit the catalytic activity of Candida ibozymes. Chem Commun.(Camb.), 313-315.

Yoo H, Sazani P and Juliano RL. (1999). PAMAM dendrimers as delivery agents for antisense oligonucleotides. Pharm.Res., 16:1799-1804.

Zinselmeyer BH, Mackay SP, Schatzlein AG and Uchegbu IF. (2002). The lowergeneration polypropylenimine dendrimers are effective gene-transfer agents. Pharm.Res., 19:960-967. 


\section{Chapter 4}

Delivery OF A DNAZYME TARgeTING $C$-MYC TO HT29 COLON Carcinoma Cells using a Gold Nanoparticulate APPROACH

Frederik Tack, Marc Noppe, Alex Van Dijck, Nathalie Dekeyzer, Bas-Jan Van Der Leede, Annette Bakker,

Walter Wouters, Michel Janicot, and Marcus E. Brewster

published in Die Pharmazie 2008; 63 (3); 221-225 
Chapter 4

\section{ABSTRACT}

The objective of the current study was to develop cellular delivery approaches for catalytic DNA enzymes (DNAzymes) which cleave targeted messenger RNA, using vectors based on colloidal gold. The model DNAzyme was a $32 \mathrm{mer}$ oligonucleotide designed to specifically interact with and cleave c-myc mRNA. Colloidal gold particles were prepared by reduction of tetrachlororauric [III] acid with sodium citrate. Particles could be produced in the $1-90 \mathrm{~nm}$ range. A cationic substrate linked to transferrin was electrostatically/hydrophobically bound to the gold particle. These vectors were then treated with the DNAzyme to yield the condensed DNA-cationic polymer-particulate product. The $\mathrm{pH}$ (4-11.5), the quantity of the DNAzymes $(0.079-0.567 \mu \mathrm{g} / \mathrm{probe})$, the cationic polymer (polylysine (PL) or polyethyleniminc (PEI)) as well as the surfactant (PVP) concentration $(0-0.5 \%)$ were varied to give stable constructs which decomplexed under the desired conditions (i.e., in lysosomes and at lower $\mathrm{pH}$ values). Cellular uptake of the FITC-labelled c-myc DNAzyme incorporated in this vector was measured using FACS analysis in human HT29 colon carcinoma cells. Data suggested that PEI gave better delivery efficiencies than PL. The use of PVP to stabilize the formed dispersions was detrimental to DNAzyme delivery when PL was used but had little effect in the PEI systems. In the best cases, delivery to $77 \%$ of the cells was possible using PEI with the PVP stabilizer and completing the DNA condensation at $\mathrm{pH} 5.5$ with $0.118 \mu \mathrm{g}$ of DNAzyme/probe. In contrast, the best conditions for PL gave only transfection to $43 \%$ of the cells (no PVP, condensed at $\mathrm{pH} 5.7$ and with a loading of $0.079 \mu \mathrm{g}$ DNAzyme/probe). The PL probe tended to be more toxic than the PEI-based systems (65\% cell death in PL transfected cells compared to $22 \%$ for PEI). These results suggest that cellular targeting using colloidal gold appears feasible for DNAzyme delivery.

\section{INTRODUCTION}

DNAzymes are synthetic, catalytic deoxyribonucleic acid derivatives that can be enginecred to bind to specific complementary RNA targets through Watson-Crick base pairing (Cairnes et al. 1999; Khachigian 2002). These DNA fragments can then cleave the targeted RNA at a predefined position resulting in gene down regulation and suppression or elimination in gene product production. DNAzymes have a number of advantages over ribozyme (the analogous RNA constructs)-based delivery, derived mainly from their greater stability to nucleolytic degradation. An example of a DNAzyme is given in Figure 1. A number of gene products have been targeted with DNAzymes including those for HIV-1 env, HIV-1 tat/rev, CCR5, BCR-ABL, PKC, Egr1, c-myc, k-ras and c-jun making these therapeutics applicable to cancer, antiviral and restenosis indications (Sun et al. 1999, Sun and Cairns 2000; Achenbach et al. 2004; Sioud and Iversen 2005; Kelley and Patterson 2006, Isaka 2007). 


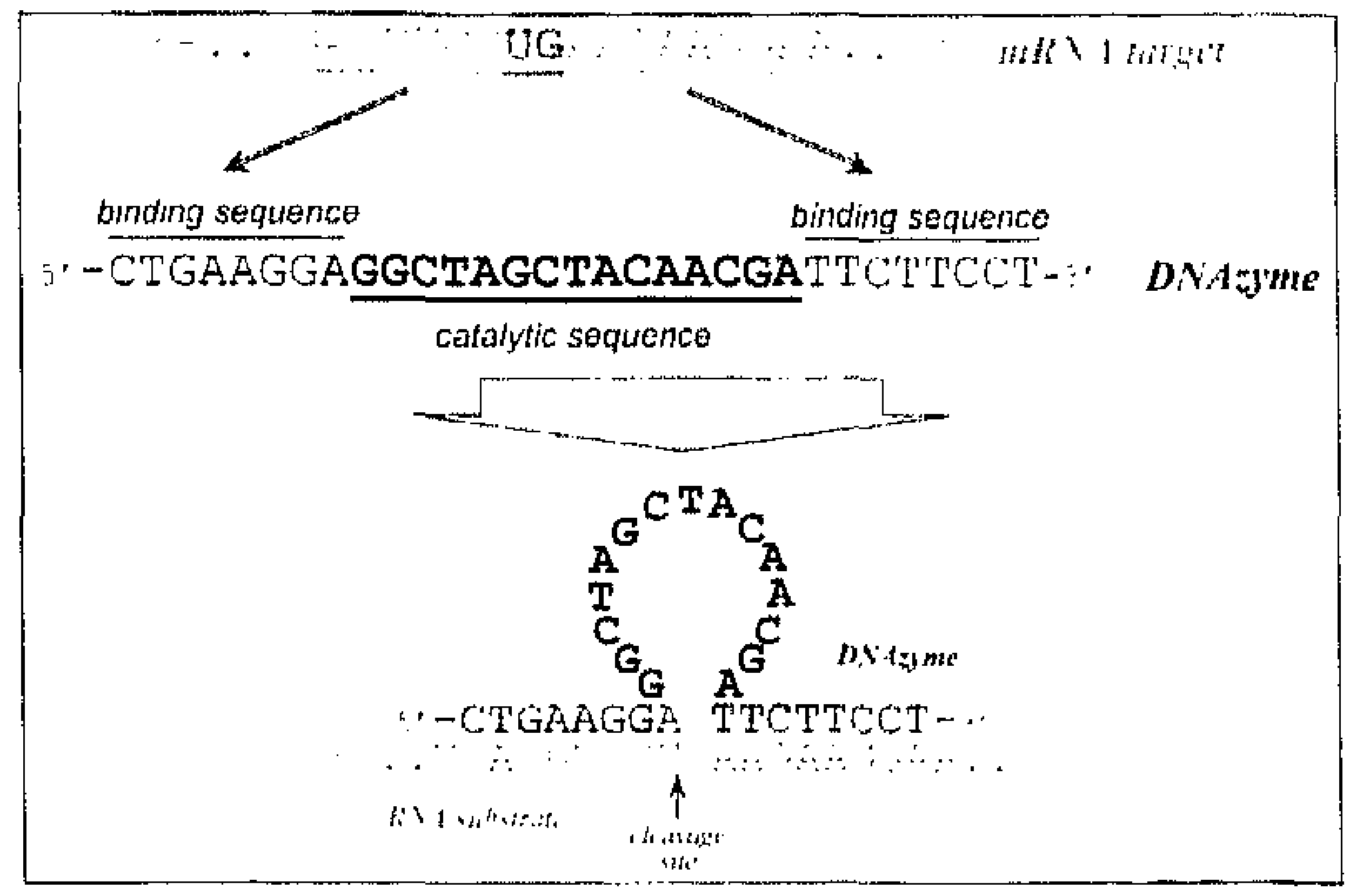

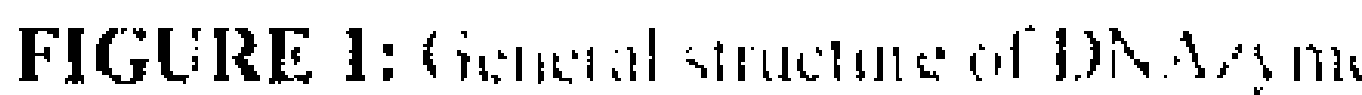

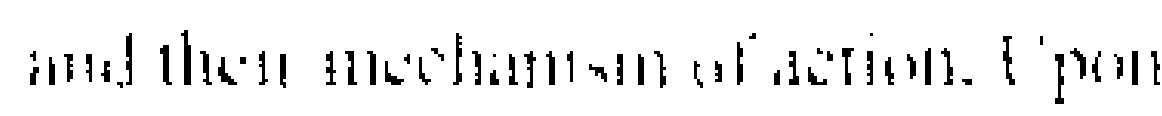

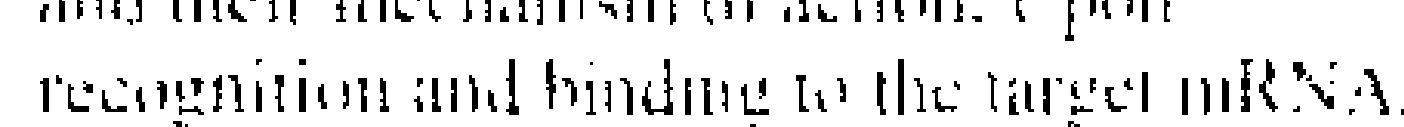

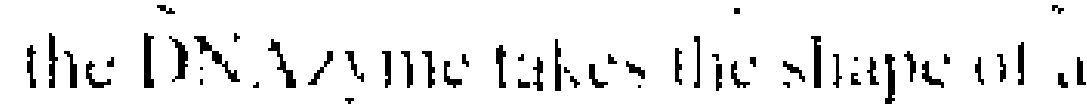

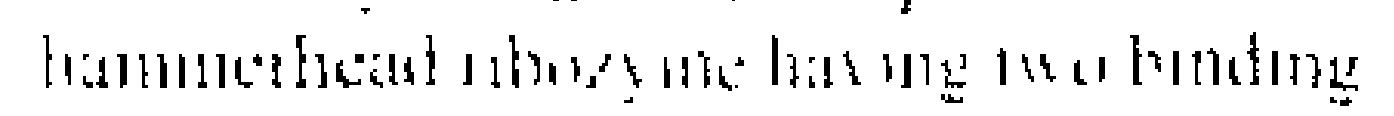

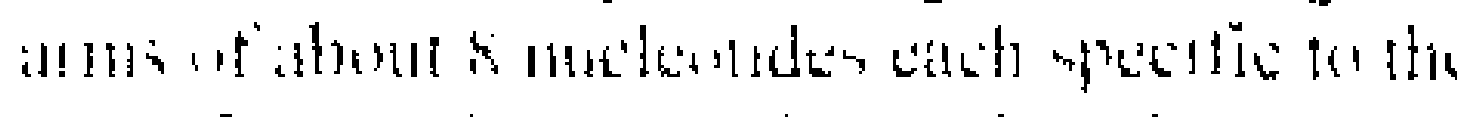

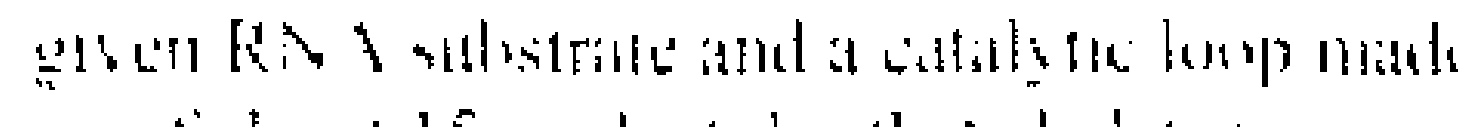

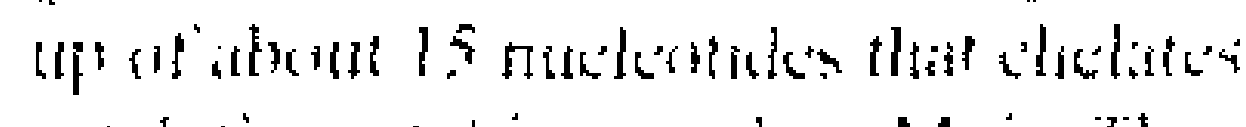
caltalytic metall in wh such at . Me' The

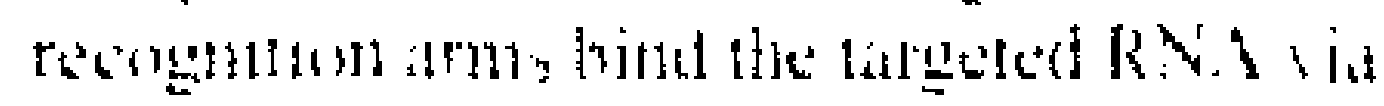

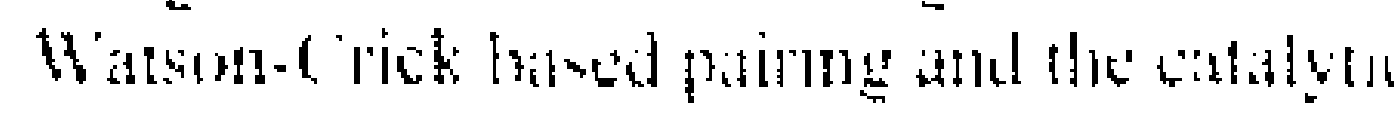

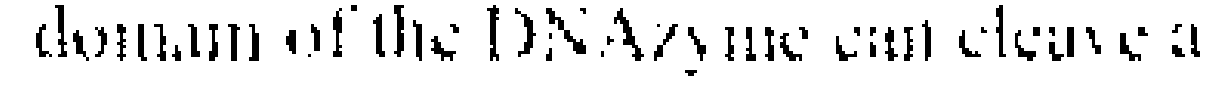

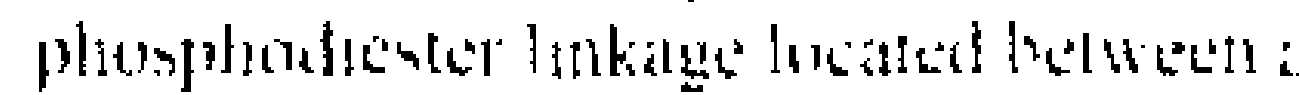

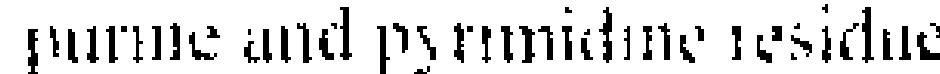

For a DNAzyme to be active, it must reach its site of action within the cells meaning it must penetrate the cell membrane, be appropriately trafficked in the cells and reach the nucleus. The challenges associated with the delivery of DNA or RNA-derived materials are numerous as has been pointed out both in the scientific literature and in the popular press: "The weak link of gene therapy is paradoxically the vehicle rather than the drug itself" (Behr 1994), "The key to success for any gene therapy strategy is having a vector able to serve as a safe and efficient gene delivery vehicle" (Friedmann 1997), "There are only three problems in gene delivery: delivery, delivery and delivery" (Jaroff 1999).

A number of methods have been brought to bear on this problems with varying degrees of success. Pun et al. (2004) described the use of cationic polymers based on cyclodextrins to deliver functional DNAzymes to cells and, in vivo, to tumors in mice. Other delivery approaches including cationic liposomes and dendrimers as well as peptide-based vectors have also been suggested for the delivery of anti-sense RNA and other genetic materials (Dass et al. 2002: Tack et al. 2006a, Tack et al. 2006b, Tack et al. 2006c). Finally, several researchers have suggested the use of colloidal metals for delivering cytokines, growth factors, chemotherapeutics agents and nucleic acids plasmids to cells of interest (Tamarkin and Paciotti 1999; Tamarkin and Paciotti 2002, O'Sullivan et al. 2003; Noh et al. 2007).

The current study was aimed at assessing the ability to deliver a model DNAzyme to cells using colloidal gold probes. Specifically, a DNAzyme based on $c-m y c$ was chosen with delivery to HT29 cells, a human colon carcinoma cell line, selected as the initial proof-ofconcept cndpoint.

\section{MATERIAL AND METHODS}

\section{Reagents}

A DNAzyme targeted towards $c-m y c$ has been described by Sun et al. (1999). The DNAzyme as well as various labcled analogs (i.e., 5'-fluorescein labelled DNAzyme) (TGAGGGGCAGGCTAGCTACAACGAGTC-CGCGCxx-3' where $x=3$ 'dG5') were 
obtained from Eurogentec (Seraing, Belgium). Stability was improved by the incorporation of a 3'dG5'-3' thymidylate inversion at the 3' end. Poly-L-lysine (MW $=10000 \mathrm{~g} / \mathrm{mol}$ ), histone Type VIl-S and methylated albumin were obtained from Sigma Chemical Co., St. Louis, MO, USA. The polyethylenime-transferrin and polylysine-transferrin conjugate was obtained from Bender MedSystems, Vienna, Austria.

\section{Preparation of Colloidal Gold}

The preparation of the colloidal gold in the $10 \mathrm{~nm}$ range was accomplished by adding 1.7 $\mathrm{mL}$ of a $10 \%$ solution of $\mathrm{HAuCl}_{4}$ to $24 \mathrm{~mL}$ of a $5 \%$ solution of sodium citrate. The colloidal gold dispersion was wine red in color. Solutions were prepared with Milli Q water which was boiled and then cooled with a stream of $\mathrm{N}_{2}$ passing through it.

\section{Carrier-Gold Interaction Studies}

To select a cationic carrier and to identify the optimal conditions for attaching the carrier to the colloidal gold, the following procedure was used: $1 \mathrm{~mL}$ of the colloidal gold dispersion preparcd above was used in these studies. The solution was adjusted to different pH's between 3 and 12 using $0.01 \mathrm{~N} \mathrm{NaOH}$. A fixed amount of the carrier of interest was then added to the solution. After several minutes, $100 \mu \mathrm{L}$ of a $10 \% \mathrm{NaCl}$ solution was added to the dispcrsion. The red solutions turned light blue and then precipitated after a few seconds if a sterically stabilized suspension was not formed by the added cationic carriers.

\section{Carrier-DNAzyme Interaction Studies}

The optimal binding conditions for the carrier and DNAzyme (in the absence of the colloidal gold) was completed using agarose electrophoresis. A fixed amount of the FITC labeled DNAzyme is added at varying concentrations of the carrier after which the solution is applied to an agarose gel. In conditions where there is no binding between the DNAzyme and carrier, the fluorescently labelcd DNAzyme migrates with the applied electric current $(2 \mathrm{~h}, 50 \mathrm{~V})$. Binding of the two components ncutralizes the DNAzyme charge resulting in a fluorescent spot which stays at the origin.

\section{DNAzyme/Carrier/Gold Interactions Studies}

Optimization of binding of the DNAzyme to the gold-carrier as a function of $\mathrm{pH}$ is completed using a spectropholometric method. Solutions of the colloidal gold and carrier are adjusted to different $\mathrm{pH}$ values. Different amounts of the labeled DNAzyme are then added the solution centrifuged. The optical density of the supernatant (at $260 \mathrm{~nm}$ ) is then assessed. Optimal binding is determined at the $\mathrm{pH}$ and inflection point where additional DNAzyme does not increase the absorption in the centrifuged solution.

\section{DNAzyme Binding Assessment}

To confirm that the DNAzyme is attached to the gold particle, a Zetaprobe binding assay is applied. A strand of DNA complementary to the DNAzyme is spotted onto Zetaprobe nitrocellulose membranes (Bio-Rad, Richmond, $\mathrm{CA}$ ) and then cross-linked to the substrate using UV light. The DNAzyme/carrier/gold probe is then applied to the substrate at different $\mathrm{pH}$ 's and allowed to stand overnight. The nitrocellulose substrate is then washed. 
If the DNAzyme is bound to the gold and to the complementary DNA substrate, a red spot will develop.

\section{Illustrative Preparation Method}

$500 \mu \mathrm{L}$ of an aqueous solution of PEI-Tf $(0.12 \mu \mathrm{g} / \mu \mathrm{L})$ was added to $2500 \mu \mathrm{L}$ of a $10 \mathrm{~nm}$ colloidal gold dispersion adjusted to $\mathrm{pH} 11.6$. The FITC-labelled DNAzyme (198 $\mu \mathrm{L}$ of a 2 $\mathrm{mg} / \mathrm{mL}$ aqueous solution) was then added as was $160 \mu \mathrm{L}$ of a $10 \%$ PVP solution (pH 9). This gave a probe in which $7 \mu \mathrm{g}$ of the DNAzyme bound to $1 \mu \mathrm{g}$ of the PEI-Tf carrier. The final concentration of PVP was $0.5 \% .100 \mu \mathrm{L}$ of the probe were then adjusted to $\mathrm{pH} 5.8$ by the addition of $7.5 \mu \mathrm{L}$ of $0.1 \mathrm{~N} \mathrm{HCl}$ and $1 \mu \mathrm{l} 0.01 \mathrm{~N} \mathrm{HCl}$.

\section{Cell Culture Examination}

HT29 cells, a human colon carcinoma cell line, were seeded at a concentration or 300,000 cell/well in 6-well culture dishes and maintained in McCoys $5 \mathrm{~A}$ media until they reached $50-80 \%$ confluence. Cells were then washed with the media which was then replaced with the transfection media which contained the DNAzyme probes of interest. After $15 \mathrm{~min}$, an additional aliquot of culture media was added and the cells were allowed to incubate for 24 $h$ at $37^{\circ} \mathrm{C}$. The cells were then collected after trypsinization and resuspended in $1 \mathrm{~mL}$ of cold PBS. Propidium iodide as then added to a final concentration of $2 \mu \mathrm{g} / \mathrm{mL}$ and the cells analysed by FACS sorting (MoFlo, Cytomation).

\section{RESULTS AND DISCUSSIONS}

Colloidal gold can be produced by reacting gold acids with various reducing agents (Oliver 1999; Schmid and Corain 2003; Daniel and Astruc 2004; Haiss et al. 2007). The conditions and reducing agents used can vary the particle size of the dispersion. Gold particles of $10 \mathrm{~nm}$ were selected since larger particle can sediment over time and smaller particle may not be adequately covered by the protein carriers of interest.

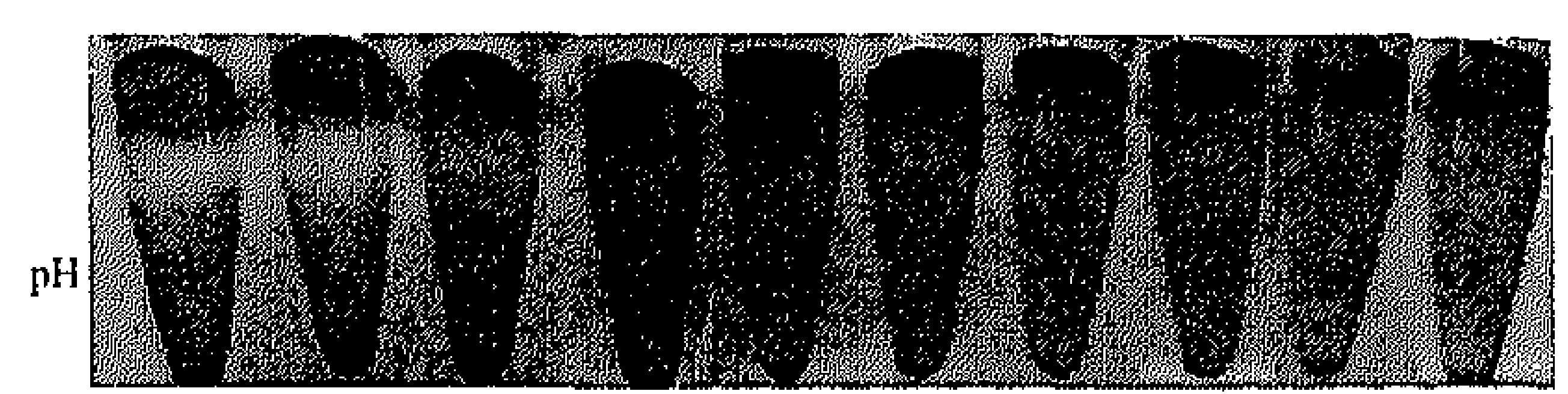

FIGURE 2: Colloid stability of 10 nm gold particles conted a th) methylated albumin at various pH values when treated with $160 \mathrm{HI}$. of at $10^{\mathrm{m}} \mathrm{in} \mathrm{NaCl}$ solution.
Coating of gold particles with methylated albumin was possible at $\mathrm{pH} 8$ and 10 with about $40 \mu \mathrm{g}$ being optimal to coat $1 \mathrm{~mL}$ of a 10 $\mathrm{nm}$ gold dispersion (as described in the Experimental Section). The particles were stable to $\mathrm{NaCl}$ induced aggregation at $\mathrm{pH}$ values between 6 and 12 (Figure 2). Histone coating was possible at $\mathrm{pH} 12$ with $15 \mu \mathrm{g}$ of carrier per $\mathrm{mL}$ of probe optimal. The systems was stable to aggregation between $\mathrm{pH} 11$ and 13. Poly-L-lysinc could be coated on gold at a pH of 10 at an optimal amount of $29 \mu \mathrm{g} / 1 \mathrm{~mL}$ of dispersion. These probes were stable between $\mathrm{pH} 11$ and 13 . 
Based on screening experiments that suggested little or no uptake of the gold probes either as such or coated with a carrier or carrier-DNAzyme, targetors were added to the probes. These targetors were designed to interact will cell-based proteins to facilitate internalization of the probe via receptor-mediated endocytosis or related processes. Based on preliminary

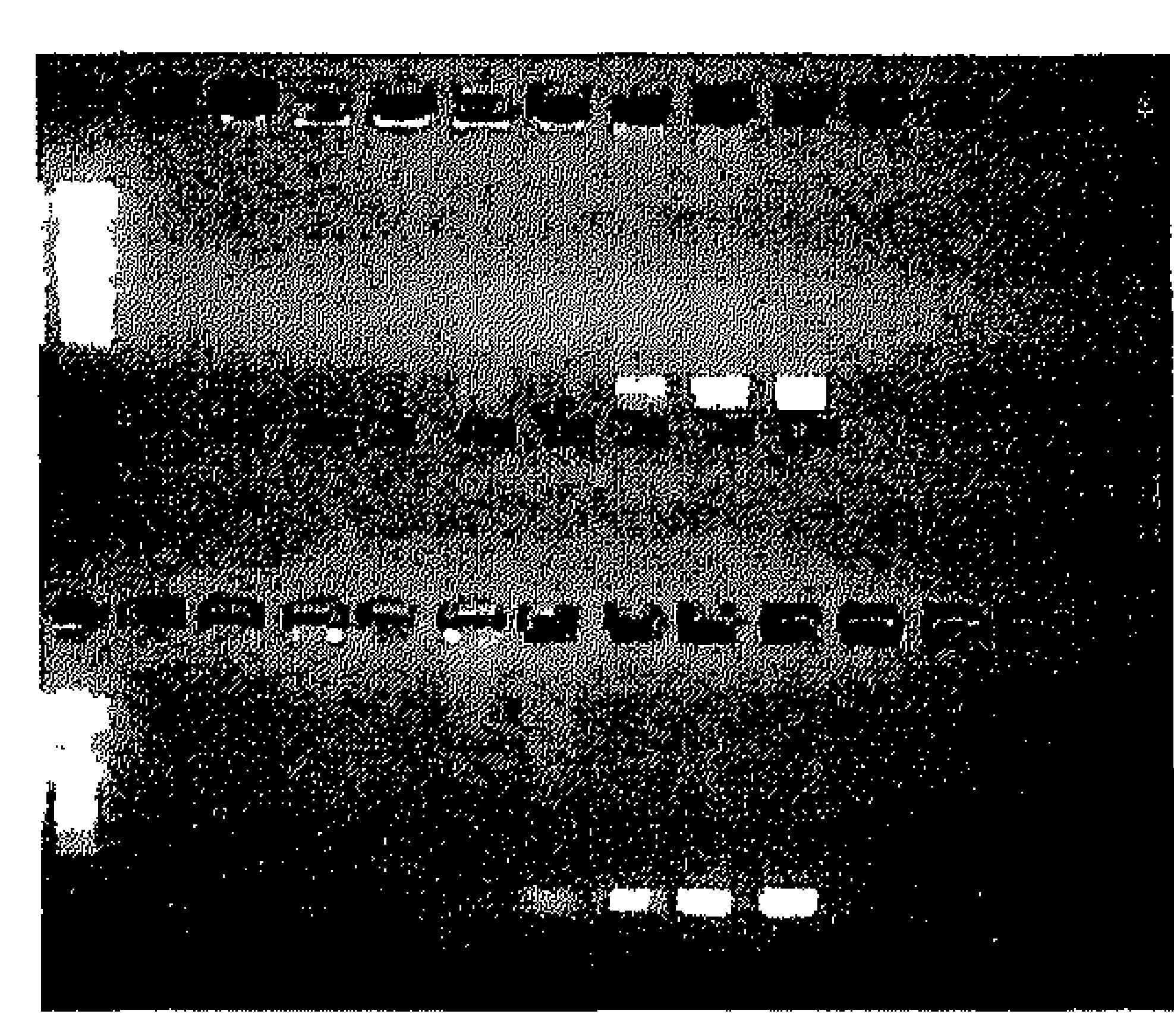

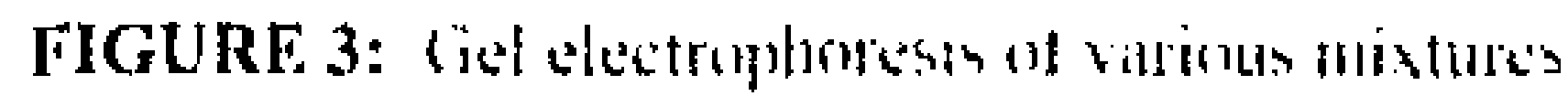

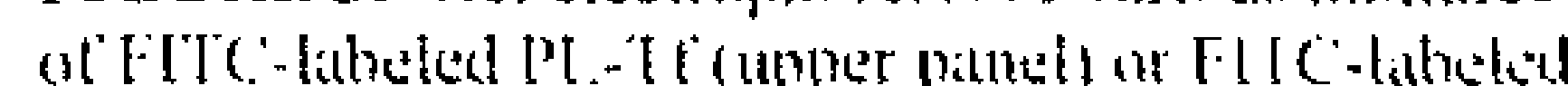

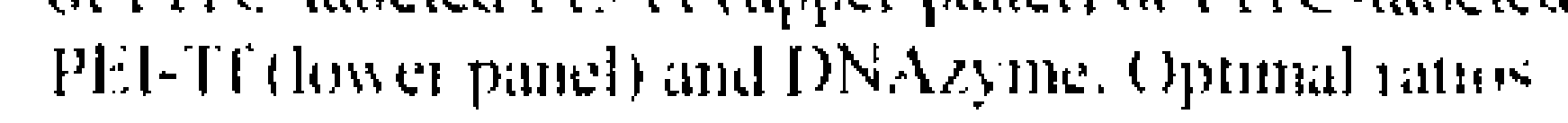

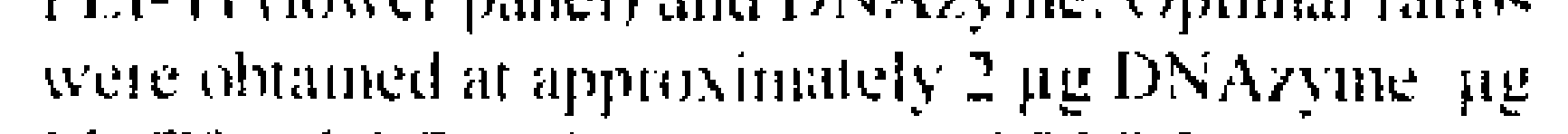

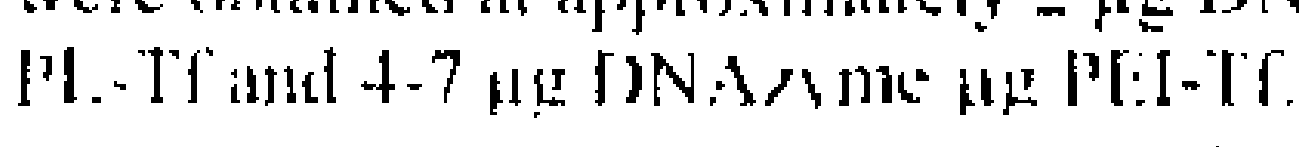

studies, the optimal carrier was a conjugate between polylysine or polyethylenimine and transferrin. These data are consistent with the observation that transferrin receptors are commonly expressed on tumor cells and can aid in drug delivery (Qian et al. 2002; Daniels et al. 2006; Kobayashi et al. 2007) and that polyethylenimine and polylysine are widely used ans successful transfecting agents (Zauner et al. 1998; Ruponen et al. 2003; Wagner and Kloeckner 2006).

Optimal binding of the PL-Tf or PEI-Tf conjugate to the DNAzyme were completed by analyzing various charge ratios of the two components on agarose gel and then looking for migration in an electric field (Noh ct al. 2007). Optimal ratios can be identified at the point when excess DNAzyme just starts to migrate on the gel (Figure 3).

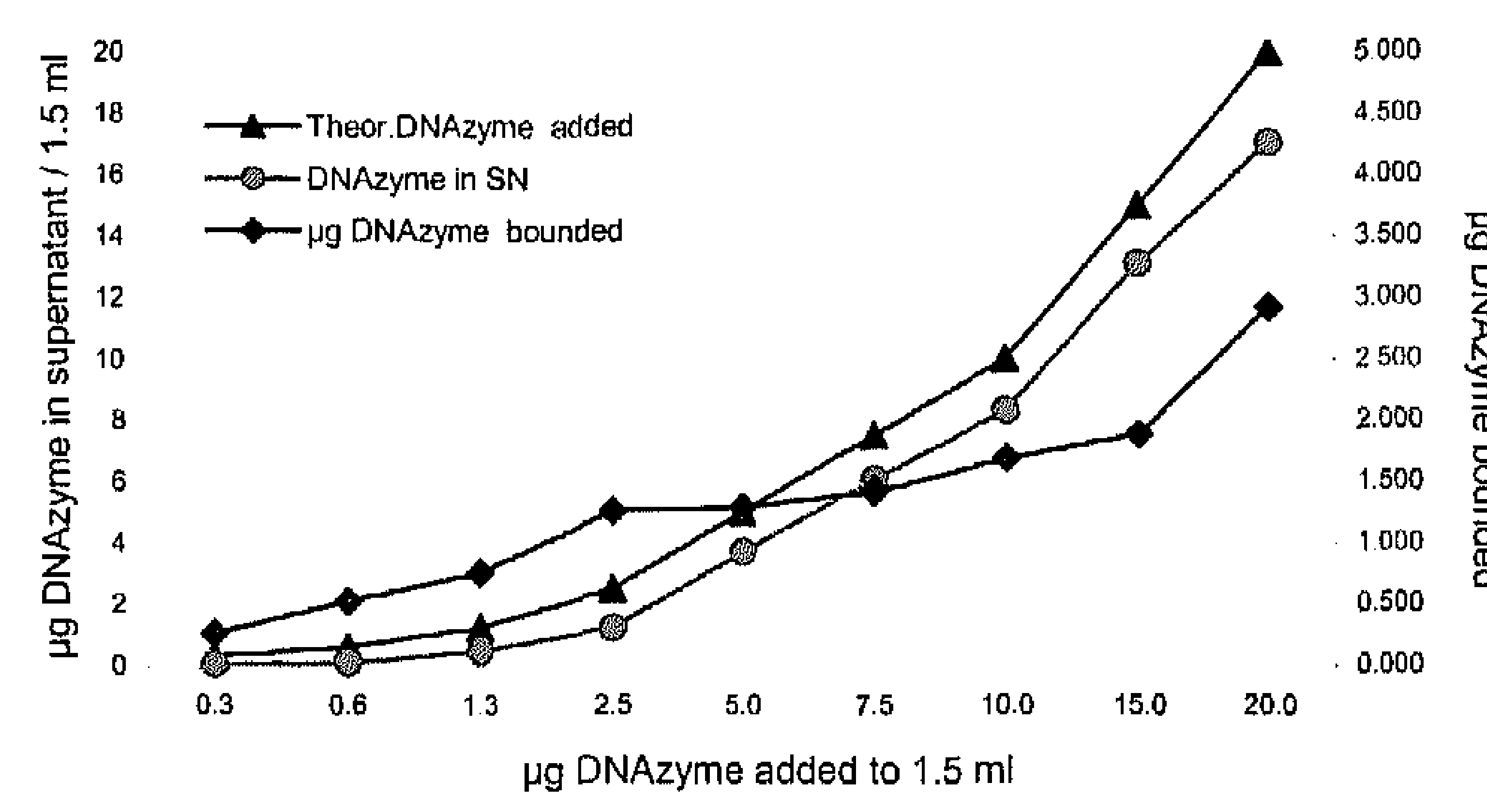

FIGURE 4: Titration curse af DNAYyus binding to a guld. PEI-Tf vector at phl 9 . The

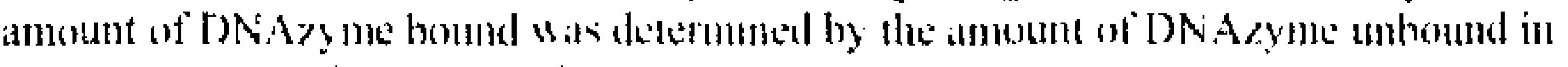

the supernitiant subtracted by the totial ammont itdeded 


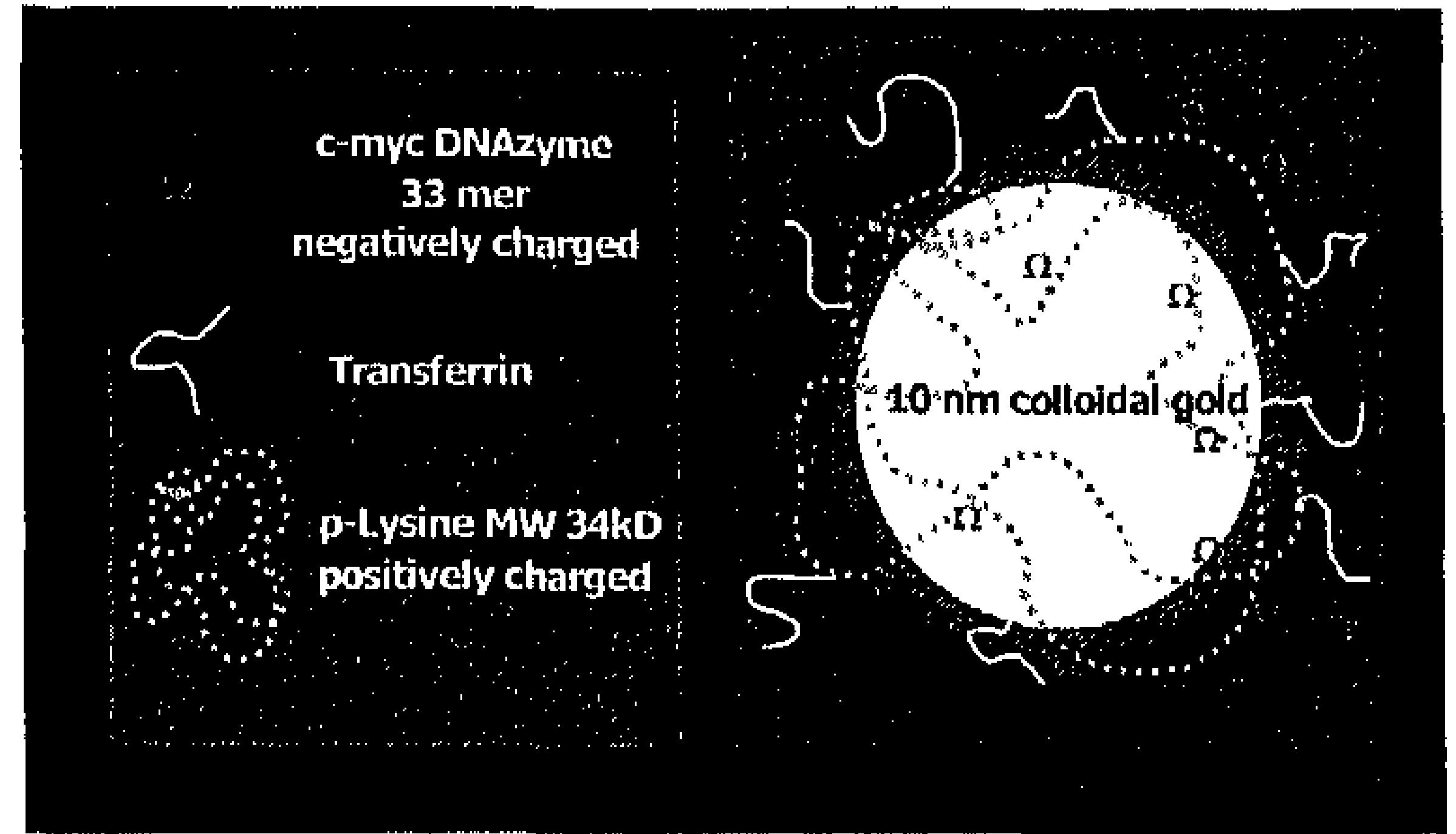

FIGURE 5: Schenatic representation of a gold probe-based

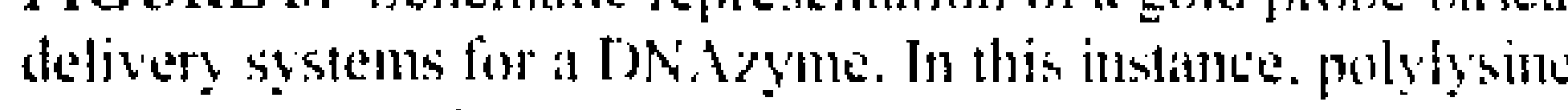
thatisferrin served as the carrier.
Optimal DNAzyme binding to the gold-polymer-Tf probe was assessed using a spectrophotometric procedure. At a particular $\mathrm{pH}$, the DNAzyme was added to a fixed concentration of the carrier-gold nanoprobe. The samples were centrifuged and the amount of DNAzyme unbound in the supernatant measured by UV spectrophotometry at $260 \mathrm{~nm}$. Maximum binding was indicated by the plateau and varied as a function of conditions. Figure 4 gives an example at $\mathrm{pH} 9$ for the binding of gold adsorbed PEI-Tf and the DNAzyme. A schematic representation of the gold probe is given in Figure 5.

Based on these preliminary experiments, a matrix was set up in which various probes were prepared and their stability assessed. In addition to what was done in previous experiments, polyvinyl pyrrolidone $(0.5 \% \mathrm{w} / \mathrm{v})$ was added as a co-stabilizer in some cases. These probes were then incubated with HT29 cells (a transferring-receptor expressing cell line derived from a human colon carcinoma) and transfection measured using FACS cell sorting. The conditions and results are given in Table II.

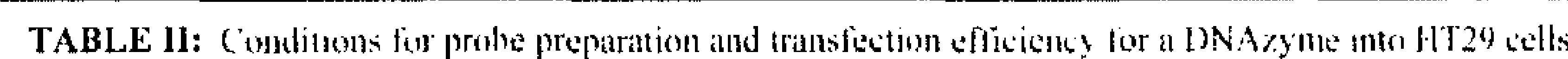

\begin{tabular}{|c|c|c|c|c|c|c|}
\hline $\begin{array}{c}\text { Fxp. } \\
\text { No, }\end{array}$ & $\mathrm{pH}$ & $\begin{array}{c}\mu \mathrm{g} \\
\text { DNAzyme/ } \\
\mu L \text { probe }\end{array}$ & Conjugate & $\begin{array}{c}\text { PVP } \\
0.5 \% \\
\text { Y/N }\end{array}$ & $\begin{array}{c}\% \text { Total } \\
\text { Transfection }\end{array}$ & $\begin{array}{c}\% \text { Live } \\
\text { Cells } \\
\text { Transfected }\end{array}$ \\
\hline 1 & 11.15 & 0.079 & PL-Tf & $\mathrm{N}$ & - & - \\
\hline 2 & 11.48 & 0.124 & PFI-Tf & $\mathrm{N}$ & 53 & 36 \\
\hline 3 & 11.20 & 0.075 & PL-Tf & $\mathrm{Y}$ & 15 & 1 \\
\hline 4 & 11.40 & 0.118 & PEL-Tf & $\mathrm{Y}$ & 73 & 28 \\
\hline 5 & 5.70 & 0.079 & PL-Tf & $\mathrm{N}$ & 43 & 28 \\
\hline 6 & 5.75 & 0.124 & PEL-Tf & $\mathrm{N}$ & 56 & 36 \\
\hline 7 & 5.80 & 0.075 & PL-Tf & $\mathrm{Y}$ & 25 & 11 \\
\hline 8 & 5.50 & 0.118 & PLI-Tf & $\mathrm{Y}$ & 77 & 60 \\
\hline
\end{tabular}

The data suggested that PEI-Tf conjugate gave better transfections than the analogous PLTf carrier. In the case of PEI-Tf, optimal delivery was possible by loading the carriers at either high or low $\mathrm{pH}$, at high DNAzyme loading and in the presence of the PVP stabilizer. Total transfection in these cases were $73 \%$ (high $\mathrm{pH}$ ) and $77 \%$ (low $\mathrm{pH}$ ). Elimination of the stabilizer reduced transfection to $53 \%$ (high $\mathrm{pH}$ ) and $56 \%$ (low pH). Interestingly, the probe prepared at low $\mathrm{pH}$ tended to be less toxic to the cells with $60 \%$ of cell transfected 
Chapter 4

surviving while the analogous probes prepared at high $\mathrm{pH}$ generated a live cell transfection value of $28 \%$. The polylysine based probes were less efficient and more toxic than the PEIbased probes. The best transfections were obtained with gold particles loaded at low $\mathrm{pH}$ and with low DNAzyme concentrations and in the absence of the PVP stabilizer. Best delivery rates were $56 \%$ (total transfection) and $36 \%$ if only live cells were counted.

\section{CONCLUSIONS}

Colloidal gold-based delivery of DNAzyme is possible through the use of cellular targetors such as transferrin. Optimal gold probes were prepared by adsorbing cationic polymer (PEI or PL)-transferrin conjugates onto the nanodispersion followed by condensation with the DNAzymes. Optimal transfections of $>75 \%$ were possible into HT 29 cells.

\section{REFERENCES}

Achenbach J, Chiuman W, Cruz R, Li Y (2004) DNAzymes: from creation in vitro to applications in vivo. Curr Pharmaceut Biotech 5: 321-336

Behr J (1994) Gene transfer with synthetic cationic amphiphiles: Prospects for gene delivery. Bioconjugate Chem. 5: 389-389.

Cairns M, Hopkins T, Witherington C, Wang L, Sun, L (1999) Target site selection for an RNA-cleaving catalytic DNA. Nature Biotech 17: 480-486.

Daniel M, Astruc D (2004) Gold nanoparticles: assembly, supermolecular chemistry, quantum-size-related properties and applications towards biology, catalysis and nanotechnology. Chem Rev 104: 293-346.

Daniels T, Delgado T, Helguera G, Penichet M (2006) The transferring receptor part II: Targeted delivery of therapeutic agents into cancer cells. Clin Immunol 121: 159-176.

Dass C, Saravolac E, Li Y, Sun L (2002) Cellular uptake, distribution and stability of 10-23 deoxyribozymes. Antisense Nucleic Acid Drug Develop 12: 289-299.

Friedmann T (1997) Overcoming the obstacles to gene delivery. Scientific American June.

Haiss W, Thanh N, Aveyard J, Fernig D (2007) Determination of size and concentration of gold nanoparticles from UV-Vis spectra. Anal Chem 79: 4215-4221.

Isaka Y (2007) DNAzymes as potential therapeutic molecules. Curr Opin Molec Therap 9: 132-136.

Jaroff L (1999) Fixing the genes. Time Magazine Jan. 11.

Kelly R, Patterson C (2006) Slice me nice: DNAzyme get close to the heart. $J$ Thromb Haemost 4: 1476-1478. 
Khachigian L (2002) DNAzymes: cutting a path to a new class of therapeutics. Curr. Opin. Molec: Therap, 4:119-121 (2002),

Kobayashi T, Ishida T, Okada Y, Ise S, Harashima H, Kiwada H (2007) Effect of transferring receptor-targeted liposomal doxorubicin in P-glycoprotein-mediated drug resistant tumor cells. Int J Pharmaceut 329: 94-102.

Noh S, Kim W, Kim J, Baek K, Oh Y (2007) Enhanced cellular delivery and transfection efficiency of plasmid DNA using positively charged biocompatible colloidal gold nanoparticles. Biochim Biophys Acta 1770: 747-752.

Oliver C (1999) Preparation of colloidal gold. Method. Molec. Biol. 115: 327-330

O'Sullivan M, Green J, Przybycien T (2003) Development of a novel gene delivery scaffold utilizing colloidal gold-polyethylenimine conjugates for DNA condensation. Gene Therapy 10: 1882-1890.

Pun S, Bellocq N, Cheng J, Grubbs B, Jensen G, Davis M, Tack F, Brewster M, Janicot M, Janssens B, Floren W, Bakker A (2004) Biodistribution of RNA-cleaving DNA enzyme (DNAzyme) to tumor tissue by transferrin-modified, cyclodextrin-based particles. Cancer Biol. Therapy 3: 641-650.

Qian Z, Li H, Sun H, Ho K (2002) Targeted drug delivery via the transferring receptormediated endocytosis pathway. Pharmacol Rev 54: 561-587.

Ruponen M, Honkakoski P, Ronkko S, Pelkonen J, Tammi M, Urtti A (2003) Extracellular and intracellular barriers to non-viral gene delivery. $J$ Control rel 93: 213-217.

Schmid G, Corain B (2003) Nanoparticulated gold: synthesis, electronics and reactivities. Eur J Inorg Chem 3089-3098

Souid M, Iversen P (2005) Ribozymes, DNAzymes and small interfering RNAs as therapeutics. Curr Drug Targets 6: 647-653.

Sun L, Cairns M, Gerlach W, Witherington C, Wang L, King A (1999) Supression of smooth muscle cell proliferation by a c-myc RNA-cleaving deoxyribozyme. $J$ Biol Chem 274: 17236-17241.

Sun L, Cairns M (2000) Design of DNAzymes that specifically target c-myc mRNA and their use for treating restenosis. World Patent WO 2000009672.

Tack F, Bakker A, Maes S, Dekeyser N, Bruining M, Elissen-Roman C, Janicot M, Brewster M, Janssen H, De Waal B, Franssen P, Lou X, Meijer E (2006a) Modified poly(propylene imine) dendrimers as effective transfection agents for catalytic DNA enzymes (DNAzymes). J Drug Target 14: 69-86.

Tack F, Bakker A, Maes S, Dekeyser N, Brusining M, Elissen-Roman C, Janicot M, Hanssen H, De Waal B, Fransen P, Lou X, Meijer W, Arien T, Brewster M (2006b) "Dendrimcric poly(propylene-imines) as effective delivery agents for DNAzymes: toxicily, in vitro transfection and in vivo delivery.

$J$ Control Rel 116: E26-E28.

Tack F. Bakker A, Maes S, Dekeyser N, Brusining M, Elissen-Roman C, Janicot M, Hanssen H, De Waal B, Fransen P, Lou X, Meijer W, Arien T, Brewster M (2006c) Dendrimeric poly(propylene-iImines) as effective delivery agents for DNAzymes: Dendrimer synthesis, stability and oligonucleotide complexation.

$J$ Control Rel 116: E24-E26. 


\section{Chapter 4}

Tamarkin L, Paciotti G (2002) Colloidal metal compositions and methods for drug targeting. World Patent WO2002087509.

Tamarkin L, Paciotti G (1999) Compositions and methods for targeted delivery of endogenous and exogenous bioactive agents. World Patent WO9924077.

Wagner E, Kloeckner J (2006) Gene delivery using polymer therapeutics. Adv Polymer Sci 192: 135-173.

Zauner W, Ogris M, Wagner E (1998) Polylysine-based transfection systems utilizing receptor-based delivery. Adv Drug Deliv Rev 30: 97-113. 


\section{Chapter 5}

\section{CHARACTERIZATION OF ANTHOZOA FLUORESCENT PROTEIN EXPRESSING TUMOR MODELS AND USE IN THE EVALUATION OF HDAC INHIBITORS AND NON VIRAL GENE DELIVERY SYSTEMS}

based on publications:

Tack F, Floren W, Janssen B, Bakker A, Grand-Perret T \& Janicot M; Engineering and characterization of Anthozoa Fluorescent Protein-Expressing Tumor Cells G.I.T Imaging and Microscopy 1/2005, 43-45

Tack F, Floren W, Janssen B, Beliën A, Bakker A, Grand-Perret T, Janicot M; Application of Anthozoa fluorescent protein expressing tumor models for the evaluation of HDAC inhibitors BioForum Europe 9/2005; 52-53 
Chapter 5

$\underline{\text { ABSTRACT }}$

Gene Therapy remains to struggle when advancing into clinical applications. The delivery of sufficient amounts of oligonucleotides specifically to the tissue of choice without exerting too many sideffects is the major hurdle. Therefore, we engineercd fluorescent cell lines that could aid in analyzing the efficacy of novel non-viral gene delivery vehicles. The intent was to knockdown the gene encoding the fluorescent protein, thereby reducing the amount of fluorescence in the cell lines. It enables the investigator to perform analysis on non-viral gene delivery vehicles in a semi high throughput manner and uses a low labor intensive, quick, optical detection as the readout of PTGS. In this paper we describe the production and a characterization of ZsGreen or DsRed2 stably expressing A2780 and $3 \mathrm{LLp}$ cells. Cellular growth rate and in vitro susceptibility to anti-cancer drugs was investigated to ensure that the introduced fluorescent protein did not alter the innate characteristics of the cell. We also demonstrate the use of the cells as an in vivo tumor model which can additionally enhance the detection capability of a whole body imaging system. Finally we show how RNAi, as a form of PTGS, can be used to knockdown one the fluorescent proteins used in the tumor model, ZsGreen. The reduction of ZsGreen occurred in a concentration dependent manner, was detectable on the mRNA and protein level and did not induce a viral related immune response.

\section{INTRODUCTION}

Current pharmacology methods to evaluate potential novel anti-cancer agents comprise the injection of tumor cells or fragments into immuno comprimized animals (mice or rats) to create experimental tumor models. These xenografts are monitored over a period of time for tumor growth comparing vehicle and candidate drug treated groups. Our group has previously reported the possibility to monitor and quantify tumor growth derived from engineered GFP expressing tumor cells using an in house developed whole body imaging (WBI) system (Bakker A et al. 2001) in nude mice with improved accuracy and reproducibility over caliper based measurements. The WBI system is investigator independent and the measured tumor volume resembles that of the actual weight as measured by post mortal tumor weighing. This advance in in vivo tumor monitoring has opened the doors for many institutions and companies to track tumor growth, visualize tumor angiogenesis and metastatic capabilities on non-anaesthetized animals in scmi high throughput. However, a major limitation of the current available fluorescent tumor models is the low fluorescence of the tumor compared to the auto-fluorescence of the skin (signal to background ratio). As a consequence, accurate calculation of tumor area might not be feasible using the automated image analysis of the WBI.

In the last few years several companics/institutes have released improved fluorescent proteins (FP), proteins that emit a higher intensity of fluorescence, that have a longer half life in cells and show a lower toxicity when expressed in eukaryotic cells compared to the 
more classical Aequorea victoria derived green fluorescent protein (GFP) and red fluorescent protein (RFP). Aiming to introduce an improved fluorescent signal in our experimental tumor models, we selected the ZsGreen and DsRed2 proteins originating from respectively Zoanthus sp. and Discosoma sp. Anthozoa reef coral. The very bright fluorescence of the ZsGreen and DsRed2 also enhances the signal to background ratio and greatly improves accuracy of tumor detection and measurement with the WBI system (Campbell RE et al. 2002, Vrzheshch PV et al. 2000, Miyawaki A 2002). This enables us to reliably detect smaller tumors and thus start tumor growth measurements earlier. The use of such highly fluorescent proteins also opens the possibilities to externally visualize deeper lying tumors (orthotopically implanted) and metastasis.

As for all gene therapy applications the most difficult hurdle remains Delivery. Although many proof of principle experiments are encouraging further research to enhance in vivo delivery could improve the feasibility of using RNAi for in vivo target validation and of applying RNAi as a therapeutic tool (McCaffrey AP 2002, Kay MA et al. 2002, Caplen NJ et al. 2004). By targeting the ZsGreen gene, RNAi can be used to evaluate the potential of gene delivery vchicles in the above mentioned animal models. Irreproducible and time consuming protein reduction measurements can therefore be circumvented and replaced by the visible reduction in fluorescence using WBI.

In this report, we describe the production and characteristics of 4 new brightly fluorescent cell lines which are able to form tumors when injected subcutaneously into nude mice. ZsGreen and DsRed2 expressing cells were compared to the parental cell line for their in vitro growth characteristics as well as for their in vitro susceptibility to anti-cancer drugs. The cells were sub sequentially injected into nude mice to ascertain their tumor formation capability and tumor growth ratc. Finally, an anti cancer study was performed with an HDAC inhibitor to determine the susceptibility to respond to a known chemotherapeutic agent. Thereby we show that the herein described fluorescent cells improve the use of the WBI system and can be used in vitro and in vivo for HDAC inhibitor screening purposes. Following the production and evaluation of the fluorescent cell lines, we demonstrate their potential use in evaluating non viral delivery agents. Using RNAi we are able to knockdown the endogenous gene and protein at low concentrations in cells targeting various regions of the mRNA. Two indicators of an activation of the anti viral immune response were shown not to be elevated indicating the genuine RNAi effect of the sequence. Delivering this siRNA enables the evaluation of non-viral delivery systems to switch to a much faster visual detection method of the WBI. It also enables the investigator to analyze the release from the vehicle and subsequent activity of the siRNA in real time, saving greatly in number of animals per study and hence in research cost.

\section{MATERIALS \& METHODS}

\section{Cells, transfections and reagents}

A2780 cells (human ovarian carcinoma) were cultured in RPMI 1640 medium (Gibco) supplemented with $5 \%$ FCS (Gibco), $2 \mathrm{mM} \mathrm{L-glutamine} \mathrm{(Gibco)}$ and $50 \mu \mathrm{g} / \mathrm{ml}$ gentamycin 
(Gibco). 3LLp cells, murine lewis lung carcinoma, were cultured in RPMI 1640 medium (Gibco) supplemented with $10 \%$ FCS, $2 \mathrm{mM} \mathrm{L-glutamine}\left(G i b c^{\prime} o\right.$ ) and $50 \mu \mathrm{g} / \mathrm{ml}$ gentamycin (Gibco). All cells were incubated at $37^{\circ} \mathrm{C}$ in a humidified incubator with $5 \% \mathrm{CO}_{2}$. Lipofectamine (Invitrogen) and Fugene (Roche) were used to transfect the A2780 and $3 \mathrm{LLp}$ cells with the pZsGrcenl-N1 (Clontech) and the pDsRed2-N1 (Clontech) plasmids. Transfected cells were selected for 10 days with $450 \mu \mathrm{g} / \mathrm{ml}$ geneticin (Gibco). siRNA transfections were performed using Lipofectamine2000 (Invitrogen). The siRNA targeting ZsGreen was designed according to the rules layed down by Tuschl (Elbashir SM et al. 2001). The sense sequence of the siRNA was 5' GGAGAUGACCAUGAAGUACCdTdT ' 3 . As negative and positive control siRNAs from Ambion were used (GAPDH silencer siRNA). Poly I:C (Amersham Biosciences) was added at concentrations from $12.5 \mu \mathrm{g} / \mathrm{ml}$ to $100 \mu \mathrm{g} / \mathrm{ml}$.

For the determination of the silencing capacity $1 \mu \mathrm{g}$ plasmid was co-transfected with 5 pmol ZsGreen siRNA or 50pmol control siRNA in SFM using Lipofectamine 2000 (LF2000). $24 \mathrm{~h}$ prior to transfection cells were seeded at $1,5^{*} 10^{5}$ cells/well in 24 well plate. DNA and RNA were added to LF2000 and incubated for $15 \mathrm{~min}$ and subsequently added to the cells. After a 4hour incubation fresh medium was added to the wells. Analysis of the ZsGreen knockdown occurred $48 \mathrm{~h}$ after transfection. For the determination of the antiviral response and the dose dependant silencing effect of the siRNA a similar protocol was followed. The amount of ZsGreen siRNA however varied from $0.2 \mathrm{pmol}$ to $200 \mathrm{pmol}$.

\section{RNA extraction and qRTPCR}

An RNeasy mini kit (Qiagen) was used to extract RNA from the 24 well plates. Per plate the 6 samples in each row were pooled as one sample. A DNase treatment was added to the protocol to remove any DNA contaminants. A Ribogreen RNA quantification kit (Molccular probes) was to quantify the amount of RNA extracted. cDNA was transcribed of the RNA as follows: $2 \mu \mathrm{g}$ RNA, $0.5 \mu \mathrm{g}$ oligo $\mathrm{dT}_{12-18}, 0.5 \mathrm{mM}$ dNTP, $5 \mathrm{mM}$ DTT, $1 \times 1^{\text {st }}$ strand buffer, 40U RNase Inhibitor and $1 \mu$ Superscript III RTPCR. The mix was placed for $60 \mathrm{~min}$ at $50^{\circ} \mathrm{C}$ and followed by $15 \mathrm{~min}$ at $70^{\circ} \mathrm{C}$ and finally stored at $-20^{\circ} \mathrm{C}$.

TAQ Universal Mastermix (Applied Biosystmes) combined with $5 \mu l$ cDNA and $X$ of FAM-TAMRA labeled primer (see table 1) was added to a 96 well plate and the PCR was run according to manufacturers protocol on a ABI PRISM 7000. All samples were analyzed in triplo with each experiment $n=3$. $\beta$-actin was used as a housekeeping gene and a standard curve was taken along on each plate. 


\begin{tabular}{|c|c|}
\hline brictin: & 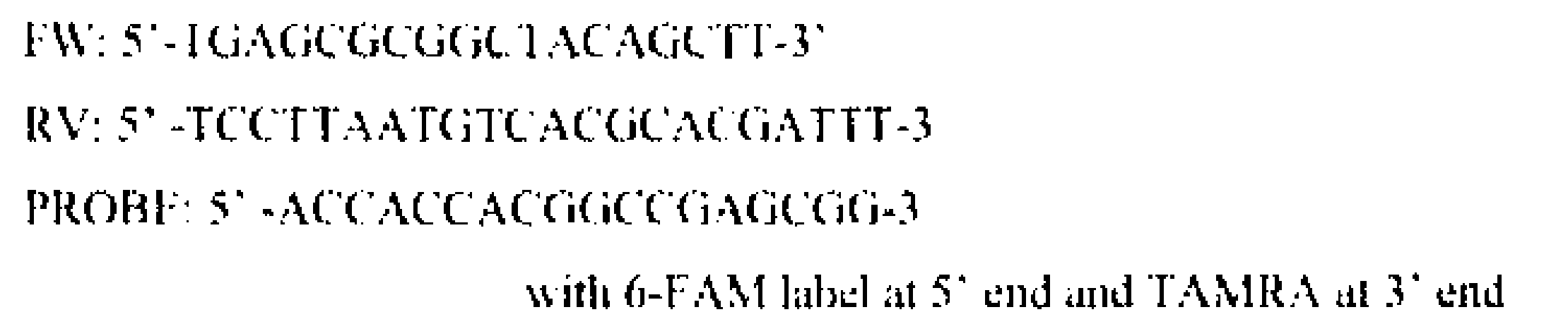 \\
\hline ZsGireen: & 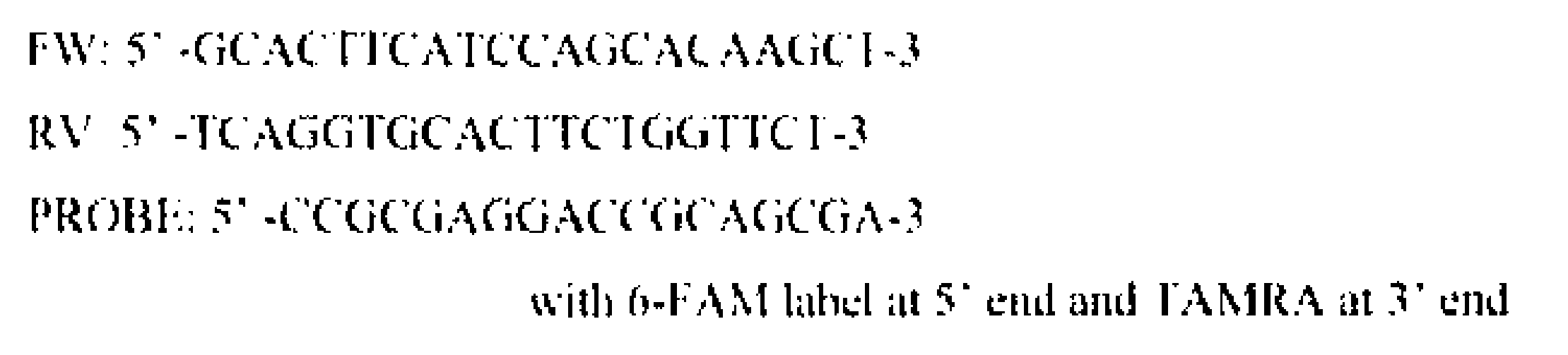 \\
\hline OAS: & 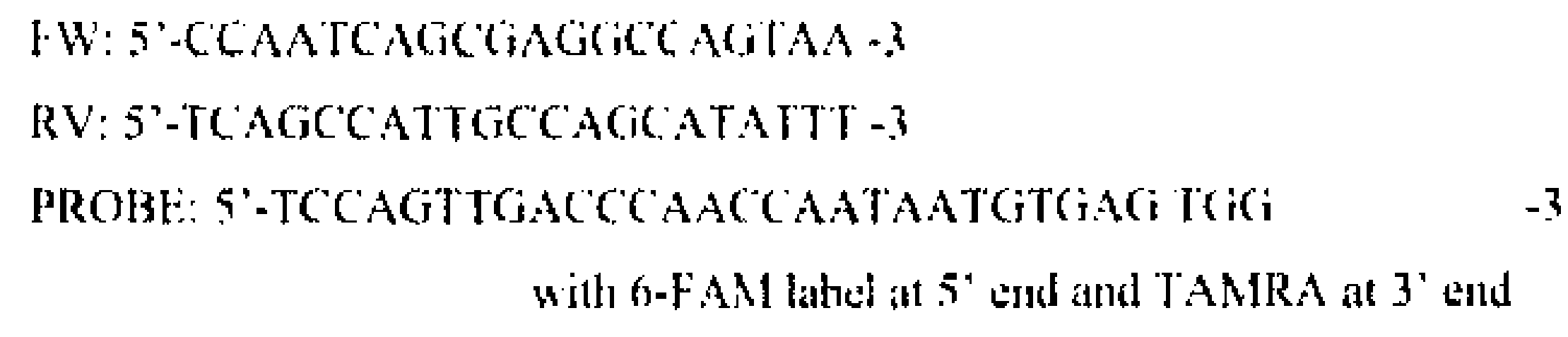 \\
\hline
\end{tabular}

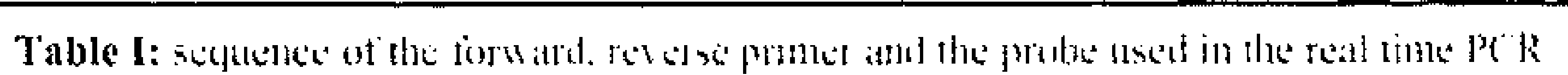

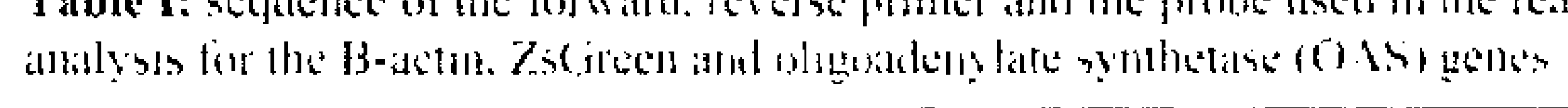

\section{Protein extraction and Western Blot}

The six wells of each row in a 24 well plate were pooled as one sample and total protein was extracted using a Ripa buffer. 20mM HEPES, $150 \mathrm{mM} \mathrm{NaCl}, 2 \mathrm{mM}$ EDTA, $12 \mathrm{mM}$ DOC, $1 \%$ NP-40, 100mM leupeptin, $10 \mathrm{mM}$ pepsatin, $0.05 \mathrm{TIU} / \mathrm{ml}$ aprotinin, ImM PMSF, $0.002 \%$ soybean trypsin inhibitor and $1 \mathrm{ml}$ phosphatase inhibitor cocktail set II were mixed and MQ water was added to reach a final volume $100 \mathrm{ml}$ at $\mathrm{pH}=6.8 .250 \mu \mathrm{l}$ buffer was added per cell pellet and the solution was passed through a Microlance $3(22 \mathrm{G})$ and placed for 15 min on ice. Sonicate the sample for $10 \mathrm{sec}$ using a Micro Tip Limit Sonicator. The sample was finally spun down at $16000 \mathrm{G}$ at $4^{\circ} \mathrm{C}$ for $10 \mathrm{~min}$ and the supernatant was stored at $-70^{\circ} \mathrm{C}$. The protein quantification was determined using a BSA standard and a Coomassie Plus Protein assay measured the OD at $595 \mathrm{~nm}$ in a spectrophotometer.

$25 \mu \mathrm{g}$ of sample was loaded on gel (Bis/Tris 4-12\%) and run in MES electrophoresis buffer at $200 \mathrm{~V}$ for $50 \mathrm{~min}$. The proteins were blotted onto nitroccllulose for $75 \mathrm{~min}$ at $30 \mathrm{~V}$. Blots were blocked with blocking buffer for lhour and subsequently incubated with the primary antibodies total eIF $2 \alpha(A b c a m)$ and phospho elF $2 \alpha$ antibody (Cell signaling) both at a dilution of $1 / 1000$ overnight at $4^{\circ} \mathrm{C}$. Blots were further incubated with the secondary antibodies for thour at $21^{\circ} \mathrm{C}$ : anti mouse Alexa Fluor 680 (Molecular Probes) anti rabbit IRDye $800 \mathrm{CW}$ (Rockland) both diluted $1 / 800$. The blots were analyzed using the Odessey $(\mathrm{Li}-\mathrm{Cor})$ to detect conjugated antibodics carrying dyes that fluoresce in the infra red.

\section{Fluorescence microscopy and ZsGreen fluorescence quantification}

Fluorescent images were taken using a AxioVert 135 (Zeiss) containing a GFP (450$490 \mathrm{~nm})$ and RFP (505-530nm) filter set. The images were analyzed using MagnaFire software (Optronics) after exposure times of $0.5 \mathrm{sec}$.

The cells were tyrpsinized, spun down and washed in PBS. The cell pellet was finally resuspended in $200 \mu 1$ PBS and transferred to a black 96 well plate Cliniplate (Labsystems) and measured in Fluorescence plate reader, Ascent Fluoroskan (Labsystems) at 485-518nm 
Chapter 5

with an integration time of $20 \mathrm{~ms}$. The cell suspension was thereafter immediately transferred to a counting vial containing $800 \mu \mathrm{l}$ PBS. The sample was then measured for viable cell density using an automated cell stainer/counter, Innovatis (Applitek). The amount of fluorescence was then calculated per viable ccll.

\section{Cell proliferation assay and Doubling time assessment}

All cell types were seeded at a density of $1500 \mathrm{cells} /$ well in a $96 \mathrm{well}$ plate (Nunc) $24 \mathrm{~h}$ prior to treatment. The cells were treated with a compound, SAHA (Aton Pharma), MS-275 (Shering), LAQ 824 (Novartis) and TSA (Calbiochem) and were further incubated for 4 days. Subsequently, $25 \mu 1$ MTT (Serva) was added to each well and the cells were incubated for an additional 2 hours. After aspiration, $25 \mu$ glycine buffer $(0.1 \mathrm{M}$ glycine, $0.1 \mathrm{M} \mathrm{NaCl}$ buffered to $\mathrm{pH} 10.5$ ) and $100 \mu 1$ DMSO (Baker) were added to each well. Plates were shaken for 10 minutes and the absorbance was measured at $540 \mathrm{~nm}$ with a spectrophotometer (BioRad-UltraMark).

All cell types were seeded at 100.000 cells per petri dish $(B D$, diam. $10 \mathrm{~cm})$ on day 0 . During 8 days, the total cell count and cell viability was measured using a cell counter/stainer (Applitek-Innovatis). Doubling time was calculated as the time required in the exponential growth phase to double the total number of viable cells

\section{High speed cell sorter}

Stable transfected cell lines were collected and resuspended at $10^{6}$ cells $/ \mathrm{ml}$ in No-Zyme PBS (JRH Biosciences) and filtered (Cell Strainer $70 \mu \mathrm{M}$, Falcon). The high speed cell sorter, MoFlo (Cytomation), is equipped with an Argon Laser (488nm; Enterprise II, Coherent) and contains a FITC (530/40) and a RFP (580/30) filter. The MoFlo data werc analyzed using Cyclops Summit v 3.1 (Cytomation) software. This apparatus enabled us to select the top $5 \%$ or top $50 \%$ fluorescent cells in the entire population. These cells were expanded and kept under geneticin restrainment.

\section{In vivo applications and visualization}

NMRI or CD1 nude mice were subcutaneous injected with DsRed2 expressing A2780/3LLp, ZsGreen expressing A2780/3LLp ( $10^{7}$ cells/200 $\left.\mu 1\right)$. The compounds were dissolved $(2 \mathrm{mg} / \mathrm{ml})$ in a solution of hydrochloric acid and $10 \% \beta$-cyclodextrin at $\mathrm{pH} 4$. Mice in the tumor growth experiment were injected orally at a daily basis with a $\beta$ cyclodextrin $(10 \%)$ solution to mimic treatment conditions. Mice in the susceptibility experiment were injected orally at a daily basis with MS-275 at $10 \mathrm{mg}$ per $\mathrm{kg}$ (mpk) for the mice containing the A2780 tumor and at $20 \mathrm{mpk}$ for the $3 \mathrm{LLp}$ tumor bearing mice. The control group were treated with a $\beta$-cyclodextrin $(10 \%)$ solution alone. All animal experiments have been carried out with ethical committee approval. The ethical guidelines that were followed meet the standards required by the UKCCCR guidelines

Tumor volume, tumor size and body weight were monitored at regular time points over a period of 35 days after injection or until the tumor size reached $\sim 10 \%$ of the total body weight. The tumor size was measured with an electronic caliper and by using a Whole Body Imaging (WBI) system (see below). In-house developed software prograns calculated the tumor volume for both in vivo tumor volume monitoring techniques. 


\section{WBI- whole body imaging-, caliper and tumor density measurements}

The WBI system consists of a fluorescent stereomicroscope (Olympus) SZX12 equipped with a GFP (excitation: $485-501 \mathrm{~nm}$; emission: $510 \mathrm{~nm}$ ) and a RFP (excitation 540-552 nm; emission: $568-643 \mathrm{~nm}$ ) filterset. Images $\left(752 \times 582\right.$ pixels) werc acquired at $1 / 60^{\text {th }}$ of a second using a (Jai) CV-M90 3-CCD RGB color camera and analyzed using an in-house developed application based on IMAQ Vision software components and LabVIEW (National Instruments). Determining the area and distances of the shortest and longest axes and assuming the image taken is an ellipsoid, a calculation of the tumor volume can be performed.

The in-house caliper system consists of an electronic caliper (Digimatic, Mitutoya) and a digital balance connected to a PC. Measurements are imported into an in-house developed software program that calculates the tumor size by using the formula: (length ${ }^{2} \mathrm{x}$ width) $/ 2$, with length being the shortest axis.

The tumor density was examined by accurately measuring the volume change when placing a tumor with a known weight in a known volume of water. These data were used to calculate the exact tumor volume from a given tumor weight.

\section{Statistical analysis}

Data obtained for in vitro and in vivo analysis are represented as averages and medians respectively and deviations are standard deviations. The calculations were performed in Excel ${ }^{(i)}$. Significant differences were calculated applying the Wilcoxon Mann-Whitney test using StatExact (Cytel Software) and considered significant at $\mathrm{P}<0.05$ at indicated in the graphs by an asterix $\left({ }^{*}\right)$. Graphs were constructed using Sigma Plot ${ }^{\text {(D) }}$.

\section{$\underline{\text { RESULTS }}$}

\section{Engineering of highly fluorescent A2780 and 3LLp cells}

To produce tumor cell lines expressing the brightly fluorescent proteins DsRed2 or ZsGreen, the ovarian carcinoma A2780 and Lewis lung carcinoma 3 LLp cells were transfected with either pZsGreen or pDsRed2 as mentioned in the methods section. Transfected cells were primarily selected for 10 days on geneticin resistance. The cells expressing the brightest fluorescence (top 5\%) were sub sequentially sorted by a high speed cell sorter. Observation of a sub-confluent population under a fluorescent microscope of the sorted population revealed a good homogeneity in fluorescence intensity. Pictures were taken at a 1 second exposure time using a CCD camera. Figure 1 clearly illustrates that a high fluorescence signal was obtained for the engineered cell lines A2780 DsRed2 $_{2}(1 \mathrm{~A})$, A2780 ZsGreen $(1 \mathrm{~B}), 3 \mathrm{LLP}_{\mathrm{DsRed} 2}(1 \mathrm{C})$ and $3 \mathrm{LLp}_{\mathrm{ZsG} \text { Green }}$ (ID). Besides cell sorting, we also tried to select highly fluorescent clones. This gave similar fluorescence intensities (data not shown), but the low heterogeneity of a cell population jeopardizes the possibility to form a tumor in vivo and increases the risk of modifying the characteristics compared to the parental cells. Hence, this approach was no longer pursued. 


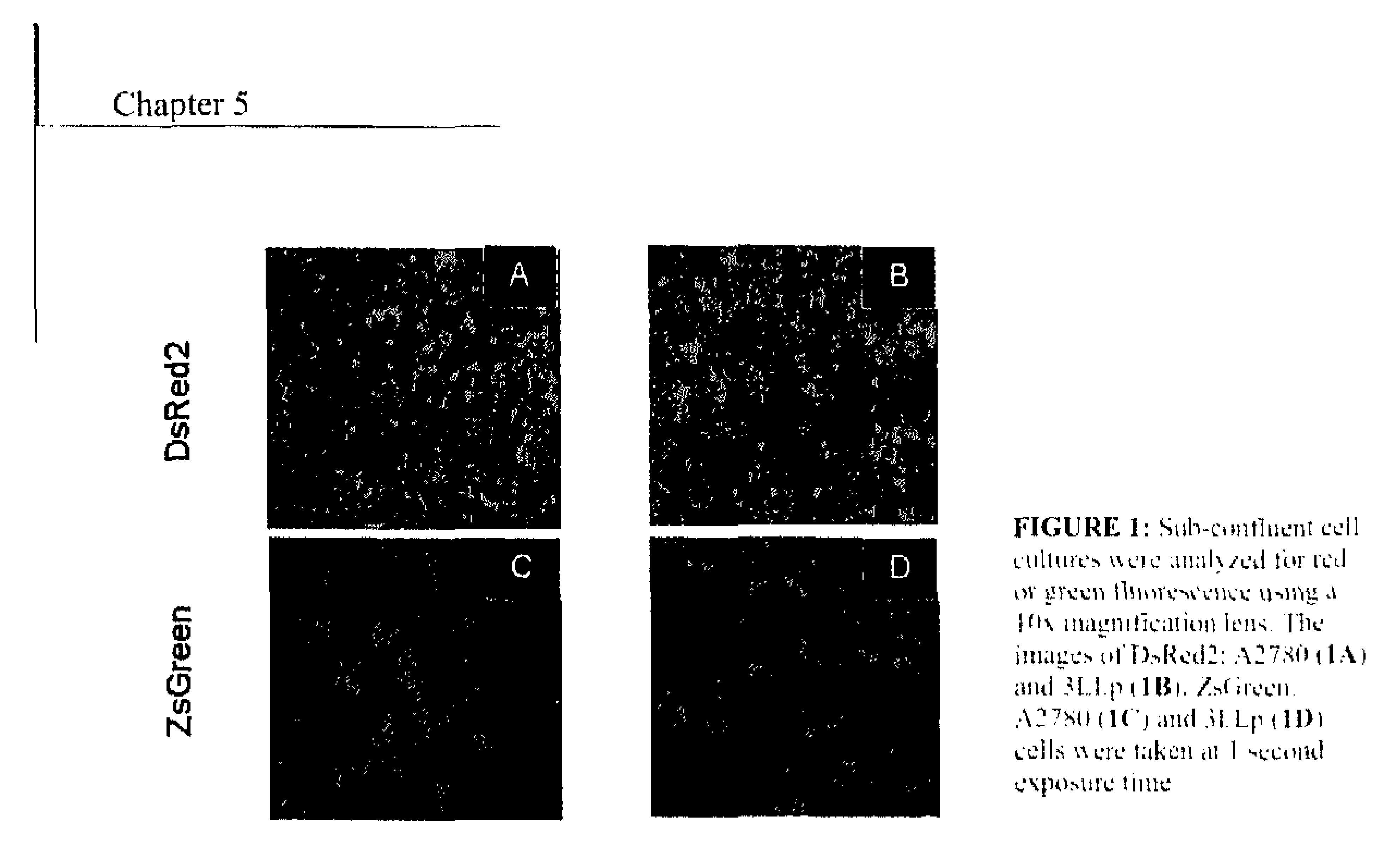

In vitro growth and susceptibility to anti-cancer drugs in the fluorescent cells vs. parental cells

To ensure that the engineered cells were representative for the parental cells, two types of assays were performed: a growth rate comparison and a cytotoxicity assay. The growth curves of the fluorescent cells were compared to those of the parental cells. After seeding in Petri dishes, the number of viable cells was quantified daily after trypsinization using an automated cell counter. The mean doubling time for each cell line has been calculated in the exponential growth phase in 3 independent experiments. As shown in Table II, there were no significant changes in the doubling time of both A2780 and 3LLp when expressing ZsGreen or DsRed2. The 3LLp parental cells have a doubling time of approximately 18hours. The engineered 3LLp cells have a doubling time of approximately 19 hours

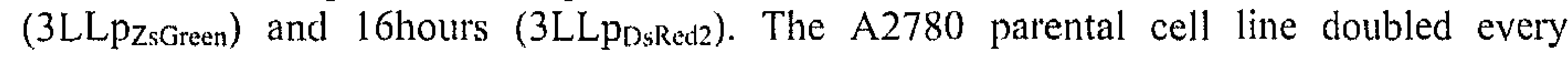
14,5 hours while the fluorescent protein expressing cells have doubling times of 15 hours

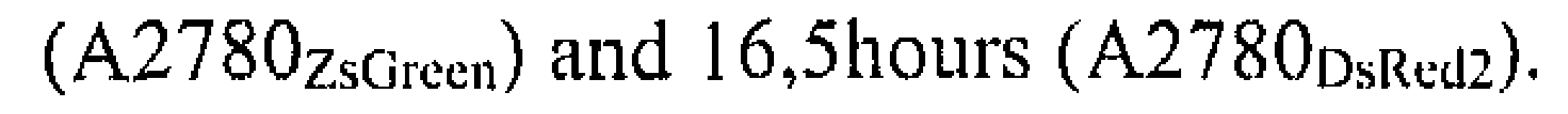

\begin{tabular}{|c|c|c|c|} 
& parental & ZsGreon & DsRod2 \\
\hline 3LLP & $18: 08 \mathrm{~h} \pm 02: 46$ & $18: 13 \mathrm{~h} \pm 00: 10$ & $15: 50 \mathrm{~h} \pm 02: 45$ \\
A2780 & $14: 38 \mathrm{~h} \pm 01: 36$ & $15: 08 \mathrm{~h} \pm 02: 46$ & $16: 29 \mathrm{~h} \pm 02: 48$ \\
& $\ldots \ldots \ldots \ldots \ldots$
\end{tabular}

TABLE II: Doubling timle of the parental and engunesed flumencent cell tines. By counting the total number of viable

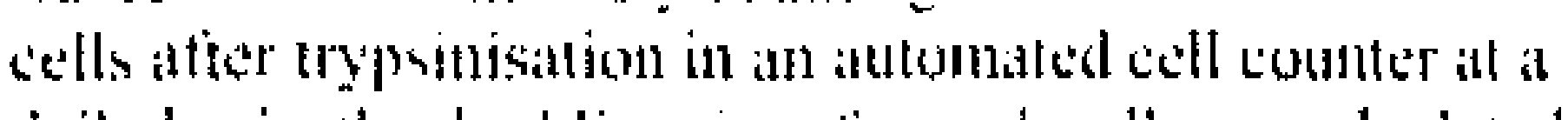
daify basis. the doubling time fir each cell wals calculited. The doubling time is expressed in heurs and minues and the average douthing tume and standard devation is mentioned for thee independemt experimetrits.

Secondly, we evaluated whether a similar response to HDAC inhibitors was achieved for the fluorescent and respective parental cells. We used several histone deacetylase (HDAC) inhibitors having various potencies to induce growth inhibitory response. Cells were treated and evaluated in a dose response from $10^{-9} \mathrm{M}$ to $10^{-5} \mathrm{M}$ with SAHA, MS-275, LAQ 824 and Trichostatin A (TSA). Four days after treatment, cell viability was assessed using an MTT assay. Concentration needed to reduce the viable cell number by $50 \%$ (IC50) is calculated for each compound in each cell type. As shown in Figurc 2A, the IC 50's for 
SAHA, MS-275, LAQ 824, and TSA in the fluorescent A2780 cell lines are similar to those of the parental cell line (respectively $2.5 \mu \mathrm{M}, 1.2 . \mu \mathrm{M}, 78 \mathrm{nM}$, and $65 \mathrm{nM}$ ).

Similarly, the fluorescent and parental 3LLp cell lines show a similar dose dependant growth inhibition towards the HDAC inhibitors. The calculated IC50's of the fluorescent cells closely resemble those of the parental: $2.2 \mu \mathrm{M}, 0.98 \mu \mathrm{M}, 39 \mathrm{nM}$ and $79 \mathrm{nM}$, respectively (Figure 2B).

Summarizing, the engineered cell lines have retained their in vitro sensitivity to respond to a specific drug class as well as kept their innate doubling time. Achieving the prerequisite, either fluorescent protein expressing cell line can be used for in vitro HDAC inhibitor screening purposes and they will be further characterized in vivo.

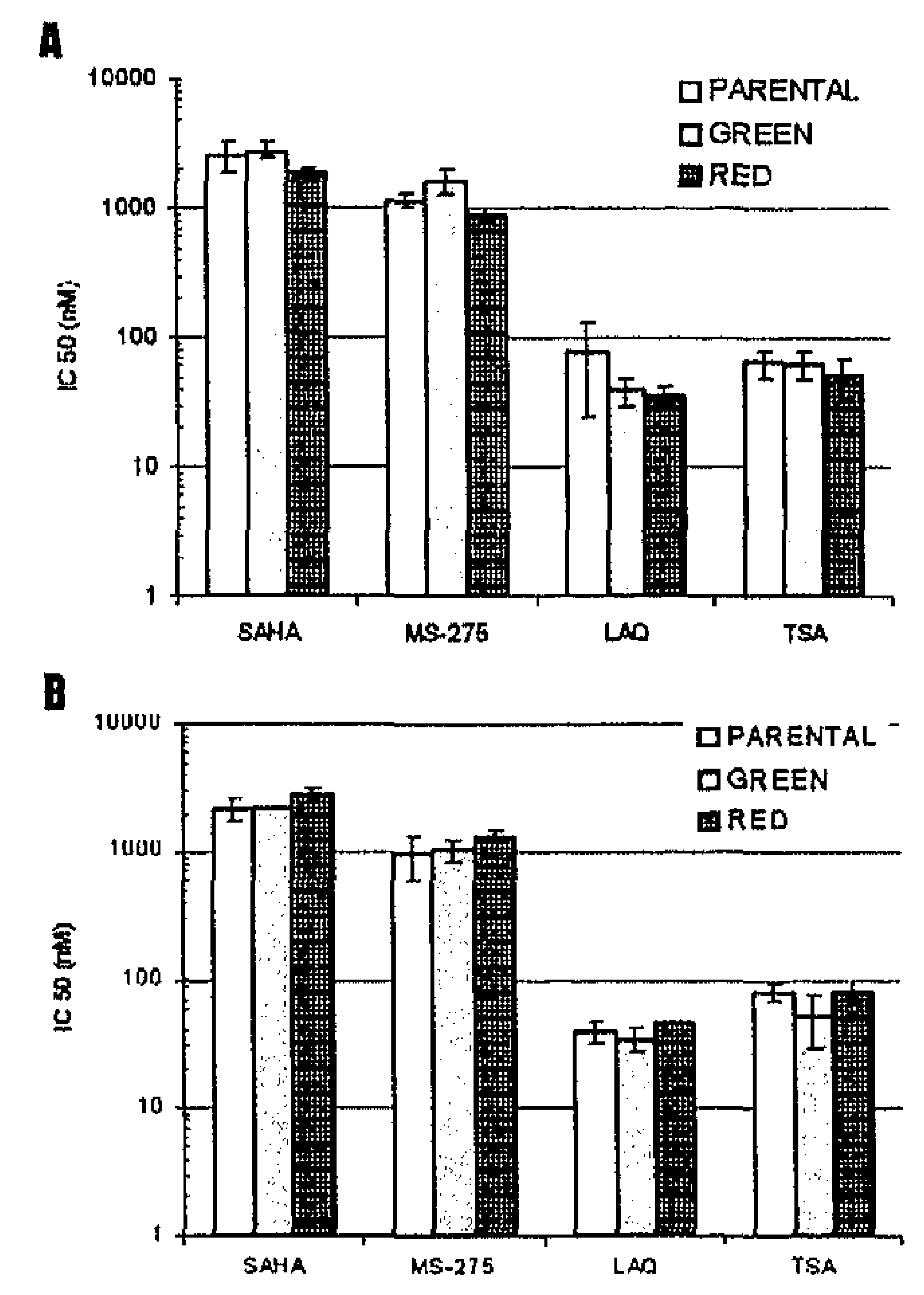

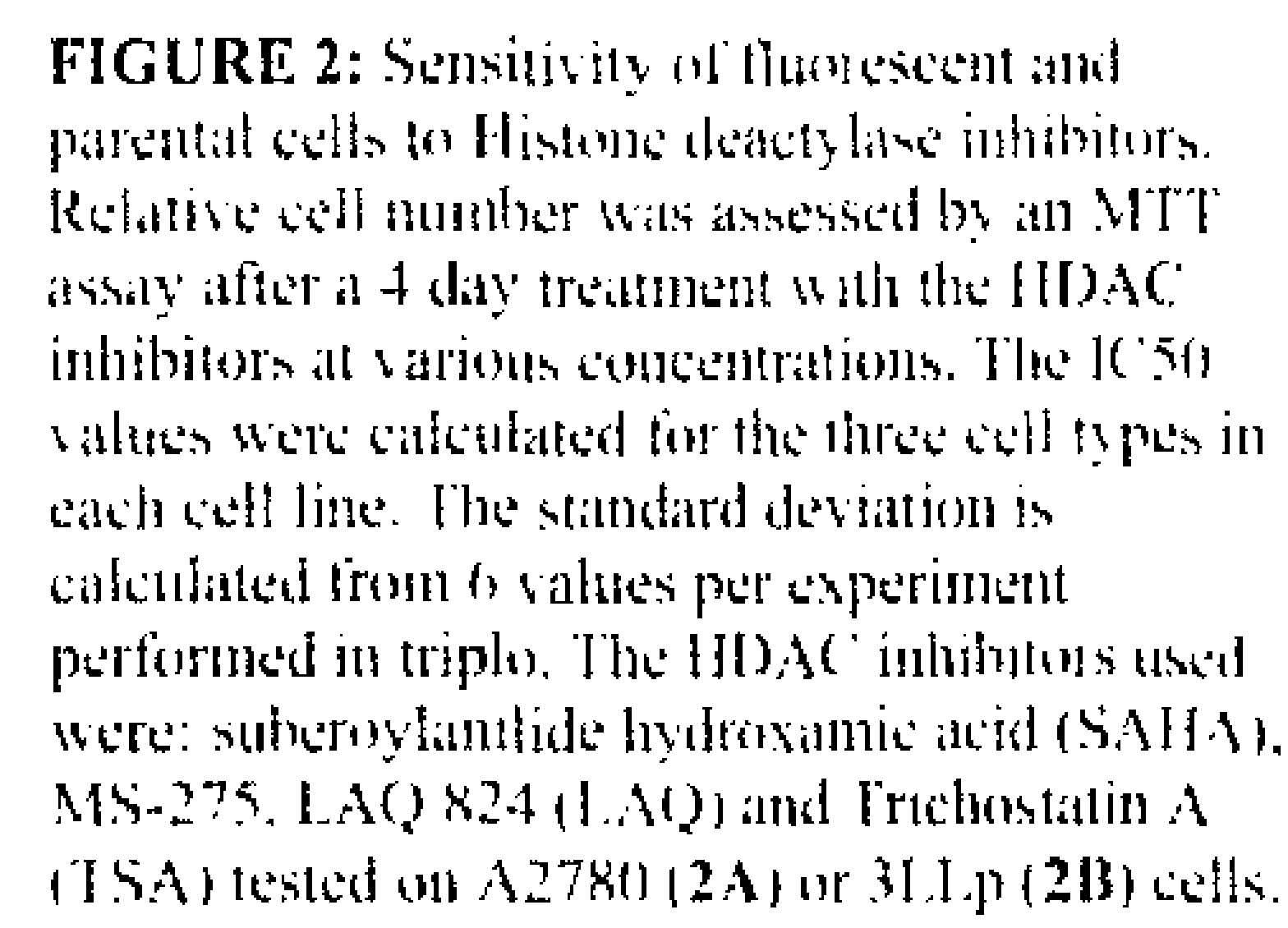

To induce tumor formation, $10^{7}$ cells were injected $s c$. in the inguinal region of the mice. To mimic the stress induced by drug treatment, the control mice were treated daily by oral administration (po) with a $\beta$-cyclodextrin solution. The ZsGreen and DsRed2 expressing tumors were measured using the WBI system. Each group $(n=10)$ was monitored for up to 30 days or until the tumor size reached $\sim 10 \%$ of the total body weight.

Figure 3 shows different growth rates of engineered A2780 and 3LLp tumors. All engincered cell lines produced subcutaneous (sc.) tumors with 100\% tumor take showing exponential tumor growth rate after several days. Results are shown as individual relative tumnor volume, as compared to tumor volume initial measurement. This facilitates visualization of exponential tumor growth (linear phase in a semi-log scale) with calculation of tumor doubling time. These were 3, 6, 3 and 4 days for A2780 DsRed2 (3A), $\mathrm{A} 2780_{\mathrm{Zs} \text { sreen }}(3 \mathrm{~B}), 3 \mathrm{LLp} \mathrm{pssed2}_{2}(3 \mathrm{C})$ and $3 \mathrm{LLp}_{\mathrm{ZsGreen}}(3 \mathrm{D})$ respectively. These results indicate 
Chapter 5

that each of the engineered cell lines was readily usable in anti-tumor studies to evaluate novel drug candidates in a reliable manner (as far as tumor growth and measurement are concerned).
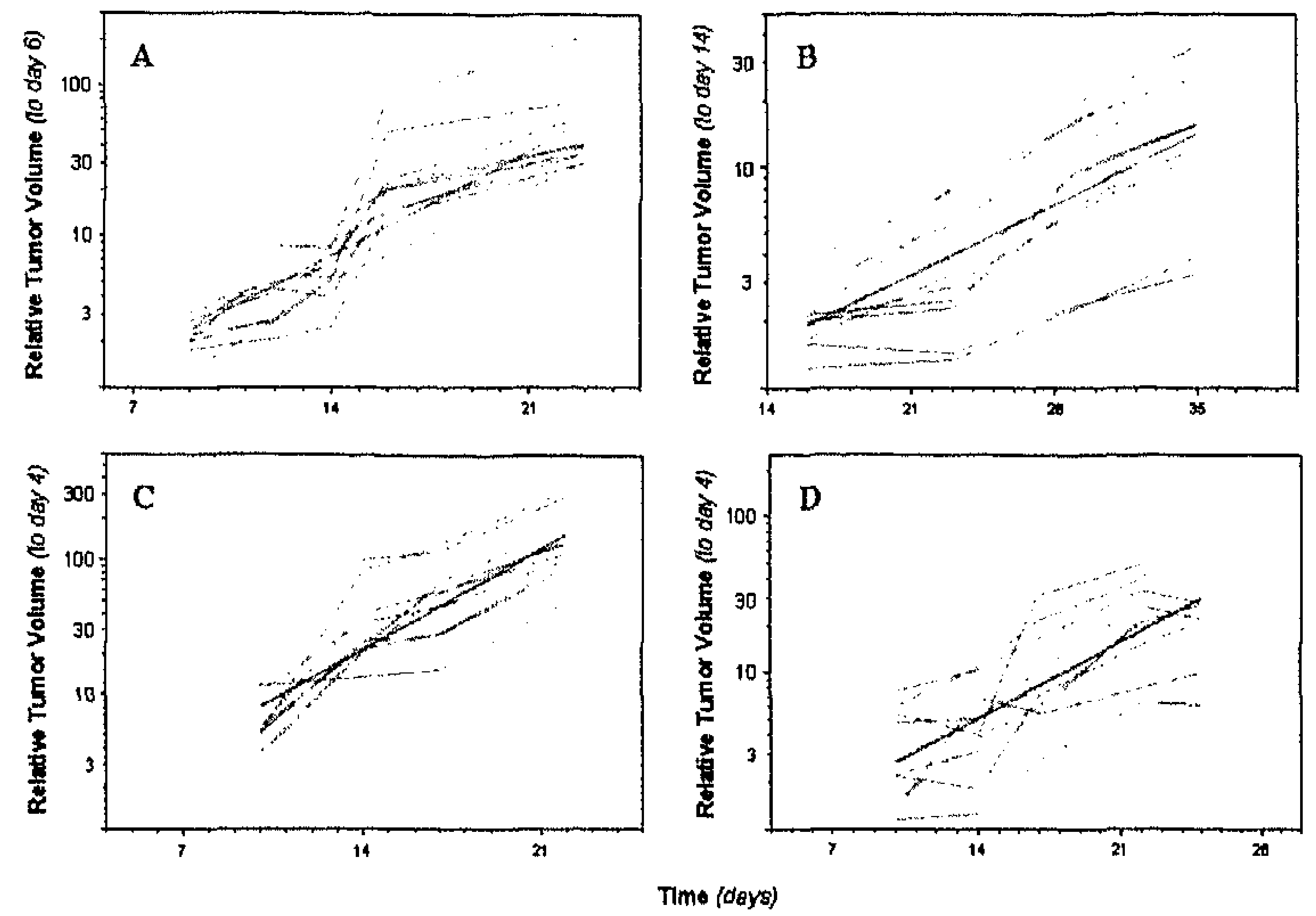

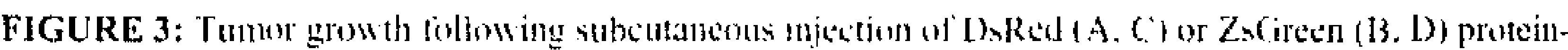

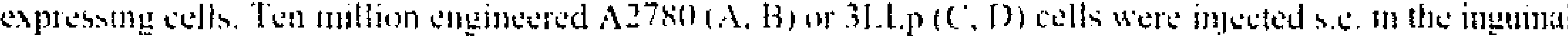

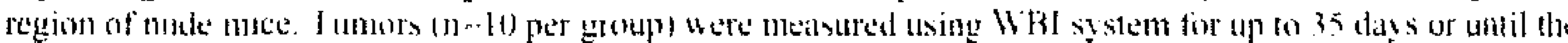

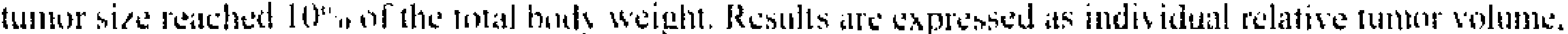

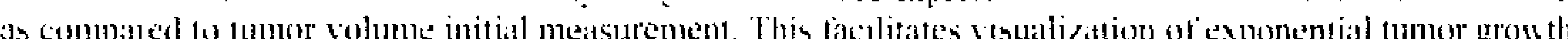

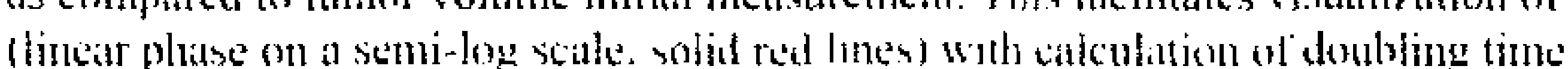

In analogy to the in vitro setup, we assessed the ability of the all tumors to respond to a drug treatment. We chose one of the HDAC compounds used in the in vitro experiments and moreover previously described as having an antitumor activity on human tumor xenografts in mice $[10,11]$. Four days after tumor cell injections, mice were administered orally at a daily basis with MS-275. The doses were respectively $10 \mathrm{mpk}$ and $20 \mathrm{mpk}$ for A2780 xenograft bearing mice and 3LLp tumor bearing mice. The control group was injected with the solvent alone. For each group $(n=10)$ of mice, tumor size was measured using the WBI system. As shown in Figure 4, the antitumoral effect of the drug on A2780 xenograft bearing mice is increasing in time. For the mice containing the ZsGreen expressing xenografts (4A) the study was terminated at day 22 with the respective tumor volumes of $7489 \mathrm{~mm}^{3}$ and $3232 \mathrm{~mm}^{3}$ for the solvent and MS-275 treated groups. This refers to a tumor volume reduction of $57 \%$. For the mice with the DsRed2 expressing xenografts 
(4B) the study was terminated at day 35 with the tumor volumes of the solvent and MS-275 treated groups bcing $1827 \mathrm{~mm}^{3}$ and $931 \mathrm{~mm}^{3}$ respectively. This calculates to a tumor volume reduction of $49 \%$. Already at day 16 a significant difference is achicved with a $\mathrm{P}$ value $<0.05$ for the ZsGreen expressing tumors. Statistical significance is reached for the DsRed2 expressing A2780 tumors between the solvent and MS-275 treated groups at day 35 with a P-value $<0.05$. This result implies that both the ZsGreen expressing - and the DsRed2 expressing A2780 tumor are candidate models for studies testing potential HDAC inhibitors. The ZsGreen model though has advantages over the DsRed2 expressing tumor model due to the much earlier achieved statistically significant anti tumor effect.

When similar experiments were repeated with the 3 LLp tumor bearing mice, we observed that both 3 LLp tumor types responded to the treatment. The anti tumor cfficacy of MS-275 resulted in a significant difference in tumor volume compared to a solvent treated group for both fluorescent tumor types. At day 22, the end of the experiment for the ZsGreen tumor bearing mice $(4 \mathrm{C})$, the tumor volume of the MS-275 treated mice was $4303 \mathrm{~mm}^{3}$ compared to the tumor volume of the solvent treated mice being $6282 \mathrm{~mm}^{3}$ (reduction of $32 \%$ ). The mice containing the DsRed2 expressing tumors (4D) were sacrificed at day 25 . The tumor volume of the solvent treated mice was $3679 \mathrm{~mm}^{3}$ whilc the tumor volume of the MS-275 treated mice was $902 \mathrm{~mm}^{3}$ (rcduction of $75 \%$ ). Statistical significance on tumor volume compared to the solvent treated group was achieved for both the DsRed2 expressing tumors and for the ZsGreen expressing tumors at day 25. Interestingly, the larger reduction in tumor volume (greater therapeutic window) implies that the DsRed2 expressing 3LLp tumor model, more so than the ZsGreen expressing 3LLp tumor model, is a suitable model for HDAC inhibitor anti tumor studies. 

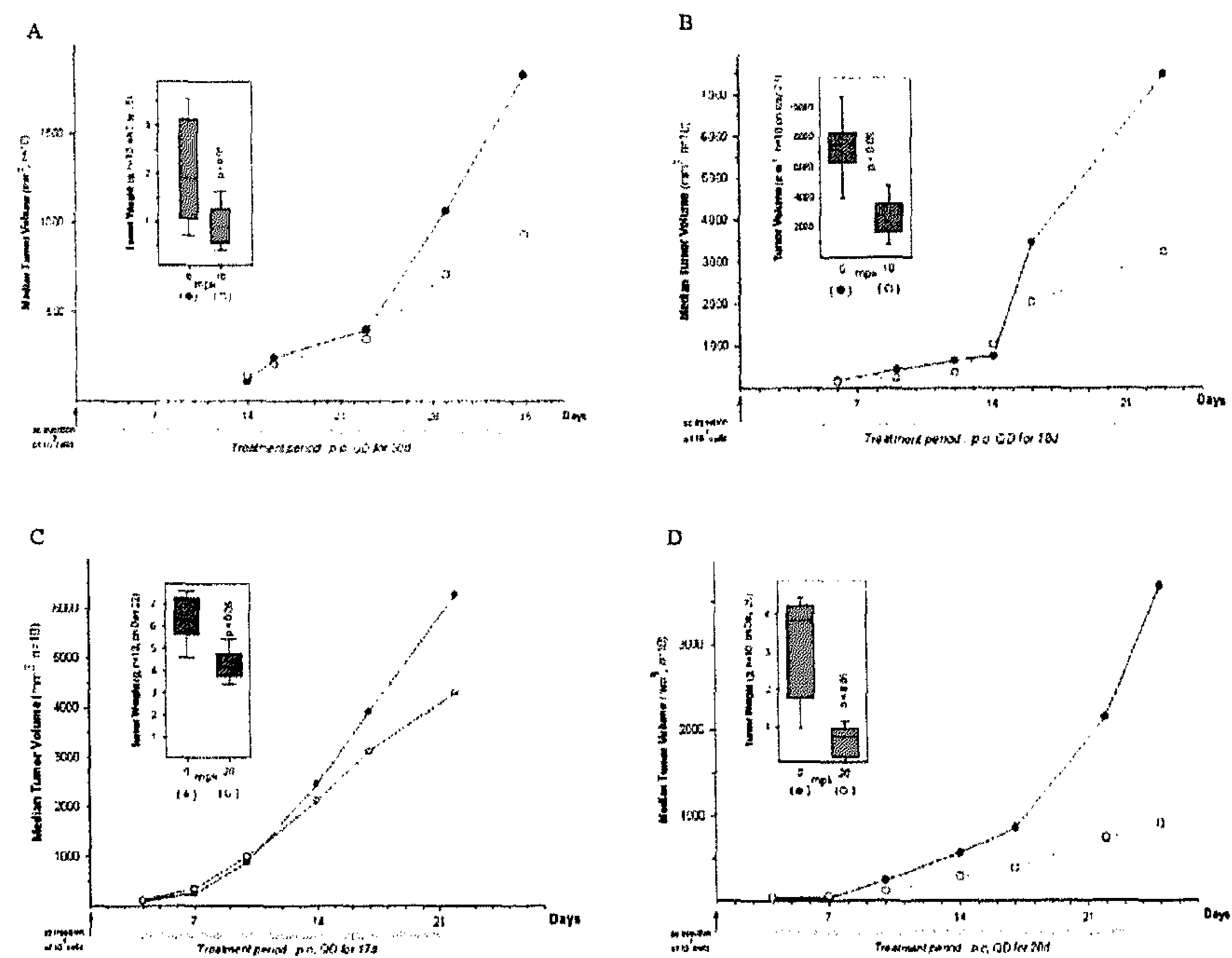

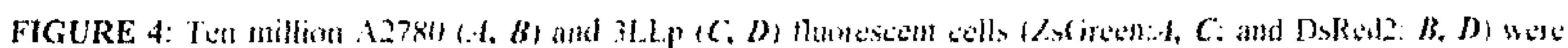

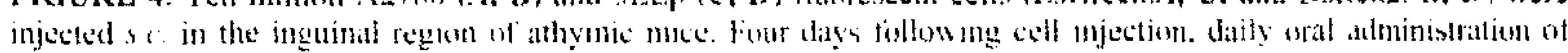

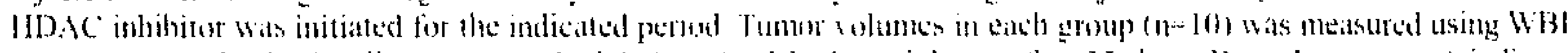

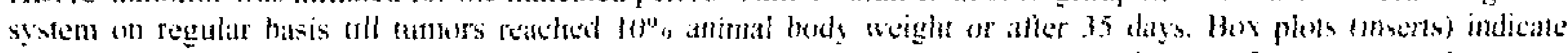

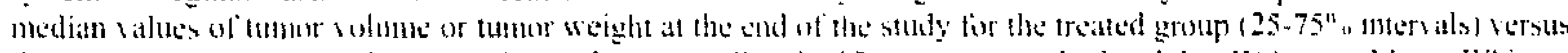

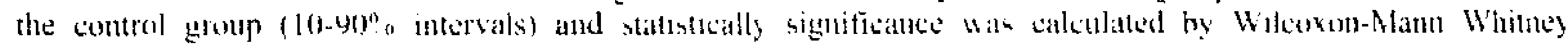

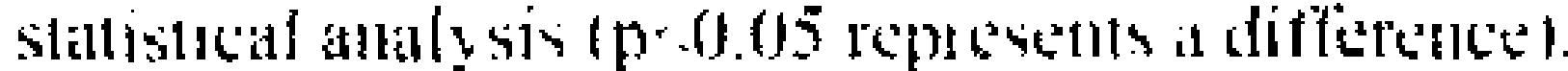

In vivo detection of metastasized $\mathrm{ZsGreen}$ and DsRed 2 tumors

The major advantage of having metastasizing tumors that fluoresce intensely as the ZsGreen and DsRed2 expressing 3LLp tumors, is the possibility to pick up metastasis at a very early time point or at a small size. The WBI system was used to detect and quantify metastasis after post mortem dissection as a way to demonstrate its feasibility. Figure 5 illustrates the possibility to detect small metastasis of the lung $(5 \mathrm{~A})$ after subcutaneous injection of ZsGreen 3LLp cells. Fluorescent metastasis' as small as $800 \mu \mathrm{m}$ could be easily detected in the WBI system (arrow). Such a small metastasis may not have been detected under normal light.

Using our image analysis software the total tumor metastasis volume, namely $175 \mathrm{~mm}^{3}$, can also be calculated $(5 \mathrm{~B})$ providing another tool for evaluating efficacy of drug candidates. 


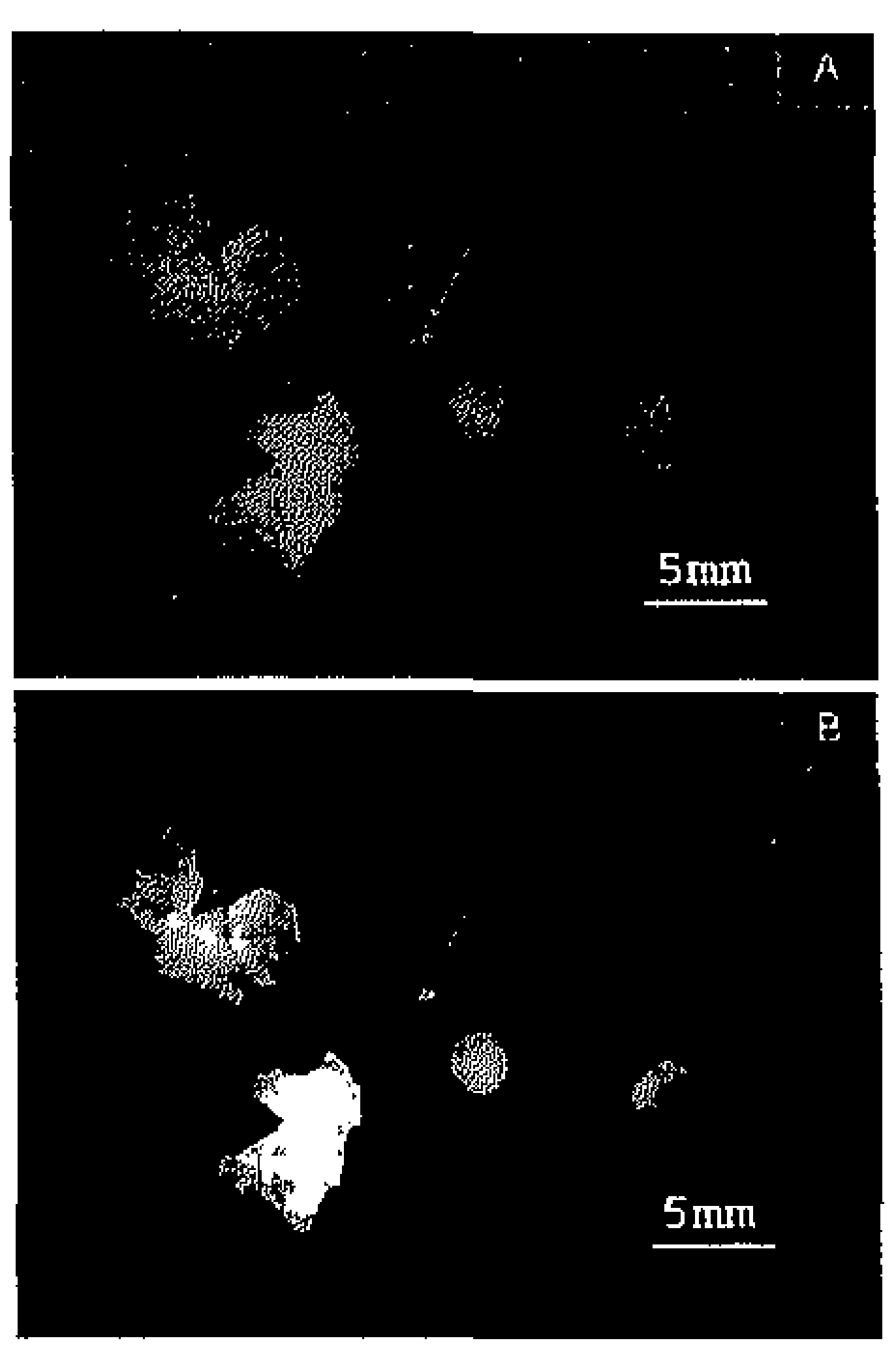

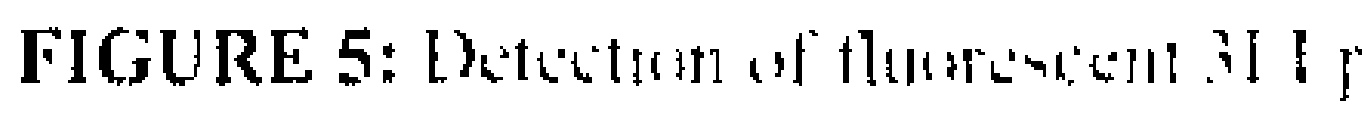

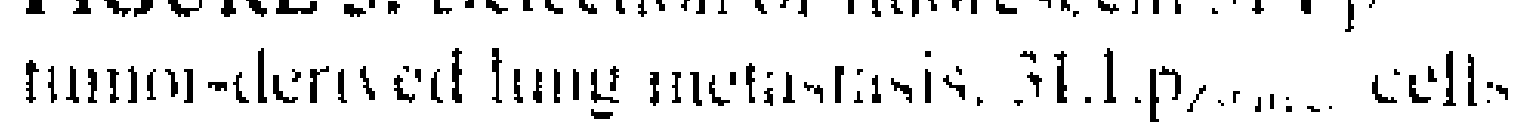
"rere ingeced intrits

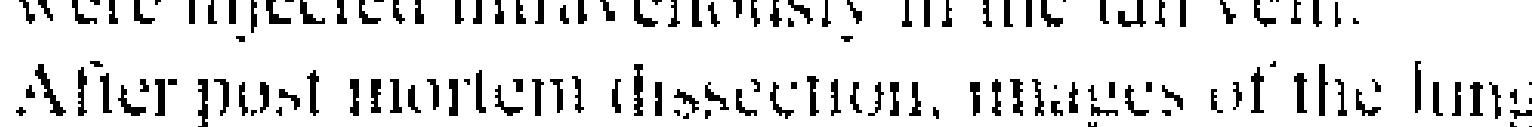

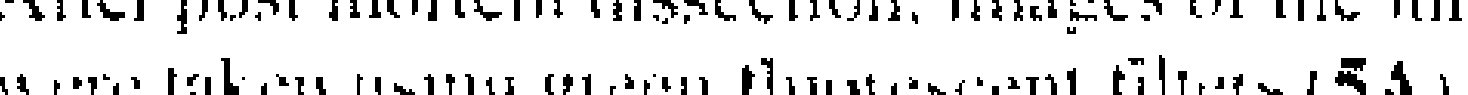

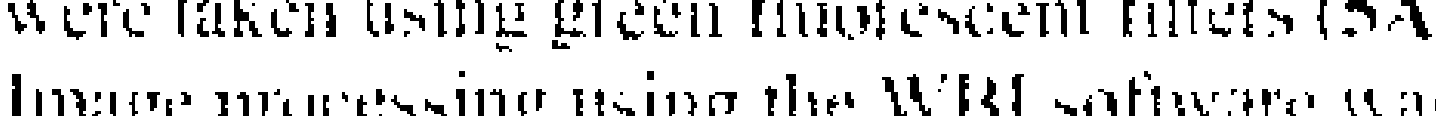

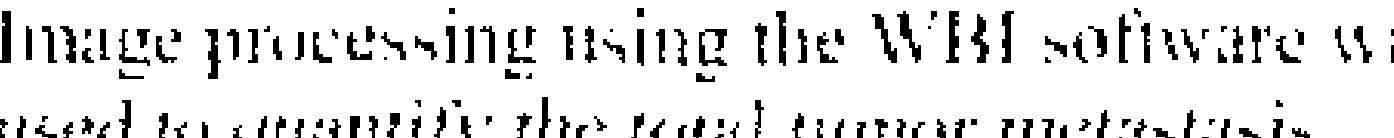

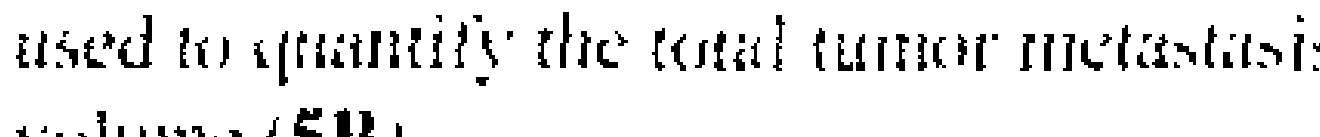
rolume $\{513$ )

\section{Comparison of tumor measurement tool: WBI vs caliper}

The easy detection of highly fluorescent tumors opens the possibility for automated high throughput measurements but it is crucial to validate accuracy and consistency between WBI and the widely used caliper-based method. To compare the accuracy of the WBI versus caliper measurements, the size of fluorescent tumors were measured using both systems and compared to the actual tumor weight $\left(\mathrm{TW}_{\mathrm{A}}\right)$, as measured after removal of the tumor. To transform the measured tumor volume data into tumor weight, the density of the tumor was taken into account. This tumor weight will be referred to as calculated tumor weight $\left(T W_{C}\right)$. The ratio of calculated tumor weight $\left(\mathrm{TW}_{\mathrm{C}}\right)$ over actual tumor weight $\left(\mathrm{TW}_{\mathrm{A}}\right)$ was used to assess the accuracy of both tumor volume measuring systems. A ratio of 1 means a perfect accuracy in tumor size evaluation.

The WBI measurements of both the ZsGreen and DsRed2 fluorescent protein expressing A2780 tumors provide an accurate estimation of the tumor weight and tumor volume (Figure 6A). With the density of the $\mathrm{A} 2780$ tumors being 1.03 , the $\mathrm{TW}_{C} / \mathrm{TW}_{\mathrm{A}}$ ratio is 1.05 \pm 0.106 and $0.849 \pm 0.149$ for the ZsGreen and DsRed 2 expressing tumors respectively. The 3LLp tumors measured with the WBI also represent an accurate estimation of the tumor volume. The density of the $3 \mathrm{LLp}$ tumors is 1.01 and the $\mathrm{TW}_{\mathrm{C}} / \mathrm{TW}_{\mathrm{A}}$ ratios for the ZsGreen and DsRed2 expressing tumors were respectively $1.038 \pm 0.083$ and $0.957 \pm$ 0.194 .

The caliper measurements however, show a non-consistent overestimation of the tumor volume (6B). The $\mathrm{TW}_{\mathrm{C}} / \mathrm{TW}_{\mathrm{A}}$ ratio for the DsRed2 expressing A2780 tumors is $1.477 \pm$ 0.249 and $1.245 \pm 0.149$ for the ZsGreen expressing A2780 tumors. The measurements taken with the caliper of the ZsGreen expressing 3LLp tumors resemble those of the actual tumor weight closely with a $\mathrm{TW}_{\mathrm{C}} / \mathrm{TW}_{\Lambda}$ ratio of $1.032 \pm 0.055$ while thosc of the DsRed2 expressing 3LLp tumors achieve a ratio of $1.27 \pm 0.172$. 
Chapter 5

In short, data acquired by the WBI represent the actual tumor size in vivo, avoiding a substantial, non-consistent overestimation of the tumor found using a caliper.

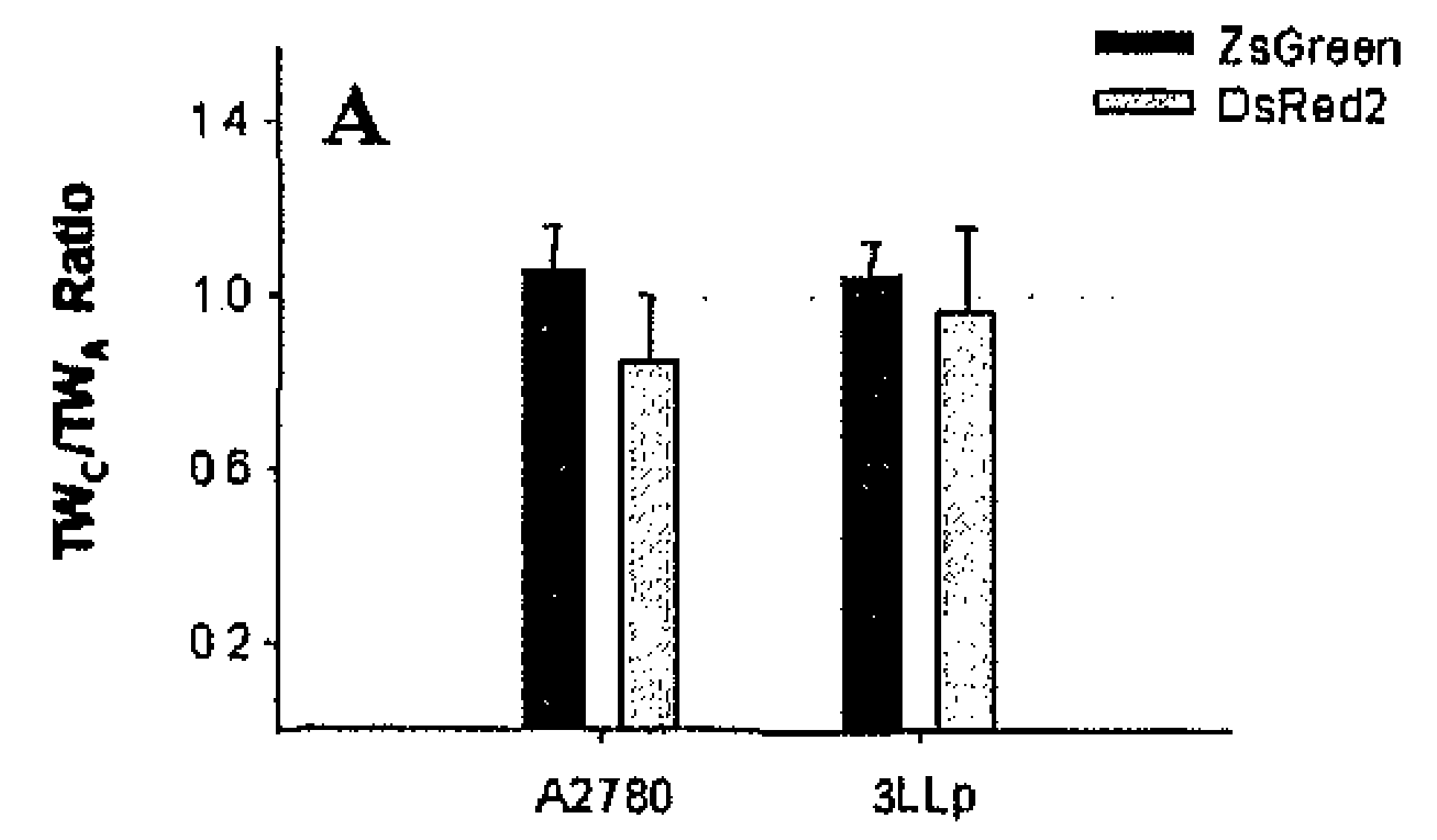

FIGURE 6: comparinem of the WBI system to the caliper batsed tumor volume methatielluents. Taking the

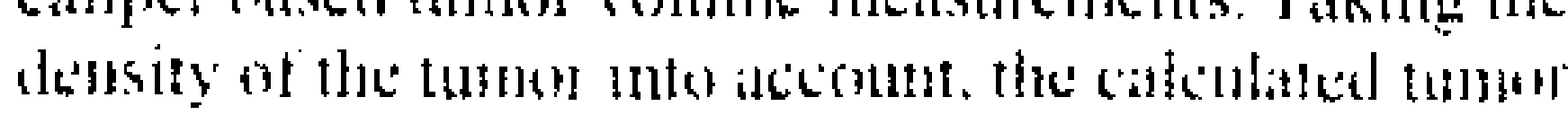
weight (TW, ) in derses from the tumor wolume ans

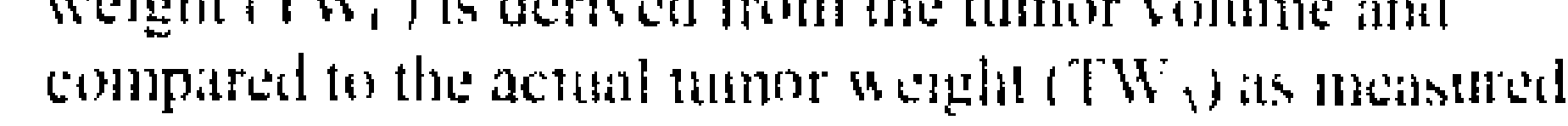
post mortent. This comparison was performed bor bohl

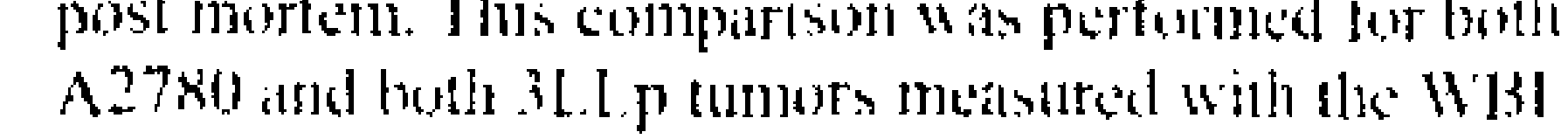
(6.) and the cahper basted systeml (ab).

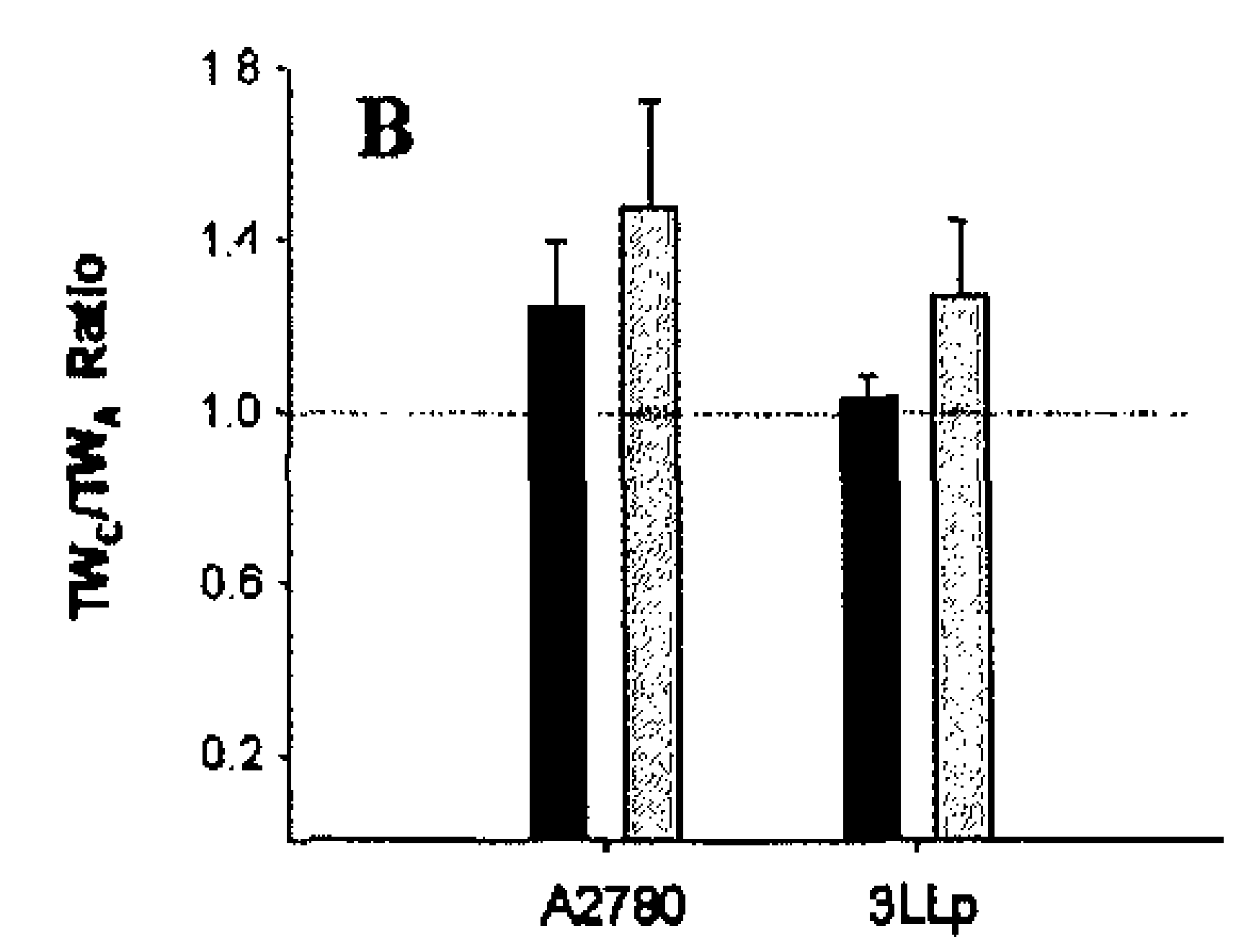

Design ZsGreen siRNA and determination of efficacy

At the time it was thought wise to assess at least 8 (the rule of thumb for antisense) various siRNAs for their inhibitory capability targeting different regions of the ZsGreen sequence. Using an in-house developed design strategy based on the rules lined out by Tuschl (REF), 6 different target sequences were identified. 3 other were designed by Eurogentec $(\mathrm{C}$ (Liege, Belgium). Out of the 8, four siRNAs (indicated in blue), targeting different regions of the ZsGreen mRNA, were chosen to be chemically synthesized (Figure 7).

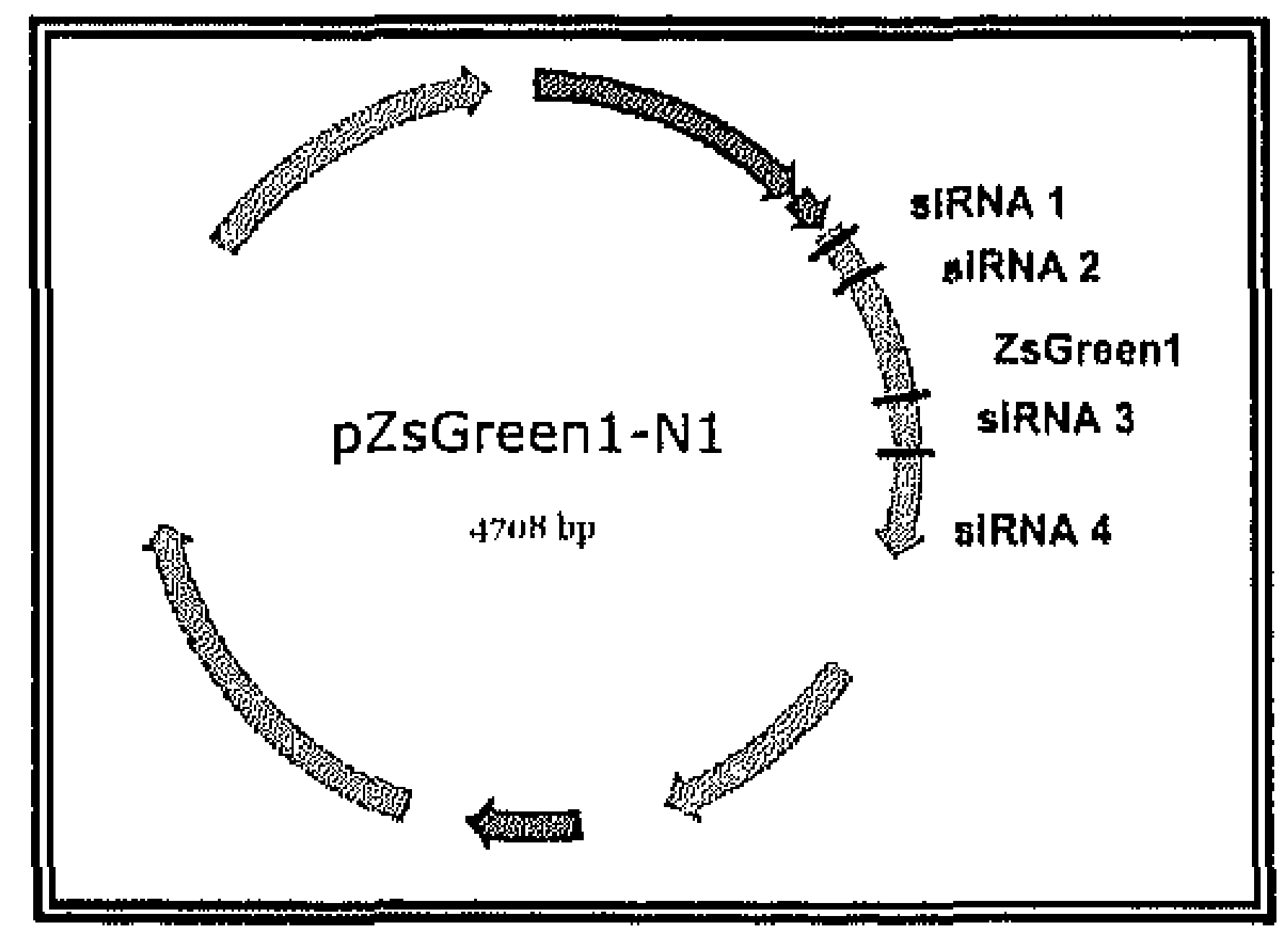

FIGURE 7: sethematic

representittion of vectur uned in

cotrams liction experiments.

The locations where the

ZsGireen siRNAs hind ate

depicted (blue)

These siRNAs were examined for their silencing efficiency. They were transfected in A2780 cells and the reduction of ZsGreen fluorescence was a measure for the siRNA efficacy. After co-transfection of plasmid and siRNA, the siRNA \#1 was shown to have the highest efficiency in reducing ZsGreen protein levels as determined by fluorescence microscopy (Figure 8A). In contrast, when the mismatch siRNA was used in co- 
transfection to the ZsGreen-Nl plasmid, a strong homogenous fluorescence was observed (8B). The other siRNAs targeting ZsGreen reduced the fluorescent intensity to a slightly lesser degree (data not shown). The ZsGreen siRNA \#1 was used in all further experiments.

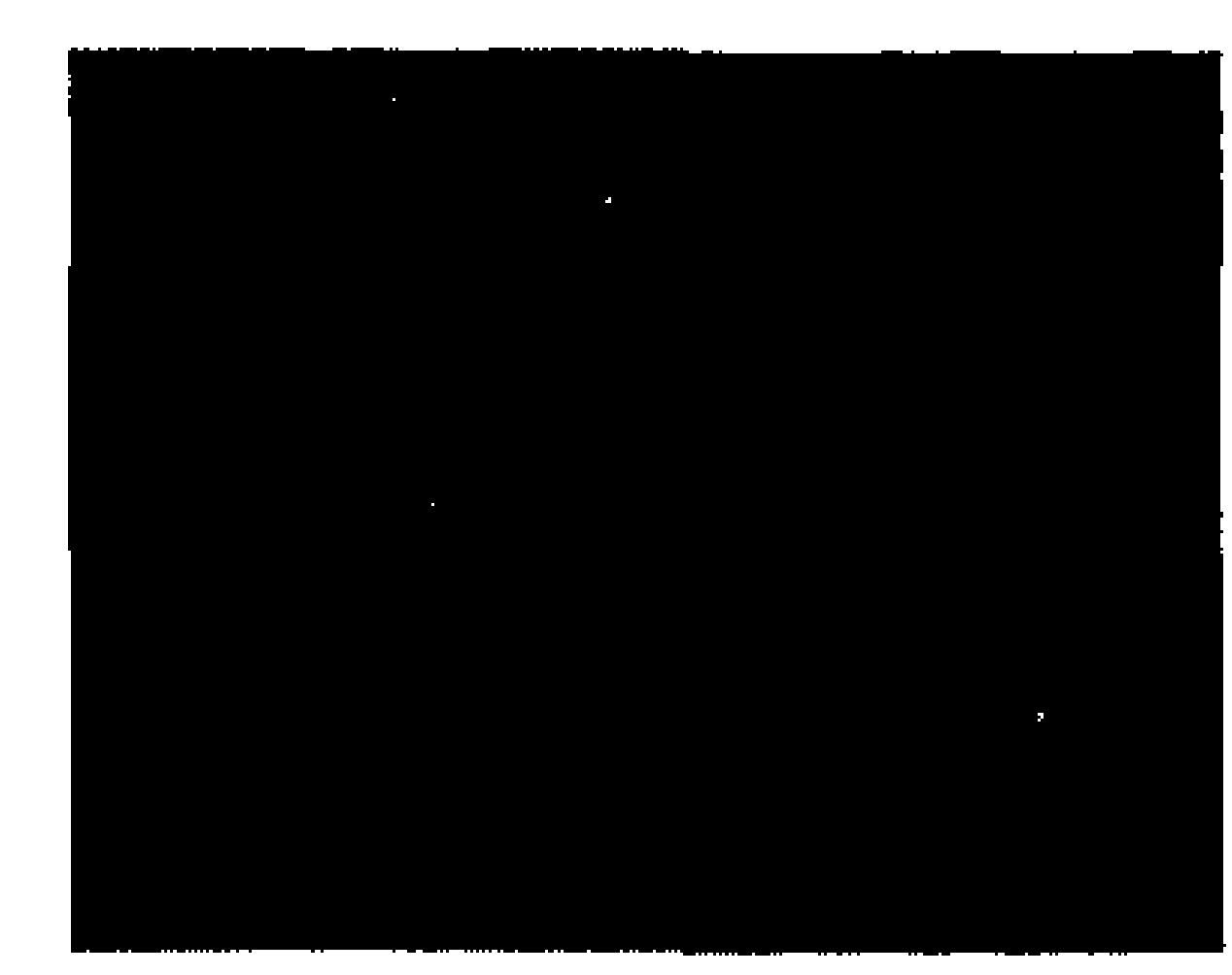

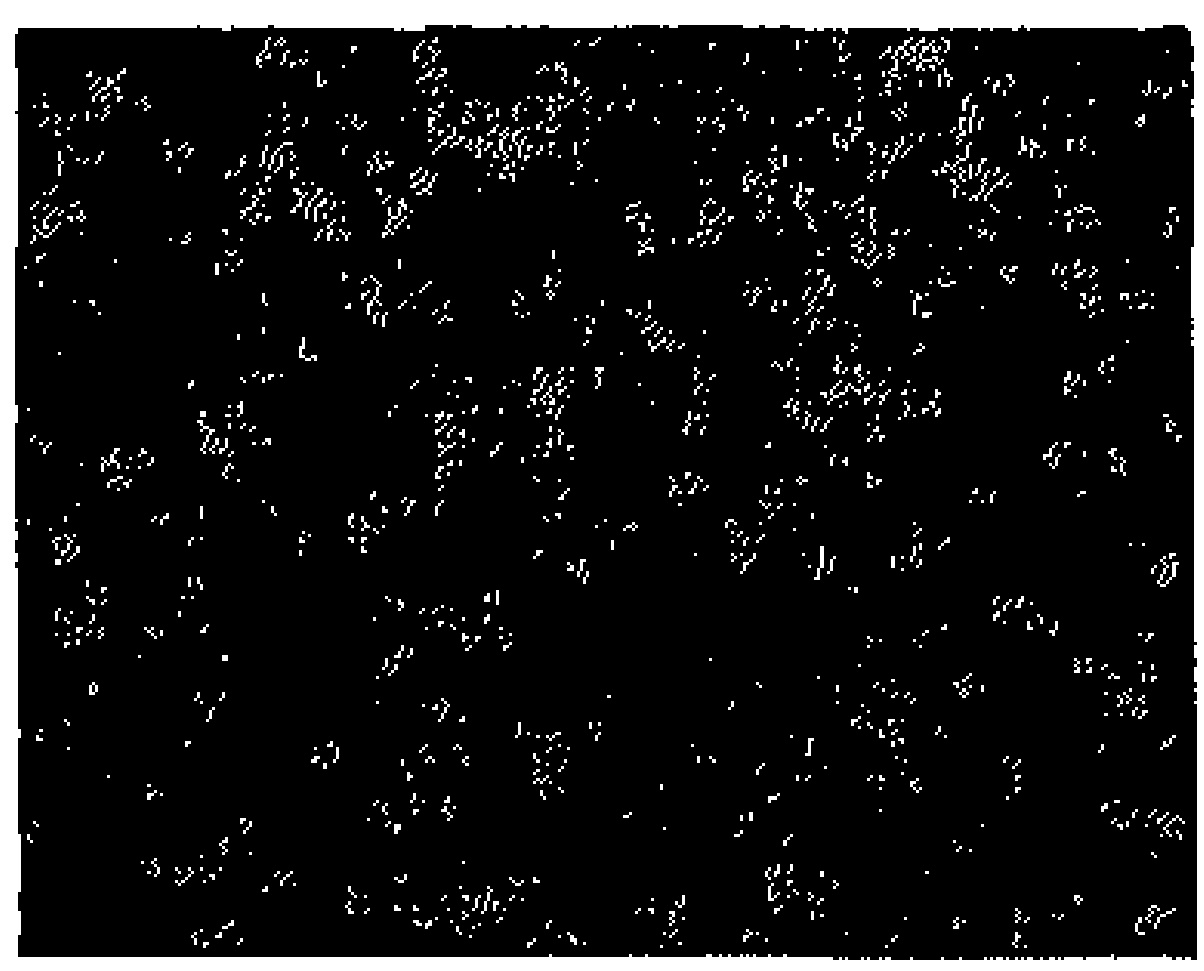

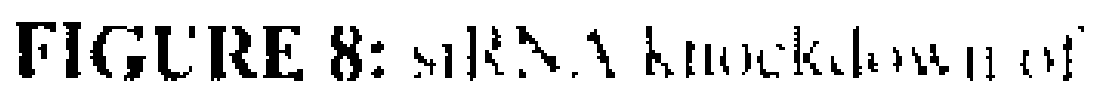

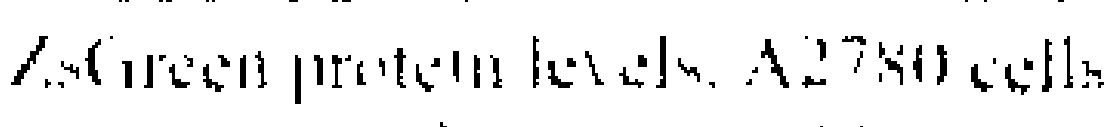

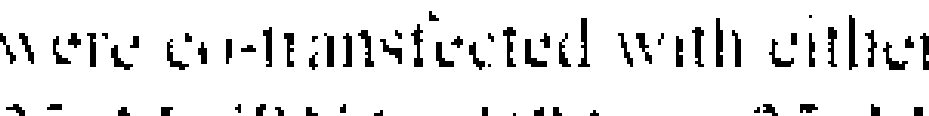
(1) 6105131 Minmath siRNA \& 8 B 1 ithd $1 \mu \mathrm{g}$

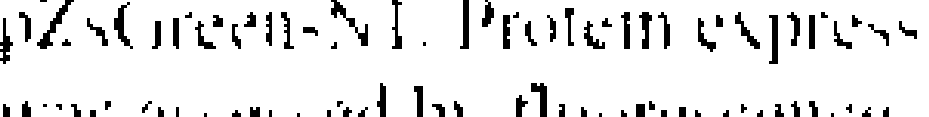

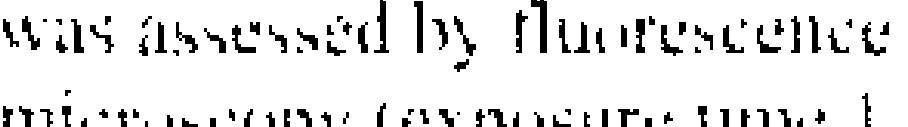

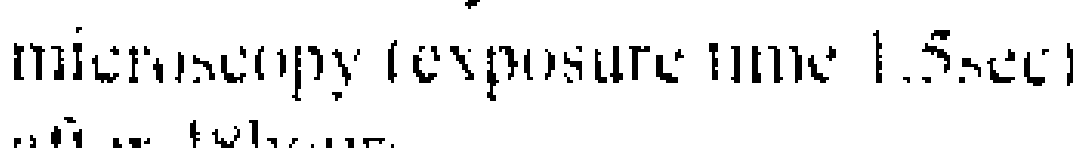
atier thloules

\section{Reduction of mRNA and protein levels of ZsGreen}

Real Time PCR enabled us to quantify mRNA levels of the samples treated with the ZsGreen siRNA vs the samples treated with the mismatch siRNA. After a co-transfection of the plasmid and siRNA, a reduction of $88.7 \%$ of the ZsGreen siRNA compared to the mismatch siRNA treated samples was achieved (Figure 9, dotted).

The negligible reduction of ZsGreen siRNA observed in the mismatch treated samples and the intense mRNA reduction in the ZsGreen siRNA treated samples illustrates the specificity of the sequence chosen. The $\beta$-actin mRNA levels were relatively equal in all samples. After $24 \mathrm{~h}$ and $72 \mathrm{~h}$ the inhibitory effect of the ZsGreen siRNA had reached approximately $50 \%$. After $48 \mathrm{~h}$ a maximum in inhibitory response was observed (data not shown).

The amount of ZsGreen protein was calculated by measuring its fluorescent activity and not by quantifying the amount of protein itself. An antibody targeting ZsGreen was not available at present times excluding classical protein quantification experiments ea Western, Elisa. The amount of fluorescence is a measure of the amount of protein present in the sample. Additionally the number of cclls in each well was quantified to obtain a measure of the amount of fluorescence per number of cells. A reduction of $91.4 \%$ was obtained by a $5 \mathrm{pmol}$ treatment of ZsGreen siRNA compared to that obtained by treatment of mismatch siRNA measured after a $48 \mathrm{~h}$ incubation. (Figure 9, striped). 


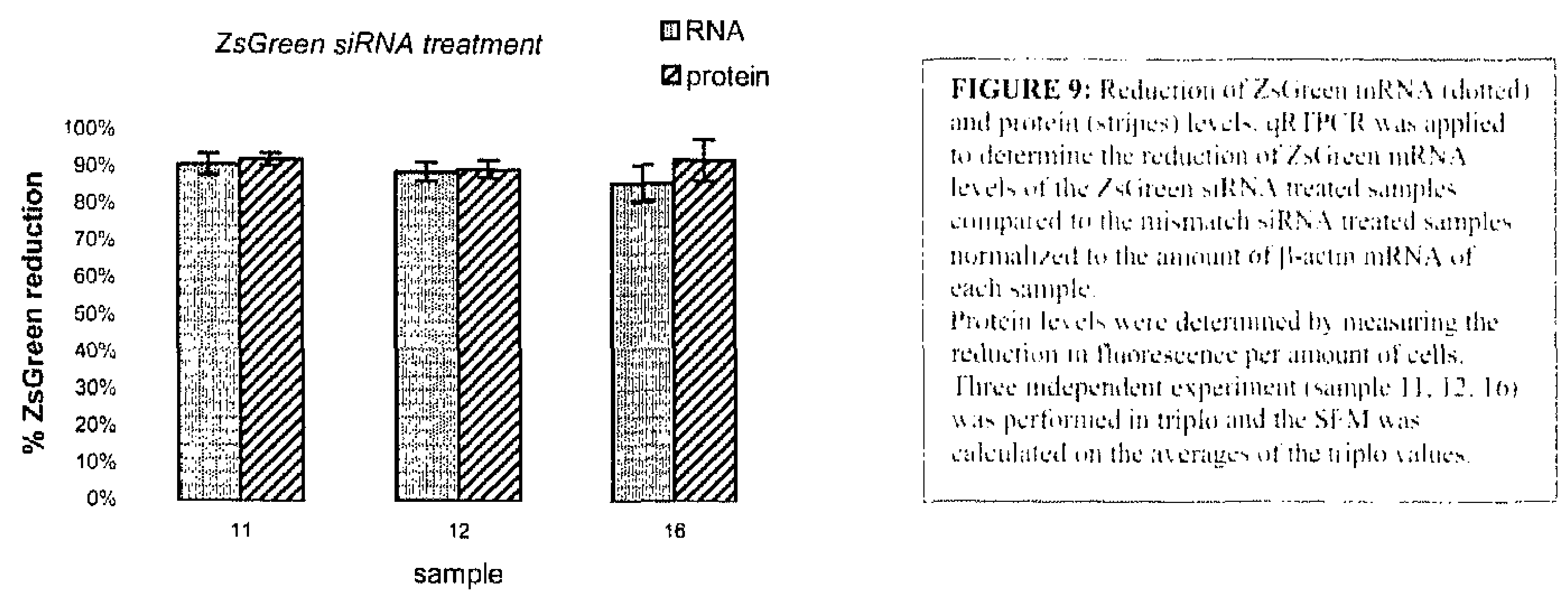

Due to the quickness in the experimental procedure, the low standard deviation observed and the comparable reduction levels of the protcin to the mRNA level, this protocol was used in all further experiments to calculate protein knockdown levels rcliably.

To ascertain whether 5pmol is the optimal amount of siRNA needed to achieve a sufficiently high knockdown of the gene of interest, a concentration range was tested from $0.4 \mathrm{nM}(0.2 \mathrm{pmol})$ to $0.4 \mu \mathrm{M}(200 \mathrm{pmol})$. After a $48 \mathrm{~h}$ incubation period with either the mismatch siRNA or with the ZsGreen siRNA, samples were measured for the fluorescence activity per cell (as a measure of ZsGreen protein levels). Figure 10 indicates a reductive capability of almost $90 \%$ was obtained at $10 \mathrm{nM}(5 \mathrm{pmol})$. This confirms the results obtained in Figure 9. Even though an increased amount of siRNA (40 times that needed to achieve a silencing of nearly $90 \%$ ) was used, no added silencing effect was observed. Lowering the concentration ZsGreen siRNA to $2 \mathrm{nM}$ reduced the silencing capacity to $80 \%$, which is still considered as being an excellent knockdown in the siRNA community. Lowering the concentration even further to $0.4 \mathrm{nM}$ reduces the silencing effect to $65 \%$.
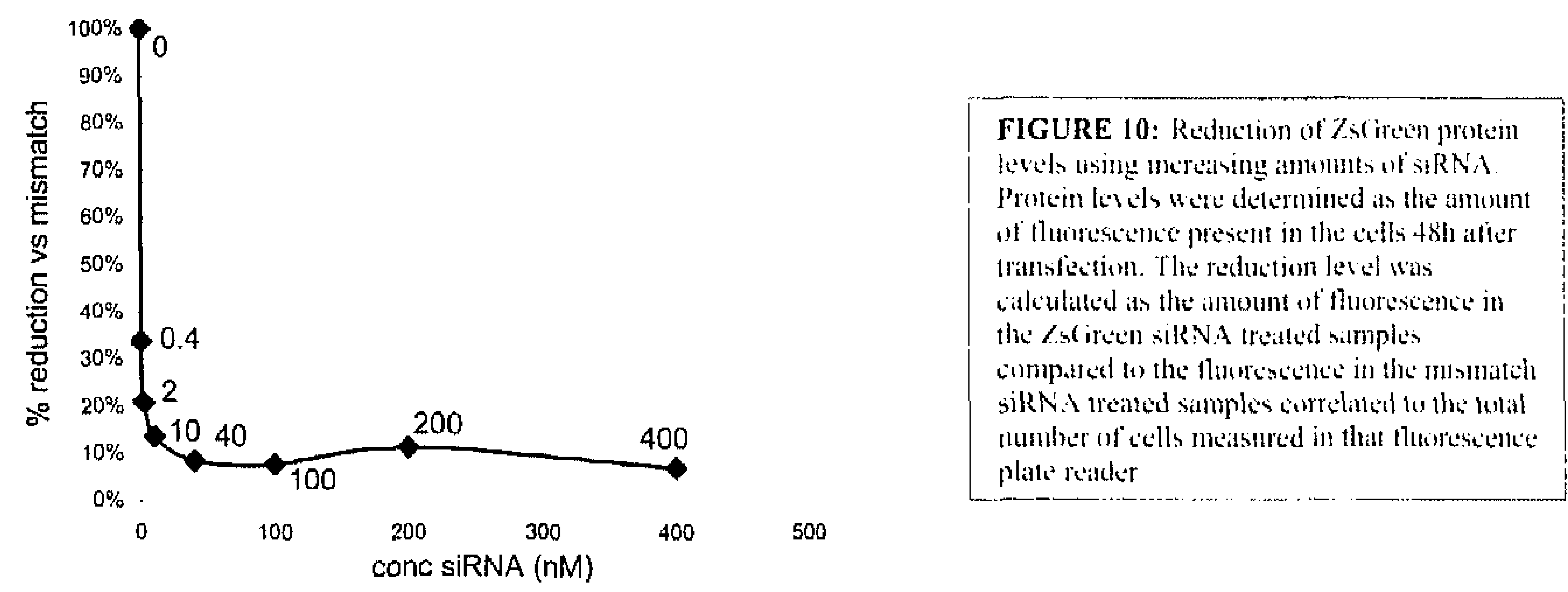


\section{Lack of response from the IFN induced pathway}

Due to the presence of dsRNA, even when cleaved to smaller $22 \mathrm{bp}$ siRNAs, an antiviral response has been reported to be activated (Sledz CA et al, 2003, Bridge A.J et al. 2003). 2 targets indicative of an IFN induced antiviral response were investigated. The siRNA applied above did not induce an antiviral response at the concentrations used in vitro compared to a synthetic, long double stranded RNA (poly I:C).

Firstly, mRNA levels of OAS were investigated as the increased expression is a marker of an enhanced Interferon (IFN) level. cRTPCR revealed that when poly I:C was applied at increasing concentrations, the mRNA levels of OAS also increased (Figure 11A). At a concentration of $25 \mu \mathrm{g} / \mathrm{ml}$ poly I:C, a plateau is reached and higher concentrations of poly $\mathrm{I}: \mathrm{C}$ do not increase the amount of OAS mRNA produced. The use of our small $22 \mathrm{bp}$ dsRNA did not increase the amount of OAS mRNA produced by the cell (Figure 11B). Even at the highest concentration of $200 \mathrm{pmol}$, no increased production of OAS mRNA could be noticed.

In a second attempt, to investigate whether the siRNAs used induced an IFN related antiviral response, we checked the phosphorylation of eIF $2 \alpha$. Phosphorylation of eIF $2 \alpha$ is a downstream effect of an IFN induced antiviral response. Activated PKR binds to eIF2 $\alpha$ and phosphorylates it at Ser51. This lcads to an inhibition in cellular protein synthesis. Western blotting with phospho-specific antibodies to this serine site of the protein cnabled us to show a dose dependant increase of phosphorylation of eIF2 $\alpha$ with the treatment of siRNAs and poly $\mathrm{I}: \mathrm{C}$ (Figure $11 \mathrm{C}$ ). At the siRNA concentration used to achieve sufficient silencing of our gene of interest $(5 \mathrm{pmol})$, no phosphorylation could be obscrved. At higher concentrations, 100 and $200 \mathrm{pmol}$, however a phosphor-specific signal emerges. With the use of poly $\mathrm{I}: \mathrm{C}$, a signal is seen at the lowest concentration tested and increases upto the maximal dose. The amount of total elF $2 \alpha$ stays relatively constant.

A

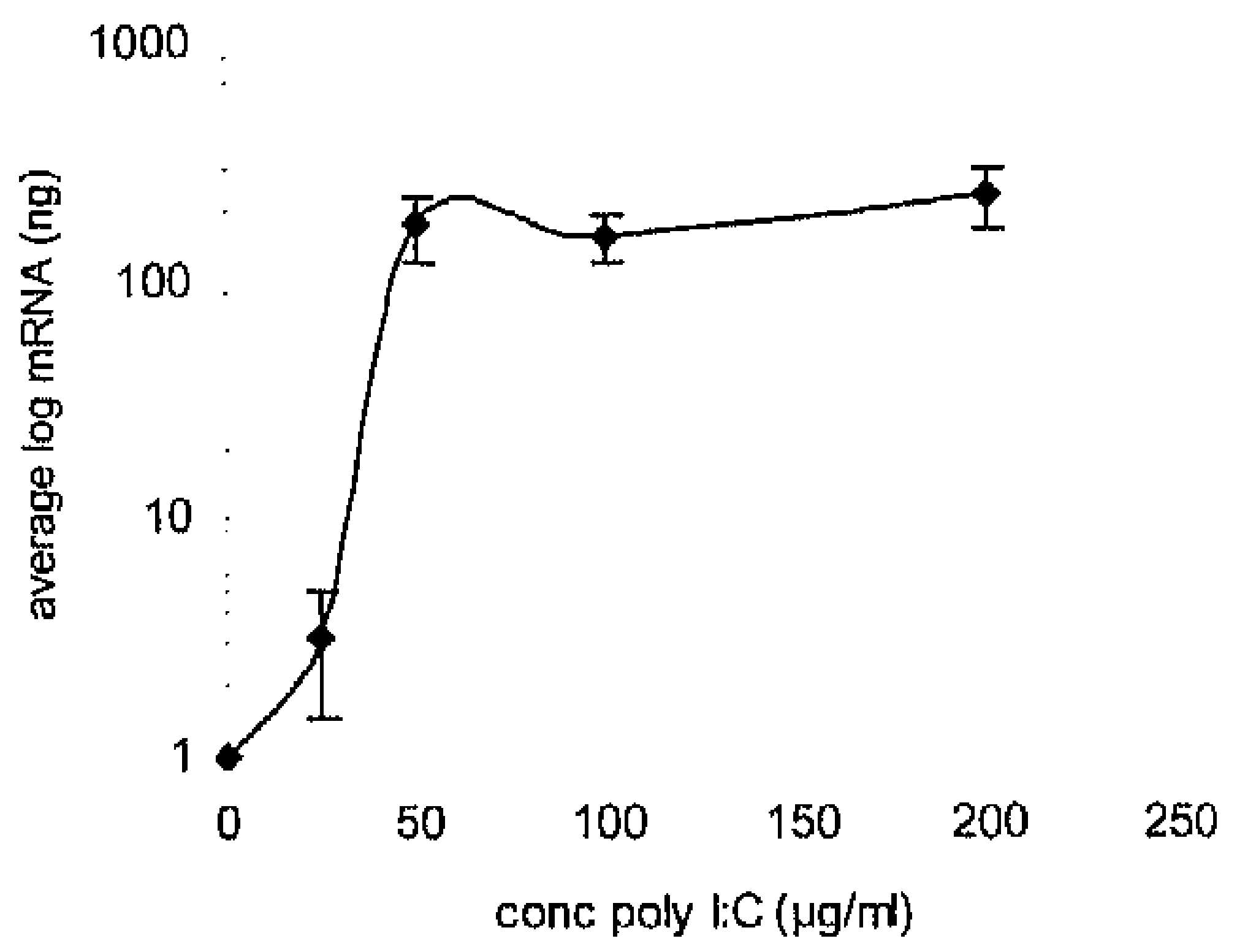

B

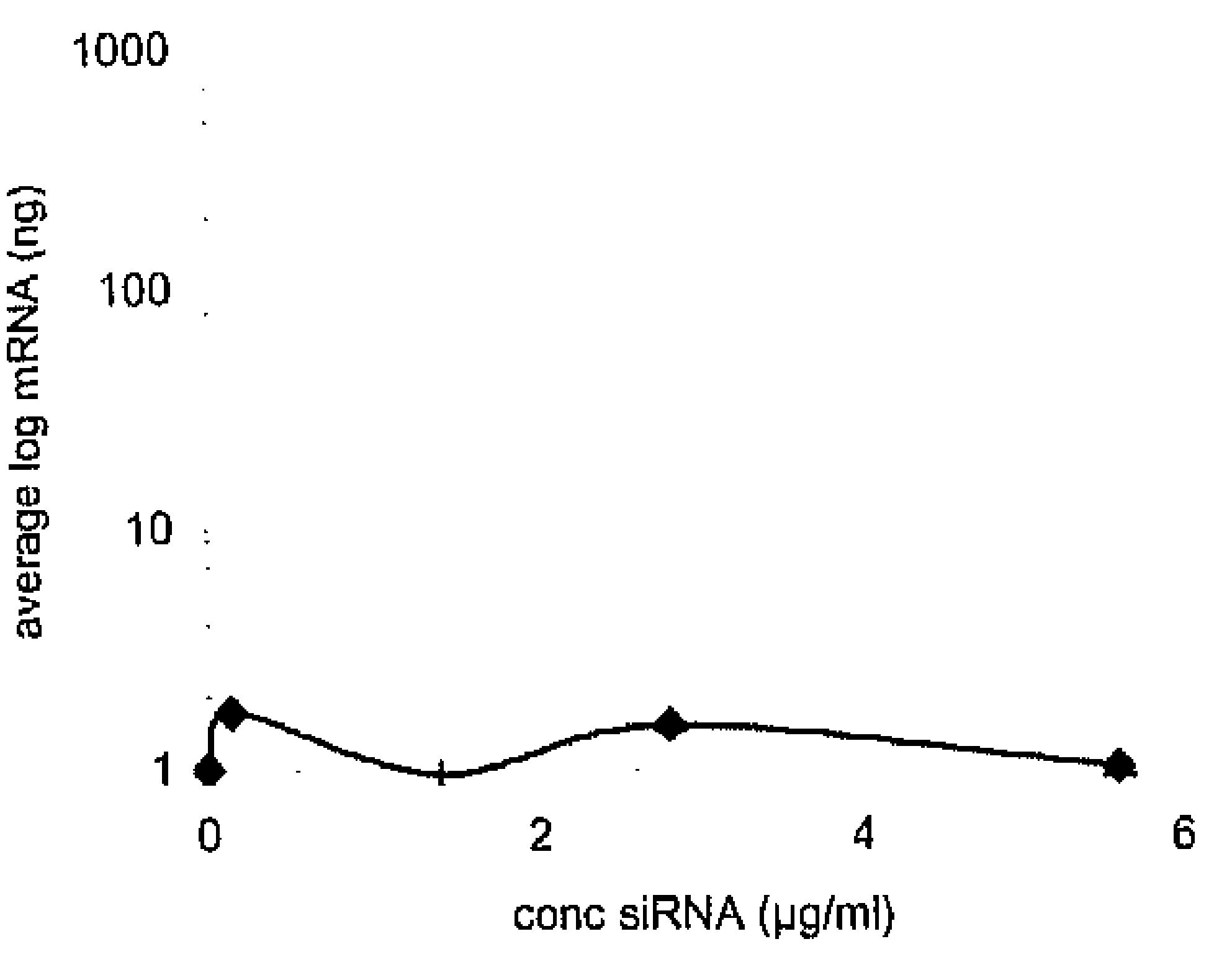


Chapter 5

C

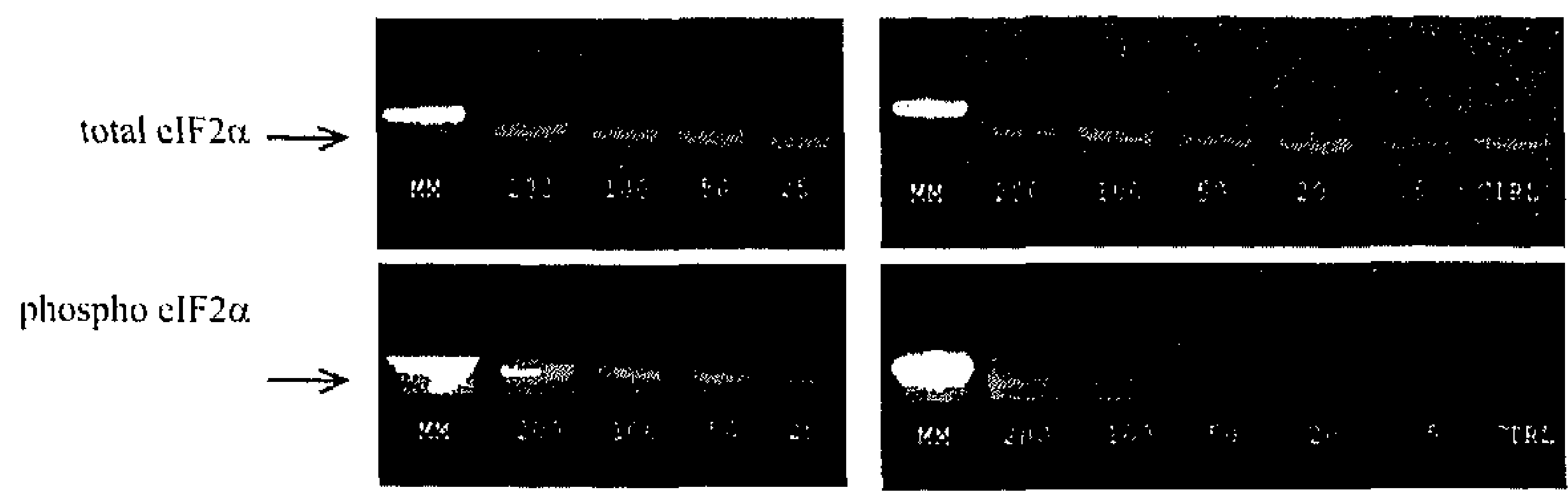

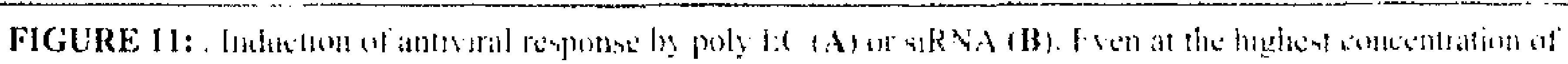

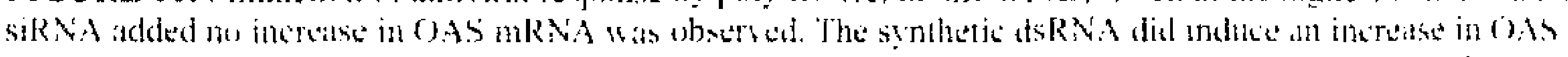

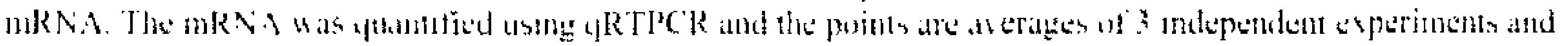

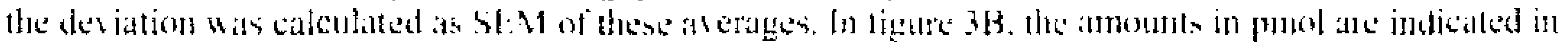

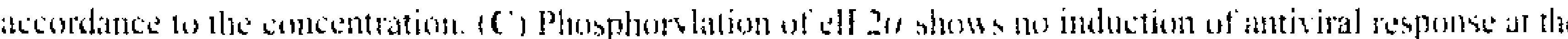

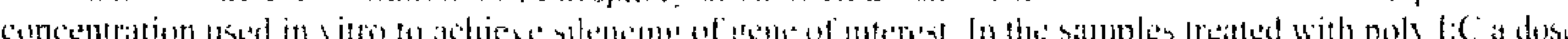

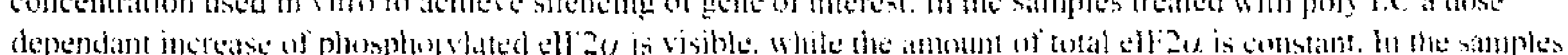

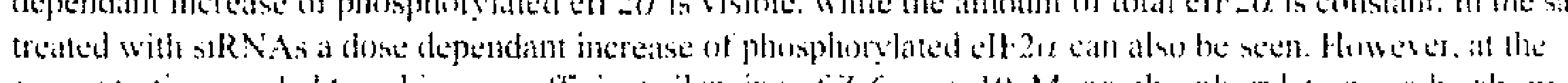

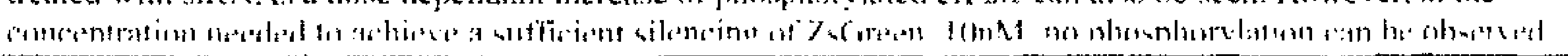

Reduction of protein levels of ZsGreen in stable expressing cells

As the initial emphasis was to knockdown the gene of interest in an in vivo model, we tested the reductive capabilities of the ZsGreen siRNA towards our stably expressing ZsGreen A2780 cells. In order to advance to in vivo applications, a significant reduction of endogenous ZsGreen protein levels should be obtained. Only then will the use of the in house developed whole body imaging system facilitate measuring the siRNA knockdown. With a reported half life of approximately $48 \mathrm{~h}$, it was suggested to assess protein knockdown after at least $72 \mathrm{~h}$. However the greatest reduction was visible after $48 \mathrm{~h}$ (Figure 12).

This reduction was noticeable but definitely not remarkable, approximately $50 \%$. Repeated transfections (once a day, every day) were applied but were not able to further reduce ZsGreen protein levels (data not shown). It was questionable whether this small reduction would be detectable when applied to a subcutaneous tumor and using this type of delivery vehicle.
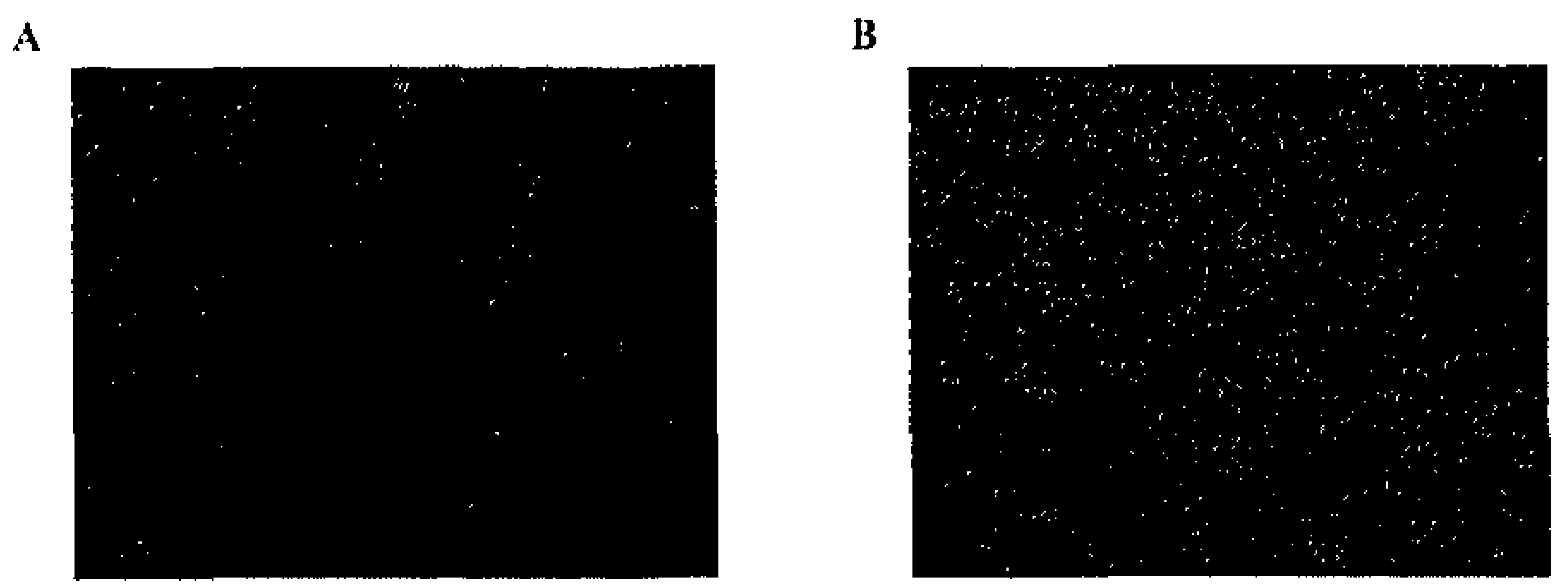

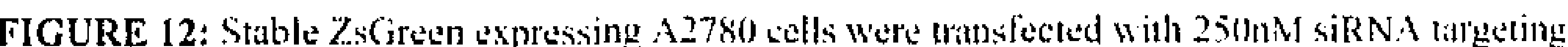

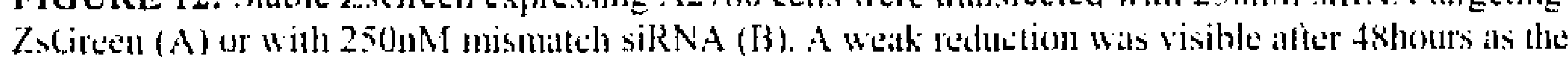

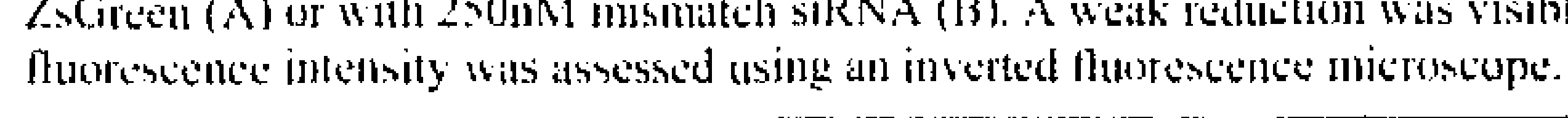




\section{DISCUSSION}

Obtaining an in vitro and in vivo validated fluorescent carcinoma cell line has great potential use in a pharmaceutical and academic environment. Whether performing basic research or evaluating novel compounds, a well established fluorescent cell line can save time, cost and effort. A drawback of the existing fluorescent cell lines is the lack of verification that FP expression will not interfere with the drug efficacy. Another drawback is the low fluorescence intensity, rendering the use in our WBI system difficult and less accurate. Matz, M. and Yanushevich, Y. (Matz MV et al. 1999, Yanushevich YG et al. 2002) have demonstrated that the use of Anthozoa derived fluorescent proteins for in vivo labeling and imaging is useful and extremely promising. Our ultimate goal in the production of fluorescent cells is to use them in a fluorescent tumor model. Anticancer studies can be facilitated immensely due to the use of fluorescent xenografts in combination with WBI. However, the complex situation of a tumor, regarding cellular growth rate and vascularization, entails a greater challenge than experimenting in in vitro conditions. Aside evaluating candidate anti cancer drugs, fluorescent cell lines can aid in the investigation of non viral gene delivery systems. Delivering an siRNA targeting the fluorescent protein enables the investigator to switch the analysis of delivery from a labour intensive and lengthy mechanistic study to a real time, semi-high throughput, non lethal visual evaluation. In this report we transfected 2 different cell lines with either pZsGreen-N1 or pDsRed2-N1. The vectors produce respectively green or red coral reef derived fluorescent proteins that have improved characteristics compared to the more common Aequoria victoria derived GFP and RFP. A longer half life, faster maturation and more intense fluorescence make them ideal for in vivo applications. We have chosen to examine both fluorescent proteins due to their different characteristics that both could be advantageous for our setup. Since DsRed2 has an emission spectrum over a higher wavelength $(583 \mathrm{~nm}$ compared to $506 \mathrm{~nm}$ of ZsGreen 1) its absorbtion by the body is less and the fluorescence can therefore be detected at a much lower intensity. ZsGreen has an emission spectrum in the same range as many body fluids ea. urine, bile, blood and skin. This high background can lead to misinterpretation of images unless the fluorescence of the fluorescent protein is bright enough to clearly overcome the background. On the other hand, DsRed2 still exerts certain cellular toxicity while ZsGreen has not yet been reported to be toxic at all. To be able to chose between two fluorescent models both fluorescent proteins were used to engineer ZsGreen A2780/3LLp and DsRed2 A2780/3LLp cells.

After transfection a typical variation in ZsGreen expression could be seen amongst the cells. Therefore it was decided to sort the top 5\% green fluorescent cells and top 50\% red fluorescent cells using a high speed cell sorter in order to obtain an intense fluorescent subpopulation.

One could argue that the characteristics observed in this fluorescent cell line are due to the selection procedure or due to the relative amount of fluorescent protein present in the particular cell line. Therefore two subpopulations of 3LLp were selected, namely the highest 5\% green fluorescent cells and the top 50\% green fluorescent cells. Because both populations showed identical patterns concerning growth rate and response to a therapeutic agent in vitro, we can firstly conclude that the sorting process does not influence the 
characteristics of the ZsGreen expressing cells. Secondly, we can conclude that the variation in intensity of the fluorescent protein did not alter the obscrved characteristics (data not shown).

As described by Hanazono, Y. (Hanazono Y et al. 1997), the introduction of an Aequoria derived GFP can lead to acute cell death and Wahlfors, J. (Wallffors J et al. 2001) nicely summarizes that discrepancies in the process of introducing a fluorescent protein such as Aequoria derived GFP, is due to the cell type and implies that investigating the cellutar toxicity is necessary. We have therefore made a comparison between the proliferation rate of the DsRed2 or ZsGreen expressing cells and the parental cells. No differences concerning in vitro growth rate were observed for either engineered cell types compared to their respective parental cell type.

To have another confirmation that the transfection did not influence the general characteristics of the cells, we examined the cells capability to respond to a particular therapeutic class. Histone deactylase inhibitors, was singled out for this purpose. Strait, K. and De Schepper, S. (Strait KA et al. 2002, De Schepper S et al. 2003 . Arts J et al. 2003) have previously shown that HDAC inhibitors have an influence on A2780 cells in vitro. The group of Kim, Kyu-Won (Kim MS et al. 2001, Mie LY et al. 2003) have shown on several occasions that various HDAC inhibitors have an effect on hypoxia induced angiogenesis in a Lewis Lung carcinoma model. Our data confirm that all HDAC inhibitors selected were able to inhibit A2780 and 3LLp cells in vitro independent of the introduction of DsRed2 or ZsGreen.

The engineered A2780 and 3LLp cells were sub sequentially injected subcutancously into nude mice to ascertain their tumor formation capability and tumor growth rate. Additionally, an anti-tumor study was also performed on these fluorescent tumors to ensure that these fluorescent mouse models can be used for HDAC inhibitors screening purposes. As all animals exerted tumor take and were able to develop the FP expressing tumor, we are confident they can be used in anti-tumor studies. Independent of the cell line, the DsRed2 expressing tumors grew slower than the ZsGreen expressing. The reason for the difference in tumor growth ratc remains unclear but may be correlated with the complex environment of a tumor model (presence of vascularization, nutrient suppliance, 3D tissue structure, ctc.) or to a slight toxicity of DsRed2.

The oncological more relevant issue of anti tumor efficacy was evaluated secondly using the fluorescent tumor model. We have chosen for MS-275 as the HDAC inhibitor to be used in vivo depending on the work performed by Jaboin, J. and Fournel, M. (Jaboin J et al. 2002 , Fournel $\mathrm{M}$ et al. 2002). They both have shown that MS-275 has an antitumor activity on human tumor xenografts in mice. Using our fluorescent tumor models, we observed that the growth of A2780 xenografts was inhibited by approximately $50 \%$ upon sacrifice of the animals when using MS-275 irrespective to which fluorescent protein was introduced. In the case of the 3LLp tumors, a tumor volume reduction was observed in the ZsGreen (32\%) and DsRed2 (75\%) after approximately 25 days.

Even though the growth rate in vivo is not similar for the DsRed2 expressing and the ZsGreen expressing tumors in either cell line, we believe that the more therapeutic-relevant issue is susceptibility to a therapeutic agent. Using MS-275 we have clearly shown that this requisite is met. A slower growing tumor may also be of special interest for the study of 
compounds requiring a longer time before exhibiting activity. Both tumor models can therefore be used in the future for studies evaluating HDAC inhibitor efficacies.

Finally, to validate that our WBI tumor measuring system is superior to the caliper based system, we performed a comparison with the actual tumor weight as reference. Bakker, A. (Bakker $A$ et al. 2001) described that the use of a whole body imaging enables a more precise tumor volume calculation and a higher user independency compared to caliper based measurements. We have confirmed this using our engineered cells by comparing the measured tumor volume (either with WBI or with caliper) to the most accurate data, the tumor weight. By measuring the precise density of the tumor and applying the physical formula, $\rho=\mathrm{m} / \mathrm{V}$, we were able to convert the measured tumor volume into a calculated tumor weight. The ratio of this calculated tumor weight $\left(\mathrm{TW}_{\mathrm{C}}\right)$ to the tumor weight measured post mortem $\left(\mathrm{TW}_{\mathrm{A}}\right)$ will be calculated for the both fluorescent models derived from both cell lines. For the A2780 xenografts and the $3 \mathrm{LLp}$ tumors all $\mathrm{TW}_{\mathrm{C}} / \mathrm{TW}_{\mathrm{A}}$ ratios were close to the ideal value of 1 , confirming that the WBI resembles the tumor weight extremcly well. The caliper data however resulted in a non consistent overestimation of tumor volume. This implies that the tumor volume obtained with WBI is an accurate measure of the tumor weight while the caliper based system overestimated the tumor volume by up to $50 \%$. As others have shown (Yang $\mathrm{M}$ et al. 2000). WBI is an ideal method to track and quantify tumor growth in a real-time, non invasive and inexpensive manner.

With the introduction of coral reef derived fluorescent proteins we have been able to develop four fluorescent tumor mouse models that represent the parental version in vitro and exert susceptibility to a HDAC inhibitor in vivo. The fluorescent subcutaneous tumors can be detected and enable tumor volume quantification via a whole body imaging system. We have proven that this tumor volume measuring system is more accurate than the commonly used caliper based system. In vitro screening of novel HDAC inhibitors and high throughput screcning of HDAC inhibitors in vivo is feasible with our highly fluorescent tumor model.

The last remaining hurdle for efficienct siRNA gene therapy, in vivo delivery, has never been more under the spotlight than the present day. An increasing amount of labs are putting their energy is evaluating novel delivery systems. An in vivo setup present in our hands, a ZsGreen expressing tumor model coupled with whole body imaging, could be extremely advantageous in screening various gene delivery vehicles. A reduction of fluorescence, easily observed and quantifiable, in non-anaesthetized mice reduces the amount of labour, cost, mice and time. The mice can be followed in real time and the kinetics (uptake in tumor tissue and siRNA release) of the delivery system can be observed. The mice do not have to be sacrificed and therefore repeated dosing can be assessed. Also long term toxicity and effects of delivery vehicle metablolites can be tracked. The tumors also need not be excised from the mice (RNA and protein degredation commences at this point) for quantification of the functional effect of the siRNA. As is often observed, extracting RNA and proteins from tumors leads to low quality material and to low reproducible results. This lengthy process of tumor excision, RNA and protein extraction and subsequent quantification is redundant in our setup.

Reports shows that the ZsGreen siRNA can in vitro reproducibly reduce RNA and protein levels to a great extent. A dose dependent decrease was observed upto $10 \mathrm{nM}$, while increasing the amount of siRNA had not effect on the reductive capacity of the siRNA. The 
lack of immune response at this concentration indicates that the reduction in fluorescence is not due to an aspecific effect but to the sequence specific reduction of ZsGrcen. After 72h, the effect of the siRNA began to disappear and the fluoreseent signal return back to baseline after approximately five days. However, knocking down this endogenous ZsGreen by our highly effective siRNA, remained difficult. In order to visualize a reduction in tumor fluorescence a stronger decrease would be needed. Repeated dosis' and longer incubation periods did not enhance the protein suppression. Alternatively, an inducible silencing construct expressing the siRNA as a hairpin, would be an attractive approach to further validate this setup. Simultaneously other delivery technologies may be able to deliver higher amounts of siRNA could be delivered into the cell obtaining a stronger silencing. As non-viral delivery vchicles remain to draw attention and are heavily investigated, the combination of a highly fluorescent cell line, the accuracy and non lethal image acquisition of whole body imaging and the high efficacy and low toxicity of an siRNA targeting the fluorescent protein gives the investigator all the tools required to evaluate novel gene delivery vehicles in vitro and potentially in vivo.

\section{REFERENCES}

Arts,J., De Schepper,S., \& Van Emelen,K. (2003) Histone deacetylase inhibitors: from chromatin remodeling to experimental cancer therapeutics. Curr. Med. Chem. 10, 2343-2350.

Bakker,A., Floren,W., Voeten,J., Janssens,B., Smets,G., Wouters,W., \& Janicot,M. (2001) Automation of whole body imaging of GFP-expressing tumors in living animals. $G$. I. T. Imaging \& Microscopy 03/2001, 52-54.

Bridge, A. J.; Pebernard, S.; Ducraux, A.; Nicoulaz, A. L.; Iggo, R. (2003) Induction of an Interferon Response by RNAi Vectors in Mammalian Cells. Nat. Genet., 34, 263-264.

Campbell,R.E., Tour,O., Palmer,A.E., Steinbach,P.A., Baird,G.S., Zacharias,D.A., \& Tsien,R.Y. (2002) A monomeric red fluorescent protein. Proc. Natl. Acad. Sci. U. S. A 99, 7877-7882.

Caplen,N. J.; (2004) Gene Therapy Progress and Prospects. Downregulating Gene Expression: the Impact of RNA Interference. Gene Ther., 11, 1241-1248.

De Schepper,S., Bruwiere,H., Verhulst,T., Steller,U., Andries,L., Wouters,W., Janicot,M., Arts,J., \& Van Heusden,J. (2003) Inhibition of histone deacetylases by chlamydocin induces apoptosis and proteasome-mediated degradation of survivin. J. Pharmacol. Exp. Ther. 304, 881-888.

Elbashir,SM; Lendeckel, W.; Tuschl, T; (2001) RNA interference is mediated by 21 - and 22-nucleotide RNAs Genes Dev., Jan 15;15(2):188-200

Fournel,M., Trachy-Bourget,M.C., Yan,P.T., Kalita,A., Bonfils,C., Beaulicu,C., Frechette,S., Leit,S., Abou-Khalil,E., Woo,S.H., Delorme,D., MacLeod,A.R., Besterman,J.M., \& Li,Z. (2002) Sulfonamide anilides, a novel class of histone deacetylase inhibitors, are antiproliferative against human tumors.

Cancer Res. 62, 4325-4330. 
Hanazono,Y., Yu,J.M., Dunbar,C.E., \& Emmons,R.V. (1997) Green fluorescent protein retroviral vectors: low titer and high recombination frequency suggest a selective disadvantage. Hum. Gene Ther. 8, 1313-1319.

Jaboin,J., Wild,J., Hamidi,H., Khanna,C., Kim,C.J., Robey,R., Bates,S.E., \& Thiele,C.J. (2002) MS-27-275, an inhibitor of histone deacetylase, has marked in vitro and in vivo antitumor activity against pediatric solid tumors. Cancer Res. 62, 6108-6115.

Kay,M.A. , McCaffrey, A. P. : (2002) A Story of Mice and Men. Gene Ther., 9, 1563.

Kim,M.S., Kwon,H.J., Lec,Y.M., Baek,J.H., Jang,J.E., Lee,S.W., Moon,E.J., Kim,H.S., Lee,S.K., Chung,H.Y., Kim,C.W., \& Kim,K.W. (2001) Histone deacetylases induce angiogenesis by negative regulation of tumor suppressor genes. Nat Med. 7, 437-443.

Matz,M.V., Fradkov,A.F., Labas,Y.A., Savitsky,A.P., Zaraisky,A.G., Markclov,M.L., \& Lukyanov,S.A. (1999) Fluorescent proteins from nonbioluminescent Anthozoa species. Nat. Biotechnol. 17, 969-973.

McCaffrey, A. P.; Meuse, L.; Pham, T. T.; Conklin, D. S.; Hannon, G. J.; Kay, M. A. (2002) RNA Interference in Adult Micc. Nature, 418, 38-39.

Mie,L.Y., Kim,S.H., Kim,H.S., Jin,S.M., Nakajima,H., Jeong,K.H., \& Kim,K.W. (2003) Inhibition of hypoxia-induced angiogenesis by FK228, a specific histone deacetylase inhibitor, via suppression of HIF-lalpha activity. Biochem. Biophys. Res. Commun. 300, 241-246.

Miyawaki,A. (2002) Green fluorescent protein-like proteins in reef Anthozoa animals. Cell Struct. Funct. 27, 343-347.

Sledz,C.A.; Holko, M.; de Veer, M. J.; Silverman, R. H.; Williams, B. R. (2003) Activation of the Interferon System by Short-Interfering RNAs. Nat. Cell Biol., 5, 834-839.

Strait,K.A., Dabbas,B., Hammond,E.H., Warnick,C.T., Iistrup,S.J., \& Ford,C.D. (2002) Cell cycle blockade and differentiation of ovarian cancer cells by the histone deacetylase inhibitor trichostatin $A$ are associated with changes in $\mathrm{p} 21, \mathrm{Rb}$, and Id proteins. Mol. Cancer Ther. 1, 1181-1190.

Vrzheshch,P.V., Akovbian,N.A., Varfolomeyev,S.D., \& Verkhusha,V.V. (2000) Denaturation and partial renaturation of a tightly tetramerized DsRed protein under mildly acidic conditions. FEBS Lett. 487, 203-208.

Wahlfors,J., Loimas,S., Pasanen,T., \& Hakkarainen,T. (2001) Green fluorescent protein (GFP) fusion constructs in gene therapy research. Histochem. Cell Biol. 115, 59-65.

Yang,M., Baranov,E., Jiang,P., Sun,F.X., Li,X.M., Li,L., Hasegawa,S., Bouvet,M., Al Tuwaijri,M., Chishima,T., Shimada,H., Moossa,A.R., Penman,S., \& Hoffman,R.M. (2000) Whole-body optical imaging of green fluorescent protein-expressing tumors and metastases. Proc. Natl. Acad. Sci. U. S. A 97, 1206-1211.

Yanushevich,Y.G., Staroverov,D.B., Savitsky,A.P., Fradkov,A.F., Gurskaya,N.G., Bulina,M.E., Lukyanov,K.A., \& Lukyanov,S.A. (2002) A strategy for the gencration of non-aggregating mutants of Anthozoa fluorescent proteins. FEBS Lett. 511, 11-14. 


\section{Chapter 6}

\section{AUTOPHOSPHORYLATION OF PLK4 CONTROLS ITS STABILITY AND OCCURS AT THE CENTROSOME IN A CELL CYCLE-DEPENDENT MANNER}

Frederik Tack, James E. Sillibourne, Nele Vloemans, An Boeckx, Sathiesan Thambirajah, Frans C. S. Ramaekers, Michel Bornens and Thierry Grand-Perret

Submitted to Journal of Cell Biology,

patent filed January $10^{\text {th }} 2008$ and named: Auto-phosphorylation of PLK4 controls its stability and occurs at the centrosome in a cell cycle dependent manner 
Chapter 6

\section{ABSTRACT}

The kinase PLK4 has been reported to play a crucial role in ccntriole duplication but the mechanism involved and the regulation remains unclear. $\mathrm{Wc}$ show that PLK4 autophosphorylates at Ser305 in the PEST-1 domain flanking the kinase domain. Mutants either kinase dead or lacking the PEST-1 domain have increased stability whereas mimicking Scr305 phosphorylation by Asp substitulion dramatically destabilizes PLK4. Assuming that Ser 305 phosphorylation reflects active PLK4, we compared the localization of total PLK4 and phosphorylated PLK4 in centrioles using phospho-Ser305 specific antibodies. In G1 phase, PLK4 is present on both mother and daughter centrioles but is not phosphorylated. At S phase PLK4 autophosphorylates at the procentrioles but major signal comes from the mother centriole. At G2, PLK4 phosphorylation remains predominant in the mother centriole but also spread to the daughter centriole. Implications for centriole physiology and PLK4 stability are discussed.

\section{INTRODUCTION}

PLK4 was identified in mouse as a serine/threonine kinase related to the Drosophila kinase Polo and involved in cell proliferation (Fode et al., 1994). Murine PLK4 has been reported to play a role in mitotic and meiotic division. Additionally, an antisense fragment to a portion of murine PLK4, referred to as SAK-a, decreased the efficiency of colony formation implying a role in suppression of cell proliferation (Fode et al., 1994). This was confirmed by suppression of hematopoietic (Yamashita et al., 2001) and CHO cell growth upon SAK-a expression while the cell remained able to cycle (Fode et al., 1994). This suppression was later shown to be due to an increase of abnormal number of multinucleated cells (Fode et al., 1996). SAK-a has been reported to be regulated at two levels: cell cycle dependent mRNA expression and protein degradation. Firstly, in NIH-3T3 cells negligible amounts of SAK-a mRNA were detected in G0 and early G1 phases while in late G1/early S phase the amount increased and remained high throughout mitosis. Therefore, PLK4 was initially suggested to play a role in $\mathrm{M}$ phase progression (Fode el al., 1996; Hudson et al., 2001). PLK4 gene expression in mammalian cells is also regulated at the post-transcriptional, protein degradation level (Winkles and Alberts, 2005). The short half life (2-3hours) of murine PLK4 has been reported to be due to ubiquitination and it is thought that the turn-over of human PLK4 is similar (Fode et al., 1996). The presence of three clusters of PEST sequences, which target proteins for rapid degradation by the ubiquitin-proteosome pathway (Rechsteiner and Rogers, 1996), corroborates this finding. Deletion of these sequences has also been shown to increase PLK4 levels upon transfection. The first PEST region appears to be more important for the regulation of protein stability than the carboxy-terminal PEST clusters (Yamashita et al, 2001). A number of studies have reported that PEST mediated proteolysis is dependent on the phosphorylation of target proteins. For instance, Weil et al. observed that, for efficient PEST dependent protein degradation, I $\mathrm{KB} \beta$ requires constitutive 
phosphorylation within its PEST sequences and the stimuli-induced phosphorylation outside the PEST elements (Weil et al., 1997). The mechanism behind the PEST mediated proteolysis of PLK4 is unknown but it has been suggested that a cytoplasmic tyrosine kinase, TEC, phosphorylates PLK4 promoting its stabilization. However, although tyrosine phosphorylation occurred serine/threonine phosphorylation appeared to be more prominent casting doubt over the role of TEC in promoting PLK4 stabilization (Yamashita et al., 2001).

The centrosome is the major microtubule organizing center within the cell and consists of two centrioles linked by a matrix of proteins (Bomens, 2002; Kuriyama and Borisy, 1981: Paintrand et al., 1992). In addition to their role as the microtubule organizing center in interphase and mitotic cells, centrosomes have also been suggested to play a role in regulation of cell cycle progression itself (Hinchcliffe et al., 2001: Mikule et al., 2007; Piel et al., 2001). During each cell cycle the centrosome duplicates and a procentriole spawns from each of the existing centrioles. These procentrioles remain engaged with the existing centrioles, preventing further duplication, until mitosis. At anaphase the centrioles disengage, allowing another round of centriole duplication to occur in the following cell cycle (Tsou and Stearns, 2006). Centrosome duplication is nomally strictly coordinated with DNA replication, however in certain cell lines multiple rounds of centrosome duplication occur when DNA replication is inhibited with hydroxyurea, cytochalasin D or aphidicolin (Balczon et al., 1995; Kuriyama and Borisy, 1981; Raff and Glover, 1988). Some key factors controlling the centrosome cycle are known for example CDK2/cyclinE, others are still under investigation (Meraldi et al., 1999). Structural centrosome abnormalities such as abnormal centriole orientation, increased pericentriolar material and excess number of centrioles have been implicated to cause a loss of cell and tissue architecture often seen in anaplasia (D'Assoro et al., 2002) and have been linked to the development of cancer (Pihan et al., 1998; Pihan et al., 2001; Pihan et al., 2003).

PLK4 has been shown to localize to the centrosome via its crypto Polobox domain (CPB) (Habedanck et al., 2005). Additionally, PLK4 has been shown to be required for centriole duplication in human cells and its overexpression results in centriole over duplication (Habedanck et al., 2005; Kleylein-Sohn et al., 2007). On the other hand, siRNA mediated knockdown of PLK4 induces a stepwise reduction in centriole number, causing aberrant spindle morphology (Habedanck et al., 2005; Ko et al., 2005) and the induction of apoptosis in HeLa cells ( $\mathrm{Li}$ et al., 2005). PLK4 has also been identified as a key regulator of centriole duplication in Drosophila (Bettencourt-Dias et al., 2005). When overexpressed in unfertilized eggs of Drosophila, PLK4 induced the de novo formation of centrioles, demonstrating that this kinase is able to induce centriole biogenesis even in the absence of pre-existing centrioles (Peel et al., 2007; Rodrigues-Martins et al., 2007). Habedanck et al. demonstrated that overexpression of PLK4 in human cells caused electron-dense material to be recruited to the parental centriole wall suggesting PLK4 plays a role in procentriole formation (Habedanck ct al., 2005). Additionally, overexpression of PLK4 in human cells triggers the formation of multiple procentrioles in a flower-like shape around a pre-existing centriole during S phase (Kleylcin-Sohn et al., 2007). It has been hypothesized that procentriole formation depends on the phosphorylation of one or more proteins at the procentriole assembly site. This is more likely to occur in the close proximity to a pre-existing centriole triggering the characteristic multiple procentrioles surrounding a single centriole. Interestingly, a similar phenotype was observed when using a proteosome inhibitor suggesting that these proteins are tightly regulated by proteosome degradation (Duensing et 
al., 2007). The activity of PLK4 is thought to be balanced by still unknown counteracting phosphatases to regulate protein stability (Nigg EA. 2007). Although multiple gene products have been identificd to be crucial for PLK4 controlled centriole biogenesis, a physiological relevant substrate of PLK4 is yet to be described (Kleylein-Sohn et al., 2007).

In this paper we demonstrate that PLK4 itself is its own substrate and identily multiple autophosphorylation sites within the protein. We show that autophosphorylation of $\$ 305$ can be used as a marker of PLK4 activity. Additionally, PLK4 appears to become active at the onset of centriole duplication and this activity occurred predominantly to the mother centriole. Finally, we propose a role for S305 phosphorylation to mediate protein degradation by activation of the PEST1 region.

\section{MATERIAL \& METHODS}

Recombinant DNA Technology, Production of PLK4 Proteins and Site directed mutagenesis

All SUMO fusion plasmids were created by polymerase chain reaction using the full length PLK4 as a template and cloned into a modified version of pSUMO (Invitrogen $\left.{ }^{(}\right)$. Fusion proteins were expressed in BL21 (DE3) cells (Invitrogen ${ }^{\mathbb{G}}$ ) and purified with HIS-Select HF Nickel affinity gel (Sigma ${ }^{\circ}$ ). To create the deltaPest fragment, deleting residues 272 to 311, a myc-tagged PLK4 was amplified by PCR. Site directed mutagenesis was performed using a Quickchange XL mutagenesis kit (Strategene ${ }^{6}$ ) according to manufacturers protocol. The PLK4-egfp wild type and kinase dead (K41M) plasmids were used as templates to produce S305 to alanine (S305A) and S305 to aspartic acid (S305D) mutants. Protein expression, purification condition and all primers sequences can be found in the Supplementary Information.

\section{Cells, Transfections and Protein Detection}

HCT116 colorectal carcinoma cells were cultured in McCoys 5A media (Gibco ${ }^{(0)}$ ) and Hams F12 media (Gibco ${ }^{\circ}$ ) supplemented with $1 \%$ L-Glutamine (Gibco ${ }^{\circ}$ ), $1 \%$ gentamycin and $10 \%$ fetal calf serum $\left(\mathrm{Gibco}^{\circ}\right)$ in a humidified incubator $\left(37^{\circ} \mathrm{C}, 5 \% \mathrm{CO}_{2}\right)$. HeLa centrin-1 GFP cells were cultered in DMEM supplemented with $10 \%$ FCS, $1 \%$ penicillin/streptomycin and $1 \% \mathrm{~L}$-glutamine.

PLK4 plasmids and/or siRNAs were transfected with Lipofectamine2000 (Invitrogen ${ }^{(0)}$ ). PLK4 specific (5'-AAGGACCTTATTCACCAGTTA-3') and Mismatch (Ambion ${ }^{(2)}$, 4611) siRNA were used at 50nM. For myc-tagged and EPFG tagged PLK4 experiments, cells were lysed in triple detergent buffer. For experiments including the detection of phosphorylated S305, cells were lysed in boiling buffer. Lysis buffer components can be found in the Supplementary Information. Proteins were transferred to nitrocellulose membrane after SDS-PAGE and detected with appropriate antibodies. 


\section{Antibodies}

Primary antibodies were obtained from the following sources: humanized anti-ninein single chain antibody (Bornens laboratory), anti-gamma tubulin monoclonal antibody (Sigma ${ }^{\text {) }}$, anti-C-Napl (BD Biosciences ${ }^{\circ}$ ), anti-PLK4 antibody (Abcam ${ }^{\circ}$ ), anti-GAPDH (Abcam ${ }^{3}$ ). Anti-PLK4 antibodies, detecting the crypto Polobox (CPB) or phosphorylated S305 (pS305), were produced and affinity purified by Agro-Bio. HRP-secondary antibodies were obtained from Santa Cruz ${ }^{\complement}$. Alexa488 and Alexa680 secondary antibodies were obtained from Molecular Probes ${ }^{2}$. Cy3, Cy5, AMCA secondary antibodies were obtained from Jackson Laboratories ${ }^{\circledR}$.

Kinase Reactions, SDS-PAGE, Protein Determination and Radioactive Analysis

Kinase reactions were incubated for thour at $22^{\circ} \mathrm{C}$ using the following buffer: $50 \mathrm{mM}$ Hepes, $50 \mathrm{mM} \mathrm{NaCl}, 10 \mathrm{mM} \mathrm{MgCl}, 1 \mathrm{mM} \mathrm{NaF}, 5 \mu \mathrm{M}$ Xylene cyanole, $1 \mu \mathrm{M}$ ATP, $1 \mathrm{mM}$ DTT, $0.3 \mu \mathrm{Ci}{ }^{33} \mathrm{P}-\gamma$-ATP and PLK4 recombinant protein. The samples were separated on a $4-12 \%$ Bis Tris NuPage gel (Invitrogen ${ }^{0}$ ), stained with SyproRuby (Molecular Probes ${ }^{\mathscr{Q}}$ ) and imaged using a LumiImager (Roche ${ }^{(0)}$ ). Gels werc destained, dried on Whatman ${ }^{(0)} 3 \mathrm{MM}$ paper, exposed onto a phosphor-imager screen and imaged using the Typhoon ${ }^{(8)}$. ImageQuant ${ }^{\circledR}$ software was used to quantify the intensity of the bands.

Peptide Synthesis and Phosphorylation Analysis

A proprietary peptide library containing putative phosphorylation sites in PLK4 was prepared by Jerini ${ }^{\circ}$ using their proprietary microscale technology. The peptides, corresponding locations in PLK4 and mutations of each peptide scanned are displayed in the Supplementary Information-Table I. The peptides were subjected to a kinase reaction using purified SUMO-PLK $4_{1-285}$ and processed as described above.

\section{Immunofluorescence imaging}

HeLa centrin-1 GFP cells growing on fibronectin/collagen-coated coverslips were washed once with PBS and fixed with methanol at $-20^{\circ} \mathrm{C}$ for 20 minutes. Coverslips were sequentially washed with PBS and antibody blocking buffer: PBS containing $1 \%$ bovine serum albumin fraction $\mathrm{V}\left(\right.$ Sigma $^{\odot}$ ) and $0.5 \%$ Triton $\mathrm{X}-100\left(\right.$ Sigma $\left.^{\odot}\right)$ prior to adding primary antibodies diluted in antibody blocking buffer. Cells were stained with primary antibodies for 1 hour at ambient temperature and washed extensively with antibody blocking buffer before incubating with secondary antibodies, diluted in the same buffer, for 30 minutes at ambient temperature. The coverslips were washed with antibody blocking buffer, DNA stained with a $0.2 \mu \mathrm{g} / \mathrm{ml}$ solution of 4',6-diamidino-2-phenylindole dihydrochloride (DAPI) (Sigma ${ }^{\circ}$ ), and sequentially washed with antibody dilution buffer and distilled water. After allowing to air-dry, the coverslips were mounted onto glass slides using Mowiol mounting medium. Images were captured on a Leica DMRA2 microscope, fitted with a CoolSNAP camera (Princeton Instruments), using a 100X 1.4 N.A. objective lens $\left(\right.$ Leica $\left.^{(}\right)$) and Metamorph software (Universal Imaging ${ }^{\mathscr{Q}}$ ). Processing of images was carried out using Metamorph software. 


\section{RESULTS}

Detection of an autophosphorylation in the amino terminal region of PLK4

A

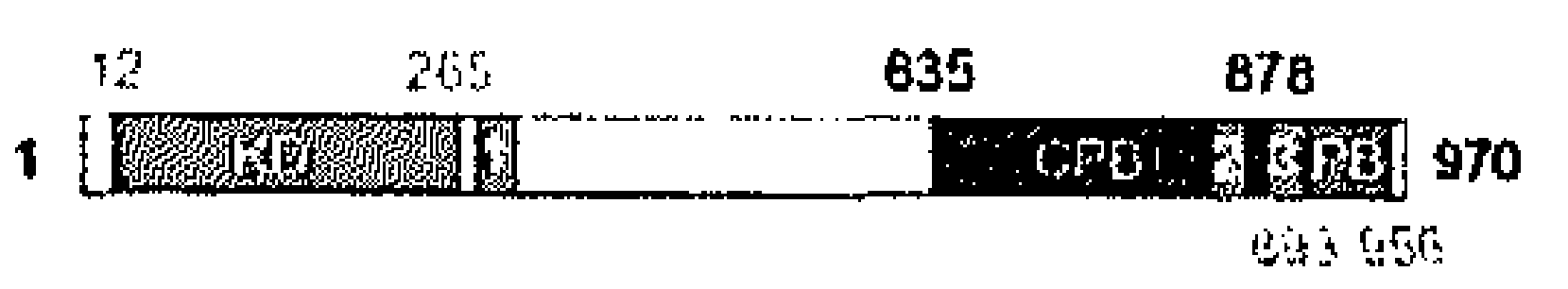

$\mathbf{B}$

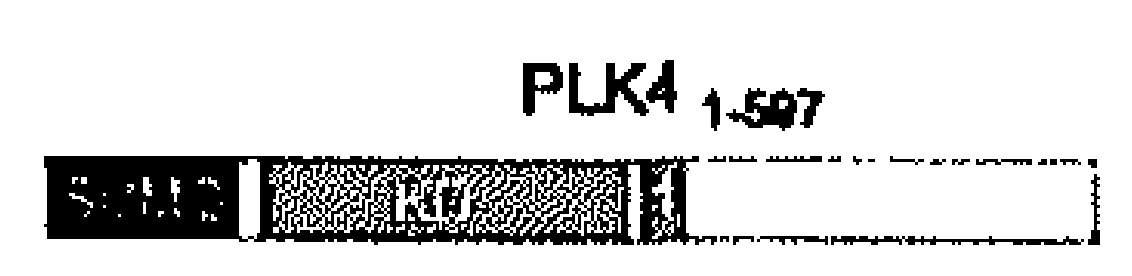

C

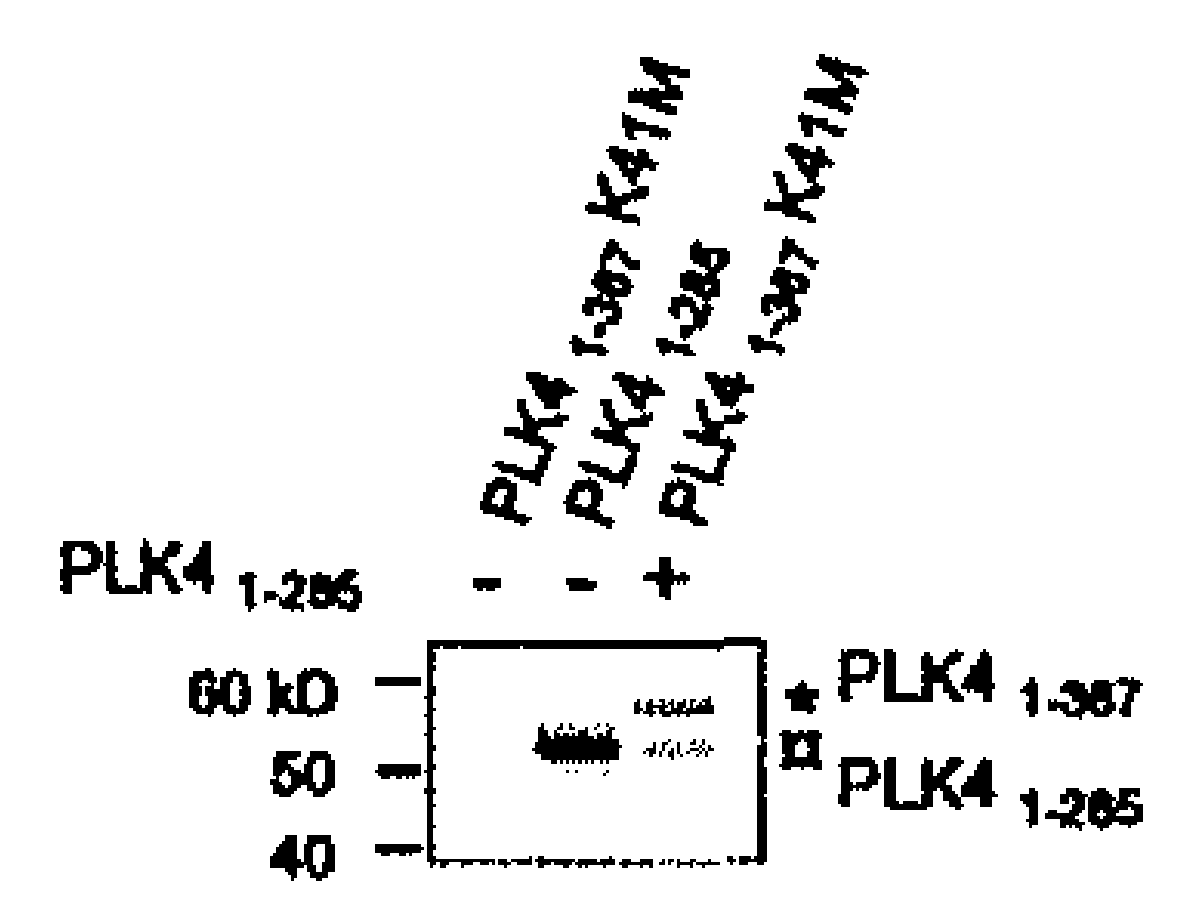

PLK4 contains an amino terminal kinase domain, a carboxy terminal crypto Polobox and Polobox domain and three PEST regions (Figure 1A). When purified full length recombinant PLK4 from E. coli was subjected to an in vitro kinase reaction, we observed autophosphorylation (Figure 1A). Multiple bands were observed indicating that the full length protein had been heavily degraded, but also raised the possibility that phosphorylation occurred at several sites within the protein. To investigate this further we generated a series of PLK4 fragments to determine where autophosphorylation primarily occurred.

A PLK4 truncation, corresponding to residues 1 to 597, lacking the $\mathrm{CPB}$ and the Polobox domains was generated in fusion with SUMO (Figure 1B). Deletion of the carboxy terminal region is believed to render the protein more stable, most likely due to the fact that only one of the three PEST sequences is present in the amino terminal end (Yamashita et al., 2001). This SUMO-PLK4 $4_{1-597}$ fusion protein was subjected to an in vitro kinase reaction and was found to be autophosphorylated as well. Coomassie staining showed that some protein degradation still occurred, with a large proportion of the degradation products being shorter $\mathrm{N}$-terminal fragments of PLK4. This was confirmed by an identical kinase

FIGURE 1: Identification of PIK4 autophosphor lation sifes within the N-terminus of the kinase. (A) A dianran show ing the position of the kinase domain (KD), crypto Pokolox (C PF). Polobous (PB) and PEST seguences (numbered blue boxes) within PLK4. Presented in the hox as an alturildogram showing the results of an in valto kinase assily using full kength PLK4. (B) The results of in sitro kinase assays using truncated PLK $1-597$ fused to SUMO. Samples of the purified protein were sepanated on gets

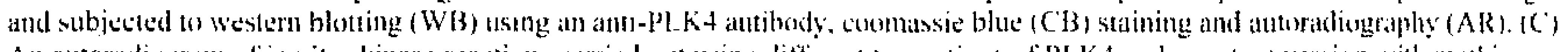

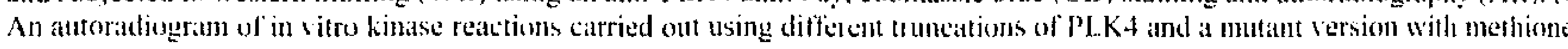
substituted for lysine at postion 11 ( $\mathrm{K}+\mathrm{l} \mathrm{M} \mathrm{M})$ wo render the kinise inactive.

reaction being western blotted using an antibody targeting the amino terminal region of PLK4.

The phosphorylation detected in the truncated PLK $4_{1-597}$ protein could either be due to inter- or intra autophosphorylation. To investigate this, we generated a kinase dead version of PLK $4_{1-367} \mathrm{~K} 41 \mathrm{M}$, where lysine41 within the ATP binding pocket, had been mutated to methionine. An in vitro kinase assay demonstrated that the kinase was inactive (Figure 1C). 
We then used PLK4 $4_{1-367} \mathrm{~K} 41 \mathrm{M}$ as a substrate in an in vitro kinase reaction with active $\mathrm{PLK}_{1-285}$, corresponding to the kinase domain of the enzyme. Interestingly, phosphorylation of PLK $4_{1-367} \mathrm{~K} 41 \mathrm{M}$ was observed, along side that of the kinase domain, indicating that inter molecular auto-phosphorylation had occurred. In brief, these results showed that autophosphorylation sites are present the amino terminus of PLK4. We then decided to investigate if other autophosphorylation sites existed within the protein.

Inter-molecular phosphorylation of PLK4 detectable in various regions of the protein

A

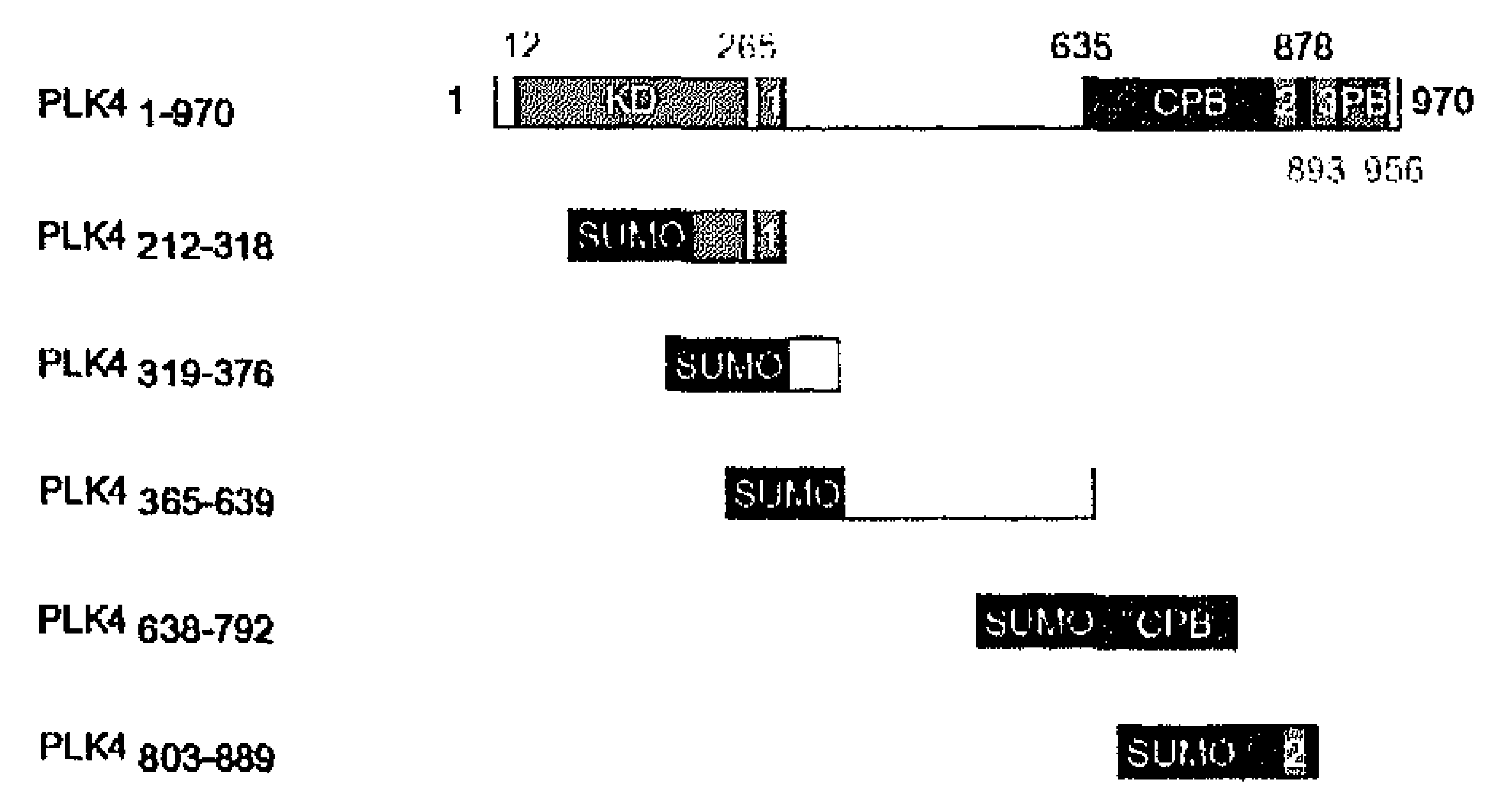

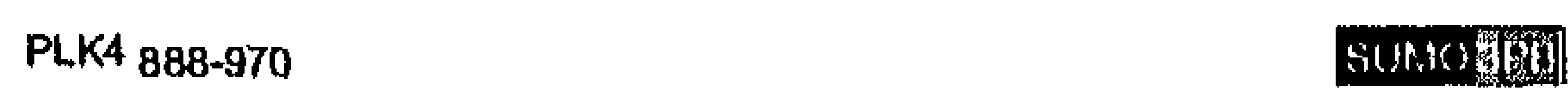

PLK4 1-367 KA1M SUP.10 I :

B

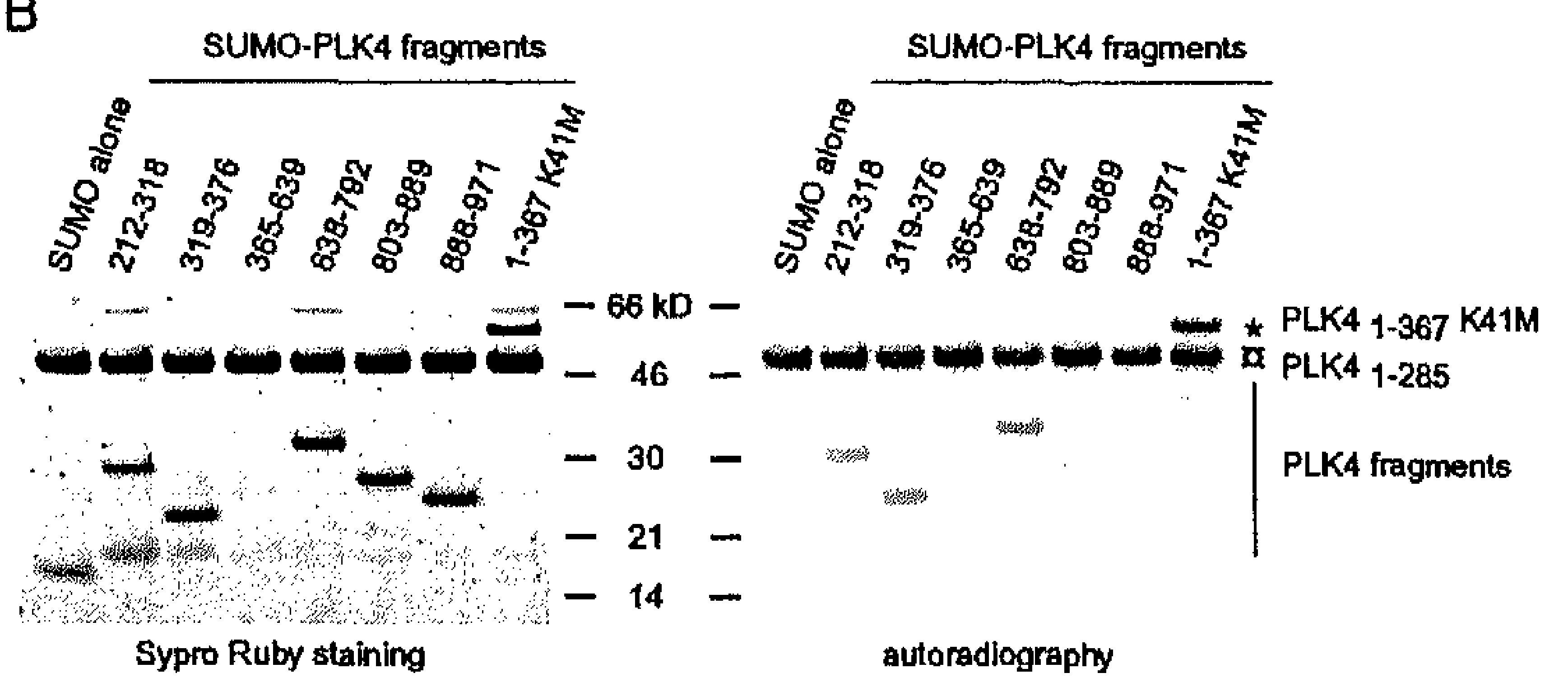

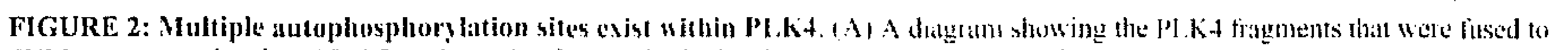

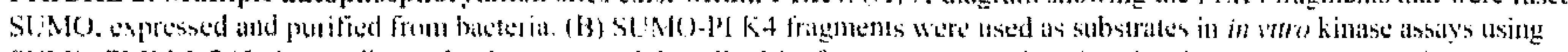

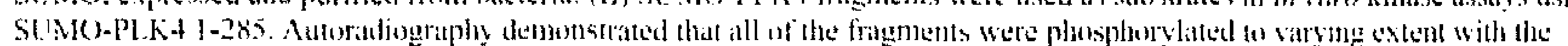

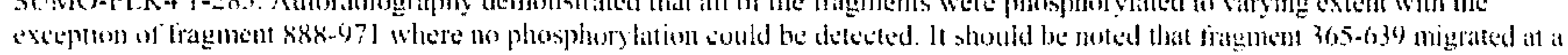

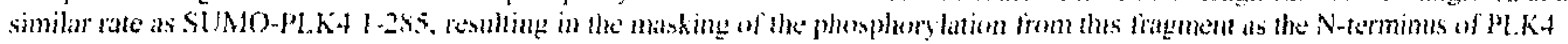

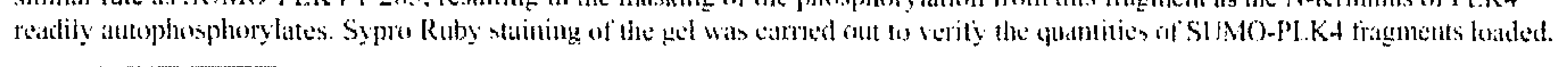


To determine if autophosphorylation occurred elsewhere in the protein, a series of PLK4 fragments fused with SUMO were created (Figure 2A). All of the fragments lacked kinase activity and thus could be used as substrates for phosphorylation by PLK4 $4_{1-285}$. A significant phosphorylation was observed in all fragments apart from PLK4 $4_{\times 03-8 \times 9}$ and PLK4 $488-970$ where weak and no phosphorylation was observed, respectively. PLK $4_{365-639}$ had a similar migration distance as PLK $4_{1-285}$, therefore masking the phosphorylation signal. SyproRuby staining confirmed that similar molarities of substrate protein were used in the kinase reaction (Figure 2B). Thesc results indicated that multiple sites at various regions of the protein can be phosphorylated by PLK4.

\section{S305 is a major autophosphorylation site in PLK4}

Commercially available peptide libraries were used to scrcen for peptidic substrates of PLK4 1-285. From these results a consensus PLK4 phosphorylation sequence was derived (data not shown), which agreed strongly with a recently described sequence (Leung et al., 2007). It was further refined using bioinformatics modeling tools and confirmed on proprietary peptide libraries (Bonnet et al. - manuscript in preparation). This algorithm was used to recognize sequences on PLK4 that corresponded to the consensus sequence and identify potential phosphorylation sites (Figure 3A). The corresponding 13-mer peptides were synthesized and used to evaluate which residues were phosphorylated the strongest. In the case where multiple serines or threonines were present on the same peptide, mutant peptides with alanine substitutions were also examined in order to unambiguously determine the phosphorylation site (see Supplementary Table I for a complete list of scanned peptides). Four peptides contained serine/threonine residues that were phosphorylated by PLK4 $4_{1285}$ (Figure 3B). The strongest phosphorylation was observed on peptide 20 containing $\$ 305$. This peptide contains another serine at residue 303 , however, when this was mutated to alanine the phosphorylation of the peptide still occurred (peptide 22). Concurringly, when the serine at residue 305 was mutated to alanine, the phosphorylation was abrogated (peptide 21). This confirmed that the phosphorylation on S305 was the key phosphorylation site in this peptide. Another serine, residue 342, which fitted well to the consensus sequence, was found to be poorly phosphorylated by PLK4 1-285. The second strongest autophosphorylation was observed on peptide 7 , which contains threonine 138 and serine 140. It was, however, impossible to attribute the phosphorylation to either of these residues definitively as mutations to alanine did not result in the disappearance of phosphorylation. This indicates that the two sites can independently from one another produce a strong phosphorylation signal. Weak phosphorylation of peptide 67 was also observed, which contained serine residues 956 and 957 . Neither of the two serines is more important than the other as phosphorylation of serine to alanine mutants was still observed. Residues 956 and 957 are located at the end of the PoloBox and may perhaps play a role in protein binding (Fode et al., 1994; Leung et al., 2002; Lowery et al., 2005). As S305 appeared the major phosphorylation site on PLK4, a phospho-specific antibody was raised against this epitope to enable a more detailed investigation of this phosphorylation site. To detect $\$ 305$ phosphorylation in vitro, affinity purified rabbit antibodies against the phosphorylated S305 site were used to probe PLK4 $4_{-367}, \operatorname{PLK} 4_{1-367} \mathrm{~K} 41 \mathrm{M}$ and lambda 
phosphatase treated PLK $4_{1-367}$ after kinase reactions. Autoradiography demonstrated that the PLK4 ${ }_{1.367}$ was autophosphorylated (Figure 4A-left panel) whereas no signal was observed in PLK4 $4_{1-367} \mathrm{~K} 41 \mathrm{M}$ and lambda phosphatase treated PLK $4_{1-367}$. The amount of protein for each sample was comparable as determined by SyproRuby staining (Figure 4Amiddle panel). When subjected to western blotling and probed with the phospho-specific S305 antibody (pS305), the phosphorylation of the PLK $4_{1-367}$ could clearly be detected (Figure 4A-right panel). No signal was observed from PLK $4_{1-367} \mathrm{~K} 41 \mathrm{M}$ or when the PLK4 $4_{\text {- }}$ 367 was treated with lambda phosphatase. We further asked if the autophosphorylation of PLK4 was detectable in vivo as well.

A

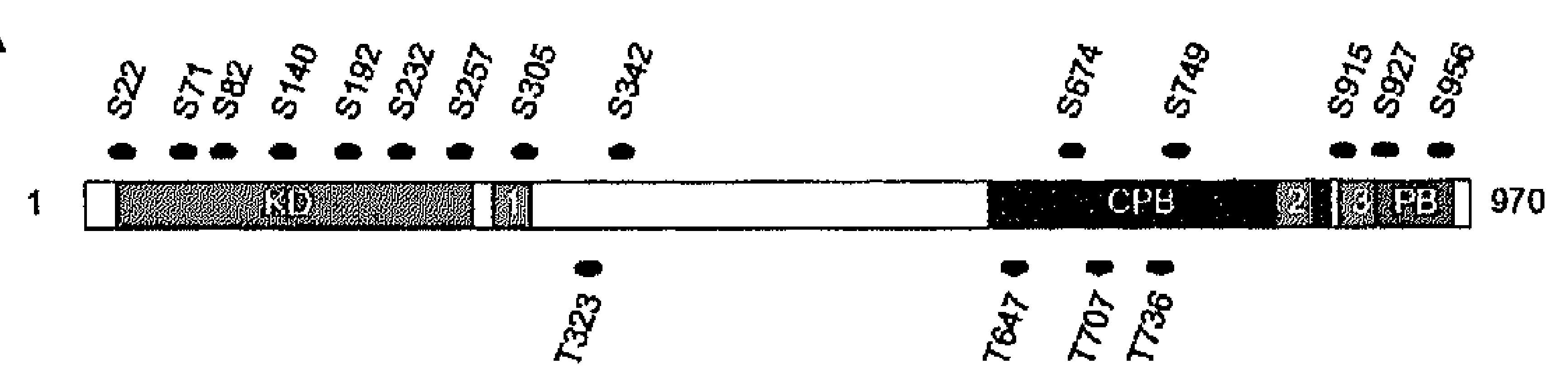

B

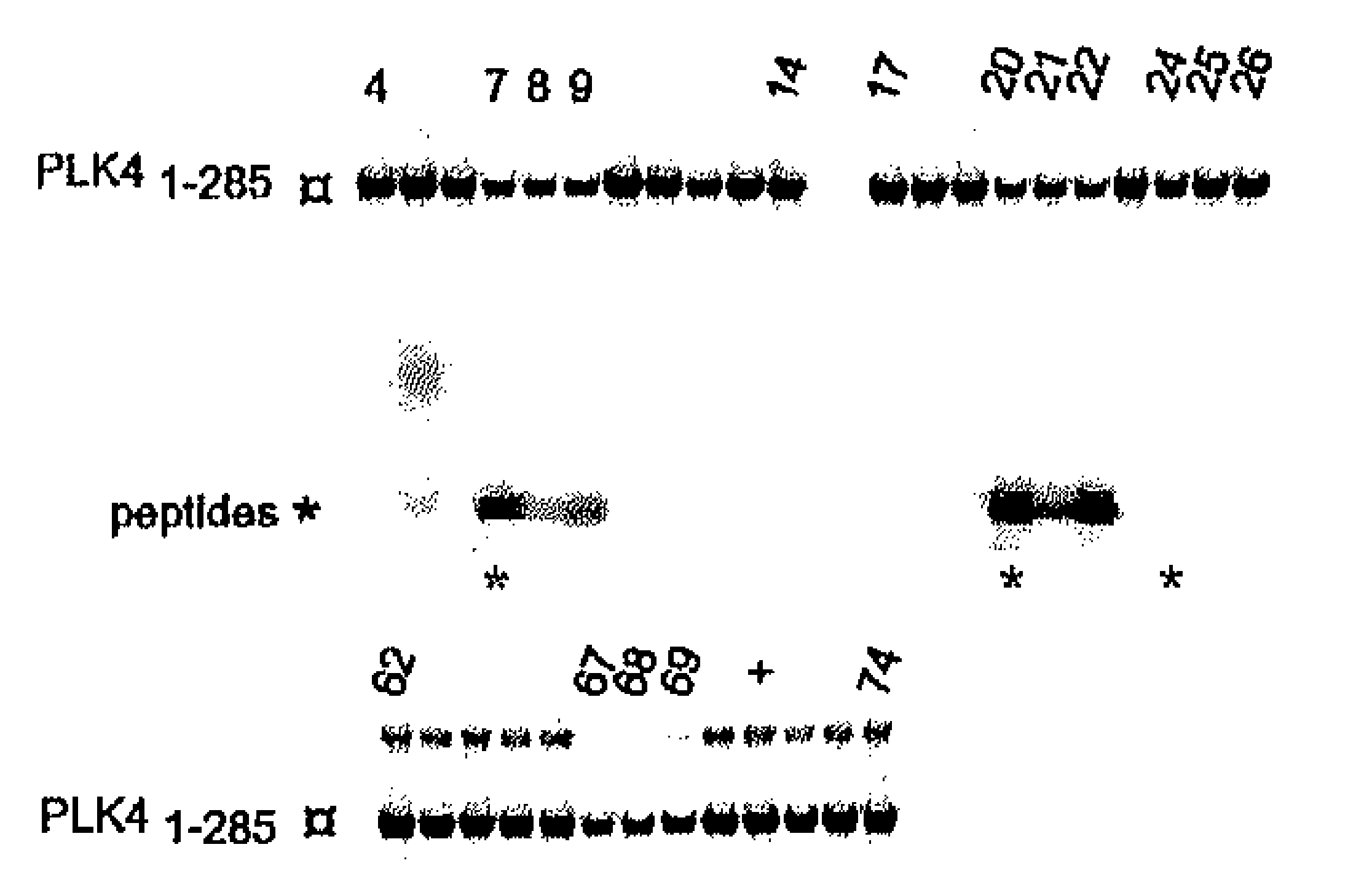

\begin{tabular}{|c|c|}
\hline & $\begin{array}{c}\text { Thr138 } \\
\text { ILHRDLILSNLLL } \\
\text { ILHRDLALSNLLL } \\
\text { ILHRDLTLANLLL }\end{array}$ \\
\hline $\begin{array}{l}20 \\
21 \\
22\end{array}$ & $\begin{array}{l}\text { Ser305 } \\
\text { SISGSLFDKRRLL } \\
\text { SISGALFDKRRLLL } \\
\text { SIAGSLFDKRRLL }\end{array}$ \\
\hline $\begin{array}{l}24 \\
25 \\
26\end{array}$ & $\begin{array}{c}\text { Ser } 342 \\
\text { DGNSFYTOWGNQ } \\
\text { DGNAFYTQWGNQ } \\
\text { DGNSFYAQWGNQ }\end{array}$ \\
\hline $\begin{array}{l}67 \\
68 \\
69\end{array}$ & $\begin{array}{l}\text { Ser95O/SerS57 } \\
\text { QKLQCLSSILLMF } \\
\text { QKLQCLASILLMF } \\
\text { OKLQCLSAILLMF }\end{array}$ \\
\hline
\end{tabular}

peptides *

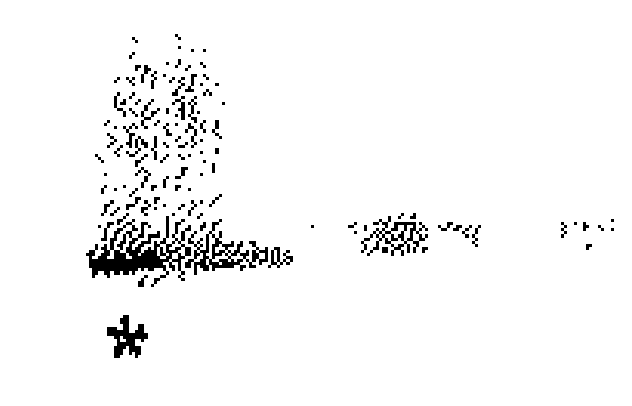

QKLQCLASILLMF

*

FIGURE 3: Identification of autophosphorylation sites in PI $K+$ ly in silfeo and peptide array sereening. (A)

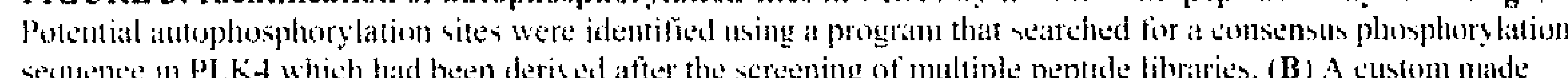

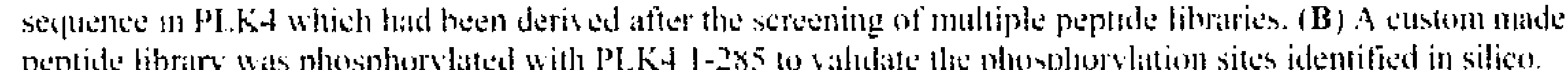

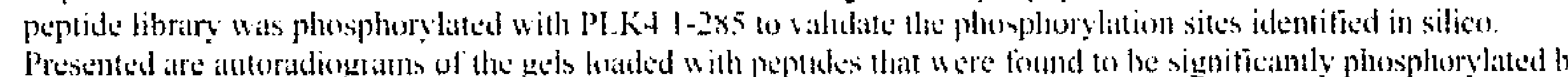

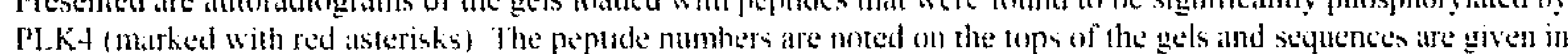

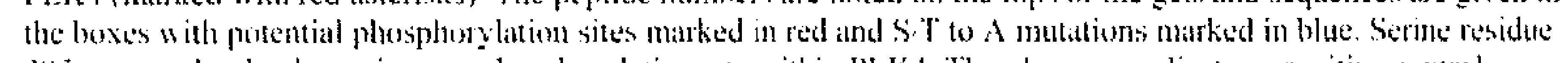

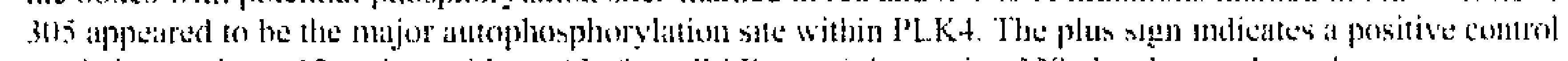
carried out using it 12 amino acid peptide from RAF combining serime 3.39 s.lesely matchng the comsensus

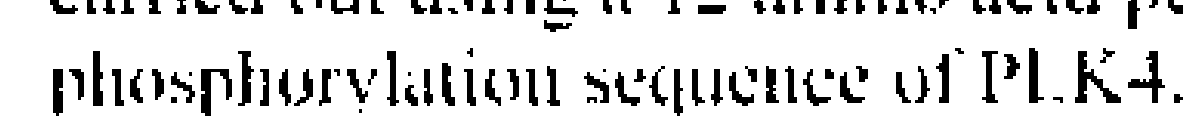

The colorectal carcinoma cell line, HCT116, was transiently transfected with plasmids encoding EGFP fused with either PLK4 or PLK4 K41M. Western blotting with antibodies 
Chapter 6

against the CPB domain or pS305 of PLK4 was carried out (Figure 4B). PLK4 and PLK4 K4IM were detected with the CPB antibody, however only active PLK4 was detected with the pS305 antibody indicating that this residue is exclusively phosphorylated by PLK4 in cells. We also observed the disappearance of the pS305 signal when the antibody was preincubated with the peptide used to raise the antibody (data not shown). Upon cotransfection of a PLK4 specific siRNA, complete ablation of total PLK4 and PLK4 K41M was observed and, more importantly, resulted a loss of signal upon detection with the pS305 antibody. Additionally, when PLK4 was immunoprecipitated with the pS305 antibody from HCT116 cells lysates, we were only able to detect PLK4 from cells overexpressing the active form of the kinase (data not shown). These data confirm that the pS305 antibody specifically recognizes its phosphorylated epitope and that S305 is an autophosphorylation site rather than a site for another kinase. This shows that $\$ 305$ is a genuine autophosphorylation site in PLK4 as it could be detected both in vitro and in vivo.

A

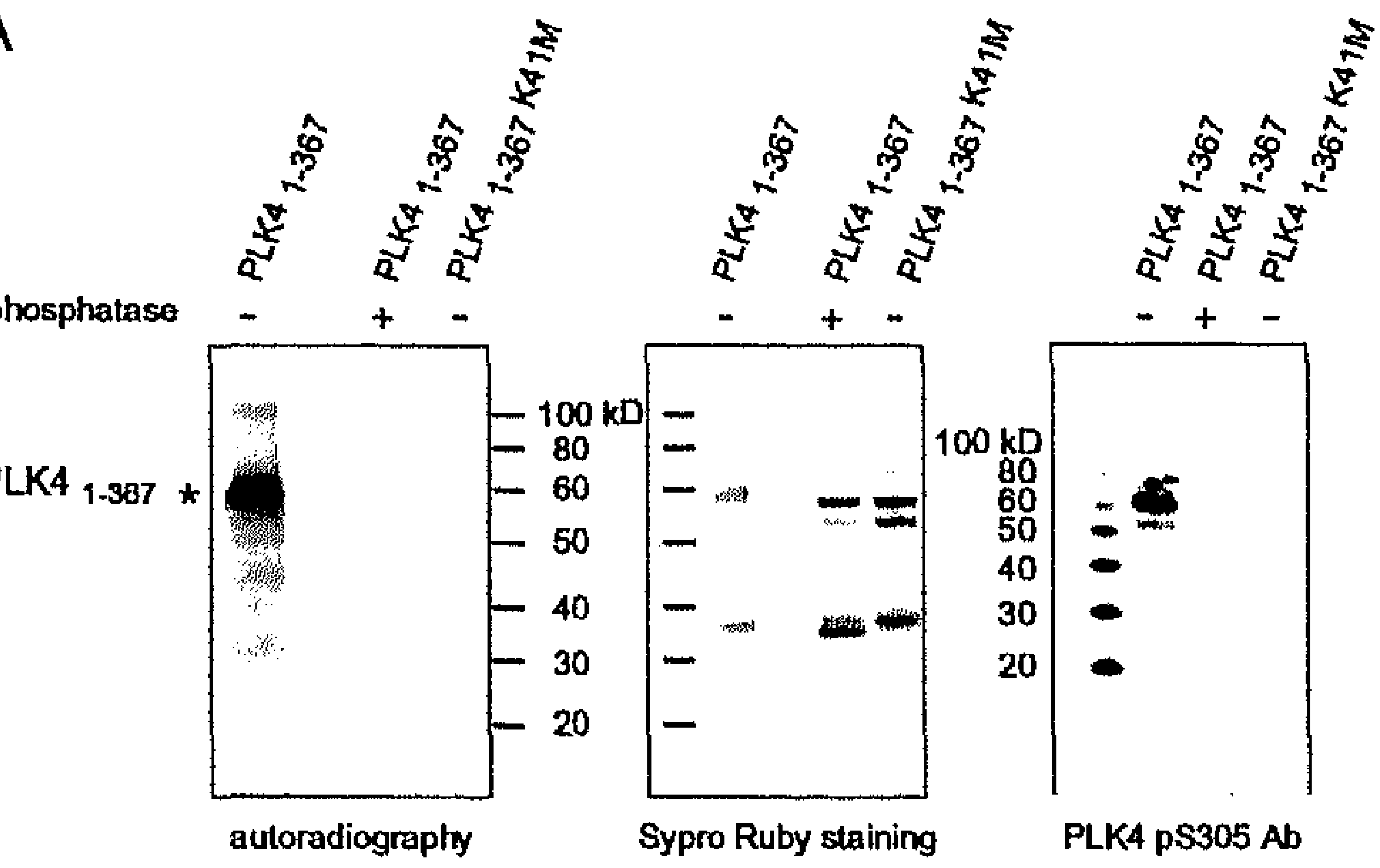

B

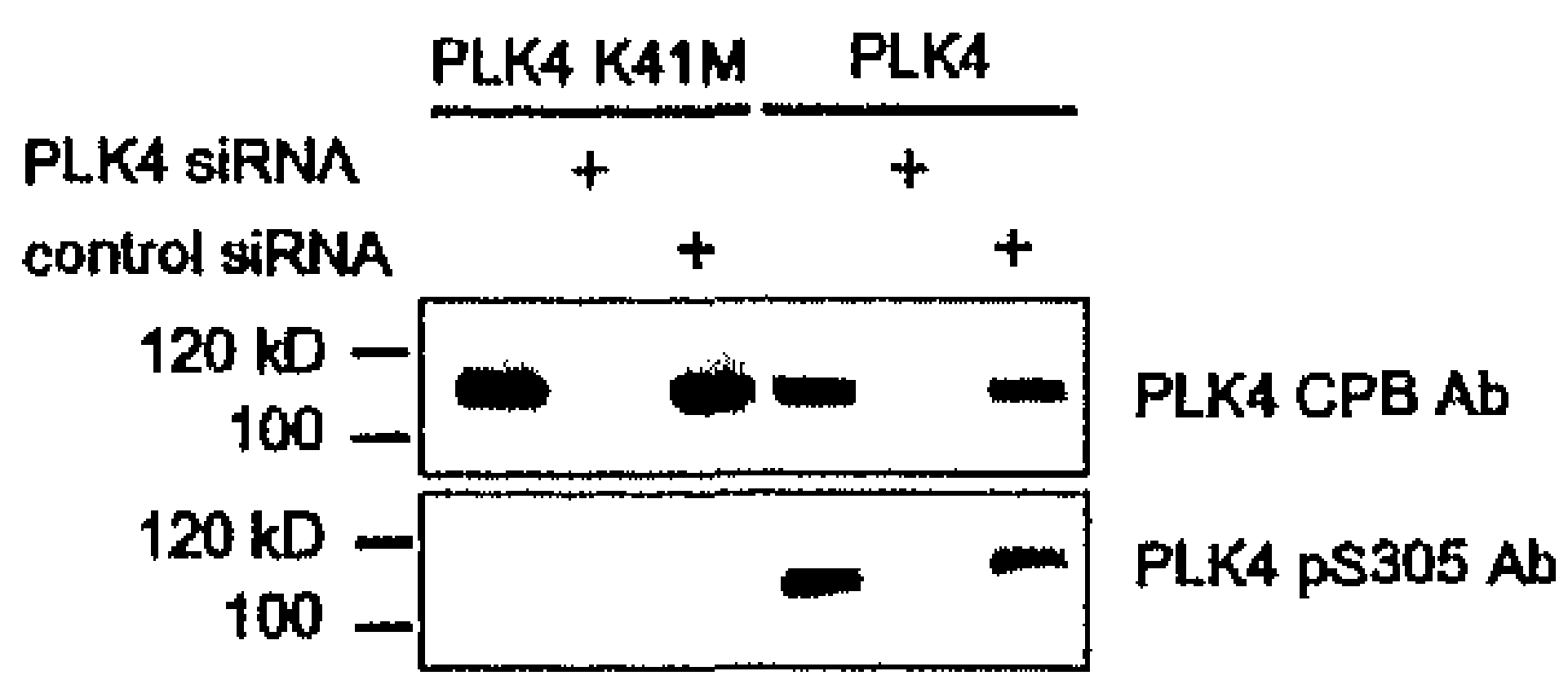

FIGURE 4: Serine 305 of Pl.Kt is antophosphorylated in vitro and in vive. (A) Satnples of in who phosphory late

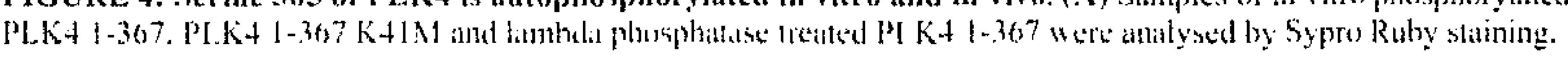

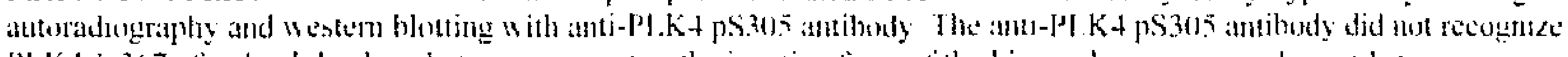

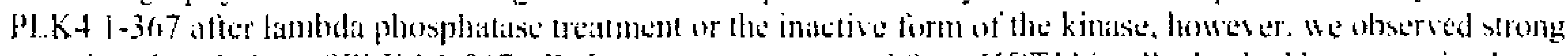

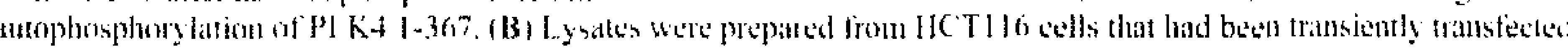

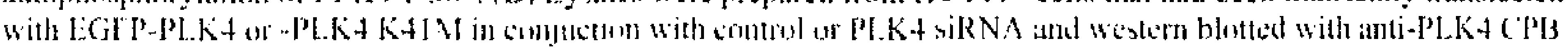

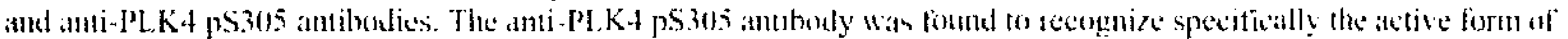
the kithane in vito 
PLK4 becomes active at the centrosome during centriole duplication

Assuming that S305 phosphorylation reflects active PLK4, we compared the localization of endogenous PLK4 and phosphorylated PLK4 in centrioles using CPB and pS305 antibodies. We used HeLa cells stably cxpressing GFP-centrinl and compared cells at various phases of the cell cycle. In Gl cells, the mother and daughter centriole could be clearly distinguished by the intensity of the GFP-centrin l signal (Piel et al.. 2000; White et al., 2000). The amount of total PLK4, detected using the CPB, was greater in the mother centriole while only a smaller amount was observed in the daughter centriole (Figure 5A). In addition the CPB staining on the mother centriole appeared as an elongated dot with one end colocalizing with GFP-centrin1, suggesting that PLK4 was present all along the centriole. Interestingly, in G1 cells active PLK4, detected using the pS305 antibody, was not present in either centriole. In carly $S$ phase, we observed the appearance of procentrioles on each centriole (Figure 5B). As in G1 cells, PLK4 was predominantly present on the mother centriole while only weakly present on the daughter. In contrast to $\mathrm{Gl}$, in $\mathrm{S}$ phase one of the centriole pairs possessed a strong pS305 signal that localized close to the proximal ends of the centrioles as depicted in the cartoon. This signal originated from the centriole pair possessing a grcater PLK4 signal, suggesting that it represented the molher centriole. In early G2 cells, we observed two pairs of centrioles with total PLK4 present on the daughter and mother centrioles (Figure 5C). In contrast to $\mathrm{S}$ phase, pS305 signal could be detected on the daughter centriole, although the signal was still predominant on the mother centriole. In late G2, the amount of pS305 increased significantly on the younger centriole pair (Supplementary Figure 1). By staining GFPcentrin 1 HeLa cells with ninein and $\gamma$-tubulin were able to confirm the observation that PLK4 was predominantly present on the mother centriole and became active during $S$ phase (Supplementary Figure 2).

To summarize, PLK4 was found to be predominantly present on the mother centriole in G1 and this trend was maintained through S and G2 phase. PLK4 activity was undetectable in $\mathrm{G} 1$, appeared at $\mathrm{S}$ and continued during G2 phase. PLK4, phosphorylated at $\mathrm{S} 305$, localized to the proximal end of the centriole and presumably at the site of procentriole budding. As the functional effect of this phosphorylation remained unknown but lied in the proximity of the PESTI region, a possible connection was investigated. 
Chapter 6

A

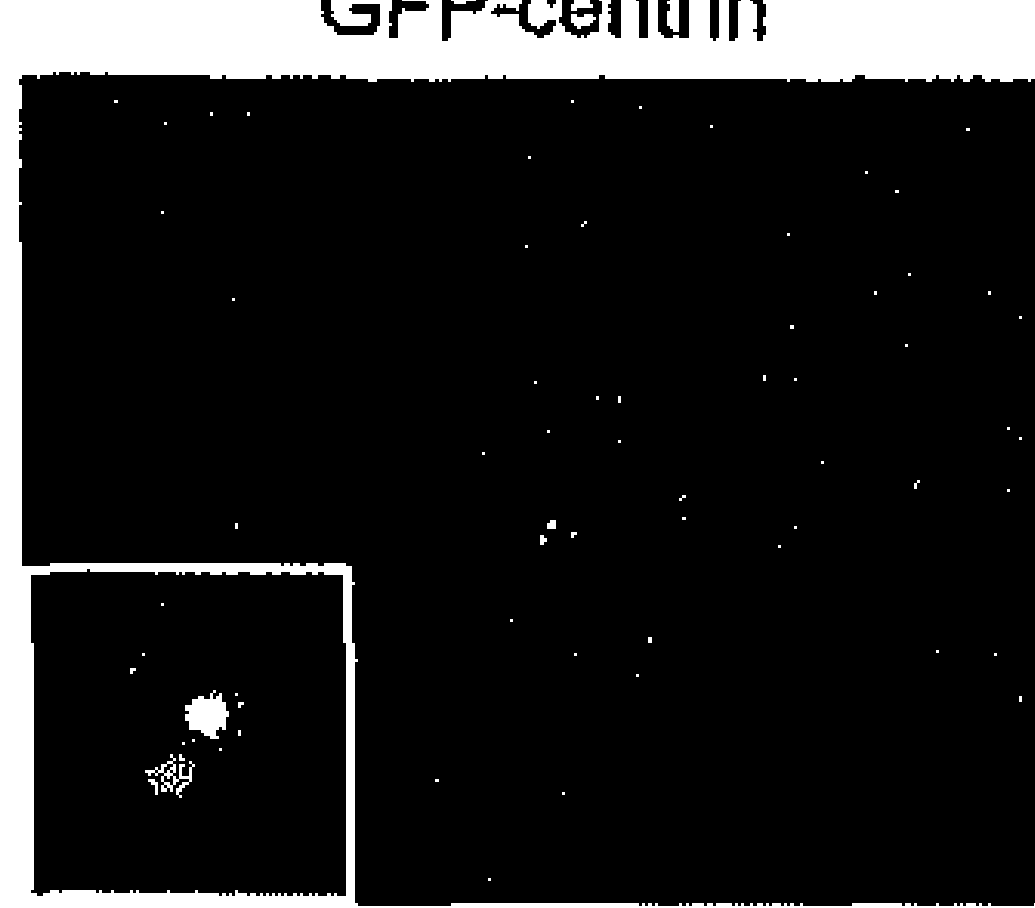

PLK4 CPB

PLK4 pS305
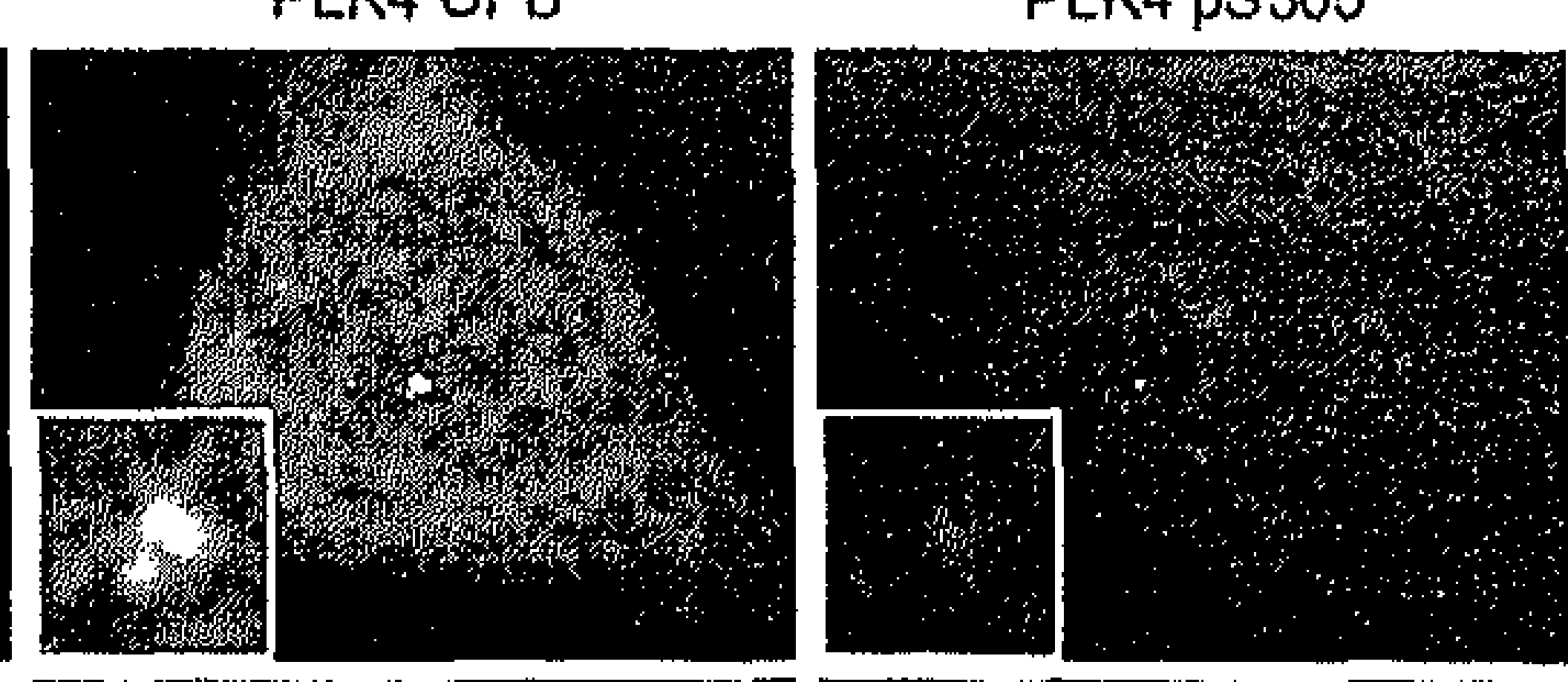

G1 phase
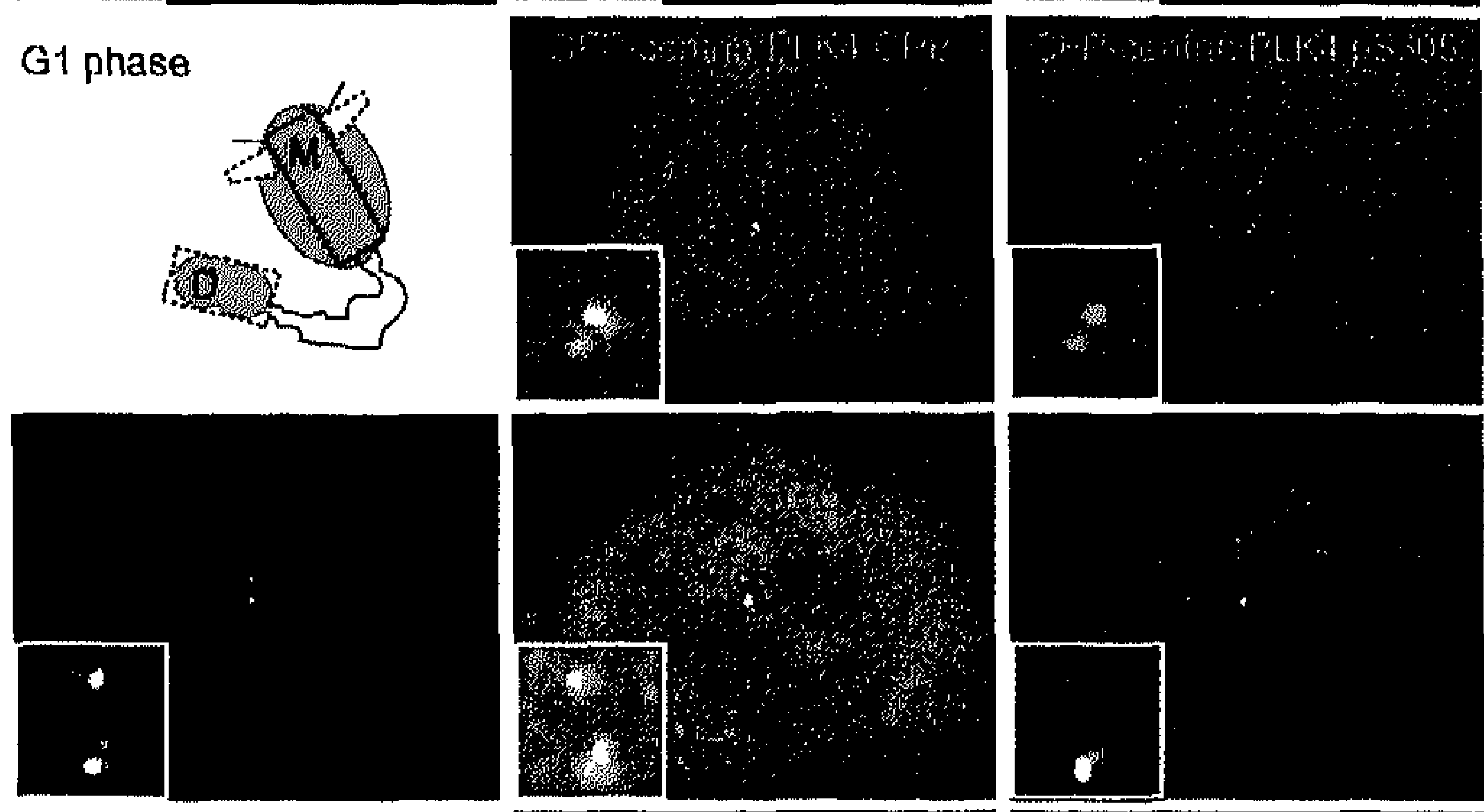

$S$ phase

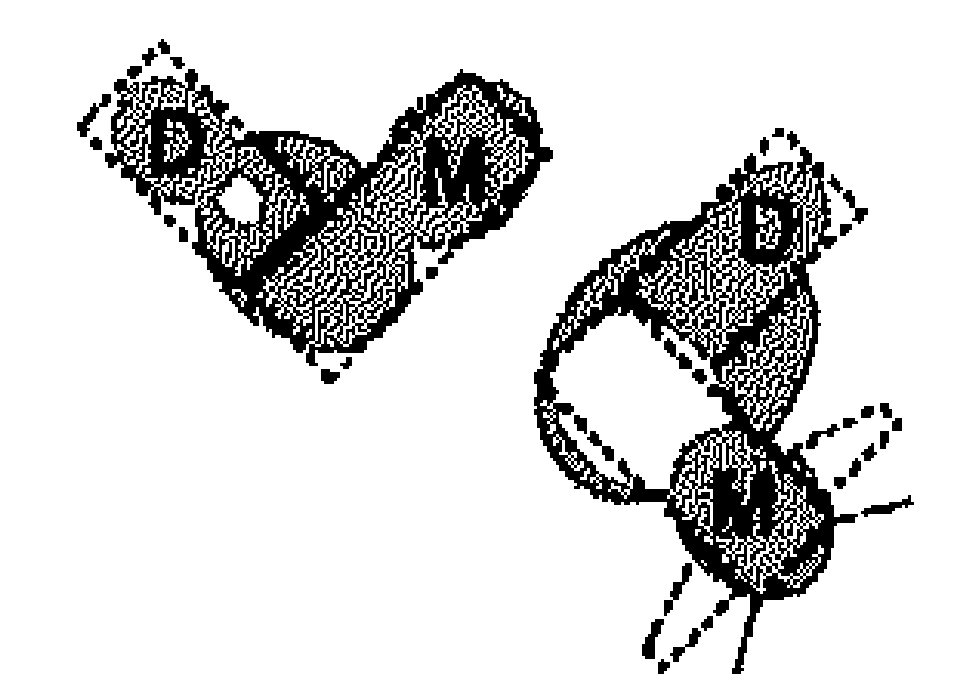

$\mathrm{C}$
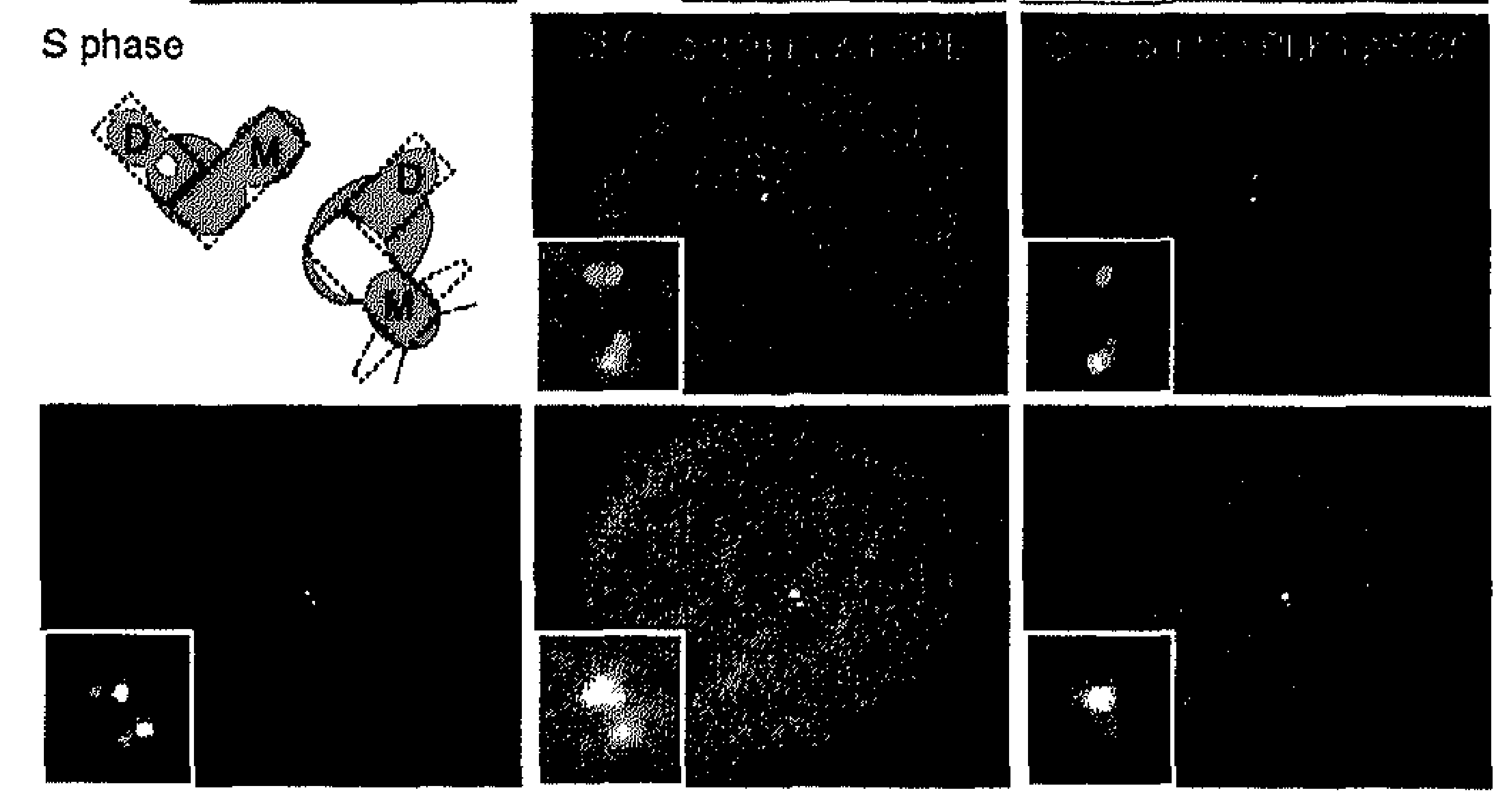

G2 phase
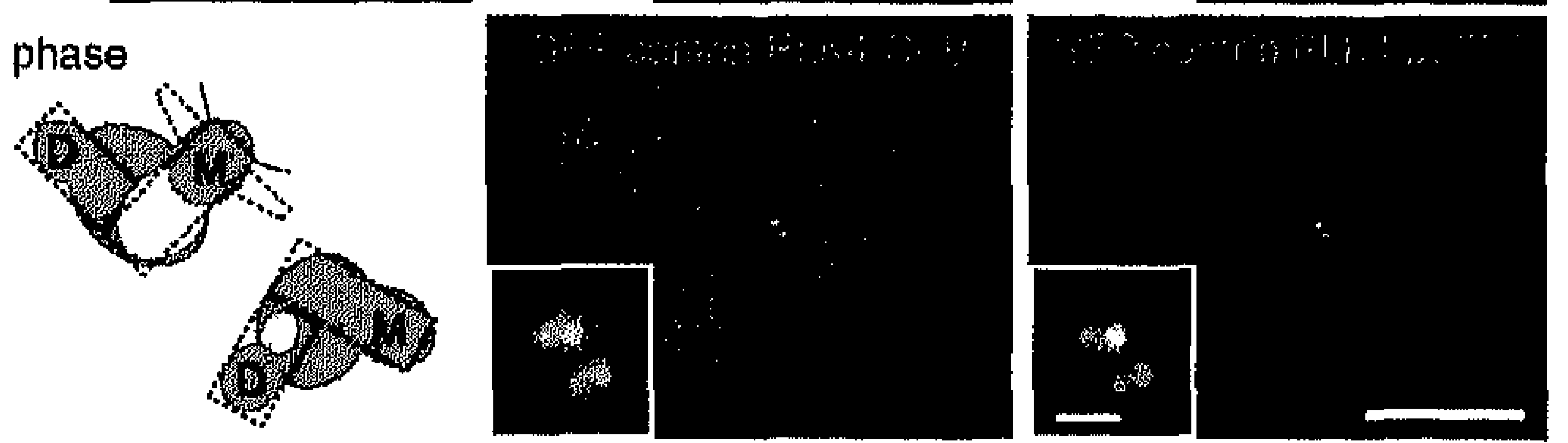

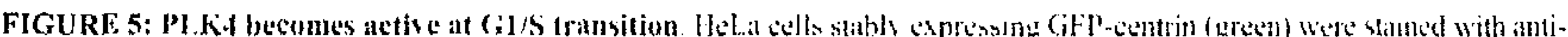

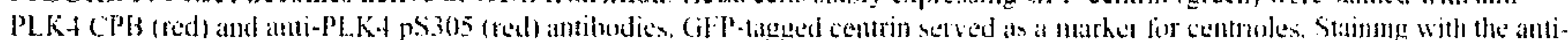

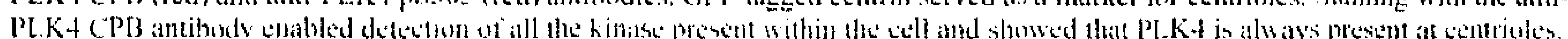

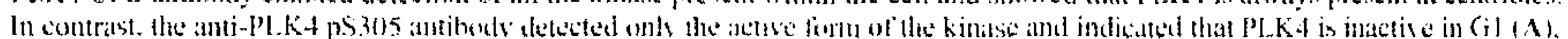

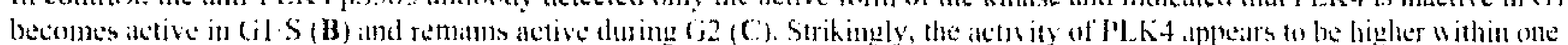

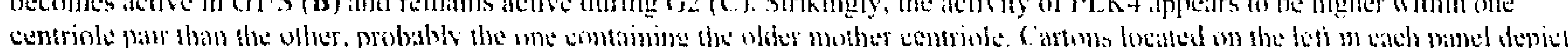

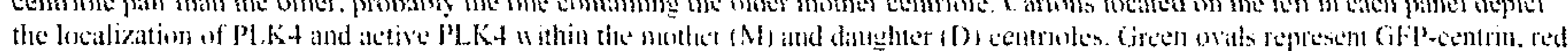

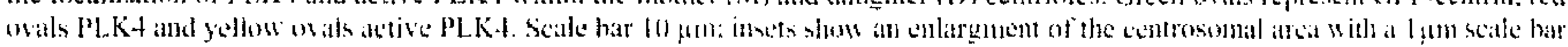




\section{Autophosphorylation of PLK4 $\mathbf{S 3 0 5}$ plays a role in regulating protein stability}

A

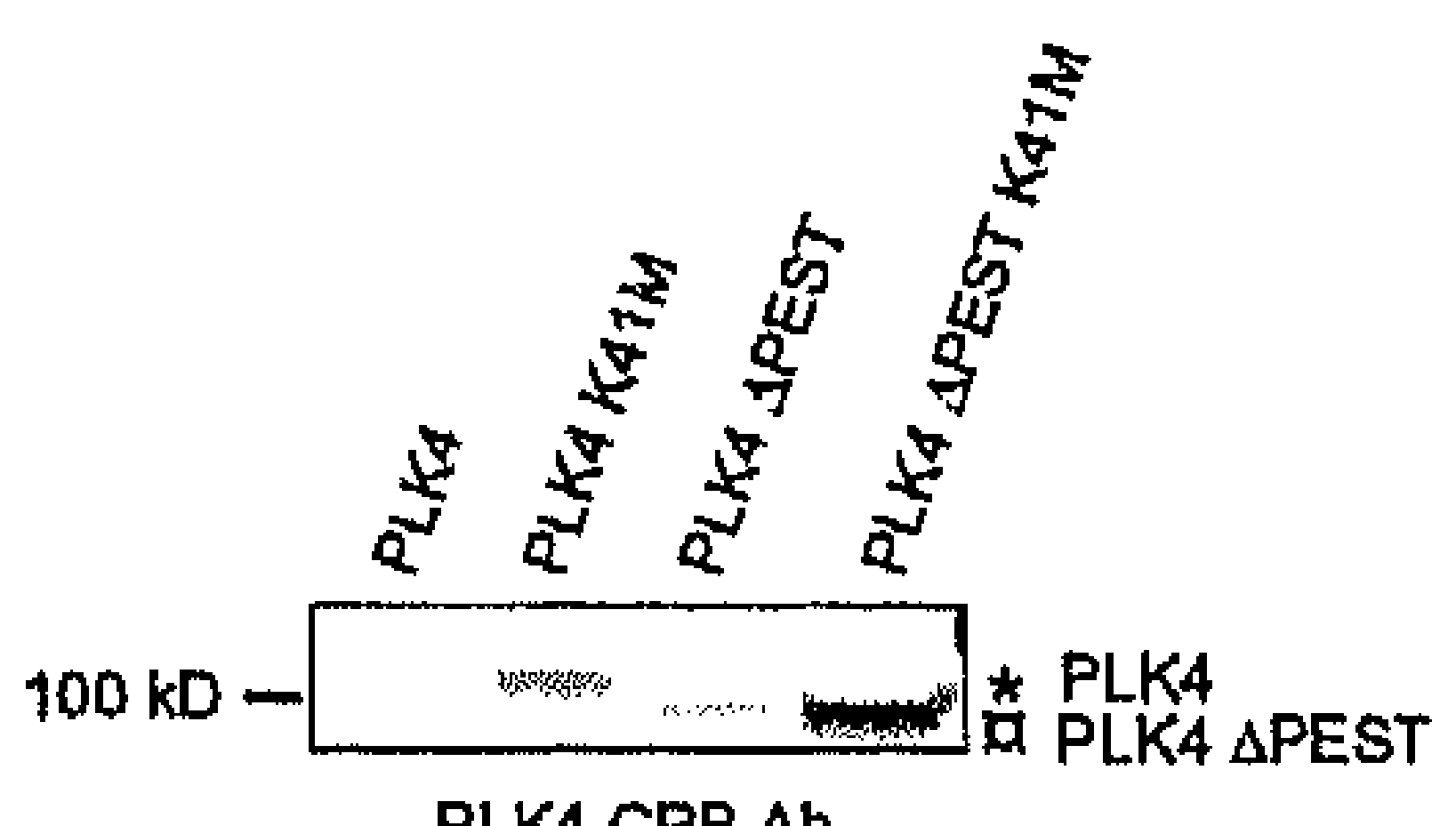

B

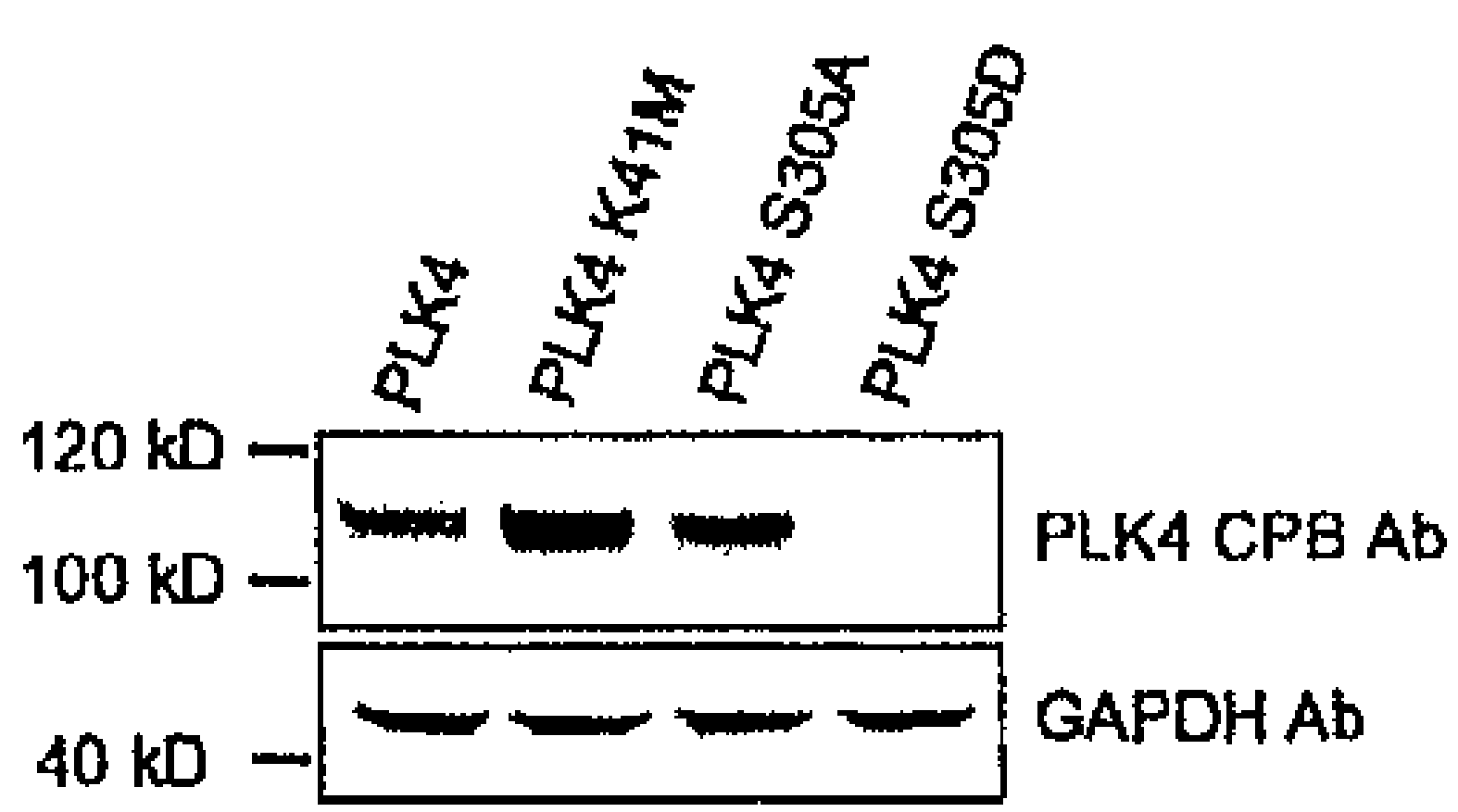

C
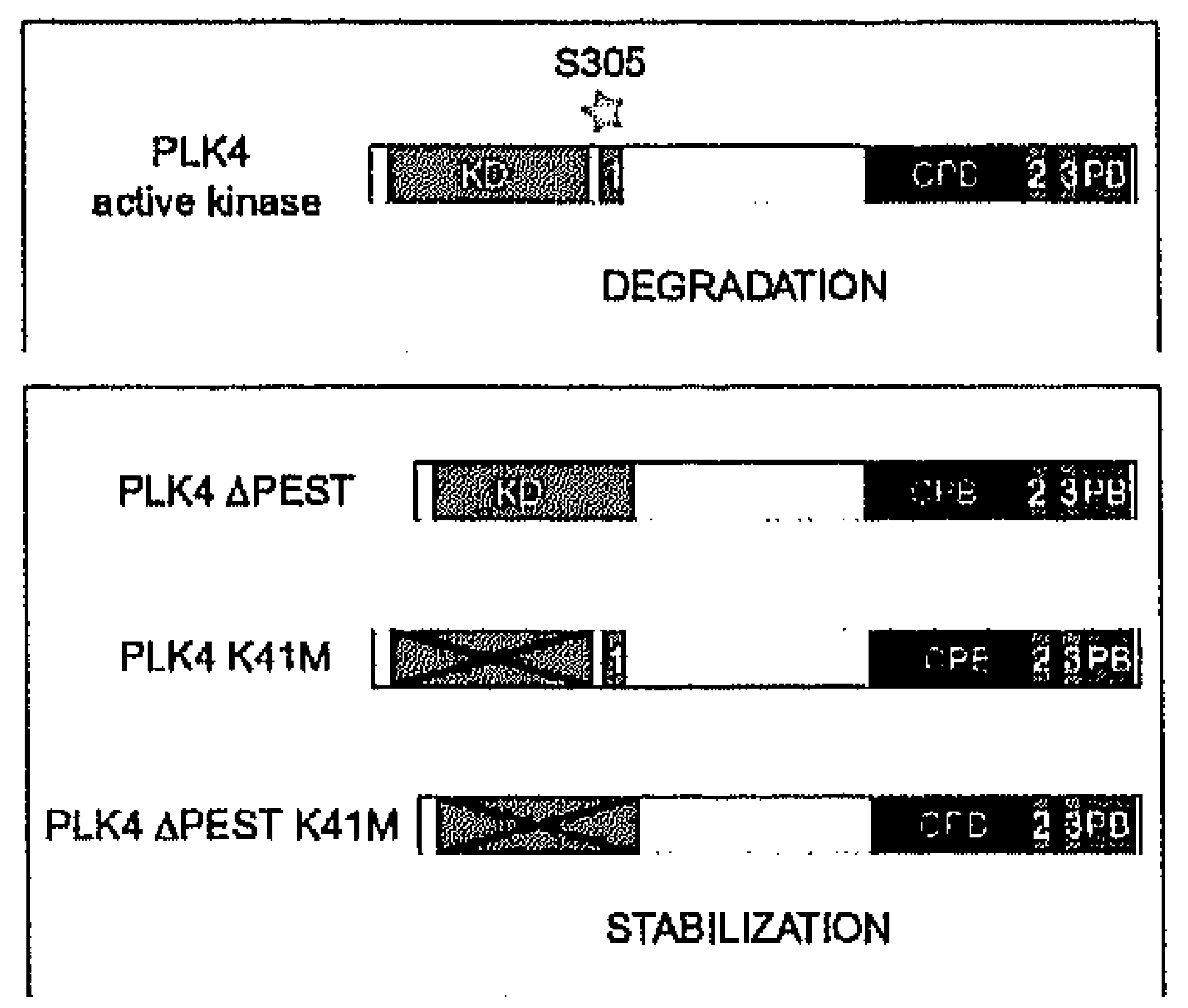

FIGURE 6: The role of S305 phosphorylation and the PEST1 sequence in regulating PI.K.t stability. (A) Lysates were prepared from HCT 1 lo cells that bad heen tlansiently transfeeted with myc-Pl K't exprescion cunstrtucts and western blotted with an inti-PLKLCPB antibody. An increase in protein slibility was observed ather mutation of lysibe +1 la a methionime. deletion of the tirst PEST sequence or both. (B) In a similur experiment. using FGFP-PIK fusions, mutalion of serine 305 w an aspartic atid resulted in the formation of al highly unstable form of the kintse that could not he detected w ith the antiPLK+ CPB antihody. GAPI)H western hlotung was carried out as a control for equal protein loading. A cartoon depicting how PLK + prolein stahility is regulated (C) KD. kinase donain: CPB crypto Pollobos: PB. Polobex;

numbered blue boxes PEST sefuences.
The PEST region of a protein is known to be involved in regulating its stability (Rechsteiner and Rogers, 1996). As S305 is in the end of the first PEST sequence in PLK4, the phosphorylation may have an effect on the stability of the protein. To verify that the PEST1 sequence of PLK4 was functional and played a role in protein degradation, we generated myc-tagged PLK4 mutants lacking residues 272 to $311:$ PLK $4_{\Delta \text { Pest }}$ and PLK4 $4_{\Delta \text { Pest }} K 41 \mathrm{M}$. These and the full length PLK4 constructs were transfected into HCT 116 cells and cell lysates were western blotted using CPB antibody (Figure 6A). We obscrved that the amount of PLK4 was significantly lower than that of PLK4 K41M. Quantification showed that roughly three times more PLK4 K41M was present compared to active PLK4, which was probably due to the lack of kinase activity as it is believed that phosphorylation regulates the stability of protein (Yamashita et al., 2001). Upon deletion of the first PEST region, stabilization of wildtype PLK4 protein was observed with an increase of two and half fold compared with the full length protein. The amount of PLK4 $4_{\Delta \text { Pest }}$ $\mathrm{K} 41 \mathrm{M}$ is slightly higher compared with that of full length PLK4 K41M and PLK $4_{\triangle \text { Pest }}$ indicating that kinase activity and the first PEST region both contribute to the regulation of PLK4 protein stability.

We also performed site directed mutagenesis to evaluate the importance of S305 in regulating the stability of PLK4 protein. We mutated the serine residue at position 305 to an alanine or aspartic acid to prevent or mimic phosphorylation on PLK4-EGFP fusions. We observed upon overexpression in HCT116 cells that the S305A mutation resulted in the moderate stabilization of PLK4 wild type as seen by a $30 \%$ higher expression level compared to the wild type protein (Figure 6B). 
Chapter 6

Remarkably, expression of the PLK4 S305D mutant protein could not be detected illustrating that mimicking of $\$ 305$ phosphorylation dramatically reduces PLK4 stability. GAPDH was used as an internal control to demonstrate equal loading.

In short, these findings indicate that: (I) the PEST1 region is responsible for targeting the protein for degradation, (II) kinase activity is required for the activation of this PEST sequence and (III) phosphorylation of S305 is a crucial event in the initiation of PLK4 degradation. One may imagine that these two are linked as is illustrated in the diagram (Figure 6C).

\section{DISCUSSION}

In this report we present data conclusively demonstrating that autophosphorylation of PLK4 occurs. This is not the first mention of possible autophosphorylation of PLK4 (Yamashita et al., 2001). However previously published data rested on PLK4 either immunoprecipitaled from human cells or expressed from baculovirus, where it is possible that other protein kinases may have phosphorylated PLK4. We expressed PLK4 in a prokaryotic system, where no other protein kinases are present, therefore the phosphorylation observed could only be attributed to PLK4 itself. Phosphorylation could have either been due to intra- or inter molecular phosphorylation. Such an inter-phosphorylation of PLK4 was shown and it is plausible that this occurs in vivo if one takes into consideration that PLK4 is believed to be a dimer (Leung et al., 2007). In addition, various PLK4 fragments covering the majority of the protein were examined and found to be phosphorylated. This implied that multiple autophosphorylation sites exist within PLK4. By peptide scanning analysis we were able to identify S305 as the major autophosphorylation site in PLK4. Using an antibody raised against pS305, which was shown to be specific for the pS305 versus the native S305, we werc able to detect this phosphorylation in vitro and in vivo. This antibody can therefore be used as a marker of PLK4 activity.

Subsequently, we carried out immunofluorescence staining to investigate where the active kinase was localized to and if the kinase was regulated in a cell cycle-dependent manner. An antibody raised against the CPB allowed detection of endogenous PLK4 and in agreement with previously published data was found to localize to centrioles (Habedanck et al., 2005; Hudson et al., 2001: Leung et al., 2002). However, we found that significantly more PLK4 was present at the mother centriole compared to the daughter. Additionally, we observed that PLK4 was present in the proximal and distal regions of the centriole (Supp Info-Figure II). This requires further investigation but could implicate PLK4 in an additional role such as protein recruitment for appendage assembly. The asymmetry in PLK4 localization between the mother and daughter centriole lead us to ask the question if the kinase was active in both centrioles. Staining with the pS305 antibody showed that in early G1 cells, despite the kinase being present at both centrioles, no active PLK4 was detected. Strikingly, in S phase cells we observed that active PLK4 was associated with the presence of PLK 4 at the mother centriole. Despite PLK4 being present at the daughtcr centriole, no activity could be detected with the pS305 antibody. It is possible that PLK4 was active on the daughter centriole but with an activity below the detection threshold. 
However, in late G2 cells PLK4 activity was observed on the maturing daughter centriole. Whether PLK4 remains present and/or active in $M$ phase and early G1 remains to be determined. Additionally, the role of PLK4 and its activity once centriole duplication has ended, is to be investigated.

The PESTl function has been shown to be important in regulating protein degradation (Rechsteiner and Rogers, 1996). This was confirmed by analysis of a PLK4 $4_{\Delta \text { Pest }}$ mutant where an increase in the amount of PLK4 protein compared to the full length was observed. We also observed that PLK4 K41M was more stable than the active kinase suggesting that phosphorylation elsewhere also plays a role in regulating the stability of the protein. The previous results and the localization of residue S305 in the first PEST region of PLK4 lead us to believe that the phosphorylation of the kinase on this residue may have an effect on the stability of the protein. Site directed mutagenesis strongly supported this hypothesis as the S305D mutation resulted in a highly unstable form of PLK4 whose expression could not be detected. Together these data indicate that the PEST1 sequence, S305 phosphorylation and PLK4 kinase activity all contribute to govern the stability of the kinase. Previously it has been suggested that TEC phosphorylation of PLK4 is not the only regulator of phosphorylation-induced PLK4 degradation (Yamashita et al., 2001).

Previously published data has shown that overexpression of PLK4 results in the formation of multiple procentrioles around each centriole during duplication (Habedanck et al,, 2005; Kleylein-Sohn et al., 2007). Conversely, depletion of the kinase by RNAi results in the sequential reduction of centriole numbers (Bettencourt-Dias et al., 2005; Habedanck et al., 2005). Together these data suggest that the amount of PLK4 is a key factor in the process of centriole duplication. Here we discovered two potential mechanisms whereby PLK4 activity could be regulated. Firstly, the kinase activity is restricted to the mother centriole. This spatial restriction implies that PLK4 substrates would need to be in the proximity of the mother centriole to be incorporated into the procentriole. This raises the intriguing possibility that the daughter centriole would obtain these substrates afterwards. Additionally, the presence of PLK4 activity on the daughter centriole is only observed in late G2, when centriole maturation occurs. Interestingly, it has recently been shown in Chlamydomonas reinhardtii that probasal body assembly occurs in prophase (Piasecki et al., 2007). One could suggest that a similar mechanism exists for centriole duplication in human cells. An alternative possibility is that the mother and daughter ccntriole might simply require different levels of activity to commence procentriole budding.

Secondly, autophosphorylation of PLK4 could control the abundance of the kinase by regulating protein degradation. The activation of the PEST1 region via S305 autophosphorylation can target the protein for destruction, thereby controlling the level of kinase present at the mother centriole. One may hypothesize that PLK4 phosphorylates substrates at the bud of the centriole, which supports what has been hypothesized previously (Nigg EA, 2007). Once this has occurred and the substrate has been fully phosphorylated, PLK4 would phosphorylate itself to initiate its own degradation. One also must anticipate the possibility that other PLK4 partncrs play a role in regulating PLK4 protein stability.

In this report we have been able to demonstrate that specific antibodies recognize the first described genuine autophosphorylation of PLK4 at residue $\$ 305$. The localization and expression levels of phosphorylated S305 PLK4 coincide with the kinase's presumed role 
Chapter 6

in centriolc duplication. Our results also open the unexpected possibility that centrosome duplication takes place in a sequential manner. PLK4 activity would be higher at the mother centriole where substrates would be phosphorylated and subsequently transferred to the daughter. Finally, we also suggest autophosphorylation of S305 to have a regulatory function in protein degradation.

\section{REFERENCES}

Balczon, R., L. Bao, W.E. Zimmer, K. Brown, R.P. Zinkowski, and B.R. Brinkley. (1995). Dissociation of centrosome replication events from cycles of DNA synthesis and mitotic division in hydroxyurea-arrested Chinese hamster ovary cells. $J$ Cell Biol. 130:105-15.

Bettencourt-Dias, M., A. Rodrigues-Martins, L. Carpenter, M. Riparbelli, L. Lehmann, M.K. Gatt, N. Carmo, F. Balloux, G. Callaini, and D.M. Glover. (2005). SAK/PLK4 is required for centriole duplication and flagella development. Curr Biol. 15:2199-207.

Bornens, M. (2002). Centrosome composition and microtubule anchoring mechanisms. Curr Opin Cell Biol. 14:25-34.

D'Assoro, A.B., S.L. Barrett, C. Folk, V.C. Negron, K. Boeneman, R. Busby, C. Whitehead, F. Stivala, W.L. Lingle, and J.L. Salisbury. (2002). Amplified centrosomes in breast cancer: a potential indicator of tumor aggressiveness. Breast Cancer Res Treat. 75:25-34.

Duensing, A., Y. Liu, S.A. Perdreau, J. Kleylein-Sohn, E.A. Nigg, and S. Duensing. (2007). Centriole overduplication through the concurrent formation of multiple daughter centrioles at single maternal templates. Oncogene. 26:6280-8.

Fode, C., C. Binkert, and J.W. Dennis. (1996). Constitutive expression of murine Sak-a suppresses cell growth and induces multinucleation. Mol Cell Biol. 16:4665-72.

Fode, C., B. Motro, S. Yousefi, M. Heffernan, and J.W. Dennis. (1994). Sak, a murine protein-serine/threonine kinase that is related to the Drosophila polo kinase and involved in cell proliferation. Proc Natl Acad Sci U S A. 91:6388-92.

Habedanck, R., Y.D. Stierhof, C.J. Wilkinson, and E.A. Nigg. (2005). The Polo kinase Plk4 functions in centriole duplication. Nat Cell Biol. 7:1140-6.

Hinchcliffe, E.H., F.J. Miller, M. Cham, A. Khodjakov, and G. Sluder. (2001). Requirement of a centrosomal activity for cell cycle progression through G1 into S phase. Science. 291:1547-50.

Hudson, J.W., A. Kozarova, P. Cheung, J.C. Macmillan, C.J. Swallow, J.C. Cross, and J.W. Dennis. (2001). Late mitotic failure in mice lacking Sak, a polo-like kinase. Curr Biol. 11:441-6.

Kleylein-Sohn, J., J. Westendorf, M. Le Clech, R. Habedanck, Y.D. Stierhof, and E.A. Nigg. (2007). Plk4-induced centriole biogenesis in human cells. Dev Cell. 13:190-202. 
Ko, M.A., C.O. Rosario, J.W. Hudson, S. Kulkarni, A. Pollett, J.W. Dennis, and C.J. Swallow. (2005). Plk4 haploinsufficiency causes mitotic infidelity and carcinogenesis. Nat Genet. 37:883-8.

Kuriyama, R., and G.G. Borisy. (1981). Centriole cycle in Chinese hamster ovary cells as determined by whole-mount clectron microscopy. $J$ Cell Biol. 91:814-21.

Leung, G.C., C.S. Ho, I.M. Blasutig, J.M. Murphy, and F. Sicheri. (2007). Determination of the Plk4/Sak consensus phosphorylation motif using peptide spots arrays. FEBS Lett. 581:77-83.

Leung, G.C., J.W. Hudson, A. Kozarova, A. Davidson, J.W. Dennis, and F. Sicheri. (2002). The Sak polo-box comprises a structural domain sufficient for mitotic subcellular localization. Nat Siruct Biol. 9:719-24.

Li, J., M. Tan, L. Li, D. Pamarthy, T.S. Lawrence, and Y. Sun. (2005). SAK, a new pololike kinase, is transcriptionally repressed by $\mathrm{p} 53$ and induces apoptosis upon RNAi silencing. Neoplasia. 7:312-23.

Lowery, D.M., D. Lim, and M.B. Yaffe. (2005). Structure and function of Polo-like kinases. Oncogene. 24:248-59.

Meraldi, P., J. Lukas, A.M. Fry, J. Bartek, and E.A. Nigg. (1999). Centrosome duplication in mammalian somatic cells requires $\mathrm{E} 2 \mathrm{~F}$ and $\mathrm{Cdk} 2$-cyclin $\mathrm{A}$. Nat Cell Biol. 1:88-93.

Mikule, K., B. Delaval, P. Kaldis, A. Jurcyzk, P. Hergert, and S. Doxsey. (2007). Loss of centrosome integrity induces p38-p53-p21-dependent G1-S arrest. Nat Cell Biol. 9:160-70.

Nigg, E.A. (2007). Centrosome duplication: of rules and licenses. Trends Cell Biol. 17:215-21.

Paintrand, M., M. Moudjou, H. Delacroix, and M. Bornens. (1992). Centrosome organization and centriole architecture: their sensitivity to divalent cations. J Struct Biol. 108:107-28.

Peel, N., N.R. Stevens, R. Basto, and J.W. Raff. (2007), Overexpressing centriolereplication proteins in vivo induces centriole overduplication and de novo formation. Curr Biol. 17:834-43.

Piasecki, B.P., M. Lavoie, L.W. Tam, P.A. Lefebvre, and C.D. Silflow. (2007). The Uni2 Phosphoprotein is a Cell-Cycle Regulated Component of the Basal Body Maturation Pathway in Chlamydomonas reinhardtii. Mol Biol Cell.

Piel, M., P. Meyer, A. Khodjakov, C.L. Rieder, and M. Bornens. (2000). The respective contributions of the mother and daughter centrioles to centrosome activity and behavior in vertebrate cells. $J$ Cell Biol. 149:317-30.

Piel, M., J. Nordberg, U. Euteneuer, and M. Bornens. (2001). Centrosome-dependent exit of cytokinesis in animal cells. Science. 291:1550-3.

Pihan, G.A., A. Purohit, J. Wallace, H. Knecht, B. Woda, P. Quesenberry, and S.J. Doxsey (1998). Centrosome defects and genetic instability in malignant tumors. Cancer Res. 58:3974-85.

Pihan, G.A., A. Purohit, J. Wallace, R. Malhotra, L. Liotta, and S.J. Doxsey. (2001). Centrosome defects can account for cellular and genetic changes that characterize prostate cancer progression. Cancer Res. 61:2212-9. 
Chapter 6

Pihan, G.A., J. Wallace, Y. Zhou, and S.J. Doxsey. (2003). Centrosome abnormalities and chromosome instability occur together in pre-invasive carcinomas. Cancer Res. 63:1398-404.

Raff, J.W., and D.M. Glover. (1988). Nuclear and cytoplasmic mitotic cycles continue in Drosophila embryos in which DNA synthesis is inhibited with aphidicolin. $J$ Cell Biol. 107:2009-19.

Rechsteiner, M., and S.W. Rogers. (1996). PEST sequences and regulation by proteolysis. Trends Biochem Sci. 21:267-71.

Rodrigues-Martins, A., M. Riparbelli, G. Callaini, D.M. Glover, and M. Bettencourt-Dias. (2007). Revisiting the role of the mother centriole in centriole biogenesis. Science. 316:1046-50.

Tsou, M.F., and T. Stearns. (2006). Mechanism limiting centrosome duplication to once per cell cycle. Nature. 442:947-51.

Weil, R., C. Laurent-Winter, and A. Israel. (1997). Regulation of IkappaBbeta degradation. Similarities to and differences from IkappaBalpha.

J Biol Chem. 272:9942-9.

White, R.A., Z. Pan, and J.L. Salisbury. (2000). GFP-centrin as a marker for centriole dynamics in living cells. Microsc Res Tech 49:451-7.

Winkles, J.A., and G.F. Alberts. (2005). Differential regulation of polo-like kinase 1, 2, 3 , and 4 gene expression in mammalian cells and tissues. Oncogene. 24:260-6.

Yamashita, Y., S. Kajigaya, K. Yoshida, S. Ueno, J. Ota, K. Ohmine, M. Ueda, A. Miyazato, K. Ohya, T. Kitamura, K. Ozawa, and H. Mano. (2001). Sak serinethreonine kinase acts as an effector of Tec tyrosine kinase.

$J$ Biol Chem. 276:39012-20. 
Chapter 7

General Discussion 


\section{INTRODUCTION}

The full validation of a drug target is crucial in the process of drug discovery and drug development. Issues such as Drug safety, ADMET properties and translation from animal models to humans are all critical to address if a drug is to succeed in the clinic. The reasons for the low number of successful drugs against novel targets are controversial, although it is undoubtedly related to the higher attrition rate during development, particularly from issues related to failures of on-target biological hypotheses and on- and off-target safety concerns. Front-loading, a work method where much of these issues are tackled carlier in the discovery process, is applied in most pharmaceutical companies at present. Front loading target validation can assist in reducing this attrition rate. This target validation can occur on various fronts. First, one would want to confirm that the protein levels are also differentially expressed across multiple independent patient samples. At this point one has a correlation between protcin expression and some observed physiology or pathophysiology. Then demonstrating that the expression of this particular target is either causative of the disease or some of the symptoms of the disease, is required.

We took two alternative approaches to perform target validation: post transcriptional gene silencing (PTGS) and peptide array technology.

Post translational gene silencing (PTGS) encompasses a large number of technologies but all contain the same ultimate goal: the reduction of protein expression due to gene knockdown resulting in an altered pathophysiological phenotype. To date, the only remaining hurdle for efficient in vivo use of oligonucleotides in PTGS is delivering these molecules to their site of action.

An alternate path in performing target validation makes use of peptide arrays. Small peptides can be used as substrates to be phosphorylated by the kinase under investigation. Identifying a specific substrale that can be used as a marker of kinase activity will aid in the precise evaluation of drug efficacy. Eventually putative off-target effects, which mask the actual inhibition of substrate expression, can be avoided.

\section{NON-VIRAL GENE DELIVERY SYSTEMS}

Therapeutic oligonucleotides (antisense oligonucleotides, ribozymes, DNAzymes, siRNAs and miRNAs) are promising anti-cancer agents because of their ability to reduce expression of target proteins. Advantages of such treatment over traditional chemotherapeutics include target specificity and the potential of reduced side effects. For cancer applications, systemic administration of the oligonucleotides is preferred for accessibility to disseminated tumors. However, efficient delivery of these materials to their target site remains a challenge. Injection of unformulated oligonucleotides requires extremely high doses due to nonspecific distribution throughout the body, nuclease mediated degradation, and rapid excretion. Using targeting moieties tissue specific distribution has been achieved. Apart from protecting the oligonucleotides from endo- and exonucleases, the carrier may assist in 
reducing oligo degradation. The majority of unformulated oligo is usually eliminated from the body by excretion in the urine, although some can be observed in the stool. This can be seen as early as a few hours after administration. Therefore not only is the delivery to the site of action important, but also the retention capability. The vehicle and package must remain present at the required location until the oligonucleotides has had time to release from its carrier and to fulfill its function.

The aims for optimal delivery of oligonucleotides comprise enhanced cellular uptake, improved exit from sub-cellular compartments and correct targeting to a particular site of action. The latter encompassing the concepts of target-matched delivery and pharmacodynamics in which effective concentrations of oligonucleotides at the target site need to be maintained for an appropriate length of time taking into account the biological half life of the target protein and the desired level of knockdown.

The cyclodextrin based polymers (CDP), the PPI dendrimers and the colloidal gold nanoparticles were successful in delivering high amounts of DNAzyme into carcinoma cells. A major advantage over classical liposomal transfection agents is their higher loading capability coupled with lower toxicity. Most liposomes have one positive charge and can therefore couple one cation. To obtain amounts that are sufficiently high enough to achieve therapeutic value, large quantities of complex need to be added. This results in extreme toxic conditions and subsequential massive cell death in vitro.

We were also able to demonstrate in vivo applicability with the CDPs and dendrimers. After intravenous administration they were shown to be able to accumulate in tumor tissue. Due to the transferrin moiety on the CDP, only transferrin receptor containing tissues were observed to have taken up the polyplex. This targeting is crucial to reduce off target effects and coupled toxicity. It was also shown that transferrin targeting does not effect biodistribution of material to the tumor, however is required for uptake and retention by tumor cells. The PPI dendrimer, containing a completely different chemical composition, showed strong uptake in the tumor without targeting. This must be due to passive uptake, as tumors have increased vascularization and pcrmeability. Additonally, we observed a high nuclear uptake in the tumor tissue. This is most uncommon and at the same time extremely intriguing. If the typical structure of the PPI dendrimer plays a role in this nuclear uptake is to be determined. Nearly all delivery agents are taken up by the cell via endocytosis. If the PPI dendrimer avoids this very inefficient process, where the vehicle-oligo complex is often degraded by endosomes and the oligo's rarely reach the site of action, also requires further investigation.

As is this case for each gene delivery system, a certain route of administration will work better than others. Size, charge, hydrophilicity and exterior modifications to reduce serum protein-induced aggregation all play a role in choosing the route of administration and analysis kinetics. Although both delivery systems investigated have different advantages, their use in target validation is demonstrated and they even have potential in gene therapy applications. The cyclodextrin based polymers, under use by a company named Calando plans to file an investigational new drug (IND) application with the US Food and Drug Administration. In the near future, a Phase I clinical trial in cancer is planned with the first targeted, systemically-delivered siRNA, inducing an inhibition of cell replication in tumors. 
Chapter 7

ENGINFERED FLUORESCENT CARCINOMA CELL LINES

When analyzing gene delivery vehicles, most work is performed in cells. Lower amounts of costly oligonucleotides and facilitated techniques to ascertain silencing efficiacy can be applied. Once moving into animal models, an investigator would prefer to test as few delivery systems as possible. Other parameters such as routes of administration, amounts of polyplex, tissue biodistribution and pharmacokinetics require further attention. With this setup we attempted to combine the extensive testing in vitro with the more demanding parameters and challenges in vivo. Delivering an oligonucleotide that is able to downreglate the gene encoding a fluorescent protein opens this possibility. A stable expressing fluorescent tumor cell line was therefore engineered. and characterized. Using whole body imaging (WBI) we are able to analyze this reduction in fluorescence in semi high throughput allowing more mice per group to be tested in a certain time frame. Secondly this technique is non-invasive so the same animal can be used for multiple time point measurements and kinetic readouts. Thirdly, using fluorescence as a readout changes the determination of efficacy from a biochemical, laborious fashion to a user independent, optical and quick manner. All this implies that multiple types of carrier can be tested immediately in an in vivo setting. This provides the investigator upfront with more valuable data, as in vivo results resemble more precisely that what is to be expected in a patient. Existing cells lines could not be used as the low fluorescence intensity resulted in a less accurate and more difficult use in our WBI system. Additionally, it needed to be confirmed that fluorescent protein expression will not interfere with the siRNA or drug efficacy. Therefore a highly metastatic Lewis Lung carcinoma and a ovarian carcinoma cell line were engineered to express either ZsGreen of DsRed2 constitutively. These Anthozoa derived fluorescent proteins have gained large interest over the past ycars, predominantly as a marker of transfection. Their improved characteristics compared to the more common Aequoria victoria derived GFP and RFP such as a longer half life, faster maturation and more intense fluorescence make them ideal for in vivo use in our WBI. Multiple steps to characterize these cell lines were undertaken. In vitro the cell growth and drug susceptibility was compared the parental cell line. In vivo the cell lines were demonstrated to form xenografts in nude mice and respond in an anti-tumor study to a HDAC inhibitor. This particular characterization demonstrated that these cell lines could be used in an in vitro and in vivo setting to screen drugs, albeit complexed to a drug delivery system. A comparison was additionally performed to ensure that WBI is more accurate than the commonly used caliper-based tumor volume measurement system. Finally, an siRNA targeting ZsGreen was evaluated for the screening of non-viral delivery systems in the engineered cell lines. A specific and concentration dependent reduction of mRNA and protein was observed, whilst no induction of a viral immune response was activated due to treatment with RNAi. Although only a moderate effect was observed when the ZsGreen targeting siRNA was transfected in the stable expressing cell lines, certain elements are to be taken into consideration. The transfection was done by Lipofectamine 2000®, where only low amount of siRNA can be added without exceeding toxicity limits. Multiple rounds of transfection were attempted however, this too stressed the cell too much resulting in increased cell death. The long half life of ZsGreen (approximately 48hours) and the 
extreme intense fluorescence (that was needed to improve the visualization using WBI), has now become a hurdle. Perhaps a destabilized version of the protein may have been advantageous. Otherwise a more potent siRNA or modifications to cnhance potency or stability may aid in silencing the endogenous gene better. Obviously, as other non-viral gene delivery systems will be investigated, the silencing effect should improve compared to the weak Lipofectamine mediated knockdown.

\section{PEPTIDE ARRAY TECHNOLOGY}

Investigating the function a protein rather than the expression of the encoding gene is more relevant to the resulting phenotype of a pathopysiological response. Protein functions are not only regulated by the presence or absence of distinct proteins but also by posttranslational modifications and proteolytic protein processing. This results in changes in compartmentalization or in the interactions and formation of complexes of specific proteins. Phosphorylation and dephosphorylation of proteins are major mechanisms mediating signal transduction throughout the cell and are intimately involved in the regulation of cell growth, physiology, differentiation, and death. When dealing with proteins, there are numerous challenges which are extremely complex, requiring intricate manipulation and care to ensure the preservation of proteins' native form and spatial orientation. Consequently, protcin-based microarray has been the subject of much discussion in recent years. However, it's "sister platform", the peptide array, is another technique which is currently being exploited for the high throughput evaluation of complex protein functions. Protein and peptide expression profiling is ultimately one step closer for relating the genome to biological response. Spotting peptides/proteins on a surface, be it a membrane or a glass slide, allows for the study of interaction between the immobilized peptide/protein and a substrate. Enzyme-substrate arrays have been described for different kinds of enzymes including restriction enzymes, peroxidase, phosphatase and protein kinases. Kinases are one of the protcin families with a high potential for drug target candidates. Thereforc, the pharmaceutical industry has a strong interest in appropriate assay systems which enable the screening of drugs candidates for kinase activity at a very early stage during drug development. Considerable challenges still exist in terms of content generation, printing, functional immobilizing, and detection when using peptide arrays.

False positive results are often obtained in peptide arrays. It is risky to translate the recognition of a small peptide by an enzyme to a full length protein. Protein folding could mask the access to this residue when the enzyme and substrate are present under physiological conditions. Other post-translational modifications could also be required to allow or contrarily block recognition.. It should also be investigated where the substrate is primarily found. A nuclear protein that has been identified as a substrate for a plasma membrane protein raises a lot of extra questions. If a consensus sequence for the recognition site within a substratc for a particular enzyme is known, this can be used to distinguish a probable from a unlikely candidate. After identifying the substrate on a peptide array, the recombinant protein must be shown to be sensitive to the enzyme in an in 
vitro assay. Additionally, in cellular models one should be able to confirm the interaction and enzymatic reaction along with the specific inhibition due to RNAi.

The identification of an auto-phosphorylation site at residue serine 305 of PLK4 was identified using a peptide array. The antibodies raised against this residue were shown to be specific in recognizing the phosphorylated version of the protein both in vitro and in vivo. We also demonstrated that this phosphorylation regulates PLK4 protcin stability and we postulate this to happen via activation of the adjacent PESTI region. We also carried out immunofluorescence staining to investigate where the active kinase was localized to and if the kinase was regulated in a cell cycle-dependent manner. We found that significantly more PLK4 was present at the mother centriole compared to the daughter. Additionally, we observed that PLK4 was present in the proximal and distal regions of the centriole. This requires further investigation but could implicate PLK4 in an additional role such as protein recruitment for appendage assembly. The asymmetry in PLK4 localization between the mother and daughter centriole lead us to ask the question if the kinase was active in both centrioles. Staining with the pS305 antibody showed that in early Gl cells, despite the kinase being present at both centrioles, no active PLK4 was detected. Strikingly, in S phase cells we observed that active PLK4 was associated with the presence of PLK4 at the mother centriolc. Despite PLK4 being present at the daughter centriole, no activity could bc detected with the pS305 antibody. It is possible that PLK4 was active on the daughter centriole but with an activity below the detection threshold. However, in late G2 cells PLK4 activity was observed on the maturing daughter centriole. Whether PLK4 remains present and/or active in $M$ phase and early Gl remains to be determined. Additionally, the role of PLK4 and its activity is once centriole duplication has ended, is to be investigated. Here we discovered two potential mechanisms whereby PLK4 activity could be regulated. Firstly, the kinase activity is restricted to the mother centriole. This spatial restriction implies that PLK4 substrates would need to be in the proximity of the mother centriole to be incorporated into the procentriole. This raises the intriguing possibility that the daughter centriole would obtain these substrates afterwards. Additionally, the presence of PLK4 activity on the daughter centriole is only observed in late $G 2$, when centriole maturation occurs. Secondly, auto-phosphorylation of PLK4 could control the abundance of the kinase by regulating protein degradation. The activation of the PESTI region via S305 autophosphorylation can target the protein for destruction, thereby controlling the level of kinase present at the mother centriole. One may hypothesize that PLK4 phosphorylates substrates at the bud of the centriole, which supports what has been hypothesized previously. Once this has occurred and the substrate has been fully phosphorylated, PLK4 would phosphorylate itself to initiate its own degradation. One also must anticipate the possibility that other PLK4 partners play a role in regulating PLK4 protein stability. 
Chapter 8

SUMMARY AND CONCLUSIONS 
Chapter 8

SUMMARY

The full validation of a drug target is crucial in the process of drug discovery and drug development. Issues such as Drug safety, ADMET properties and translation from animal models to humans are all critical to address if a drug is to succeed in the clinic. Prior to all this however, the target against which the drug is designed must be shown to be valid. Firstly, this implies that one would confirm that the protein levels of the drug target are differentially expressed across multiple independent patient samples. This inidicates that there is a correlation between protein expression and some observed physiology or pathophysiology. Additionally, it should be demonstrated that the expression of this particular target is either causative of the disease or some of the symptoms of the disease. Although clinicians will aptly prove, the only true validated targets are those for which there are already drugs shown to be efficacious in man. Nonetheless, already fighting this uphill battle in early stages of drug discovery will reduce the number of failures due to misbeliefs concerning on-target biological hypotheses and on- and off-target safety concerns.

Post translational gene silencing (PTGS) encompasses a large number of technologies but all contain the same ultimate goal: the reduction of protein expression due to gene knockdown resulting in an altered pathophysiological phenotype. To date, the only remaining hurdle for efficient in vivo use of oligonucleotides is delivering these molecules to their site of action.

An alternate path in performing target validation makes use of peptide arrays. Small peptides can be used as substrates to be phosphorylated by the kinase under investigation. Identifying a specific substrate that can be used as a marker of kinase activity will aid in the precise evaluation of drug efficacy. Eventually putative off-target effects, which mask the actual inhibition of substrate expression, can be avoided.

In this report, these two approaches in performing target validation were investigated. Various delivery vehicles were investigated for their in vitro and in vivo capability to transport and allow release of oligonucleotides. Additionally, we successfully engineered and characterized multiple fluorescent carcinogenic cell lines that can be used for the screening of non-viral gene delivery vehicles. We also demonstrate the use of peptide arrays and recombinant DNA technology to identify an auto-phosphorylation site of PLK4, that can be used to specifically measure its kinase activity.

In Chapter One an introductory word is given on the challenges that the pharmaceutical industry face in drug development. We also discuss how target validation can aid to decrease attrition rate. Additionally, the aim of this thesis is explained.

In Chapter Two we demonstrate how a cyclodextrin-based polymer was used to delivery a fluorescent labeled DNAzyme. Certain modifications were done to enhance this gene delivery vehicle such as the addition of adamantine and PEG to stabilize the molecule and the coating with transferrin particles to enhance tumor targeting. Besides characterizing the polyplex in vitro, biodistribution and clearance kinetics were investigated in tumor bearing 
mice. Various routes of administration using a variety of polyplex formulations, lead to strong cellular uptake in the tumor with an increased retention capability.

In Chapter Three modified poly(propylene imine) dendrimers were examined as a nonviral gene delivery vehicle. Exterior and interior modifications were applied to improve its characteristics as an effective transfection agent. Interior tertiary amines producing multiple quarternized cationic sites allow increased amount of oligonucleotides to be bound. PEG tails or acetyl groups were added to the surface to improve stability and in vivo biodistribution. Additionally, we tested varying sizes of PPI dendrimers to ascertain their transfection efliciency. Highly serum- and thermal stable polyplexes were shown to be taken up by the cell readily without exerting toxicity. Finally, we demonstrated that a high nuclear uptake of fluorescently labeled oligonucleotides was observed following an intravenous administration into nude mice.

In Chapter Four we described a third non-viral gene delivery vehicle. A transferrin coupled cationic substrate, a DNAzyme in this study, was bound to a colloidal gold particle with sub $100 \mathrm{~nm}$ size. Optimization of the $\mathrm{pH}$ stabilty, the quantity of oligo, and type and amount of linker, either being polylysine or polyethylenimine, were examined. The polymer coupled oligo was shown to effectively, and with low toxicity, achieve cellular uptake in human carcinoma cells.

In concurrence to the previous chapter, we engineered fluorescent cell lines that could aid in analyzing the efficacy of novel non-viral gene delivery vehicles. The intent was to knockdown the gene encoding the fluorescent protein, thereby reducing the amount of fluorescence in the cell lines. It enables the investigator to perform analysis on non-viral gene delivery vehicles in a semi high throughput manner and uses a low labor intensive, quick, optical detection as the readout of PTGS. Moreover, for in vivo purposes the combination of inhibiting the fluorescent protein, which is expressed in an engineered and characterized cell line, and whole body imaging is even more significant. Finally, this setup may provide information on PTGS release- and efficacy kinetics and allows the potential investigation of orthotopic and/or metastatic deeper lying tumors. In Chapter Five we describe the production and a characterization of ZsGreen or DsRed2 stably expressing A2780 and 3LLp cells. Cellular growth rate and in vitro susceptibility to anti-cancer drugs was investigated to ensure that the introduced fluorescent protein did not alter the innate characteristics of the cell. We also demonstrate the use of the cells as an in vivo tumor model which can additionally enhance the detection capability of a whole body imaging system. Finally we show how RNAi, as a form of PTGS, can be used to knockdown one the fluorescent proteins used in the tumor model, ZsGreen. The reduction of ZsGreen occurred in a concentration dependent manner, was detectable on the mRNA and protein level and did not induce a viral related immune response.

In Chapter Six we applied an alternative approach to PTGS when performing target validation. In order to evaluate PLK4 as a good drug target, the drug induced inhibition of PLK4 activity would need to be measured. As no known substrates of PLK4 existed, determining its activity was difficult. Using recombinant DNA technology and peptide 
Chapter 8

microarray, we were able to identify an auto-phosphorylation site on PLK4. Antibodies raised against the phosphorylated version of residue Serine 305, demonstrated their specificity and use as a way to detect active PLK4. As PLK4 is reported to play a key role in centriole duplication, we investigated where active PLK4 is localized in the centrosomes during the cell cycle. We demonstrate how endogenous PLK4 is asynchronously distributed over the mother and daughter centriole and that PLK4 activity is predominantly attributed to the mother centriole during procentriole formation and elongation. Finally, we demonstrate how phosphorylation at $\$ 305$ plays a role in regulating PLK4 protein stability.

In Chapter Seven we discuss the above mentioned results in light of the present knowledge on target validation. With the attrition rate of drugs being as high as it is in the pharmaceutical industry, fully validating the drug larget will save time, cost and effort in the long run.

\section{CONCLUSIONS}

Post transcriptional gene silencing and peptide arrays are powerful tools in performing drug target validation. Although gene delivery remains the major hurdle within PTGS, new approaches to create non-viral delivery vehicles are continuously being reported. Additionally, peptide arrays are known to often identify false positives as substrates but nonetheless can be, definitely in combination with molecular- and cellular biology, fundamental in understanding a mechanism of action of a particular enzyme.

In this thesis various non viral delivery systems were investigated for their potential to delivery an oligonucleotide. Although complete different vehicles, they did give insight into certain issues troubling the world of gene delivery and gene therapy. The fluorescent cell line, engineered to aid in the screening of such gene delivery systems, demonstrated great potential in saving cost, time and effort. At the same time, we demonstrated how intensely fluorescent cells can eventually be counter productive to the initial intent. Although the peptide array and recombinant DNA technology identified Serine305 as being a genuine auto-phosphorylation site within PLK4, it was the cellular biology that boosted its credibility. The immunofluorescence data will certainly intrigue centriole biologists and will merely mark the beginning of more investigation into the mechanism of action behind PLK4. 
Conclusions made on the basis of this thesis are:

1. Cyclodextrin based polymers were a successful tool to deliver DNAzymes to transferrin receptor containing tumor cells both in vitro and in vivo

2. Poly(propylene imine) dendrimers can be used to achieve high nuclear uptake of DNAzymes into carcinoma cells both in vitro and in vivo

3. Colloidal gold particles bound to a transferrin coupled cation can be delivered with low toxicity to carcinoma cells

4. ZsGreen or DsRed2 protein expressing cell lines can be used to perform anti-cancer drug screening both in vitro and in vivo

5. ZsGreen or DsRed2 protein expressing cell lines offer improved characteristics to whole body imaging, which is shown to be superior to caliper-based tumor volume measuring.

6. ZsGreen or DsRed2 protein expressing cell lines in combination with RNAi targeting the fluorescent protein, may aid in analyzing non-viral gene delivery velicles.

7. Serine 305 is the first described auto-phosphorylation site of PLK4 and plays a role in regulating PLK4 protein degradation.

8. Active PLK4 is differentially expressed compared to total PLK4, with an emergence during $S$ phase on the proximal end of the mother centriole. 
Chapter 9

SAMENVATting EN CONCluSiES 
Chapter 9

\section{SAMENVATTING}

In het huidige geneesmiddelenonderzoek is een complete validatie van het doelwit van uiterst belang. Hindernissen zoals veiligheid, ADMET eigenschappen en cen diermodel dat representatief is voor de mens, moeten allemaal behandeld worden om het succes te garanderen voor het genecsmiddel bij behandeling van patiënten. Allereerst moet cr echter een validatic van het doelwit plaatsvinden. Om te beginnen, moet aangetoond worden dat het eiwit niveau van het doelwit cen variërend expressie patroon vertoont in verschillende onafhankelijke patiëntenstalen. Dit betekent dat er een correlatie zou kunnen bestaan tussen het expressie niveau van het eiwit en de waargenomen pathosfysiologie. Bovendien moet aangetoond worden dat de expressie van het eiwit ofwel de oorzaak van de ziekte is ofwel de oorzaak van ććn van de symptomen van de zickte. Artsen zullen altijd de eersten zijn om aan te tonen dat de enige echte gevalideerde doelwitten diegene zijn die al bewezen hebben te werken in patiënten. Desondanks deze opvatting moet deze strijd reeds in de beginfase van het geneesmiddel onderzoek uitgevoerd worden. Dit leidt tot cen verlaagd aantal mislukkingen te wijten aan foutc opvattingen betreffend doelwitgerichte biologische hypotheses en -veiligheidszorgen.

'Post translational gene silencing' (PTGS) omvat een groot aantal tcchnologieën maar deze hebben hetzelfde einddoel: een verlaging van het eiwit niveau door middel van inhibitie van het overeenkomstige gen. Dit leidt uiteindelijk tot een veranderd pathosfysiologisch fenotype. Tot en met vandaag blijft er maar één hindernis voor de in vivo ingebruikname van oligonucleotiden voor PTGS: het kunnen transporteren naar de juiste locatie.

Een alternatief middel om doelwit validatic uit te voeren is door middel van zogenaamde peptide arrays. Kleine peptiden kunnen als substraat gebruikt worden om door het onderzochte kinase gefosforyleerd te worden. Het identificiëren van een dergelijk substraat, dat gebruikt wordt om specifiek de activiteit van een kinase te meten, helpt bij het cvalueren van de doeltreffendheid van een geneesmiddel. Mogelijke reacties, niet gelinkt aan het doelwit, die de inhibitie van substraat expressie verhinderen of verdoczelen, kunnen hiermee vermeden worden.

In dit rapport worden deze twee manieren om doclwit validatie uit te voeren van naderbij bekeken. Verschillende transportmechanismen werden onderzocht met betrekking tot hun in vitro en in vivo mogelijkheden om oligonucleotiden te transporteren en los te laten. Bovendien hebben we meerdere fluorescente carcinogene cellijnen ontworpen en gevalideerd. Deze kunnen gebruikt worden bij het evalueren van de onderzochte non-virale transportmechanismen. Ten slotte wordt de toepasbaarheid van peptide arrays in combinatie met recombinant DNA technologie gedemonstreerd om een autofosforylatie plaats in het eiwit PLK4 te identificeren. Deze autofosforylatie plaats kan dan gebruikt worden om de kinase activiteit specifiek te meten.

Hoofdstuk Eén: Een inleidend woordje omtrent de moeilijkheden die de farmaceutische industrie vandaag de dag kent. Er wordt eveneens uitgelegd hoe de validatie van een doelwit kan leiden tot het verminderen van falingen in de eindfase van 
geneesmiddelontwikkeling. Ten slotte wordt in dit hoofdstuk het streefdoel van de onderzoeksstudie uitgelegd.

Hoofdstuk Twee: Hierin wordt getoond hoe een cyclodextrin polymeer gebruikt is om fluorescente DNAzymes te transporten. Bepaalde aanpassingen om het gen transport tc verbeteren, zoals de toevoeging van adamantine en PEG om het molecule te stabiliseren, zijn hiervoor aangebracht. Daamaast werden transferrine moleculen aan de buitenkant bevestigd om specifieke tumoropname te vergemakkclijken. Naast een in vitro karakterisatie van het polymeer werd biodistributie en afscheidings kinetiek onderzocht in naakte muizen met xenograften. Verschillende toedieningsmanieren met verscheidene polyplex formulaties werden uitgetest. Dit leidde tot een goede cellulaire opname met een verhoogde relentic in de tumor.

Hoofdstuk Drie: Gemodifieerde poly(propyleen imine) dendrimeren werden onderzocht als non viraal gen transport systeem. Exterieur en interieur aanpassingen werden onderzocht om de eigenschappen als transfectie agens te verbeteren. Interieur tertiaire amines zorgen voor verschillende gekwarternizeerdc kationische punten. Dit zorgt voor een verhoogd aantal plaatsen waar oligonucleotides kunnen binden. PEG staarten of acetyl groepen werden aan het oppervlak gebonden om de stabiliteit en biodistributie in vivo te verbeteren. De transfectie efficiëntie van verschillende groottes van PPI dendrimeren werden bepaald. Zeer stabiele polyplexen werden, onder invloed van temperatuur of in de aanwezigheid van serum, vlot door de cel opgenomen zonder enig teken van toxiciteit. Ten slotte werd een zeer hoge nucleaire opname aangetoond van fluorescent DNAzymes na een intravencuze toediening in naakte muizen.

Hoofdstuk Vier: Een derde non viraal gen transport systeem werd besproken. Een kationisch substraat, een DNAzyme in deze studie, gekoppeld aan transferrine, werd aan een colloidaal goud partikel met sub $100 \mathrm{~nm}$ dimensies gebonden. Optimalisatie van de $\mathrm{pH}$ stabiliteit, de kwantiteit aan oligo, type en hoeveelheid linker molecule (polylysine ofwel polyethylenimine) werd onderzocht. Het polymeer gekoppeld oligo werd succesvol en zonder hoge toxiciteit in humane carcinoma cellen opgenomen.

In overeenstemming met de voorgaande hoofdstukken werden fluorescente cellijnen gecreëerd, die bij de evaluatie van de doeltreffendheid van non viraal gen transport systemen kunnen helpen. Met de intentie om het gen dat codeert voor de fluorescente proteïne uit te schakelen, kon de reductie in fluorescentie gemeten worden in de diverse cellijnen. Dc enige variabele was dan het transport systeem onder evaluatic. Hierdoor konden de onderzoekers de non viraal gen transport systemen in een semi-hoge doorvoer wijze analyseren. Volgende bijkomstig voordelen zijn de lage arbeidsintensiviteit en een snelle \& optische detectie methode om PTGS te onderzoeken. Bovendien hielp deze opzet bij in vivo toepassingen waar nu gebruik gemaakt wordt van gekarakteriseerde cellijnen en de reductie in fluorescentie gemeten kan worden via 'whole body imaging'. Ten slotte kan ook informatic bekomen worden omtrent de bevrijdingskinetiek uit het transportsystemen 
en de doeltreffendheid van het transport systeem net als mogelijk onderzoek naar orthotopische en/of metastatische dieper gelegen tumoren. In Hoofdstuk Vijf wordt de productie en karakterisatie van ZsGreen en DsRed2 stabiele A2780 en 3LLp cellijnen beschreven. Om te garanderen dat enkele eigenschappen van de cel zelf niet gewijzigd werden, werd de cellulaire groeisnelheid en in vitro gevoeligheid voor antikanker geneesmiddelen onderzocht. We laten ook het gebruik zien van deze cellen als tumor model in vivo, wat uiteindelijk de detectie capaciteit van 'whole body imaging' kan verbeteren. Ten slotte werd gedemonstreerd hoe RNAi tegen ZsGreen, als voorbeeld van PTGS, gebruikt kan worden om deze fluorescente eiwitten in het tumor model uit te schakelen. De reductie van ZsGreen gebeurde in een concentratie afhankelijke wijze, was detectecrbaar om zowel mRNA als eiwit niveau en gaf geen inductie in het viraal gerelateerd immuun respons systecm.

Hoofdstuk Zes: Hier werd een alternatieve manier gebruikt om aan PTGS binnen doelwit validatie te doen. Om PLK4 als een goed doelwit in het geneesmiddelen onderzoek te evalueren, moet de vermindering van PLK4 activiteit onder invloed van een geneesmiddel gemeten kunnen worden. Omdat er geen substraten van PLK4 bckend zijn, was het bepalen van die verminderde activiteit moeilijk. Gebruik makend van recombinant DNA technologie en peptide arrays werd een autofosforylatie punt in PLK4 ontdekt. Antilichamen tegen de gefosforyleerde versie van dit residue Scrine305 werden aangemaakl. Vervolgens werd hun specificiteit en werking, om actief PLK4 te meten, aangetoond. Omdat men weet dat PLK4 een cruciale rol speelt in centriool duplicatie, werd onderzocht waar PLK4 in de centrosomen actief is tijdens verschillende fasen van de celcyclus. Er werd aangetoond dat endogeen PLK4 asynchronisch verdeeld is tussen de moeder en dochter centriool. Bovendien is PLK4 activieit voornamelijk geassocicerd aan de moeder centriool tijdens procentriool vorming en elongatic. Ten slotte werd aangetoond hoe de fosforylatie op residu S305 een belangrijke rol speclt in de regulatie van PLK4 eiwit stabiliteit

Hoofdstuk Zeven: De bovenvermelde resultaten werden besproken in de context van de huidige kennis omtrent doelwit validatie. Met het hoge falingspercentage van geneesmiddelen in de farmaceutische sector zijn goed gevalidecrde geneesmiddel doelwitten essentieel om op lange duur tijd te winnen en geld \& moeite te besparen.

\section{CONCLUSIES}

'Post transcriptional gene silencing' en peptide arrays zijn handige en informatierijke technieken bij het uitvoeren van geneesmiddel doelwit validatie. Desondanks dat gen transport de grootste hindernis binnen PTGS blijft, worden nieuwe technieken en non viraa! gen transport systemen continu gepubliceerd. Anderzijds zijn peptide arrays, ook al hebben 
ze als nadeel dat ze vals positieven kunnen identificeren tussen de mogelijke substraten, in combinatie met moleculaire en cellulaire biologie fundamenteel bij het onderzoek naar het werkingsmechanisme van een cnzyme.

In deze thesis zijn verschillende non viraal gen transport systemen onderzocht met betrekking tot hun potentieel om oligonucelotiden an te brengen. Hoewel totaal verschillend als transport systemen, hebben ze toch inzicht gegeven naar bcpaalde zorgen binnen de wereld van gentransport en gentherapie. De fluorescente cellijn, geproduceerd om de screening van zulke gentransport systemen te vergemakkelijken, toonde groot potentieel in het verlagen van kosten, tijd en moeite. Tezelfdertijd werd opgemerkt hoe enorm intense fluorescente cellijnen contraproducticf kumnen zijn naar het oorspronkelijk doel. Ten slotte werd aangetoond dat, hoewel peptide arrays en recombinant DNA technologic Serine305 als autolosforylatie plaats in PLK4 geïdentificeerd hadden, het de cellulaire biologie was die met sluitende data afkwam. De immunofluorescentie zal zonder twijfel centriool biologen intrigeren en een extra vonk geven naar het verdere onderzoek rond het werkingsmechanisme van PLK4.

Conclusies die gemaakt kunnen worden op basis van deze thesis zijn:

1. Cyclodextrine polymeren vormen een succesvol middel om DNAzymes naar transferrine receptoren positieve tumor cellen te brengen, dit zowel in vitro als in vivo.

2. Poly(propylene imine) dendrimeren kunnen gebruikt worden om een sterke nucleaire opname van DNAzymes in carcinoma cellen te bekomen, dit zowel in vitro als in vivo.

3. Colloidaal goud deeltjes gebonden aan transferrine gekoppelde cationen kunnen zonder hoge toxiciteit in carcinoma cellen gebracht worden.

4. ZsGreen en DsRed2 eiwit producerende cellijnen kunnen gebruikt worden als platform bij het uitvoeren van antikanker screenings, dit zowel in vitro als in vivo.

5. ZsGreen en DsRed2 eiwit producerende cellijnen hebben verbeterde karakteristieken voor het gebruik van whole body imaging. WBI werd op zijn beurt superieur bevonden ten opzichte van tumor volume metingen met een schuifpasser.

6. ZsGreen en DsRed2 eiwit producerende cellijnen in combinatie met RNAi, gericht tegen het fluorescente eiwit, kan gebruikt worden bij het analyseren van non viraal gen transport systemen.

7. Serine 305 is het eerst beschreven autofosforylatie punt in PLK4 en speelt een rol in de regulatie van PLK4 eiwit afbraak.

8. Actieve PLK4 komt anders tot expressie in vergelijking met totaal PLK4, met een opkomst tijdens $\mathrm{S}$ phase op het proximale uiteinde van de moeder centriool. 


\section{Dankwoord}

Na zoveel jaren zwoegen is het cr eindelijk. Mijn thesis is af en was zondermeer een project van lange adem. Zonder menige mensen had ik dit nooit kunnen bereiken!

Ik besef maar al te goed dat dit eindresultaat een gevolg is van verwezenlijkingen die ver terug gaan. Ik begin zo'n 8jaren terug. Ik wil de leraren aan de Katholieke Hogeschool Limburg bedanken om mij de weg te tonen naar het behalen van een Nederlands Ingenieurs diploma. Hans Blankert die me destijds begeleidde in Etten-Leur, toonde me de spannende en wondere wcreld van het onderzoek. Hans, bedankt om de lont aan te steken. Binnen deze opleiding koos ik voor een stage op de afdeling Oncologie bij Janssen Pharmaceutica, onder leiding van Annette Bakker. Annette was ook degene die me de wonderlijke kans gegeven heeft om mijn doctoraat op Janssen te doen. Annette, ik ben jc enthousiasme, vriendelijke aanpak en medeleven altijd blijven appreciëren, bedankt om in mij te geloven! $\mathrm{Na}$ enkele jaren werd Thierry Grand-Perret mijn nieuwe promotor. Thierry heeft in het begin heel wat geduld met mijn enthousiaste en ietwat gehaaste aanpak moeten hebben. Thierry heeft me enorm veel geleerd, gaande van experimenteel werk tot het verwerken van resultaten en schrijven van artikels. Thierry, bedankt om zo vaak al je werk te laten vallen voor mij en met mijn moeilijke situatie om te gaan. Ook jij geloofde in wat ik kon en gaf me met de jaren nieuwe uitdagingen om mij gemotiveerd te houden.

Michel Janicot was, toen ik mijn stage en doctoraat op Oncologie uitvoerde, het afdelingshoofd. Hij geloofde ook in mijn kunnen en ging volledig akkoord met het aanbieden van deze opportuniteit. Het is echter naar het einde toe dat Michel mij vaak en heel wat geholpen heeft. Toen alles scheef liep in Rotterdam, bleef Michel diplomatisch naar een oplossing zoeken. Ook al was hij ondertussen geen afdelingshoofd meer, hij bleef me ondersteunen om een oplossing te vinden. Twee jaar later zijn we er eindelijk aan toe. Michel, bedankt voor de steun die ik van je kon krijgen tijdens die moeilijke jaren.

Marcel Borgers en Frans Ramaekers deden de deur voor mij open bij de Universiteit van Maastricht. Op korte tijd werd alles goedgekeurd en ingediend, dit was voor een groot deel dankzij jullie inspanning. Desondanks ons korte kennismaking, voel ik me zeer dankbaar jullie te kennen.

Tijdens mijn doctoraat heb ik ook via verschillende samenwerkingen data kunnen produceren waarmee we een manuscript hebben kunnen publiceren. To the group of Mark Davis at Insert Therapeutics, Suzie Pun in particular, thank you for your cooperation in our 
joint project. Voor de mensen bij SyMO-Chem. Dr. Henk Janssen in het bijzonder: bedankt voor de langdurige collaboratie, de ontelbare uren dat we samen aan het patent en manuscript gewerkt hebben en de vriendschappelijke band die ontstaan is. To the group of Michel Bornens at the Curie Institute in Paris, James Sillibourne in particular, thank you very much for the experience of working together. A firiendship that commenced with my visit to your lab and prolonged while we searched for answers. The numerous visits afterwards and finally, our extensive labour in writing the patent and manuscript.

Marcus Brewster heeft ook een grote contributie gemaakt tijdens die 6jaar dat ik in Beerse werkte. Verschillende samenwerkingen van Oncologie werden met zijn goedkeurende oog afgesloten. Hij was er altijd om advies te geven en me te ondersteunen indien nodig. Thanks Marcus for your wisdom and kindness!

Ten laatste wil ik iedereen bedanken die me bijgestaan heeft tijdens mijn doctoraat. De collega's bij Functional Genomics, bedankt om me te helpen met het onderzoek. De collega's van Oncologie, ik heb hier verschillende vrienden voor het leven gemaakt. Velen wisten van mijn moeilijkheden en hebben me vaak aangemoedigd om te blijven vechten. Ze waren er voor me op professioneel en privé vlak en dat zal ik niet snel vergeten. Een luisterend oor en een schouderklopje kan soms net het verschil maken tussen opgeven en het nog een keer proberen.

Een dankwoord zou natuurlijk niat volledig zijn zonder diegenen te bedanken die je savonds na het werk, in het weekend en tijdens feestlagen laten weten dat ze an je denken. Mijn familie, vrienden en Joyce waren er onvoorwaardelijk voor me en hebben me maar al te vaak aangemoedigd om me 'nog even' in te spannen en dat het gauw voorbij zou zijn. Vooral de laatste twee jaren waren stressvolle tijden en Joyce, de vele uren gezaag zijn nu voorbij! Bedankt om me op te vangen wanneer nodig, je bent een engel!

Mama en Papa, niet alleen bedankt voor de emotionele steun die ik van jullic mocht ontvangen maar ook om mij de kans te geven in Diepenbeek en Etten-Leur te studeren. Dankzij jullie hulp kan ik mijn carricre ambities nastreven.

Icdereen, dank je wel hiervoor, dit werk zou er niet tot stand zijn gekomen zonder jullie.

\section{THE END.}




\section{Curriculum Vitae}

The author of this thesis was born on February the $4^{\text {th }} .1979$ in Lebanon. Tennessee in the United States. After growing up in a small mining town, Carthage, he moved to Belgium at the age of twelve. He attended secondary school in Borgloon and in 1997 decided to study Biochemistry. In 2000 he graduated as a Bachelor in Biochenistry at the Katholieke Hogeschool Limburg in Diepenbeek. As part of his degree. a traineeship was required which was performed at the University Hospital in Maastricht. That year he continued his studies in Etten-Leur (Netherlands), where he enrolled in a program Biological and Medical Laboratorium Technologies. In 2001, after having performed a trainceship at the Oncology department within Janssen Pharmaceutica. he received his second Bachelor degree. In 2002, he commenced his 4year PhD with the main theme: use of post transcriptional gene silencing techniques and peptide microarray to perform target validation. He performed his work at Ortho Biotech Oncology in Beerse and finished his contract at the end of 2005. For the following two years he performed drug discovery research under a Postdoctoral contract. On the $12^{\text {th }}$ of June 2008 , he will finally receive his degree as $\mathrm{PhD}$. 


\section{List Of Publications}

1. Suzie H. Pun, Frederik Tack, Nathalie C. Bellocq, Jianjun Cheng, Brendan II. Grubbs, Gregory S. Jensen. Mark E. Davis, Marcus Brewster, Michel Janicot, Boudewijn Janssens, Wim Floren, Annette Bakker ; 'TARGited Delivery of RNA-CleAving DNA ENZYME (DNAZYME) TO TUMOR TISSUF BY' Transferrin-Modified, CyClodeXTRIN-BAsed PARTICLES, Cancer Biol Ther. 2004 Jul; $3(7): 641-50$

2. Frederik Tack. Annette Bakker, Sophie Maes, Nathalie Dekeyser, Monique Bruining, Cristina Elissen-Roman, Henk M. Janssen, B.F.M. de Waal. P.M. Fransen, X. Lou, E.W. Meijer. Michel Janicot \& Marcus Brewster; MODIFIED POLY (PROPYLENE IMINE) DENDRIMERS AS EFFECTIVE TRANSIEC TION AGENTS FOR CATALYTIC DNA FNZYMES (DNAZYMES), Journal of Drug Targeting $2006 ; 14(2): 69-86$

3. Frederik Tack, Mare Noppe, Alex Van Dijck, Nathalie Dekeyzer. Bas-Jan Van Der Leede, Annette Bakker, Walter Wouters, Michel Janicot, and Marcus E. Brewster; Del.IVERY' OF A DNAZYME

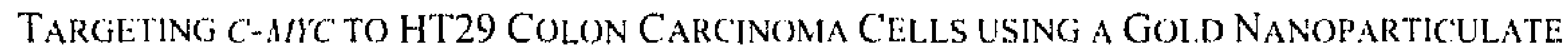
APPROACH, Die Pharmazie 2008; 63 (3); 221-225

4. Frederik Tack, Wim Floren, Boudewijn Janssen, Annette Bakker, Thierry Grand-Perret \& Michel Janicot ; ENGiNeERING AND CHARACTERIZATION OF ANTHOZOA FLUORESCENT PROTEIN-EXPRESSING TUMOR C.FLI.S, G.I.T Imaging and Microscopy 1/2005, 43-45

5. Frederik Tack, Wim Floren, Boudewijn Janssen, Ann Beliën, Annette Bakker, Thicrry Grand-Perret \& Michel Janicol : APPLICATION OF A.VTHOZOA FLUORESCENT PROTEIN EXPRESSING TUMOR MODELS FOR THE EVALUATION OF HDAC INHBITORS, Bioforum Europe 9/2005; 52-53

6. Frederik Tack, James E. Sillibourne, Nele Vloemans, An Boeckx, Sathiesan Thambirajah, Frans C. S. Ramaekers, Michel Bomens and Thierry Grand-Perret ; AUTOPHOSPHORYLATION OF PLK4 CONTROLS ITS STABILITY AND OCCURS AT THF CENTROSOME IN A CELL CYCLE-DEPENDENT MANNER, Submitted to Journal of Cell Biology

\section{PATENTS}

1. Efficient Dendritic Transfection Agents for DNAzymes patent filed 08 July 2005 with filing number EP05106266.9

2. Auto-phosphorylation of PLK4 controls its stability and occuls at the centrosome in a cell cycle dependent mamner patent filed January $10^{\text {th }} 2008$ 